The Centennial and Millennial Variability of the IndoPacific Warm Pool and the Indonesian Throughflow

By

Fern Tolley Gibbons

B.S. in the Geophysical Sciences

University of Chicago, 2004

Submitted in partial fulfillment of the requirement for the degree of

Doctor of Philosophy

at the

Massachusetts Institute of Technology

and the

Woods Hole Oceanographic Institution

February 2012

(C) 2012 Fern Tolley Gibbons. All rights reserved.

The author hereby grants to MIT and WHOI permission to reproduce paper and electronic copies of this thesis in whole or in part and to distribute them publicly.

Signature of Author

Joint Program in Oceanography/Applied Ocean Sciences

Woods Hole Oceanographic Institution

Massachusetts Institute of Technology

Certified by

Dr. Delia W. Oppo

Thesis Supervisor

Accepted by

Dr. Rob L. Evans

Chair, Joint Committee for Marine Geology and Geophysics

Woods Hole Oceanographic Institute 


\section{Abstract (Short version)}

As the only low-latitude connection between ocean basins, the Indonesian Throughflow allows the direct transmission of heat and salinity between the Pacific and Indian Oceans. The $\mathrm{Mg} / \mathrm{Ca}$ and $\delta^{18} \mathrm{O}$ of calcite of Globigerinoides ruber (G. ruber) were used to estimate the sea surface temperature (SST) and $\delta^{18} 0$ of water, an indicator of hydrologic conditions, over the past 20,000 years. I also attempted to estimate thermocline structure using Pulleniatina obliquiloculata, but the $\mathrm{Mg} / \mathrm{Ca}$ and $\delta^{18} 0$ of calcite data yield conflicting interpretations, indicating further work on this proxy is required. The G. ruber $\mathrm{Mg} /$ Ca results suggest that the SST of the outflow passages were influenced by high latitude Southern Hemisphere temperature. At approximately 10,000 years before present, there was a warming in the Makassar Strait. This local warming was coincident with the flooding of the Sunda Shelf, which opened a connection between the South China Sea and the Indonesian Throughflow. Regional $\delta^{18} \mathrm{O}$ of seawater reconstructions suggest that the mean position of the Intertropical Convergence Zone (ITCZ) was approximately the same as modern at the last glacial maximum and was displaced to the south during the Younger Dryas and Heinrich Stadial 1, suggesting the ITCZ responds to changes in the interhemispheric temperature gradient. 


\title{
The Centennial and Millennial Variability of the IndoPacific Warm Pool and the Indonesian Throughflow
}

\author{
By \\ Fern Tolley Gibbons \\ Submitted to the Department of Marine Geology and Geophysics, \\ Massachusetts Institute of Technology \\ and the \\ Woods Hole Oceanographic Institution \\ Joint Program in Oceanography/Applied Ocean Sciences \\ on January 27,2012 \\ in partial fulfillment of the requirement for the degree of \\ Doctor of Philosophy
}

\begin{abstract}
As the only low-latitude connection between ocean basins, the Indonesian Throughflow allows the direct transmission of heat and salinity between the Pacific and Indian Oceans. Despite its potential importance, the role of the Indonesian Throughflow in global ocean circulation and regional climate is still not clear due to sparse measurements and the relative difficulty of modeling the region. The $\mathrm{Mg} / \mathrm{Ca}$ and $\delta^{18} 0$ of calcite of the calcitic planktic foraminifera Globigerinoides ruber ( $G$. ruber) were used to estimate the sea surface temperature and $\delta^{18} 0$ of water, an indicator of hydrologic conditions, over the past 20,000 years. I also attempted to estimate thermocline structure using the foraminifera, Pulleniatina obliquiloculata, but the $\mathrm{Mg} / \mathrm{Ca}$ and $\delta^{18} \mathrm{O}$ of calcite data yield conflicting interpretations, indicating further work on this proxy is required. The $G$. ruber $\mathrm{Mg} / \mathrm{Ca}$ results suggest that the sea surface temperature of the outflow passages was influenced by high latitude
\end{abstract}


Southern Hemisphere temperature. This connection is likely via intermediate waters that upwell in the Banda Sea. At approximately 10,000 years before present, there was a warming in the Makassar Strait. This local warming was coincident with the flooding of the Sunda Shelf, which opened a connection between the South China Sea and the Indonesian Throughflow. Regional $\delta^{18} 0$ of seawater reconstructions show that during the last glacial maximum the $\delta^{18} 0$ of seawater pattern was very similar to modern, but there were relatively enriched values over the equatorial IndoPacific during high latitude Northern Hemisphere cold events (Heinrich Stadial 1 and the Younger Dryas). From these results we postulate that the mean position of the Intertropical Convergence Zone was approximately the same as modern at the last glacial maximum and was likely displaced to the south during the Younger Dryas and Heinrich Stadial 1, suggesting the Intertropical Convergence Zone primarily responds to changes in the interhemispheric temperature gradient. These results shed light on the primary controls of the temperature and hydrology of Indonesian Throughflow region. 


\section{Acknowledgements}

While there is certainly a sense of relief to be finishing my thesis, it is also bittersweet. It will be extremely difficult for me to leave behind my good friends and colleagues.

I could not ask for a better advisor (and friend and mentor) than Delia Oppo. Her commitment to her students, family, and science is an inspiration. She is extremely patient, and was always willing to let me do things my way, though I would have likely finished my degree two years early had I just listened to her in the first place. I did listen to her regarding family, when she told me, "By the time you want children, it will be too late." My son and I are particularly grateful for this piece of advice.

I owe a big thank you to my committee members. Bill Curry, Jake Gebbie, and Kerry Emanuel guided my research and helped me create a stronger thesis.

I could not have finished without the help of Olivier Marchal. Olivier's eagerness to answer any question I had (and perhaps some I had not yet realized I had) was always appreciated. His willingness to read my thesis and chair my defense on 24 hours notice is a testament to his generosity.

We are lucky to have excellent collaborators. Mahyar Mohtadi (University of Bremen) and Brad Linsley (LDEO) have provided excellent feedback on many drafts of this thesis. Yair Rosenthal (Rutgers University) and his lab group were a tremendous source of support: logistic, moral, and scientific.

There are many others who contributed to my scientific education. My long talks with Kris Karnauskas about the dynamics of the tropics for hours helped me change the way I view the climate system. Let's hope this is for the better. A thank you Paola Rizzoli and David McGee for demonstrating to me the strength of the Joint Program.

My only complaint about the Joint Program Academic Programs Office is that they have spoiled me. I have never worked with an administrative office that was so friendly and responsive. Jim Yoder has provided me with excellent career advice and Julia Westwater's kind support was greatly appreciated. And thank you to Tricia Gebbie for answering my flood of thesis-related questions.

Of course, school (and life) would have been much less fun without my friends, with whom I've spent many great hours laughing, talking, brewing beer, and eating. A thanks to Sharon and Jessie who helped guide me at the start. To Alysia and Caitlin for being excellent, though intermittent, roommates. To Karin and Camilo and Kerstin and Andre who opened their homes to me, and whose generosity in hospitality was only exceeded by their generosity in friendship. And thank you to my good friends Ali and Dan who have made my life richer. 
And finally a big thank you to my family, who have given more to me than I've been able to return. To my aunts and uncles and cousins, who helped fill in the gaps, especially Regina, Joseph, Edward, and Bob. To my husband, Nathaniel, who has lovingly and steadfastly supported and encouraged me throughout the years and my son, Zeke, who has filled my life with joy and laughter. To my dad, whose words of advice would have been, "slow down, you have all the time in the world." To my mom, for providing tremendous love and support, without which it would have been impossible for me to finish. To my younger brother, who never questioned why I was still in school. And of course, to my older brother, who was my biggest cheerleader, partner in crime, and favorite playmate. Whose enthusiasm for life and quest for adventure was the perfect balance to my more cautious ways. May we remember it is a magical world.

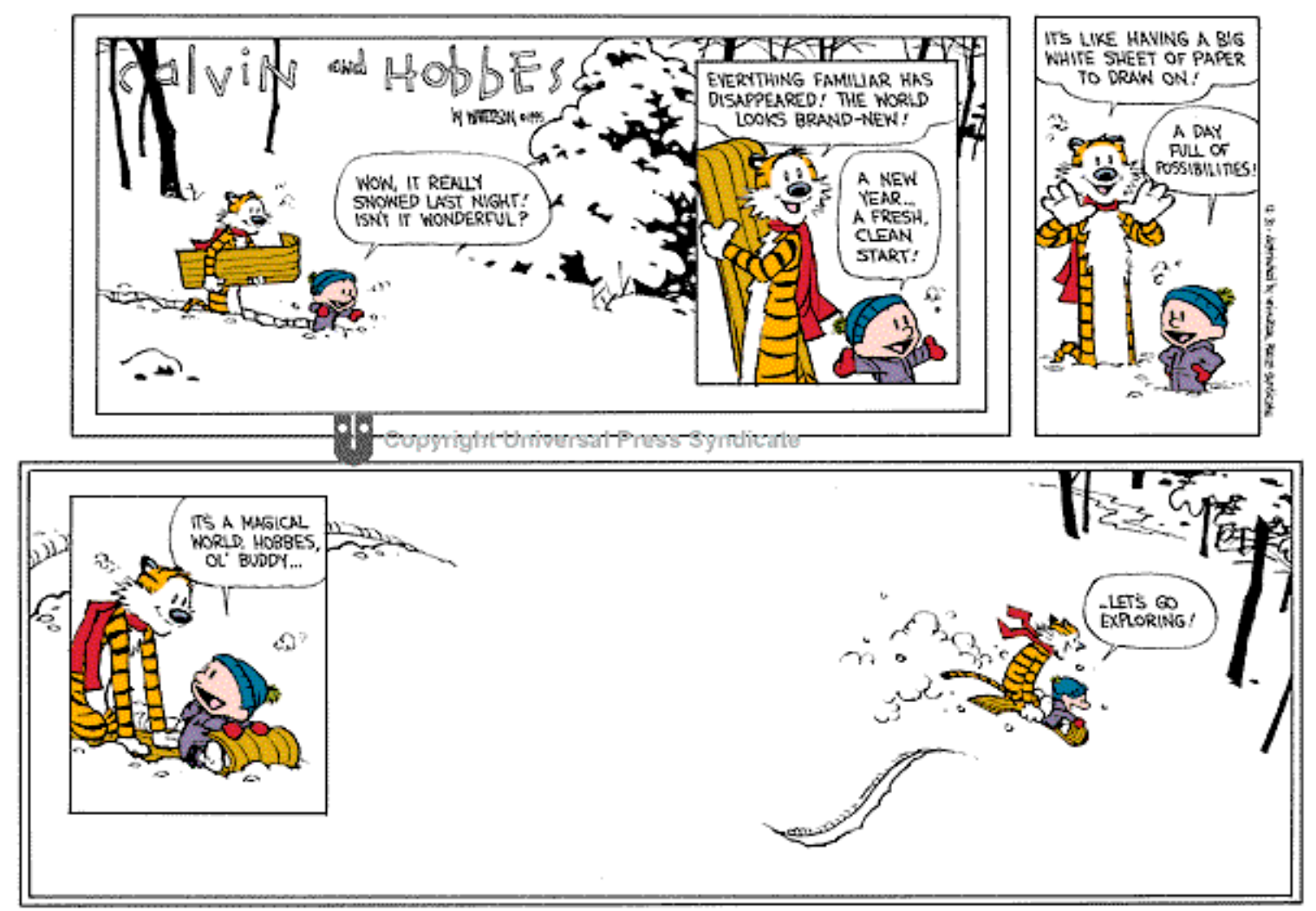

Calvin and Hobbes (c) 1995 Watterson. Used by permission of Universal Uclick. All rights reserved.

This work was supported by an MIT Presidential Graduate Fellowship, WHOI Academic Programs Office Funds, the USGS, and the following grants from the National Science Foundation: OCE 07-26986, OCE 05-02960, and OCE 10-03974. 


\section{Contents}

$\begin{array}{ll}\text { Abstract (short version) } & 3\end{array}$

$\begin{array}{lr}\text { Abstract (Full version) } & 5\end{array}$

$\begin{array}{ll}\text { Acknowledgements } & 7\end{array}$

Chapter 1 - Introduction 13

Chapter 2 - Southern Hemisphere Influence on the Indonesian Throughflow

Chapter 3 - The deglacial hydrologic variability of the Tropical Pacific and Indian Oceans inferred from $\delta^{18} 0$ of seawater reconstructions

Chapter 4 - The thermocline structure of the IndoPacific Warm 99 Pool from the Last Glacial Maximum until Present

Conclusions

Appendix A $-{ }^{14} \mathrm{C}$ dates

Appendix B - Coretop data 145

$\begin{array}{lc}\text { Appendix C - Downcore data } & 147\end{array}$ 


\section{Figures and Tables}

\section{Chapter 1}

Figure 1: Map of Indonesian Throughflow. 20

Figure 2: Hydrographic data from within the Indonesian Seas. 21

\section{Chapter 2}

Figure 1: Map of the Indonesian Throughflow area. 39

Figure 2: Coretop excess Mg/Ca versus salinity. 40

Figure 3: Mg/Ca-based sea surface temperature estimates from this paper, along with previously published data.

Figure 4: Comparison of sea surface temperature records to

Southern Hemisphere records.

Figure S1: Sea surface salinity and height of the ITF.

Figure S2: Figure S2: Boxes used to calculate sea surface height difference for Fig S3.

Figure S3: Difference in sea level height.

Figure S4: SST ENSO correlation.

Figure S5: Alternate hypotheses to explain the cooling in the outflow passages.

Figure S6: Excess Mg/Ca versus depth. $\quad 58$

Table S1: Core locations.

Table S2: Summary of cleaning method and $\mathrm{Mg} / \mathrm{Ca}$ - temperature equation used on each core.

Table S3: Correlation matrix of SST stacks and Dome Fuji $\delta^{18} 0$.

\section{Chapter 3}

Table 1: Cores used in this study.

Figure 1: Core locations and mean annual sea surface salinity

Figure 2: Foraminifera-based reconstructed "modern" $\delta^{18} \mathrm{O}_{\text {seawater }}$ estimates plotted against modern WOA05 salinity data.

Modern water $\delta^{18}$ Oseawater and salinity data are also shown.

Figure 3: Data from 69-3.

Figure 4a: $\delta^{18} \mathrm{O}_{\text {calcite }}$ data from all cores used in this study.

Figure 4b: $\mathrm{Mg} / \mathrm{Ca}$-based temperature data from all cores used in this study.

Figure 4c: $\delta^{18} \mathrm{O}_{\text {seawater-icevolume }}$ reconstructions from all cores used in this study.

Figure 5: A comparison of climate records.

Figure 6: Top panel is eigenvector elements/loadings for PC1.

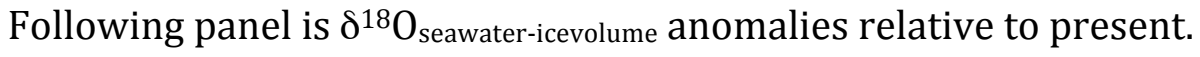

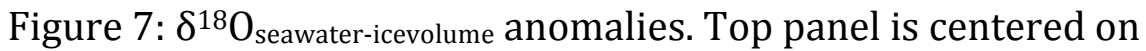
$12.5 \mathrm{kyr}$ BP and bottom panel is centered on $14.5 \mathrm{kyr}$ BP.

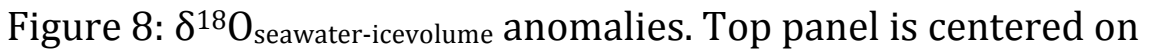
$15.5 \mathrm{kyr} \mathrm{BP}$ and bottom panel is centered on $17.5 \mathrm{kyr} \mathrm{BP}$. 


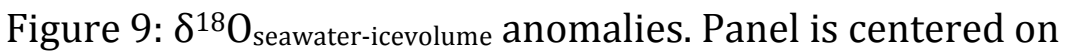
19.5 kyr BP (the LGM).

\section{Chapter 4}

Table 1: Core locations and depths.

Table 2: Difference in radiocarbon dates between $G$. ruber $/ G$. sacculifer and P. obliquiloculata.

Figure 1: Map of study location.

Figure 2: Core top results.

125

Figure 3: Downcore records from 69-3 (Savu Sea).

126

Figure 4: Downcore records from 70GGC

(Southern Makassar Strait).

Figure 5: Downcore records from 23GGC

(Southern Makassar Strait).

Figure 6: Downcore records from MD41

(Sulu Sea).

Figure 7: Downcore records from 136GGC

(Flores Sea).

Figure 8: Coretop summary.

Figure 9: Temperature and $\delta^{18} \mathrm{O}_{\text {calcite }}$ gradients from selected timeslices.

Figure 10: Excess Mg/Ca and salinity from G. ruber. 


\section{Chapter 1}

\section{Introduction}

Approximately 10-15 Sv (1 Sv = a million cubic meters per second) of water makes its way from the Pacific Ocean into the Indian Ocean, meandering through a series of straits known as the Indonesian Throughflow [Gordon, 2005; Sprintall et al., 2009]. The water's path is not straightforward; there are rich seasonal and interannual cycles, topographic barriers, and vigorous tidal and wind driven mixing [Ffield and Gordon, 1996; Gordon et al., 2010; Koch-Larrouy et al., 2008]. There are three main entrances into the Indonesian Throughflow: the Makassar Strait, the Java Sea, and the Eastern Passages. Of these the Makassar Strait dominates volumetrically, supplying water from the subtropical North Pacific [Gordon et al., 2008]. The Java Sea adds freshwater from the South China Sea [Qu et al., 2006] and the Eastern Passages contain the only deep entrance (the Lifamatola Strait, sill depth 2,000m) [Talley and Sprintall, 2005]. There are also three outflow passages: the Timor Strait, the Ombai Strait, and the Lombok Strait (Fig 1). Each outflow passage has its own characteristics as well. The smallest, the Lombok Strait, is the most influenced by the seasonal reversal of the winds (the monsoons). During the 
boreal winter months, the Lombok Strait occasionally loses its status as an outflow passage; its flow is reversed by the winds, particularly, at the surface. The Ombai Strait also has occasional seasonal flow reversals in the surface, and the largest passage, the Timor Strait has very little seasonal variability [Sprintall et al., 2009]. Though volumetrically the most important, and relatively well studied, the Makassar Strait is still poorly understood. Initial measurements indicated the flow of the surface layer reversed with the seasons, with a strong and constant thermocline flow. This reduced surface flow was attributed to a plume of freshwater from the Java Sea blocking flow during the boreal winter [Gordon et al., 2003], though it could also be explained by the Ekman transport caused by the monsoon winds [Sprintall and Liu, 2005]. Later work showed that the surface flow is inhibited throughout the year, and the maximum flow is always in the thermocline [Gordon et al., 2008]. Neither of the proposed mechanisms explains a year round suppression of surface flow. The reason for this year round suppression of the surface flow is still not clear. Here, we propose an alternative mechanism: the persistently higher sea level of the southern Java Sea compared to the Flores Sea creates a pressure gradient. A surface northward geostrophic flow is established, inhibiting surface flow. The thermocline flow is unaffected since the sill depth between the Java Sea and the Indonesian Throughflow is only $40 \mathrm{~m}$.

\section{Oceanography (Chapter 2):}


What can our climate reconstructions add to our understanding of the Indonesian Throughflow? Quite a lot, it turns out. We can test some of the emerging hypotheses about the Indonesian Throughflow. We can start with a very basic question: does the water exiting the Indonesian Throughflow resemble the water going in? Not at all. The water that enters the Indonesian Throughflow is warm and salty. What comes out is relatively cool and fresh (Fig 2). The fundamental nature of this great transformation is the focus of work in modern oceanography [Fang et al., 2010; Gordon et al., 2003; Koch-Larrouy et al., 2008]. How can the paleo record help us understand this issue? A current hypothesis for explaining the cool, fresh nature of the Indonesian Throughflow is that water from the Java Sea blocks the warm surface flow through the Makassar Strait. The flow of the cooler subsurface water is unaffected and therefore this cooler water dominates [Gordon et al., 2003]. In a stroke of geological good luck, the Java Sea is so shallow that 20,000 years ago when the great continental ice sheets robbed the oceans of water and sea level was 120 meters lower, the entire Java Sea was exposed shelf area. Thus by reconstructing oceanographic conditions as sea levels rose to modern, we can examine what, if any, effect the Java Sea water had on the Indonesian Throughflow.

Our long records can also give us insight into the major controls on the temperature of the Indonesian Throughflow. Here, we find something unexpected; the opening of the Java Sea when sea levels rose did not appear to affect the sea surface temperatures of the outflow passages. Instead, over the past 20,000 years the sea surface temperatures of the Indonesian Throughflow outflow paralleled high latitude Southern Hemisphere temperature variations recorded in ice cores. This is 
not a temperature pattern we see in the inflow area to the Indonesian Throughflow. How does this temperature pattern get to the Indonesian Throughflow? We suggest that there is more deep water entering through a poorly studied passage, the Lifamatola Strait, than is currently estimated. This water is then vigorously mixed in the Banda Sea, which brings deep water to the surface. It is likely that this mixing is the primary source of the cool the Indonesian Throughflow waters in the modern, as our records suggest the Java Sea inflow does not change the sea surface temperature of the outflow passages. Further observational work in the Indonesian Throughflow region will allow us to test this hypothesis.

\section{Hydrology (Chapter 3):}

The primary controls on the sea surface temperature of the Indonesian Throughflow turned out to be much more complicated than expected and highly dependent on the unique topography of the region. As is turns out, the major changes in hydrology are much more straightforward. Along the equator, winds from the north and south meet over warm water. At this point of convergence, air rises and heavy precipitation occurs. This area of convection is the Intertropical Tropical Convergence Zone (ITCZ). The ITCZ migrates with the seasons and gets tugged towards the warmer hemisphere. Due to the current continental configuration, the northern hemisphere is slightly warmer, and the position of the ITCZ is biased to the north [Koutavas and Lynch-Stieglitz, 2005]. What would happen if the interhemispheric temperature gradient were reduced? Temperature 
compilations show that during times of rapid cooling in the northern hemisphere (for example during Heinrich Event 1 and the Younger Dryas), the southern hemisphere warmed, decreasing the interhemispheric temperature gradient [Shakun and Carlson, 2010]. The expectation is that the ITCZ would lose some of its northward bias. Our hydrologic proxies show exactly that. Our data suggest that, despite the complexity of the Indonesian Throughflow, the ITCZ responded uniformly to these high latitude northern hemisphere cooling events and its mean position shifted southward.

\section{Proxies (Chapter 4):}

In order to reconstruct temperature and hydrology on timescales longer than the instrumental record, we have turned to proxies. Proxies can give us estimates of past oceanographic conditions. The data in this thesis is based on the geochemistry of planktic foraminifera. Foraminifera are single celled organisms that build shells, specifically of calcium carbonate $\left(\mathrm{CaCO}_{3}\right)$, and we utilize the chemical variation in these shells. The amount of ${ }^{18} \mathrm{O}$ compared to ${ }^{16} \mathrm{O}$ (or $\delta^{18} \mathrm{O}$ ) that is incorporated into a foraminifera's shell depends on both the temperature and the $\delta^{18} 0$ of the water in which the shell grows [Emiliani, 1970]. The $\delta^{18} 0$ of the water can tell us about hydrologic processes, but we need an independent temperature estimate to isolate the $\delta^{18} 0$ of seawater component. Here we take advantage of the observation that foraminifera growing at higher temperatures incorporate more Mg into their shells. 
Thus, the $\mathrm{Mg} / \mathrm{Ca}$ ratio in a shell can be used estimate past temperatures [Rosenthal et al., 1997].

We investigate two types of foraminifera. Globigerinoides ruber (G. ruber) has photosynthetic symbionts and is primarily found in the mixed layer. Pulleniatina obliquiloculata (P. obliquiloculata) lives in the upper thermocline at $\sim 80-100 \mathrm{~m}$. By measuring both species, the hope was to reconstruct thermocline structure. This was a very exciting prospect. Firstly, early observational results from the Makassar Strait showed that thermocline temperature, but not surface temperature was correlated to Makassar Strait transport [Ffield et al., 2000]. Secondly, temperature anomalies associated with the Indian Ocean Dipole are often larger in the subsurface than in the surface [Shinoda et al., 2004]. Finally, modeling simulations of the Last Glacial Maximum suggest that thermocline temperatures in the Western Equatorial Pacific may be the best diagnostic for past changes in the Walker Circulation [DiNezio et al., 2011]. Thus, the depth habitat of P. obliquiloculata makes this foraminifera well suited to address several important climatic questions.

While our $\delta^{18} \mathrm{O}_{\text {calcite }}$ and $\mathrm{Mg} / \mathrm{Ca}$-based temperature results from G. ruber are self-consistent, and can be reconciled with modern conditions and other climate reconstructions (and are the basis for the results described in Chapters 2 and 3), our P. obliquiloculata results are difficult to interpret. We use the difference between the $\mathrm{Mg} /$ Ca-based temperatures of G. ruber - P. obliquiloculata to infer the thermocline structure. Using the $\delta^{18} \mathrm{O}_{\text {calcite }}$ of G. ruber and P. obliquiloculata we make a similar estimate. In the coretop data, these two methods yield qualitatively similar results. In the downcore records, they predict a different sign of change in the thermocline 
structure, making an oceanographic interpretation difficult. While previous authors have suggested that the unique oceanographic conditions at their study sites cause this inconsistency [Steinke et al., 2010; Xu et al., 2008], we suggest that the difficulty of using the combination of G. ruber and P. obliquiloculata to reconstruct thermocline conditions is pervasive throughout the IndoPacific Warm Pool. We urge caution in using the geochemistry of $P$. obliquiloculata to reconstruct water column structure and suggest more work is required before this proxy can be reliably used.

\section{Summary}

Not only is the Indonesian Throughflow at an oceanic crossroads, this thesis demonstrates it is also a climatic balancing point between the Northern and Southern Hemisphere. High latitude Southern Hemisphere temperature variation appears to influence the sea surface temperature of the outflow passages. On the

other hand, the hydrology of the entire region responds in concert with changes in the interhemispheric temperature gradient. This suggests that the geometry of the Indonesian Seas has an influence on local sea surface temperatures, but the hydrologic changes are primarily influenced by extratropical forcings. 


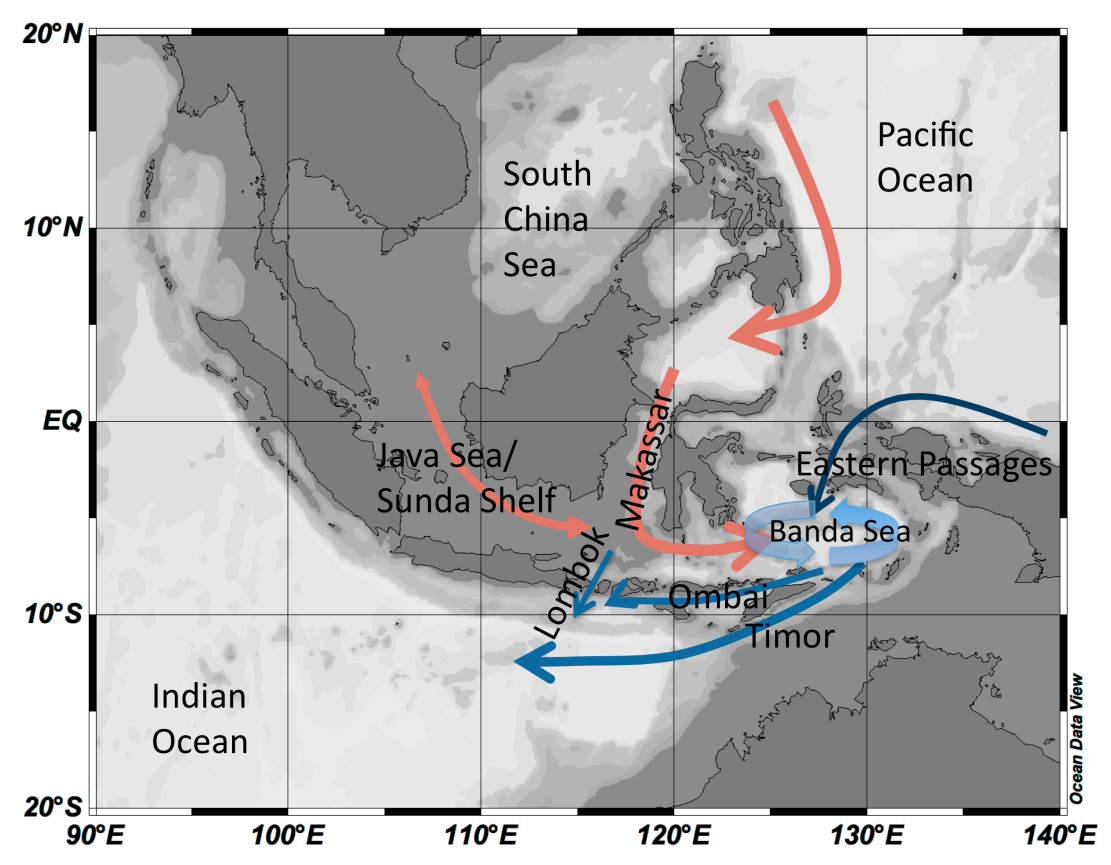

Figure 1: Map of Indonesian Throughflow. Water flows from the Pacific into the Indian Ocean through the Indonesian Throughflow. Water from the three major inflow passages (the Makassar Strait, the Java Sea, and the Eastern Passages) is mixed within the Banda Sea and flows out via the Timor Sea, the Ombai Strait, and the Lombok Strait. The circulation schematic is based on [Fang et al., 2010; Gordon et al., 2010; Tomczak and Godfrey, 1994]. 

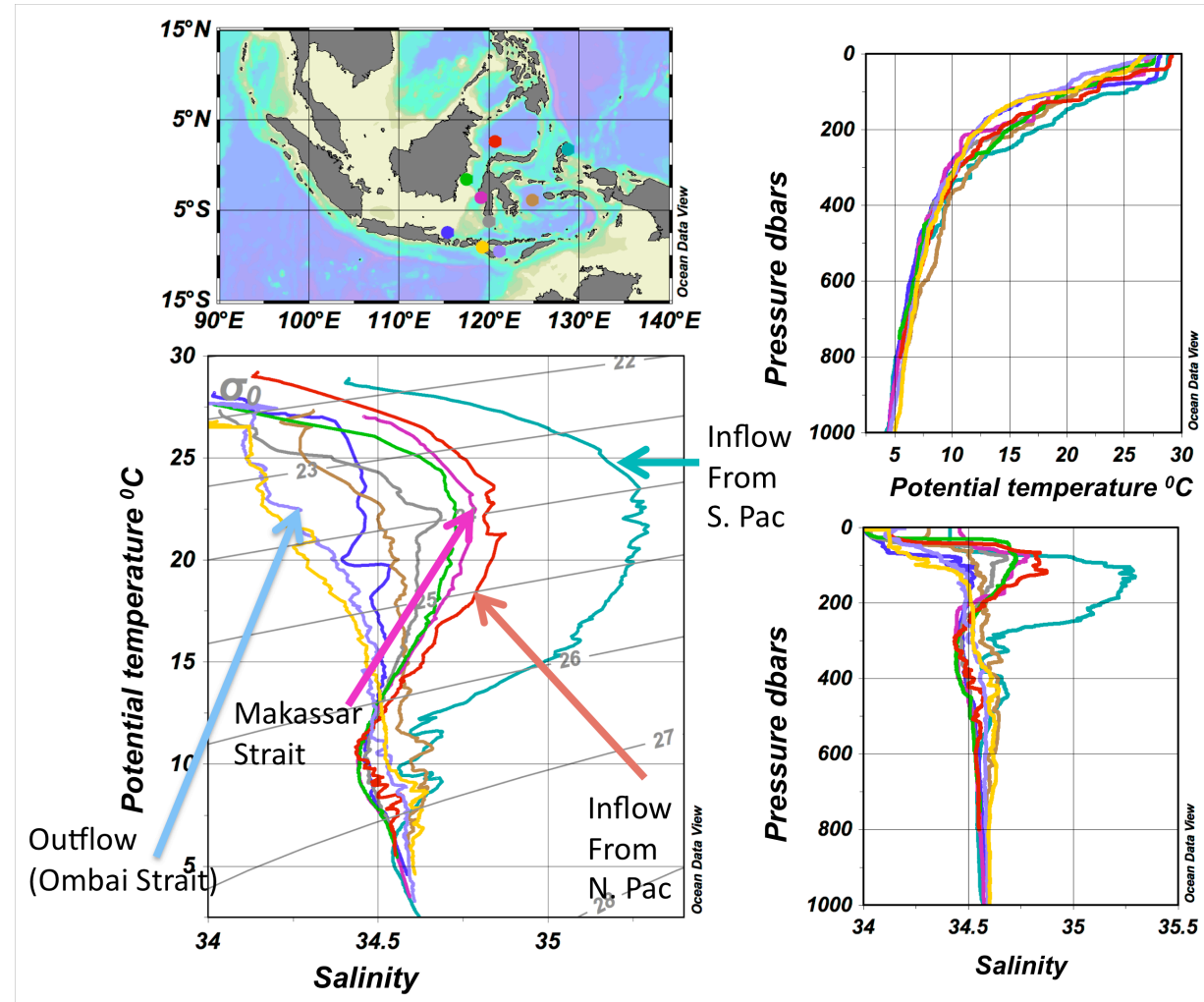

S. Pac

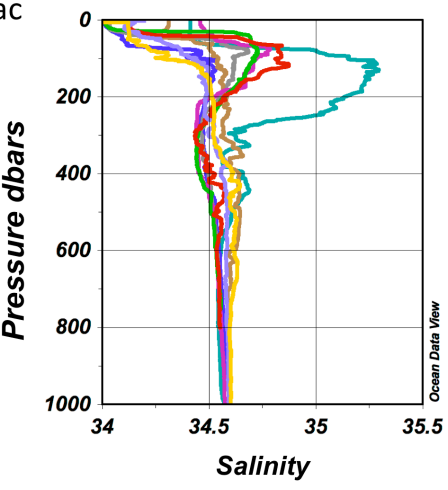

Figure 2: Hydrographic data from within the Indonesian Seas. Data are from CTD casts from two cruises, BJ8-03 and S0184, both of which took place during the boreal summer. The inflow from both the North Pacific (red) and the South Pacific (teal) have subsurface salinity maxima. Vigorous mixing and freshwater influx (both from the Java Sea and local precipitation) erode these salinity maxima and water exits the Indonesian Throughflow fresher than it enters. 
DiNezio, P. N., et al. (2011), The response of the Walker circulation to Last Glacial Maximum forcing: Implications for detection in proxies, Paleoceanography, 26. Emiliani, C. (1970), Pleistocene Paleotemperatures, Science, 168(3933), 822-825. Fang, Q., et al. (2010), Volume, heat, and freshwater transports from the South China Sea to Indonesian seas in the boreal winter of 2007-2008, Journal Of Geophysical Research, 115(C12020).

Ffield, A., and A. L. Gordon (1996), Tidal Mixing Signatures in the Indonesian Seas, Journal of Physical Oceanography, 26, 1924-1937.

Ffield, A., et al. (2000), Temperature variability within Makassar Strait, Geophysical Research Letters, 27(2), 237-240.

Gordon, A. L., et al. (2003), Cool Indonesian throughflow as a consequence of restricted surface layer flow, Nature, 425(6960), 824-828.

Gordon, A. L. (2005), Oceanography of the Indonesian Seas and Their Throughflow, Oceanography, 18(4), 14-27.

Gordon, A. L., et al. (2008), Makassar Strait throughflow, 2004 to 2006, Geophysical Research Letters, 35(24).

Gordon, A. L., et al. (2010), The Indonesian throughflow during 2004-2006 as

observed by the INSTANT program, Dynamics of Atmospheres and Oceans, 50(2), 115-128.

Koch-Larrouy, A., et al. (2008), Physical processes contributing to the water mass transformation of the Indonesian Throughflow, Ocean Dynamics, 58(3-4), 275-288. Koutavas, A., and J. Lynch-Stieglitz (2005), Variability of the marine ITCZ over the eastern Pacific during the past 30,000 years: Regional perspective and global context, Springer.

$\mathrm{Qu}, \mathrm{T}$., et al. (2006), South China Sea throughflow: A heat and freshwater conveyor, Geophysical Research Letters, 33(L23617), doi:10.1029/2006GL028350.

Rosenthal, Y., et al. (1997), Temperature control on the incorporation of magnesium, strontium, fluorine, and cadmium into benthic foraminiferal shells from Little Bahama Bank: Prospects for thermocline paleoceanography, Geochimica Et Cosmochimica Acta, 61(17), 3633-3643.

Shakun, J. D., and A. E. Carlson (2010), A global perspective on Last Glacial Maximum to Holocene climate change, Quaternary Science Reviews, 29(15-16), 1801-1816. Shinoda, T., et al. (2004), Surface and subsurface dipole variability in the Indian Ocean and its relation with ENSO, Deep-Sea Research Part I-Oceanographic Research Papers, 51(5), 619-635.

Sprintall, J., and T. Liu (2005), Ekman Mass and Heat Transport in the Indonesian Seas, Oceanography, 18(4), 88-97.

Sprintall, J., et al. (2009), Direct estimates of the Indonesian Throughflow entering the Indian Ocean: 2004-2006, Journal of Geophysical Research-Oceans, 114.

Steinke, S., et al. (2010), Reconstructing the southern South China Sea upper water column structure since the Last Glacial Maximum: Implications for the East Asian winter monsoon development, Paleoceanography, 25(PA2219).

Talley, L. D., and J. Sprintall (2005), Deep expression of the Indonesian Throughflow: Indonesian Intermediate Water in the South Equatorial Current, Journal of Geophysical Research, 110. 
Tomczak, M., and J. S. Godfrey (1994), Regional Oceanography: An Introduction, Butterworth-Heinemann.

$\mathrm{Xu}$, J., et al. (2008), Changes in the thermocline structure of the Indonesian outflow during Terminations I and II, Earth and Planetary Science Letters, 273(1-2), 152-162. 


\title{
Chapter 2
}

\section{Southern Hemisphere Influence on the Indonesian Throughflow}

\begin{abstract}
In the modern ocean, vigorous vertical mixing in the Banda Sea combines North Pacific and South China Sea surface and thermocline waters with intermediate water from the southern hemisphere to create a distinctive Indonesian Throughflow water mass that flows from the tropical Pacific into the Indian Ocean [Gordon et al., 2003; Koch-Larrouy et al., 2008]. The Indonesian Throughflow contributes to the warm water return path of the meridional overturning circulation, but the controls on and the influence of the Indonesian Throughflow on deglacial and Holocene sea surface temperature evolution are unknown. Here, we present $\mathrm{Mg} / \mathrm{Ca}$-based sea surface temperature reconstructions from the Makassar Strait, the main path for North Pacific water to enter the Indonesian Throughflow, and from the Savu Sea, where Indonesian Throughflow exits into the eastern Indian Ocean. We show that during the last deglaciation surface temperature trends in both the Makassar Strait and the Indonesian Throughflow outflow resemble high-latitude southern hemisphere temperature trends. In contrast to the high-latitude southern
\end{abstract}


hemisphere, the Makassar Strait warmed 10,000 years ago, when sea level rise permitted the inflow of South China Sea water across the previously exposed Sunda Shelf [Linsley et al., 2010], which apparently isolated the Makassar Strait from southern hemisphere influence. We argue that sea surface temperatures of the outflow passages of the Indonesian Throughflow were unaffected. We suggest that a sustained oceanic connection between the southern hemisphere and the Indonesian Throughflow through the mixing in the Banda Sea provides a mechanism for Southern Source Water to influence tropical Indian Ocean sea surface temperatures.

\section{Introduction:}

The Indonesian Throughflow (ITF) transfers approximately 10-15 Sv (1 Sv = $10^{6} \mathrm{~m}^{3} / \mathrm{s}$ ) of water from the Pacific to the Indian Ocean through the Indonesian Seas, and plays an important role in the global oceanic circulation. Water enters the ITF via three routes: the Sulawesi Sea, the Java Sea, and the Eastern Passages (Figure 1) [Gordon et al., 2003; Koch-Larrouy et al., 2008]. North Pacific surface and thermocline water flows through the Sulawesi Sea and into the Makassar Strait. From the Makassar Strait, some flows into the Indian Ocean via the Lombok Strait, with the rest flowing to the Flores Sea, and then eastward into the Banda Sea [Gordon et al., 2003; Koch-Larrouy et al., 2008]. Relatively fresh surface water from the South China Sea is advected across the shallow Sunda Shelf and through the Java Sea, and into the southern Makassar Strait and Flores Sea [Fang et al., 2010].

Approximately $2.5 \mathrm{~Sv}$ of Southern Source Waters enter the ITF through the Eastern Passages between Sulawesi and Irian Jaya [Van Aken et al., 2009]. The 
Southern Source Water is composed of both of Antarctic $\left(\theta=-1.31^{\circ} \mathrm{C}\right.$, salinity $=$ 34.62) and Subantarctic water $\left(\theta=5.09^{\circ} \mathrm{C}\right.$, salinity $\left.=34.25\right)$ (potential temperature and salinity estimates are from Gebbie and Huybers [2011]). Water from the Eastern Passages, Makassar Strait and Java Sea enter the Banda Sea, where vigorous vertical mixing, both tidal and wind driven, combines the water masses, mixing down relatively fresh surface water throughout the column [Koch-Larrouy et al., 2008], and creating characteristic cool, low-salinity ITF water [Fang et al., 2010; Gordon et al., 2003]. This ITF water then flows into the Indian Ocean via the Ombai Strait and the Timor Sea.

Though a relatively small net volumetric contribution [Fang et al., 2010], the flow from the South China Sea plays a key role in setting the character of ITF water and transport [Gordon et al., 2003; Koch-Larrouy et al., 2008]. It has been proposed that the advection of freshwater from the South China Sea (Figure S1) creates a northward pressure gradient within the Makassar Strait, increasing the residence time of surface water in the Strait, resulting in thermocline-intensified flow [Gordon et al., 2003]. We suggest an alternate explanation is required since the reduced surface flow relative to the thermocline occurs throughout the year [Gordon et al., 2008], even in boreal summer when the surface flow is towards the South China Sea. In all seasons, the sea level of the southern Java Sea is higher than the Banda Sea [Carton and Giese, 2008] (Figure S1-3). The resulting pressure gradient may be associated with a northward geostrophic flow that opposes southward transport through the Makassar Strait. Since the sill between the Java Sea and the ITF is only 
$40 \mathrm{~m}$, this pressure gradient is not present at thermocline depths, explaining the relatively enhanced subsurface flow.

Previous studies have shed light on the role of the South China Sea Throughflow by focusing on the effect of the flooding of the shallow Sunda Shelf $\sim 10,000$ years before present (yr BP). This flooding opened a connection for South China Sea Throughflow to enter the Makassar Strait, freshening the ITF relative to the Western Pacific Warm Pool [Linsley et al., 2010]. Additionally, cooling in the thermocline of the ITF outflow was attributed to thermocline intensified flow that resulted from this fresh South China Sea inflow [Xu et al., 2008]. Previous work has also shown that the deglacial sea surface temperature (SST) changes in the Makassar Strait and Antarctica were synchronous [Visser et al., 2003]. The link was attributed to a switch between an El Niño-like climate during glacial times to a La Niña-like climate during deglacial times.

Here, we evaluate the link between high latitude southern hemisphere temperatures and the ITF in greater detail, and re-evaluate the influence of the South China Sea on SST. We present core-top and downcore Mg/Ca-based SST estimates, using the surface mixed-layer planktic foraminifera Globigerinoides ruber (G. ruber), to study past changes in the SST of the ITF region.

\section{Materials and Methods}

Approximately, 40 G. ruber (white, morphotype sensu stricto; 212-300um) were used for $\mathrm{Mg} / \mathrm{Ca}$ analysis. Samples were gently crushed; cleaned using a 
method that included reductive followed by oxidative steps; and run on an Element XR ICP-MS at Rutgers University or an Element 2 ICP-MS at Woods Hole Oceanographic Institution.

The age models for all sediment records presented here are based on the radiocarbon ages of planktic foraminifera (Appendix A). All radiocarbon ages were converted to calendar ages using the Marine09 calibration [Reimer et al., 2009] and no local reservoir age adjustment (see also supplementary discussion).

\section{Results:}

In agreement with a previous study [Arbuszewski et al., 2010], and in contrast with another [Mathien-Blard and Bassinot, 2009], our new core top data, in conjunction with data from other regions [Arbuszewski et al., 2010; Dahl and Oppo, 2006; Ferguson et al., 2008; McConnell and Thunell, 2005; Mohtadi et al., 2011a; Regenberg et al., 2006], demonstrate that there is no discernable salinity influence on the $\mathrm{Mg} / \mathrm{Ca}$-based temperature estimates of G. ruber at low salinities. Arubszewski et al. [2010] suggest this threshold is 35 . With more data from fresh regions, we suggest the threshold is 36 (Figure 2 and supplementary discussion); thus, we can interpret the $\mathrm{Mg} / \mathrm{Ca}$ data strictly in terms of temperature with no correction for salinity effects.

Our new high-resolution SST record from the Savu Sea (GeoB10069-3, here 69-3) is bathed in water supplied by the ITF entering the Indian Ocean (Figure 1) via the Ombai Strait. In addition we generated a high-resolution SST record from the 
Flores Sea (BJ8-03 136GGC, here 136GGC) and a low-resolution SST record from the Makassar Strait (BJ8-03-23GGC, here 23GGC).

We group temperature reconstructions of our new records and published records into three regions: the Western Pacific Warm Pool [Rosenthal et al., 2003; Stott et al., 2007], the Southern Makassar Strait [Linsley et al., 2010; Visser et al., 2003], and the outflow of the ITF [Levi et al., 2007; Xu et al., 2008] (Figure 1, Table S1), and reconstruct regional averages (Figure 3 and 4). We include 136GGC in our Makassar Strait group since it is geographically close, though it is in the nearby Flores Sea.

Western Pacific Warm Pool SSTs warmed continuously throughout the deglacial as noted previously [Kiefer and Kienast, 2005]. This continuous warming lacked the characteristic millennial scale variability of Antarctic records. Western Pacific Warm Pool SSTs peaked at $\sim 10,000$ yr BP, and cooled slightly during the remainder of the Holocene (Figures 3,4).

Deglacial SST evolution in the Southern Makassar Strait differed from the Western Pacific Warm Pool. The three longer records suggest a plateau in warming that began at $\sim 14,000 \mathrm{yr}$ BP and lasted $\sim 2,000 \mathrm{yr}$. These sites then warmed until $\sim 8,000$ yr BP (Figure 3,4). SSTs in the Makassar Strait cool only slightly after peaking in the mid-Holocene.

In the ITF outflow sites, SSTs rose from $\sim 20,000 \mathrm{yr}$ BP (Figures 3,4) to $\sim 15,000$ yr BP, remained constant between $\sim 15,000$ yr BP and $\sim 12,000$ yr BP, peaked at $\sim 10,000 \mathrm{yr} \mathrm{BP}$ and then cooled by about $1^{\circ} \mathrm{C}$ into the late Holocene. The temperature pattern of the outflow records differs from the pattern in other areas of 
the eastern Indian Ocean. For example, SST reconstructions from sites to the north of the outflow, off the coasts of western Java and central Sumatra, differ in that they show continuous warming from 20,000 yr BP until $~ 5,000 \mathrm{yr}$ BP and lack a Holocene cooling [Mohtadi et al., 2010].

\section{Discussion:}

A strong Antarctic-type signal [e.g. Kawamura et al., 2007] is seen in the outflow sites (Figure 4). Not only did warming at each of the sites cease during the Antarctic Cold Reversal (Figure 3), but the sites reached peak temperature at approximately the same time as Antarctica, and then cooled in concert with the Indian Ocean sector of Antarctica. In fact, the outflow passage SST stack correlates more strongly with the Dome Fuji record than it does with either the WPWP or Makassar Strait stack (Table S3). This deglacial and Holocene temperature pattern is also suggested in a SST reconstruction from the Chatham Rise, east of New Zealand [Pahnke et al., 2003] (Figure 4). The close correspondence between all these records suggests a strong high-latitude southern hemisphere imprint on SSTs of the outflow region.

We propose that the similar deglacial SST trends in the ITF outflow and highlatitude southern hemisphere are due to the direct oceanic connection between Southern Source Water and the ITF provided by the Eastern Passages [Van Aken et al., 2009]. Additionally, while small, the deep flow in the Timor Sea is from the Indian Ocean [Sprintall et al., 2009], which may contribute Southern Source Water to the ITF. The Southern Source Water is mixed throughout the water column in the 
Banda Sea, and thus affects ITF outflow SSTs. Although the inflow of Southern Source Water through the deep Eastern Passages only makes up 20\% of the ITF [Van Aken et al., 2009], the apparently much larger reconstructed temperature variations at the higher latitudes (as seen at the Chatham Rise [Pahnke et al., 2003]) would cause water sourced from these high southern latitude regions to have a disproportionate influence in the southern Indonesian region.

We test whether our hypothesis of a Southern Source Water influence at the outflow passages is consistent with modern observations of the ITF. We estimate the portion of Southern Source Water (SSW) required to cause the Holocene SST decrease in the outflow passages using the following equations:

Equation 1: $\mathrm{T}_{\text {ITF outflow }}\left(\mathrm{t}_{1}\right)=\alpha_{\text {ssw }} \mathrm{T}_{\text {ssw }}\left(\mathrm{t}_{1}\right)+\Sigma \alpha_{\mathrm{i}} \mathrm{T}_{\mathrm{i}}\left(\mathrm{t}_{1}\right)$

Equation 2: $\mathrm{T}_{\text {ITF outflow }}\left(\mathrm{t}_{2}\right)=\alpha_{\text {ssw }} \mathrm{T}_{\text {ssw }}\left(\mathrm{t}_{2}\right)+\Sigma \alpha_{\mathrm{i}} \mathrm{T}_{\mathrm{i}}\left(\mathrm{t}_{2}\right)$

Where $T_{\text {ITF outflow }}\left(t_{i}\right)$ is the outflow temperature at time $t_{i}$. This temperature is determined by the water temperature at all source regions and the portion of water $(\alpha)$ that comes from each source region. Using the Chatham Rise record to estimate the temperature of the Southern Source Water $\left(\mathrm{T}_{\text {ssw }}\right)$, we estimate the portion of SSW $\left(\alpha_{\text {ssw }}\right)$ required to cause the Holocene cooling in the outflow passages. The SSTs at all other source regions are assumed unchanged. Equation 2 is subtracted from Equation 1 to obtain:

$\Delta \mathrm{T}_{\text {ITF outflow }}=\alpha_{\text {ssw }} \Delta \mathrm{T}_{\text {ssw }}$

The temperature change from the Early to Late Holocene is $\sim 1.2^{\circ} \mathrm{C}$ at the outflow passages ( $\Delta \mathrm{T}_{\text {ITF outflow }}$ ), and $\sim 3^{\circ} \mathrm{C}$ at the Chatam rise $\left(\Delta \mathrm{T}_{\text {ssw }}\right.$ ) [Pahnke et al., 2003]. This would require the ITF to be composed of $40 \%$ Southern Source Water, 
which is much higher than the $20 \%$ ( $2.5 \mathrm{~Sv}$ of a total $13 \mathrm{~Sv}$ transport) suggested by the INSTANT monitoring program [Gordon et al., 2010; Van Aken et al., 2009]. We note, however, that a Holocene TEX 86 record off the coast of West Antarctica shows a $6^{\circ} \mathrm{C}$ Holocene cooling [Shevenell et al., 2011]. Weighting the Chatham Rise record and the West Antarctica record equally suggests a $4.5^{\circ} \mathrm{C}$ cooling in Southern Source Water. This reduces the portion of Southern Source Water required to $\sim 25 \%$. If the other source regions for the ITF in fact cooled slightly (the WPWP average cools by $0.6^{\circ} \mathrm{C}$, Fig 4), then even less Southern Source Water would be required.

In summary, if the Chatham Rise is representative of Southern Source Water temperature entering the ITF, and the temperature at the rest of the source regions to the ITF did not change over the course of the Holocene, our proposed mechanism is not consistent with the most recent modern observations of the ITF. However, if we consider additional temperature records from Southern Source regions and the apparent cooling of the WPWP, then our proposed mechanism is consistent with modern estimates of ITF transport.

Though Makassar Strait SSTs appear to follow an Antarctic pattern through the deglacial, during the Holocene, Makassar Strait SST warms compared to both the outflow passages and Antarctic trends. We hypothesize that the warming of the Makassar Strait is due to a change in the influence of Banda Sea water. In the modern, some Banda Sea water enters the Makassar Strait during the southeast monsoons [Fallon and Guilderson, 2008; Gordon et al., 2003]. We propose that prior to the flooding of the Sunda Shelf there was a greater influx of Banda Sea water. After the flooding of the Sunda Shelf, the influence of the South China Sea increased 
the residence time of the surface waters within the Makassar Strait, which warmed the Makassar Strait relative to the ITF outflow passages. We suggest that the reduction of surface transport through the Makassar Strait trapped a portion of the heat that was previously exported, leading to a surface warming in the Makassar Strait.

We draw on our new data, modern observations, and a modeling study to suggest that there was no discernable effect of the flooding of the Sunda Shelf on the SST of the ITF outflow. We note that both before and after the Sunda Shelf flooding, outflow temperatures closely follow Antarctic temperature trends.

As described above, today, the South China Sea Throughflow into the southern Makassar Strait reduces surface transport through the Makassar Strait. Results from an Ocean General Circulation Model suggest that this reduction in surface transport leads to a $0.18 \mathrm{PW}\left(1 \mathrm{PW}=10^{15}\right.$ Watts $)$ decrease in heat transport through the Makassar Strait, lowering the Makassar Strait transport-weighted temperature by $2^{\circ} \mathrm{C}$ [Tozuka et al., 2007]. Here we hypothesize that this decrease in heat transport does not result in cooler outflow temperatures as previously suggested [Gordon et al., 2003]. Modern observations show that the South China Sea Throughflow is a source of $0.2 \mathrm{PW}$ of heat to the ITF [Qu et al., 2006], enough to compensate for the decreased heat transport through the Makassar Strait, implying a zero net balance for the heat budget of the ITF outflow. Therefore, we propose that the opening of the Java Sea that occurred with the flooding of the Sunda Shelf at $\sim 9,500$ yr BP did not influence ITF outflow surface temperatures. Rather, we 
postulate that the deglacial and Holocene trends in the ITF outflow SSTs are due to the influence of high latitude southern hemisphere temperature.

We explore alternate hypotheses to explain our temperature reconstructions, some of which we are able to rule out, while others require further work. These hypotheses include an ENSO-like teleconnection, changes in local insolation, changes in wind driven mixing, and changes in tidal mixing.

It is possible that a direct atmospheric connection with Antarctica [Visser et al., 2003] is the source of the deglacial SST variability in the ITF outflow records. However, the absence of a significant correlation between ENSO and SSTs in the outflow region during the instrumental era (Figure S4) strongly suggests that an ENSO-Antarctica teleconnection is not the source of the connection between the ITF and Antarctica.

Changes in radiative forcing via either mean annual insolation or $\mathrm{CO}_{2}$ are unlikely to be the source of the SST variability in the outflow region. Firstly, we note that all three regions (WPWP, the Makassar Strait, and the Outflow Passages) would experience similar radiative forcing as they are geographically close. Additionally, peak SSTs in our outflow region occur at 10,000 BP, coincident with a minimum in mean annual insolation (Fig S5) [Laskar et al., 2004]. Similarly, $\mathrm{CO}_{2}$ values rise during most of the Holocene [Monnin et al., 2004], so $\mathrm{CO}_{2}$ greenhouse warming would not explain the cooling in our outflow passages.

A change in wind-driven upwelling is another potential source of variability in the outflow passages. The percentage of Globigerina bulloides (G. bulloides) relative to the total number of planktic foraminifera was used as a proxy for 
upwelling, with a higher percent of $G$. bulloides corresponding to more upwelling [Prell, 1984]. The percent of G. bulloides in both 69-3 and a nearby site off the southern coast of Java (10053-7) [Mohtadi et al., 2011b] suggest there is a peak in upwelling at $\sim 10,000 \mathrm{BP}$, with a decrease in upwelling throughout the Holocene (Fig S5). If upwelling were the primary control on SSTs in the outflow passages, we would expect coolest SSTs at 10,000 BP and increasing SSTs throughout the remainder of the Holocene. However, our SST reconstructions show the opposite trend.

The transformation of water properties within the Indonesian Sea has been attributed to tidal mixing [Ffield and Gordon, 1996]. Modeling results suggest that tides cause a majority of the mixing that occurs within the ITF [Koch-Larrouy et al., 2008]. Changes in sea level [e.g. Clark and Mix, 2002] likely altered the amount of tidal mixing, and in particular how tidal dissipation was partitioned between the continental shelves and the deep ocean [Egbert et al., 2004; Wunsch, 2005]. The degree to which changes in sea level may have changed the mixing within the ITF is unknown. Even today, estimates of tidal dissipation within the ITF region suffer from large uncertainties [Ray et al., 2005]. In the modern, much of the tidal mixing occurs when the main flowpath of the ITF is over shallow sills or narrow passages [Hautala et al., 1996; Ray et al., 2005]. Since the vertical mixing at these choke points is influenced by the details of sill topography [Hatayama, 2004] past sea level differences may have changed the location and/or amount of tidal mixing. The degree to which mixing within the Indonesian Seas changed in the past could be empirically evaluated with benthic foraminifera temperature reconstructions along 
depth transects. Within the modern Banda Sea, the entire water column is mixed, but the intensity of local insolation restratifies the water column with respect to temperature. In the modern, temperatures are uniform only below $1,000 \mathrm{~m}$ [Tomczak and Godfrey, 1994]. A change in depth of this temperature gradient would suggest a change in mixing intensity. This, along with modeling the influence of reduced sea level on the mixing that occurs at the ITF's choke points would give insight into the potential role of changes in tidal mixing on ITF water properties.

\section{Conclusions:}

Our study demonstrates a persistent link between SSTs in the eastern ITF outflow region and high latitude southern hemisphere temperature during the last 20,000 years, which we suggest is through an oceanic pathway. Southern Source Water enters the Indonesian Seas primarily through the Eastern Passages and to a lesser extent through the Timor Stait. Subsequently, it is mixed upward in the Banda Sea, where it enters the main ITF. This direct oceanic connection between Antarctic temperature and tropical SSTs would allow the transmission of southern high latitude climate signals to the ITF outflow and into the Indian Ocean. Our proposed mechanism of a direct oceanic connection appears as a testable hypothesis of the modern controls on the ITF outflow.

Our results also highlight the importance of the South China Sea Throughflow for sea surface temperatures in the ITF region. Prior to the establishment of the South China Sea Throughflow, southern hemisphere climate had a greater impact on Makassar Strait SST. The South China Sea Throughflow, however, changed the 
surface circulation so that the Makassar Strait was no longer strongly influenced by the southern hemisphere. Makassar Strait SSTs warmed, and remained elevated throughout the Holocene. 


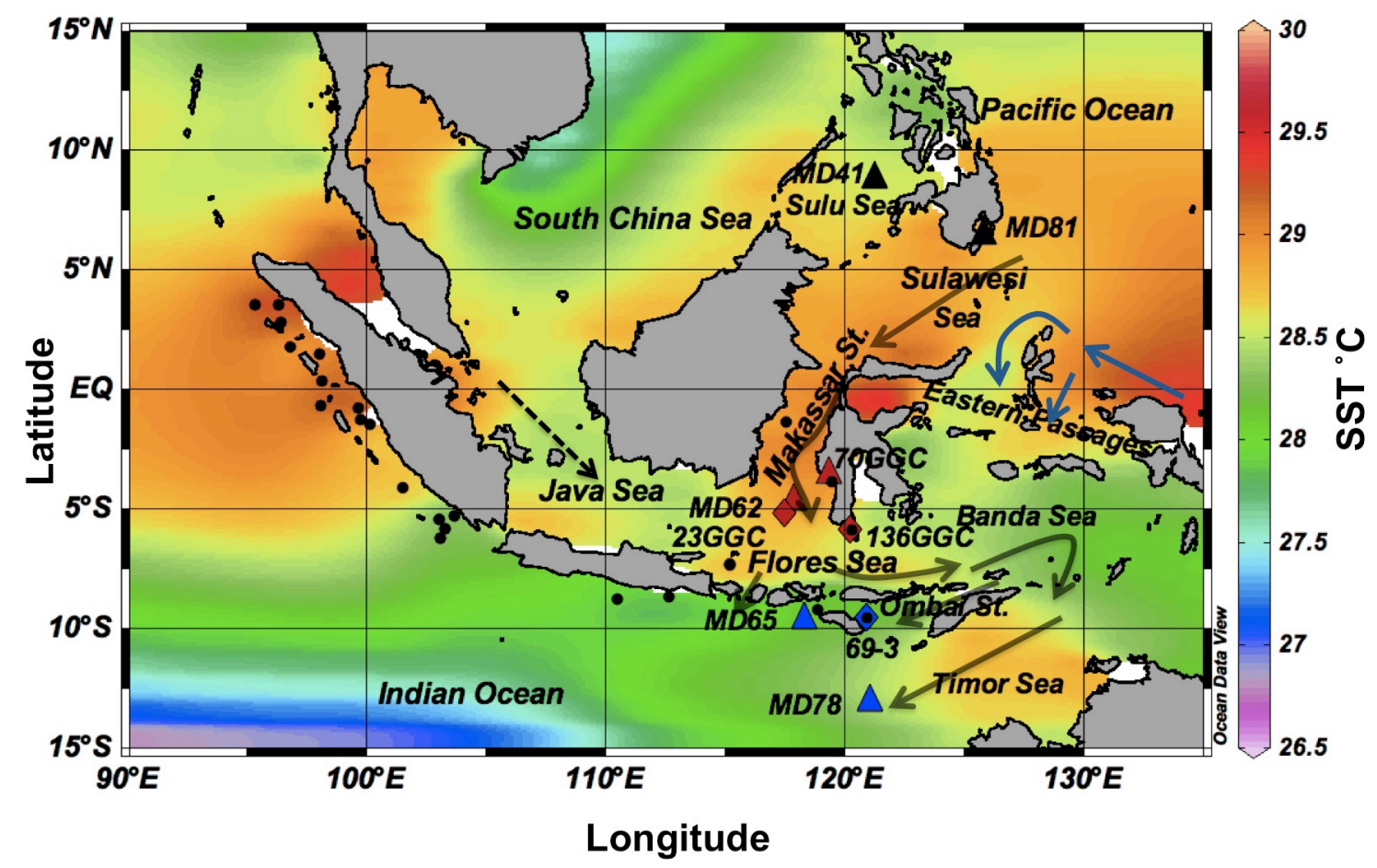

\section{Figure 1:}

Map of the Indonesian Throughflow area. The primary flow path of surface water is shown in gray arrows. The freshwater flow from the Java Sea is indicated by a dashed arrow. The flow of deep water through the Eastern Passages is shown by blue arrows. Coretops are indicated by filled circles, new downcore records are indicated with diamonds, and triangles indicate downcore data from previously published records. Black triangles correspond to Western Pacific Warm Pool sites, red triangles and diamonds with Maskassar Strait sites, and blue triangles and dimonds with outflow passage sites. This color coding corresponds with the records shown in figures 3-4. Background color shows mean annual SST from the World Ocean Atlas 05 dataset [Locarnini et al., 2006]. 


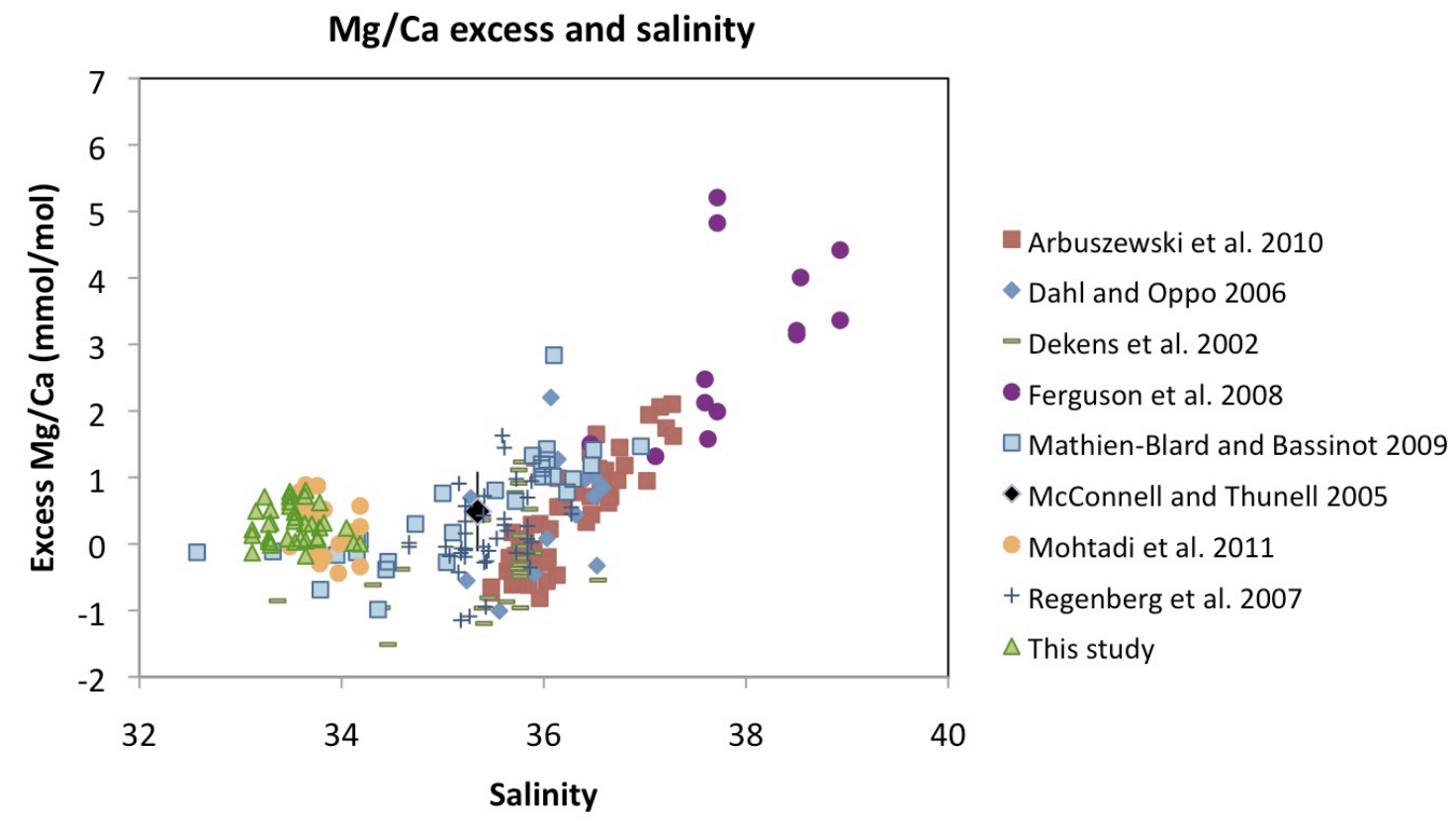

Figure 2:

Coretop excess Mg/Ca versus salinity. Excess Mg/Ca [Arbuszewski et al., 2010] is calculated by subtracting the expected $\mathrm{Mg} / \mathrm{Ca}$ based on observed sea surface temperatures from measured $\mathrm{Mg} / \mathrm{Ca}$. These data suggest that the influence of salinity on $\mathrm{Mg} / \mathrm{Ca}$ is small below 36. 


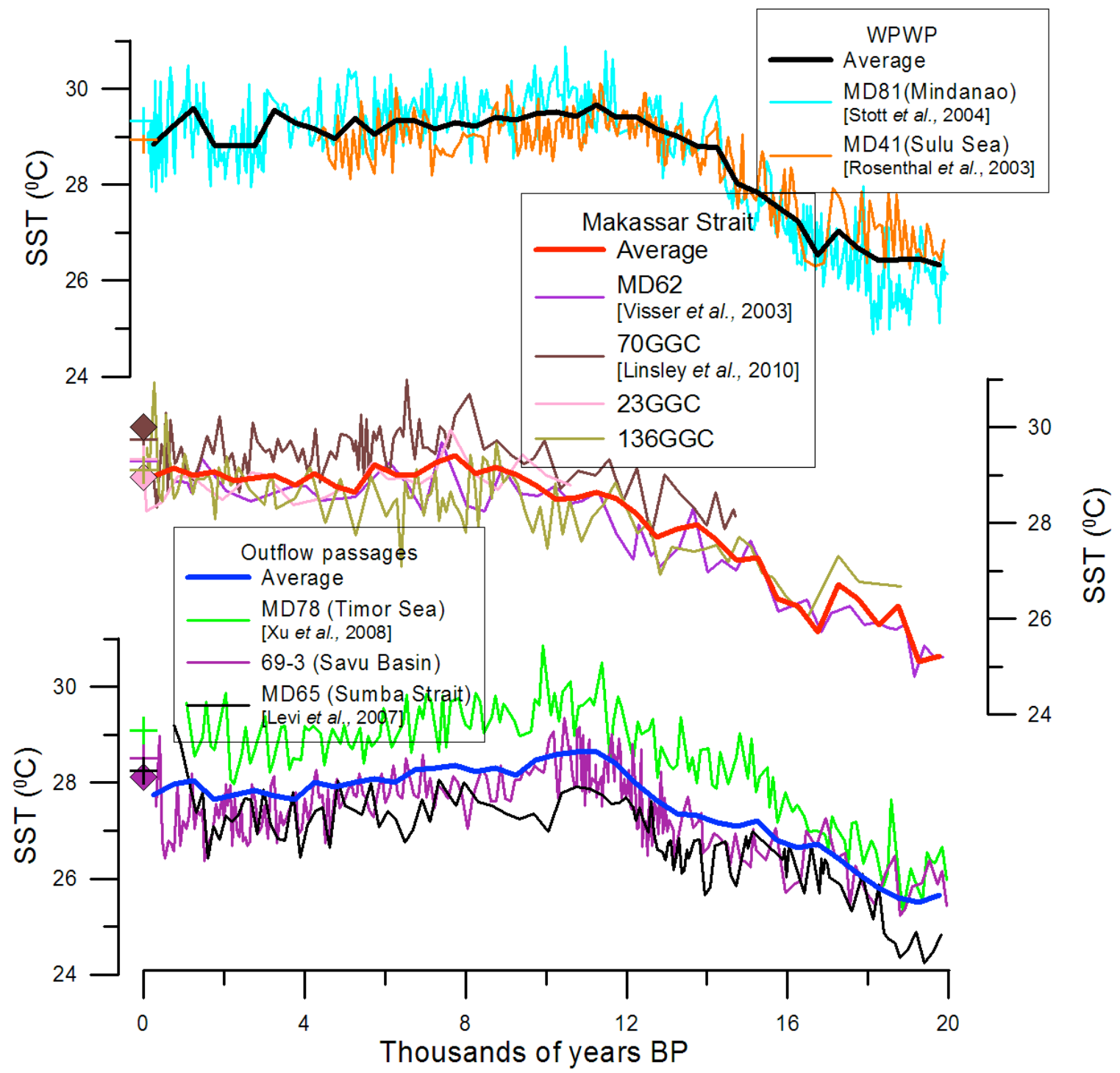

\section{Figure 3:}

$\mathrm{Mg} / \mathrm{Ca}-\mathrm{based}$ sea surface temperature estimates from this paper, along with previously published data. All records are converted to temperature using a multispecies equation [Anand et al., 2003], except for MD41, for which we used the published sea surface temperatures [Rosenthal et al., 2003] (see also the supplementary discussion). Thin lines connect raw data, bold lines are 500 year averages from the Western Pacific Warm Pool (black), the Makassar Strait (red), and the outflow passages (blue). Mean annual sea surface temperatures measured by satellite are indicated for each core site (+) and modern sea surface temperature estimates from multi-core samples are indicated by diamonds. 


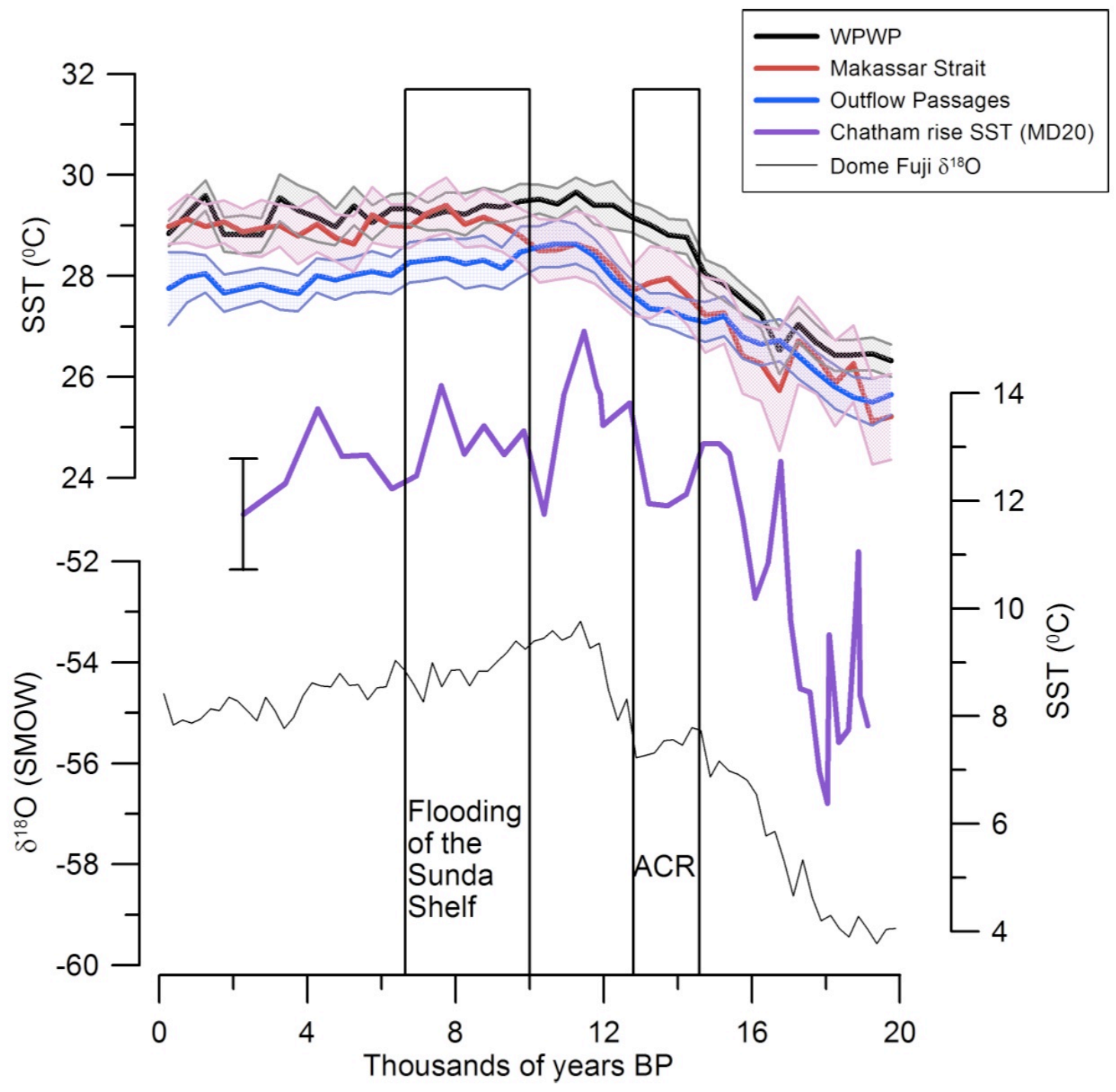

\section{Figure 4:}

Comparison of sea surface temperature records to Southern Hemisphere records. $\mathrm{Mg} / \mathrm{Ca}$-based sea surface temperature records, placed into 500-year, nonoverlapping bins and averaged, with the shading around the bins representing the propagated error that includes both the analytical error and the error in the $\mathrm{Mg} / \mathrm{Ca}$ temperature calibration (see supplementary discussion for a detailed discussion). A $\mathrm{Mg} / \mathrm{Ca}$-based sea surface temperature record from the Chatham Rise [Pahnke et al., 2003] is shown in purple (vertical bar is uncertainty, see supplementary discussion for details) and $\delta^{18} 0$ from the Indian Ocean sector of Antarctica (Dome Fuji) is shown in black [Kawamura et al., 2007]. Black rectangles denote the Antarctic Cold Reversal (timing inferred from Dome Fuji data) and the timing of the Sunda Shelf flooding [Sathiamurthy and Voris, 2006]. 
Anand, P., et al. (2003), Calibration of $\mathrm{Mg} / \mathrm{Ca}$ thermometry in planktonic foraminifera from a sediment trap time series, Paleoceanography, 18(2), 15. Arbuszewski, J., et al. (2010), On the fidelity of shell-derived $\delta 180$ seawater estimates, Earth and Planetary Science Letters, 300(3-4), 185-196.

Carton, J. A., and B. S. Giese (2008), A Reanalysis of Ocean Climate Using Simple Ocean Data Assimilation (SODA), Monthly Weather Review, 136, 2999-3017. Clark, P. U., and A. C. Mix (2002), Ice sheets and sea level of the Last Glacial Maximum, Quaternary Science Reviews, 21(1-3), 1-7.

Dahl, K. A., and D. W. Oppo (2006), Sea surface temperature pattern reconstructions in the Arabian Sea, Paleoceanography, 21.

Egbert, G. D., et al. (2004), Numerical modeling of the global semidiurnal tide in the present day and in the last glacial maximum, Journal of Geophysical ResearchOceans, 109(C3).

Fallon, S. J., and T. P. Guilderson (2008), Surface water processes in the Indonesian throughflow as documented by a high-resolution coral D14C record, Journal of Geophysical Research, 113, C09001.

Fang, Q., et al. (2010), Volume, heat, and freshwater transports from the South China Sea to Indonesian seas in the boreal winter of 2007-2008, Journal Of Geophysical Research, 115(C12020).

Ferguson, J. E., et al. (2008), Systematic change of foraminiferal Mg/Ca ratios across a strong salinity gradient, Earth and Planetary Science Letters, 265, 153-166.

Ffield, A., and A. L. Gordon (1996), Tidal Mixing Signatures in the Indonesian Seas, Journal of Physical Oceanography, 26, 1924-1937.

Gebbie, G., and P. Huybers (2011), How is the ocean filled?, Geophysical Research Letters, 38.

Gordon, A. L., et al. (2003), Cool Indonesian throughflow as a consequence of restricted surface layer flow, Nature, 425(6960), 824-828.

Gordon, A. L., et al. (2008), Makassar Strait throughflow, 2004 to 2006, Geophysical Research Letters, 35(24).

Gordon, A. L., et al. (2010), The Indonesian throughflow during 2004-2006 as observed by the INSTANT program, Dynamics of Atmospheres and Oceans, 50(2), 115-128.

Hatayama, T. (2004), Transformation of the Indonesian throughflow water by vertical mixing and its relation to tidally generated internal waves, Journal of Oceanography, 60(3), 569-585.

Hautala, S. L., et al. (1996), The distribution and mixing of Pacific water masses in the Indonesian Seas, Journal Of Geophysical Research-Oceans, 101(C5), 12375-12389. Kawamura, K., et al. (2007), Northern Hemisphere forcing of climatic cycles in Antarctica over the past 360,000 years, Nature, 448, 912-916.

Kiefer, T., and M. Kienast (2005), Patterns of deglacial warming in the Pacific Ocean: a review with emphasis on the time interval of Heinrich event 1, Quaternary Science Reviews, 24, 1063-1081.

Koch-Larrouy, A., et al. (2008), Water mass transformation along the Indonesian throughflow in an OGCM, Ocean Dynamics, 58(3-4), 289-309.

Laskar, J., et al. (2004), A long-term numerical solution for the insolation quantities of the Earth, Astronomy \& Astrophysics, 428(1), 261-285. 
Levi, C., et al. (2007), Low-latitude hydrological cycle and rapid climate changes during the last deglaciation, Geochemistry Geophysics Geosystems, 8(5), Q05N12. Linsley, B. K., et al. (2010), Holocene evolution of the Indonesian throughflow and the western Pacific warm pool, Nature Geoscience, 3, 578-583.

Locarnini, R. A., et al. (2006), World Ocean Atlas 2005, Volume 1: Temperature, NOAA Atlas NESDIS 61.

Mathien-Blard, E., and F. Bassinot (2009), Salinity bias on the foraminifera $\mathrm{Mg} / \mathrm{Ca}$ thermometry: Correction procedure and implications for past ocean hydrographic reconstructions, Geochemistry Geophysics Geosystems, 10(12).

McConnell, M. C., and R. C. Thunell (2005), Calibration of the planktonic foraminifera $\mathrm{Mg} / \mathrm{Ca}$ paleothermometer: Sediment trap results from the Guaymas Basin, Gulf of California, Paleoceanography, 20(PA2016).

Mohtadi, M., et al. (2010), Glacial to Holocene surface hydrography of the tropical eastern Indian Ocean, Earth and Planetary Science Letters, 292, 89-97.

Mohtadi, M., et al. (2011a), Reconstructing the thermal structure of the upper ocean: Insights from planktic foraminifera shell chemistry and alkenones in modern sediments of the tropical eastern Indian Ocean, Paleoceanography, 26.

Mohtadi, M., et al. (2011b), Glacial to Holocene swings of the Australian-Indonesian monsoon, Nature Geoscience, 4(8), 540-544.

Monnin, E., et al. (2004), Evidence for substantial accumulation rate variability in Antarctica during the Holocene, through synchronization of $\mathrm{CO} 2$ in the Taylor Dome, Dome C and DML ice cores, Earth and Planetary Science Letters, 224(1-2), 45-54.

Pahnke, K., et al. (2003), 340,000-Year Centennial-Scale Marine Record of Southern Hemisphere Climatic Oscillation, Science, 301(948), 948-952.

Prell, W. L. (1984), Variation of Monsoonal Upwelling: A response to changing solar radiation, Climatic Processes and Climate Sensitivity; Geophysical Monograph, 29, 4857.

Qu, T., et al. (2006), South China Sea throughflow: A heat and freshwater conveyor, Geophysical Research Letters, 33(L23617), doi:10.1029/2006GL028350.

Ray, R. D., et al. (2005), A Brief Overview of Tides in the Indonesian Seas, Oceanography, 18(4), 74-87.

Regenberg, M., et al. (2006), Assessing the effect of dissolution on planktonic foraminiferal $\mathrm{Mg} / \mathrm{Ca}$ ratios: Evidence from Caribbean core tops, Geochemistry Geophysics Geosystems, 7(7).

Reimer, P. J., et al. (2009), INTCAL09 AND MARINE09 Radiocarbon age calibration curves, 0-50,000 years cal BP, Radiocabon, 51(4), 1111-1150.

Rosenthal, Y., et al. (2003), The amplitude and phasing of climate change during the last deglaciation in the Sulu Sea, western equatorial Pacific, Geophysical Research Letters, 30(8).

Sathiamurthy, E., and H. Voris (2006), Maps of Holocene Sea Level Transgression and Submerged Lakes on the Sunda Shelf, The Natural History Journal of Chulalongkorn University, Supplement 2, 1-44.

Shevenell, A. E., et al. (2011), Holocene Southern Ocean surface temperature variability west of the Antarctic Peninsula, Nature, 470, 250-254.

Sprintall, J., et al. (2009), Direct estimates of the Indonesian Throughflow entering the Indian Ocean: 2004-2006, Journal of Geophysical Research-Oceans, 114. 
Stott, L., et al. (2007), Southern Hemisphere and Deep-Sea Warming Led Deglacial Atmospheric CO2 Rise and Tropical Warming, Science, 318, 435-438.

Tomczak, M., and J. S. Godfrey (1994), Regional Oceanography: An Introduction, Butterworth-Heinemann.

Tozuka, T., et al. (2007), Dramatic impact of the South China Sea on the Indonesian Throughflow, Geophysical Research Letters, 34(12).

Van Aken, H. M., et al. (2009), The deep-water motion through the Lifamatola Passage and its contribution to the Indonesian throughflow, Deep-Sea Research Part I, 56, 1203-1216.

Visser, K., et al. (2003), Magnitude and timing of temperature change in the IndoPacific warm pool during deglaciation, Nature, 421, 152-155.

Wunsch, C. (2005), Speculations on a schematic theory of the Younger Dryas, Journal of Marine Research, 63(1), 315-333.

$\mathrm{Xu}$, J., et al. (2008), Changes in the thermocline structure of the Indonesian outflow during Terminations I and II, Earth and Planetary Science Letters, 273(1-2), 152-162. 


\section{Supplementary material:}

\section{Coretop study - The influence of salinity on the $\mathrm{Mg} / \mathrm{Ca}$-temperature relationship}

All our samples for the coretop study were taken with a multi-coring device on three cruises in the Indonesian Throughflow region and the Eastern Indian Ocean (Figure 1, dots; also see Appendix B).

The influence of salinity on $\mathrm{Mg} / \mathrm{Ca}$ was explored by combining our new coretop data with previously published G. ruber data. All our samples were prepared using a full trace metal cleaning, including reductive and oxidative steps [Boyle and Keigwin, 1985/6; Rosenthal et al., 1997]. However, some of the previously published data were from samples that were not cleaned with a reductive step. To account for this, we added $10 \%$ to the $\mathrm{Mg} / \mathrm{Ca}$ of all samples cleaned using both oxidation and reduction following Abruszewski et al. [2010].

We evaluate how well the $\mathrm{Mg} / \mathrm{Ca}$ measurements predict temperature by calculating the "excess Mg/Ca" [Arbuszewski et al., 2010].

Excess $\mathrm{Mg} / \mathrm{Ca}=$ measured $\mathrm{Mg} / \mathrm{Ca}-$ predicted $\mathrm{Mg} / \mathrm{Ca}$

In order to determine predicted Mg/Ca we used the Anand et al. [2003] multispecies calibration in conjunction with modern data from either World Ocean Atlas 2005 (WOA05) temperature data [Locarnini et al., 2006], or the temperature data presented in the original publication. 
Anand multispecies equation: $\frac{M g}{C a}=0.38 e^{0.09 T}$

When excess Mg/Ca is compared with salinity (again either WOA05 data [Antonov et al., 2006] or the salinity from the original publication was used), there is no correlation below 36 (Figure $2, \mathrm{r}^{2}=0.001$ ). This finding supports a recent paper which found a salinity threshold of 35 [Arbuszewski et al., 2010], but conflicts with another, which suggests that the influence of salinity on $\mathrm{Mg} / \mathrm{Ca}$ is a concern at all salinities [Mathien-Blard and Bassinot, 2009]. This discrepancy is likely due to two reasons. First there were very few $\mathrm{Mg} / \mathrm{Ca}$ data from relatively fresh sites in previous publications. The new data presented here address this issue. Secondly, one must use caution if using $\delta^{18} \mathrm{O}_{\text {calcite }}$ and $\delta^{18} \mathrm{O}_{\text {seawater }}$ measurements to estimate calcification temperature.

We did not consider calculating the calcification temperature based on $\delta^{18} \mathrm{O}_{\text {calcite }}$ and $\delta^{18} \mathrm{O}_{\text {seawater }}$ because of the very limited $\delta^{18} \mathrm{O}_{\text {seawater }}$ data in our study area. We suggest the gridded database of $\delta^{18} \mathrm{O}_{\text {seawater [LeGrande and Schmidt, 2006] }}$ is not appropriate to use in this case because it uses both PO4* and salinity to

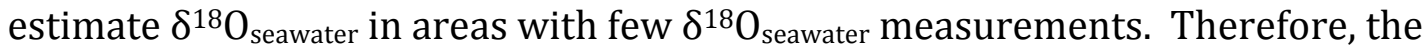
most robust manner to evaluate salinity's effect on $\mathrm{Mg} / \mathrm{Ca}$ is to calculate excess $\mathrm{Mg} / \mathrm{Ca}$ with modern temperature data and not estimated isotopic temperature. This avoids the circularity of including a salinity-based $\delta^{18} \mathrm{O}_{\text {seawater }}$ estimate in a comparison with salinity.

We also explored the influence of core depth on our samples by examining the relationship between $\mathrm{Mg} / \mathrm{Ca}$ excess and core depth (Figure S6, $\mathrm{R}^{2}=0.005$ ). The 
lack of correlation between depth and $\mathrm{Mg} /$ Ca suggests that preferential dissolution is not the source of the $\mathrm{Mg} / \mathrm{Ca}$ excess.

\section{Modern SST}

Modern SST data were downloaded from NASA's Ocean Color Radiometry Online Visualization and Analysis Global Monthly Products (http://reason.gsfc.nasa.gov/Giovanni/).

Our Mg/Ca-based modern temperature estimates for the Makassar Strait and ITF outflow regions are consistently cooler than satellite-derived mean annual temperature, though they are all within the seasonal range. This could be due to a growth preference during the upwelling season and/or because G. ruber may calcify throughout the upper $30 \mathrm{~m}$ [Wang, 2000], even in regions with a shallow mixed layer.

\section{Downcore records}

\section{Temperature calibration (cleaning method adjustments)}

Previous work [Arbuszewski et al., 2010; Barker et al., 2003; Rosenthal et al., 2004] has shown that the reductive step in $\mathrm{Mg} / \mathrm{Ca}$ cleaning reduces the $\mathrm{Mg} / \mathrm{Ca}$ of a sample by approximately $10 \%$. The $\mathrm{Mg} / \mathrm{Ca}$-temperature calibration [Anand et al., 2003] we used was based on samples that were cleaned without a reductive step. To account for this we add $10 \%$ to the $\mathrm{Mg} / \mathrm{Ca}$ of samples that were cleaned with the full (with oxidative and reductive steps) cleaning method [Boyle and Keigwin, 1985/6; Rosenthal et al., 1997]. 
Original Anand et al. (2003) multispecies equation [Anand et al., 2003]:

$$
\frac{M g}{C a}=0.38 e^{0.09 T}
$$

Revised equation for the full cleaning method:

$$
\begin{gathered}
\frac{M g}{C a}+0.1 \frac{M g}{C a}=0.38 e^{0.09 T} \\
\text { or } \\
\frac{M g}{C a}=0.345 e^{0.09 T}
\end{gathered}
$$

\section{Errors on our temperature estimates}

There are two primary sources of error in converting $\mathrm{Mg} / \mathrm{Ca}$ to temperature. The first is within the $\mathrm{Mg} / \mathrm{Ca}$-temperature calibration equation, and the second is the reproducibility of $\mathrm{Mg} / \mathrm{Ca}$ measurement.

We used the values and associated errors on the Anand multispecies equation [Anand et al., 2003]:

$$
\begin{aligned}
& \frac{M g}{C a}=b e^{a T} \\
& \mathrm{~b}=0.38(+/-0.02) ; \mathrm{a}=0.090(+/-0.003){ }^{\circ} \mathrm{C}^{-1} \\
& \text { or for the full cleaning equation: } \\
& \mathrm{b}=0.345(+/-0.02) ; \mathrm{a}=0.090(+/-0.003){ }^{\circ} \mathrm{C}^{-1}
\end{aligned}
$$

Our estimate of the reproducibility of our $\mathrm{Mg} / \mathrm{Ca}$ measurements is based on comparing samples from the same depth. The foraminifera from these duplicates were not homogenized prior to running, so this should be a conservative estimate of 
reproducibility based on both the natural variability that a sample may contain and instrumental error. The standard deviation of the $\mathrm{Mg} / \mathrm{Ca}$ difference between 17 such duplicates was 0.21 .

These two sources of error were propagated [Bevington and Robinson, 1992] as follows:

$\sigma_{S S T}^{2}=\left(\frac{\partial S S T}{\partial a} \sigma_{a}\right)^{2}+\left(\frac{\partial S S T}{\partial b} \sigma_{b}\right)^{2}+\left(\frac{\partial S S T}{\partial M g / C a} \sigma_{M g / C a}\right)^{2}$

where

$$
\frac{\partial S S T}{\partial a}=\frac{1}{a^{2}} \ln \left(\frac{M g}{b}\right),
$$$$
\frac{\partial S S T}{\partial b}=\frac{1}{a b},
$$

and

$$
\frac{\partial S S T}{{ }^{M g} / \mathrm{Ca}}=\frac{1}{a} \frac{1}{M g / C a}
$$

For each core, if there was a single data point in the 500 year bin, the error was simply $\sigma_{S S T}$, as determined above. If there was more than one temperature value within the 500 year bin, the errors were calculated in the following manner [Bevington and Robinson, 1992], where $\mathrm{n}$ is the number of data points in each bin, $\sigma_{\text {binSST }}^{2}=\frac{1}{n^{2}} \sum_{i=1}^{n} \sigma_{S S T i}^{2}$

The errors on each 500 year bin in the regional stack were determined by summing the square of the errors $\left(\sigma^{2}\right.$ binsST $)$ from each individual core. 


$$
\sigma_{\text {averageSST }}^{2}=\frac{1}{n^{2}} \sum_{i=1}^{n} \sigma_{\text {binSSTi }}^{2}
$$

The error on the Chatham Rise core (MD97-2120) was determined by propagating the reported analytical relative uncertainty (5.8\%) [Pahnke et al., 2003], and the reported calibration error $\left( \pm 0.8^{\circ} \mathrm{C}\right)$ [Mashiotta et al., 1999] which gives a total error of $\pm 1^{\circ} \mathrm{C}$.

Our approach to error propagation is conservative in that a portion of the calibration error is due to the analytical uncertainty in the $\mathrm{Mg} / \mathrm{Ca}$ measurements. By also including our analytical uncertainty in our error propagation we are likely overestimating the errors.

\section{Radiocarbon calibration and age model construction}

All radiocarbon dates were converted into calendar ages using the Calib 6.0 program and the Marine 09 calibration [Reimer et al., 2009]. No local reservoir correction was applied as modern measurements suggest the regional $\Delta \mathrm{R}$ is close to zero [Bowman, 1985; Southon et al., 2002]. The median probability was used for constructing age models. All dates used, and their associated errors, can be found in Appendix A.

In cases where the first standard deviation of calendar ages had two modes, we reported a range of calendar ages that encompasses both peaks, as a conservative estimate. In cases where we used a polynomial or linear fit, we estimated error at the age control points by summing the squares of both the 
radiocarbon calibration errors (first standard deviation) and an estimate of the polynomial's error at these points (also first standard deviation). These values are included in Appendix A.

For cores 23GGC, 70GGC, 136GGC, 69-3, MD62, and MD65, age models were constructed by linearly interpolation between dates. The age models for MD41, MD78, and MD81 were constructed by utilizing the equations listed below.

Polynomial for MD97-2141

$y=-0.00000000124 x^{5}+0.000001404 x^{4}-0.0007356 x^{3}+0.1782 x^{2}+31.90 x+4314$

$\mathrm{R}^{2}=0.979$

Linear fit for MD01-2378 (the intercept was set at 1050 years, to produce a realistic coretop age)

$y=48.884 x+1050$

$\mathrm{R}^{2}=0.991$

Polynomial for MD98-2181

$y=-0.000000002262 x^{4}+0.000004298 x^{3}+0.006586 x^{2}+4.412 x+107$

$\mathrm{R}^{2}=0.997$

There is also uncertainty in the age model of the Dome Fuji record of approximately $+/-1,000$ years [Kawamura et al., 2007]. For a detailed explanation of the errors associated in that age model, refer to that paper's supplementary material. 

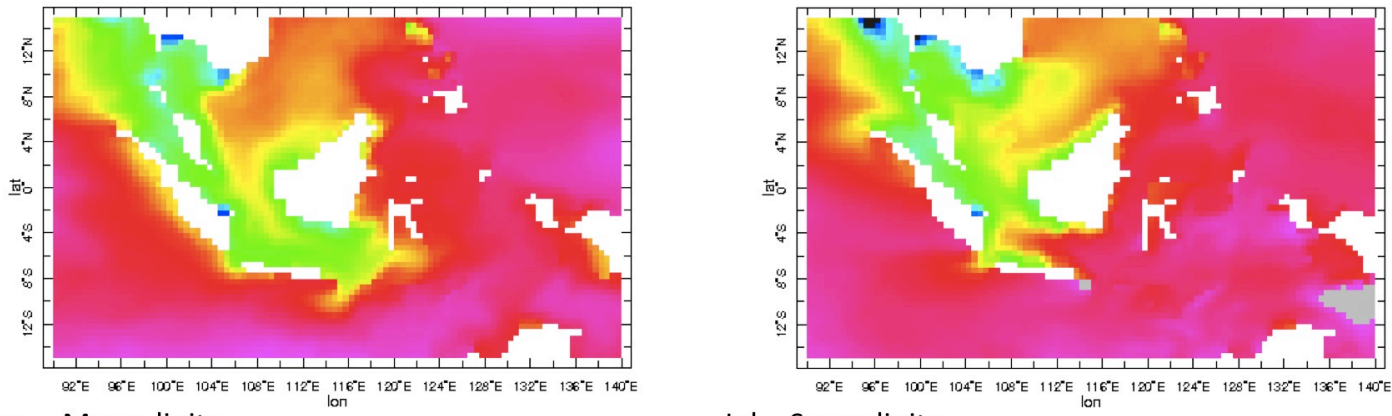

Jan - Mar salinity

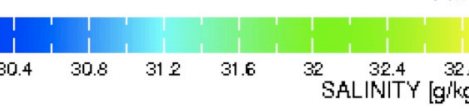

Jul - Sep salinity

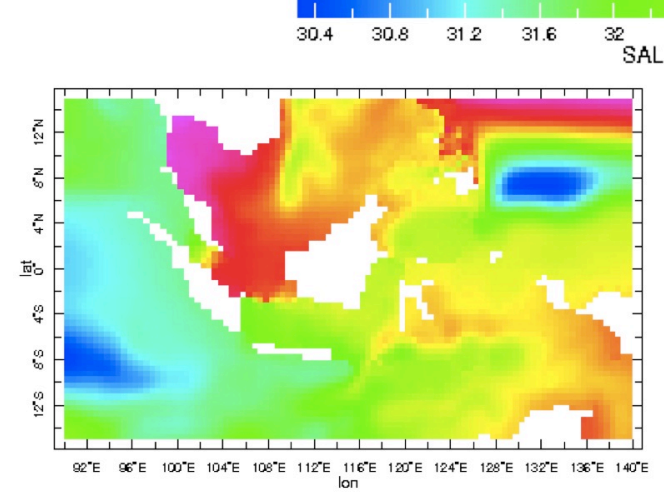

Jan - Mar sea level height

$$
\begin{array}{lllll}
332 & 33.6 & 34 & 34.4
\end{array}
$$

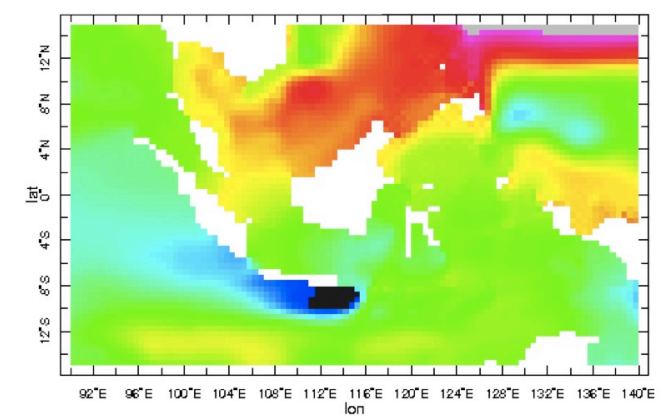

Jul - Sep sea level height

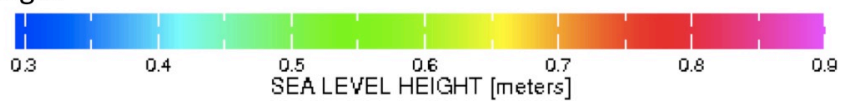

Figure S1: Sea surface salinity and height of the ITF. January through March and July through September climatologies were creating using the SODA reanalysis product [Carton and Giese, 2008]. We note caution is required when using a reanalysis product and/or climatologies as these products create the appearance of complete data coverage, which is not the case, particularly in an area such as the Indonesian Throughflow, which has relatively sparse measurements. 


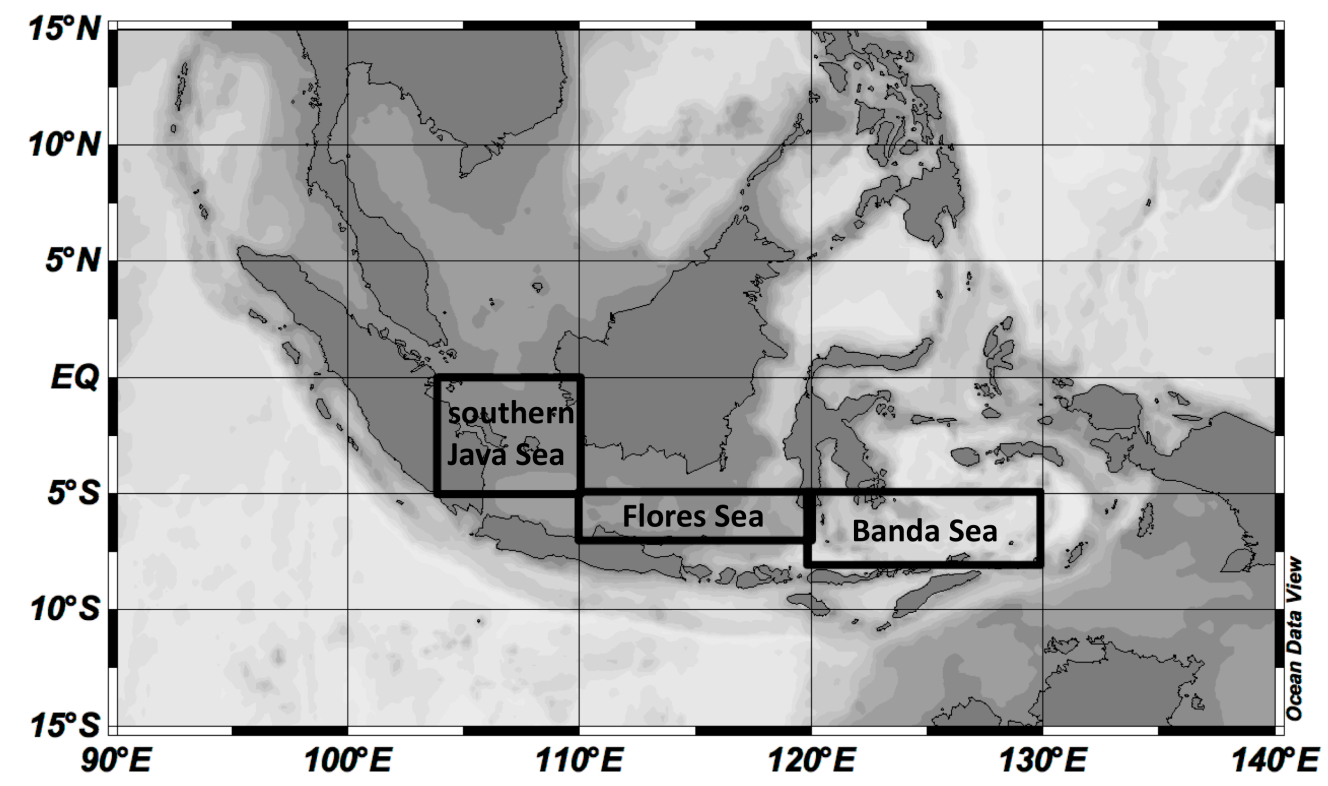

Figure S2: Boxes used to calculate sea surface height difference for Fig S3. 


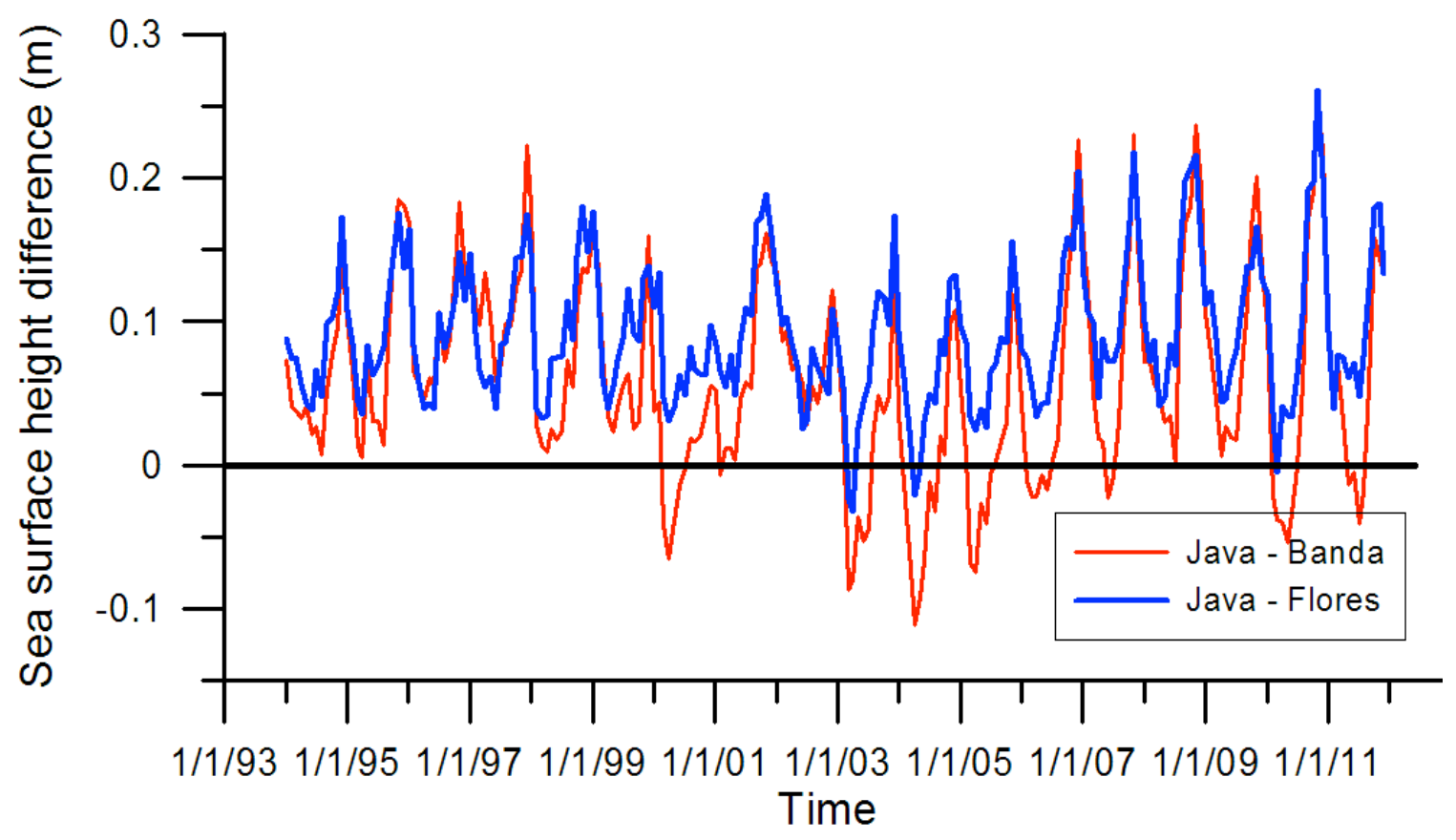

Figure S3: Difference in sea level height. The difference in sea level height [Carton and Giese, 2008] between the southern Java Sea and the Banda Sea (red line) and the southern Java Sea and the Flores Sea (blue line). The sea level of the southern Java Sea is nearly always higher than the Flores Sea. Boxes used to average the sea level height are shown in Fig S2. 


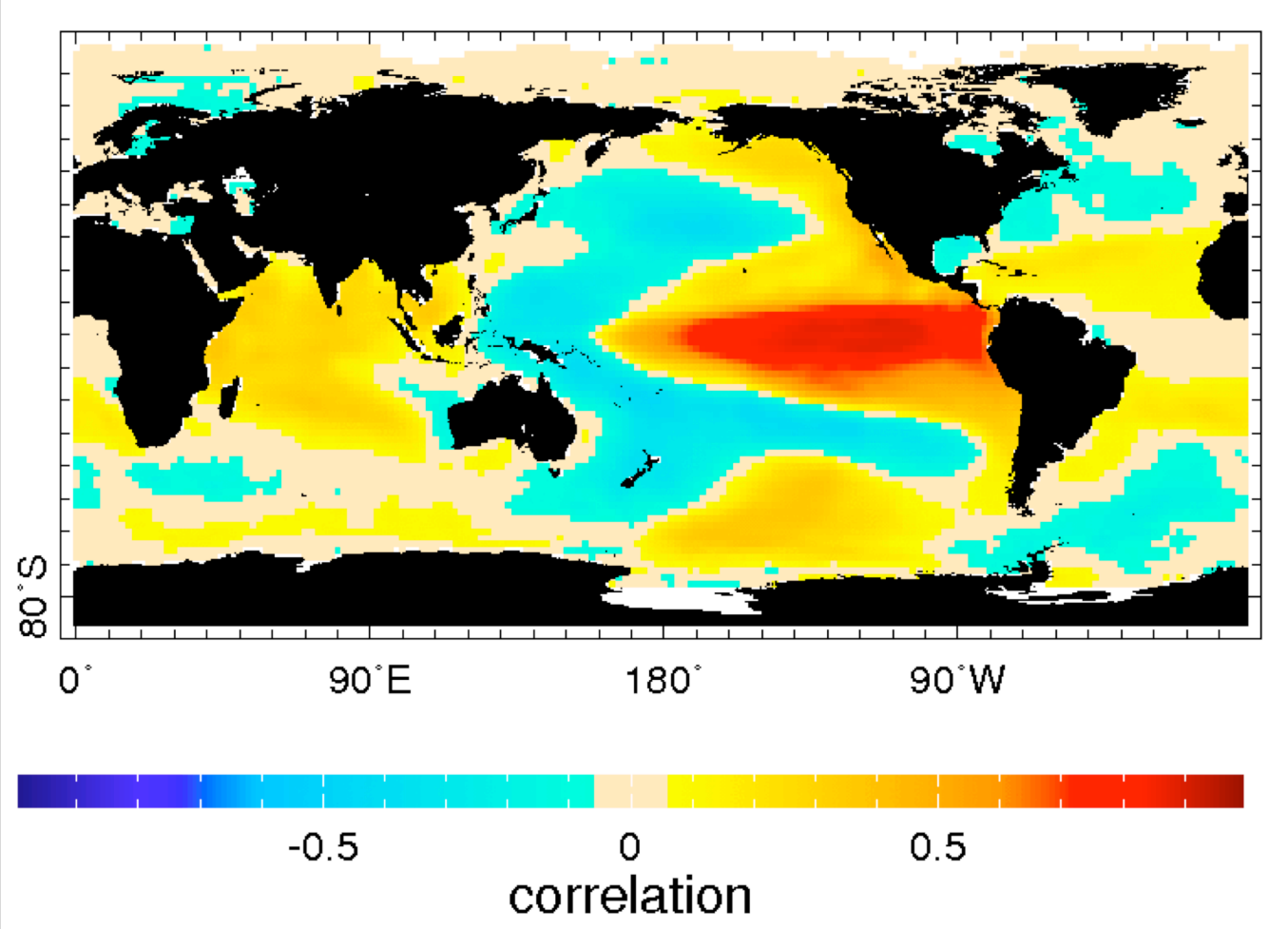

Figure S4: SST ENSO correlation. The linear correlation coefficient between the NINO3 index [Kaplan et al., 1998; Reynolds et al., 2002] and global reconstructed monthly SST anomalies [Smith et al., 2008; Xue et al., 2003] from January 1900 until December 2010. Tan coloring indicates no significant correlation at the 95\% level. The lack of correlation between the NINO3 index and SST anomalies in the ITF outflow region suggests that an ENSO teleconnection cannot be the source of SST variability in the region. 


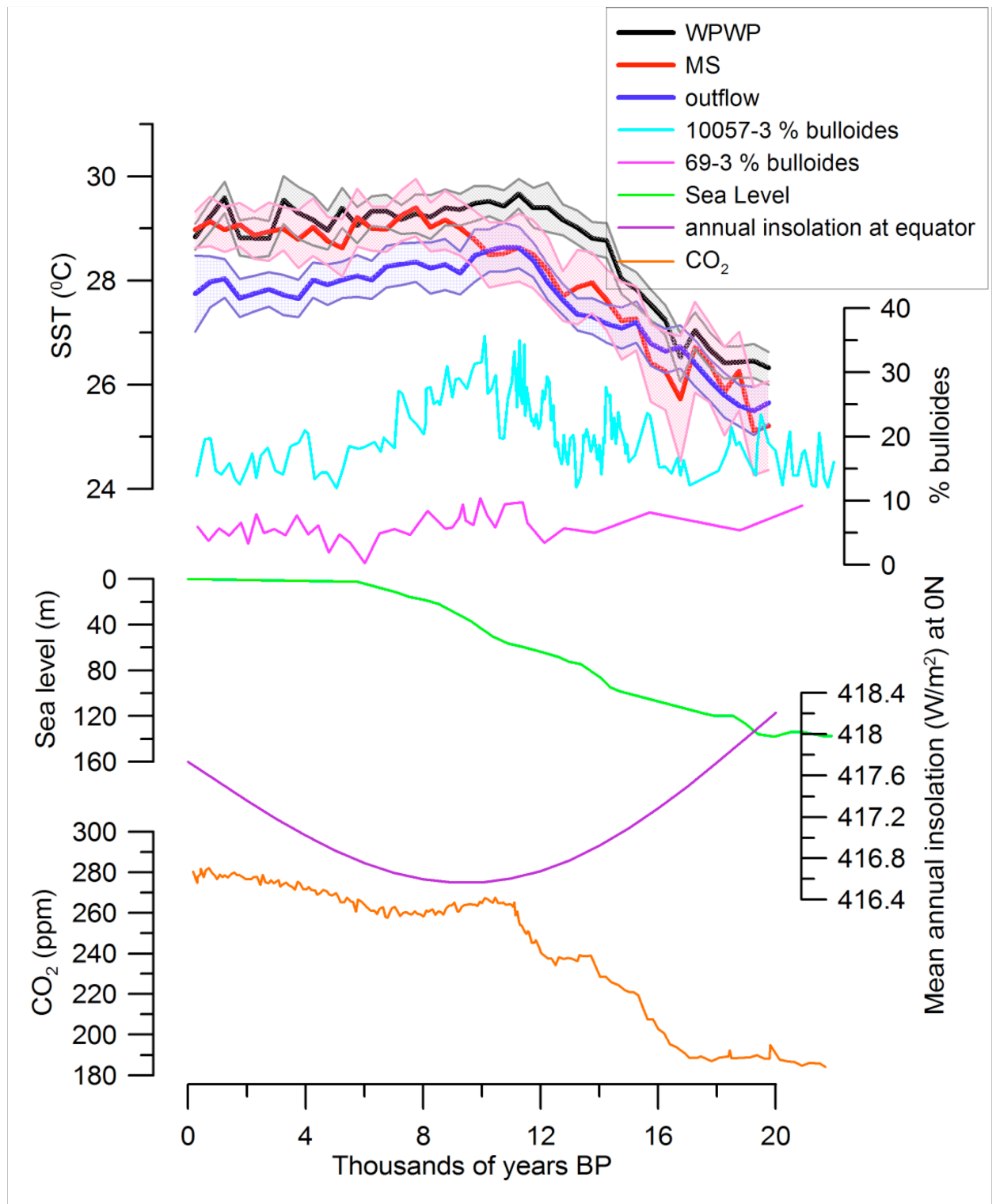

Figure S5: Alternate hypotheses to explain the cooling in the outflow passages. An upwelling indicator (\% G. bulloides) from a core off the southern coast of Java [Mohtadi et al., 2011] and 69-3 suggest either a no change in upwelling or a maximum upwelling when SSTs were warmest at the outflow passages. Mean annual insolation at the equator has minimum during the early Holocene, which cannot explain the peak in temperatures at the outflow passages, and $\mathrm{CO}_{2}[$ Monnin et al., 2004] rises throughout the Holocene, while SSTs at the outflow passages decrease. The change in sea level [Clark and Mix, 2002] may influence tidal mixing throughout the deglaciation. 


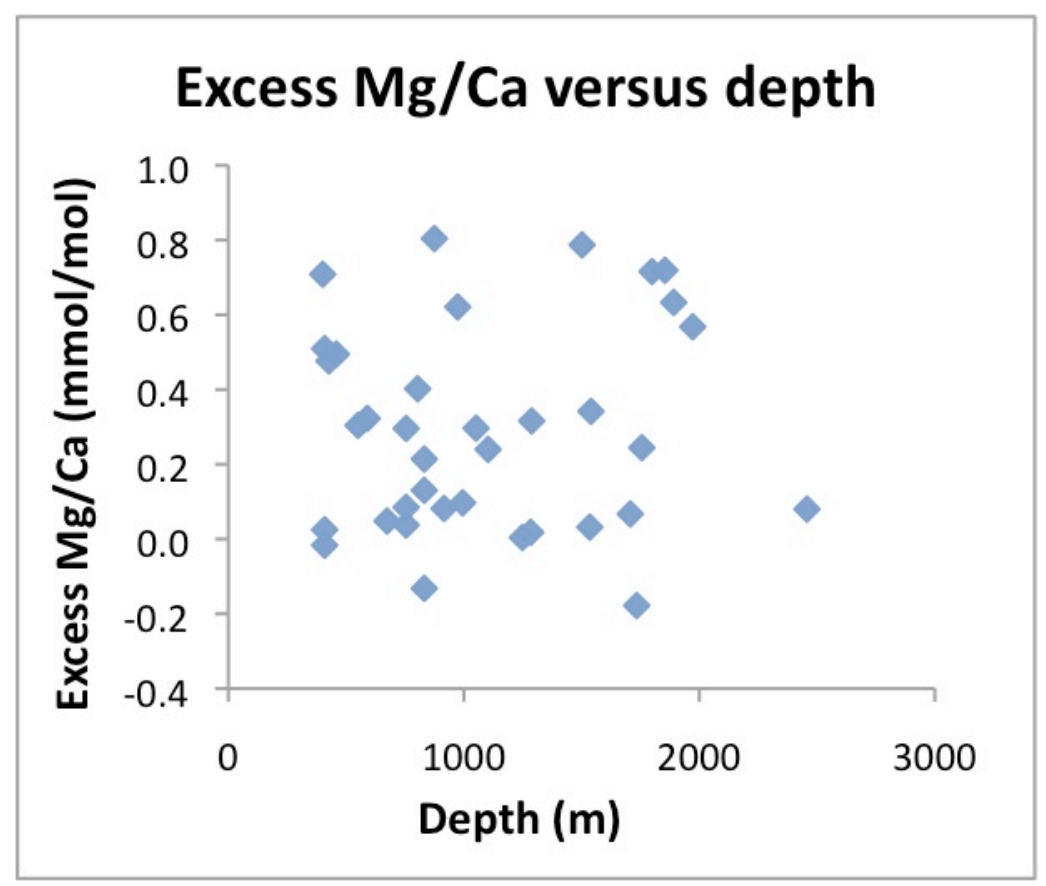

Figure S6: Excess Mg/Ca versus depth. Excess $\mathrm{Mg} / \mathrm{Ca}$ is calculated by subtracting climatological [Anand et al., 2003] SSTs from Mg/Ca based SST estimates. The lack of correlation between core depth and excess $\mathrm{Mg} / \mathrm{Ca}$ suggests that there is no preferential dissolution in our coretop data. 


\begin{tabular}{|c|c|c|c|c|c|}
\hline Core ID, location & $\begin{array}{l}\text { Core ID in } \\
\text { text }\end{array}$ & Lat./Long. & $\begin{array}{l}\text { Water } \\
\text { depth } \\
\text { (m) }\end{array}$ & $\begin{array}{l}\text { Sample } \\
\text { interval } \\
\text { (yrs) }\end{array}$ & Reference \\
\hline $\begin{array}{l}\text { BJ8-03 23GGC, S } \\
\text { Makassar Strait }\end{array}$ & $23 \mathrm{GGC}$ & $\begin{array}{l}5^{\circ} 12^{\prime} \mathrm{S}, 117^{\circ} \\
29^{\prime} \mathrm{E}\end{array}$ & 1189 & 180 & this study \\
\hline $\begin{array}{l}\text { BJ8-03 70GGC, SW } \\
\text { Sulawesi, Makassar Strait }\end{array}$ & 70GGC & $\begin{array}{l}3^{\circ} 34^{\prime} \mathrm{S}, 119^{\circ} \\
23^{\prime} \mathrm{E}\end{array}$ & 482 & 125 & Linsley et al., 2010 \\
\hline $\begin{array}{l}\text { BJ8-03 136GGC, Flores } \\
\text { Sea }\end{array}$ & 136GGC & $\begin{array}{l}5^{\circ} 56^{\prime} \mathrm{S}, 120^{\circ} \\
14^{\prime} \mathrm{E}\end{array}$ & 526 & 200 & this study \\
\hline GeoB10069-3 Savu Sea & $69-3$ & $\begin{array}{l}9^{\circ} 36^{\prime} \mathrm{S}, 120^{\circ} \\
55^{\prime} \mathrm{E}\end{array}$ & 1,250 & 190 & this study \\
\hline MD97-2141, Sulu Sea & MD41 & $\begin{array}{l}8^{\circ} 47^{\prime} \mathrm{N} \\
121^{\circ} 17^{\prime} \mathrm{E}\end{array}$ & 3,633 & 90 & Rosenthal et al., 2003 \\
\hline $\begin{array}{l}\text { MD98-2162, S. Makassar } \\
\text { St. }\end{array}$ & MD62 & $\begin{array}{l}4^{\circ} 41^{\prime} \mathrm{S}, 117^{\circ} \\
54^{\prime} \mathrm{E}\end{array}$ & 1,855 & 415 & Visser et al., 2003 \\
\hline MD98-2165, Sumba St. & MD65 & $\begin{array}{l}9^{\circ} 39^{\prime} \mathrm{S}, 118^{\circ} \\
20^{\prime} \mathrm{E}\end{array}$ & 2,100 & 200 & Levi et al., 2007 \\
\hline MD01-2378, Timor Sea & MD78 & $\begin{array}{l}13^{\circ} 05^{\prime} \mathrm{S} \\
121^{\circ} 47^{\prime} \mathrm{E}\end{array}$ & 1,783 & 125 & $\begin{array}{l}\text { Xu et al., 2008; } \\
\text { Sarnthein et al., } 2011\end{array}$ \\
\hline $\begin{array}{l}\text { MD98-2181, W. Pacific, } \\
\text { Mindanao }\end{array}$ & MD81 & $\begin{array}{l}6^{\circ} 27^{\prime} \mathrm{N} \\
125^{\circ} 50^{\prime} \mathrm{E}\end{array}$ & 2,114 & 50 & Stott et al., 2007 \\
\hline
\end{tabular}

Table S1: Core locations. 


\begin{tabular}{|l|l|l|l|}
\hline Core & Reference & Cleaning Method & Equation used \\
\hline BJ8-03 23GGC & this study & $\begin{array}{l}\text { oxidative and } \\
\text { reductive }\end{array}$ & modified Anand \\
\hline BJ8-03 70GGC & Linsley et al., 2010 & $\begin{array}{l}\text { oxidative and } \\
\text { reductive }\end{array}$ & modified Anand \\
\hline $\begin{array}{l}\text { BJ8-03 } \\
\text { 136GGC }\end{array}$ & this study & $\begin{array}{l}\text { oxidative and } \\
\text { reductive }\end{array}$ & modified Anand \\
\hline GeoB10069-3 & this study & $\begin{array}{l}\text { oxidative and } \\
\text { reductive }\end{array}$ & modified Anand \\
\hline MD97-2141 & Rosenthal et al., 2003 & oxidative & $\begin{array}{l}\text { SST from original } \\
\text { publication }\end{array}$ \\
\hline MD98-2162 & Visser et al., 2003 & oxidative & Anand \\
\hline MD98-2165 & Levi et al., 2007 & oxidative & Anand \\
\hline MD01-2378 & Xu et al., 2008 & $\begin{array}{l}\text { oxidative and } \\
\text { reductive }\end{array}$ & modified Anand \\
\hline MD98-2181 & Stott et al., 2007 & oxidative & Anand \\
\hline
\end{tabular}

Table S2: Summary of cleaning method and $\mathrm{Mg} / \mathrm{Ca}$ - temperature equation used on each core. 


\begin{tabular}{|l|r|r|r|r|}
\hline & \multicolumn{1}{|l|}{ WPWP } & \multicolumn{1}{l|}{ Mak } & Outflow & \multicolumn{1}{l|}{ Dome Fuji } \\
\hline WPWP & 1 & 0.9626 & 0.9582 & 0.9717 \\
\hline Mak & 0.9626 & 1 & 0.9414 & 0.9335 \\
\hline Outflow & 0.9582 & 0.9414 & 1 & 0.9825 \\
\hline Dome Fuji & 0.9717 & 0.9335 & 0.9825 & 1 \\
\hline
\end{tabular}

Table S3: Correlation matrix of SST stacks and Dome Fuji $\boldsymbol{\delta}^{18} \mathbf{0}$. All correlations are significant $(n=45 ; \mathrm{p}<<0.01)$. 
Anand, P., et al. (2003), Calibration of $\mathrm{Mg} / \mathrm{Ca}$ thermometry in planktonic foraminifera from a sediment trap time series, Paleoceanography, 18(2), 15. Antonov, J. I., et al. (2006), World Ocean Atlas 2005, Volume 2: Salinity, NOAA Atlas NESDIS 62.

Arbuszewski, J., et al. (2010), On the fidelity of shell-derived $\delta 180$ seawater estimates, Earth and Planetary Science Letters, 300(3-4), 185-196.

Barker, S., et al. (2003), A study of cleaning procedures used for foraminiferal $\mathrm{Mg} / \mathrm{Ca}$ paleothermometry, Geochemistry Geophysics Geosystems, 4(9).

Bevington, P. R., and Robinson (1992), Data Reduction and Error Analysis for the Physical Sciences.

Bowman, G. M. (1985), Oceanic Reservoir Correction For Marine Radiocarbon Dates From Norwestern Australia, Australian Archaeology, 20, 58-67.

Boyle, E. A., and L. D. Keigwin (1985/6), Comparison of Atlantic and Pacific Paleochemical Records for the Last 215,000 Years - Changes in Deep Ocean Circulation and Chemical Inventories, Earth and Planetary Science Letters, 76(1-2), 135-150.

Carton, J. A., and B. S. Giese (2008), A Reanalysis of Ocean Climate Using Simple Ocean Data Assimilation (SODA), Monthly Weather Review, 136, 2999-3017. Clark, P. U., and A. C. Mix (2002), Ice sheets and sea level of the Last Glacial Maximum, Quaternary Science Reviews, 21(1-3), 1-7.

Kaplan, A., et al. (1998), Analyses of global sea surface temperature 1856-1991, Journal Of Geophysical Research, 103(18), 567-589.

Kawamura, K., et al. (2007), Northern Hemisphere forcing of climatic cycles in Antarctica over the past 360,000 years, Nature, 448, 912-916.

LeGrande, A. N., and G. A. Schmidt (2006), Global gridded data set of the oxygen isotopic composition in seawater, Geophysical Research Letters, 33(12), 5.

Locarnini, R. A., et al. (2006), World Ocean Atlas 2005, Volume 1: Temperature, NOAA Atlas NESDIS 61.

Mashiotta, T. A., et al. (1999), Glacial-interglacial changes in Subantarctic sea surface temperature and 8180 -water using foraminiferal Mg, Earth and Planetary Science Letters, 170, 417-432.

Mathien-Blard, E., and F. Bassinot (2009), Salinity bias on the foraminifera Mg/Ca thermometry: Correction procedure and implications for past ocean hydrographic reconstructions, Geochemistry Geophysics Geosystems, 10(12).

Mohtadi, M., et al. (2011), Glacial to Holocene swings of the Australian-Indonesian monsoon, Nature Geoscience, 4(8), 540-544.

Monnin, E., et al. (2004), Evidence for substantial accumulation rate variability in Antarctica during the Holocene, through synchronization of CO2 in the Taylor Dome, Dome C and DML ice cores, Earth and Planetary Science Letters, 224(1-2), 45-54. Pahnke, K., et al. (2003), 340,000-Year Centennial-Scale Marine Record of Southern Hemisphere Climatic Oscillation, Science, 301(948), 948-952.

Reimer, P. J., et al. (2009), INTCAL09 AND MARINE09 Radiocarbon age calibration curves, 0-50,000 years cal BP, Radiocabon, 51(4), 1111-1150.

Reynolds, R. W., et al. (2002), An Improved In Situ and Satellite SST Analysis for Climate, Journal of Climate, 15, 1509-1625. 
Rosenthal, Y., et al. (1997), Temperature control on the incorporation of magnesium, strontium, fluorine, and cadmium into benthic foraminiferal shells from Little Bahama Bank: Prospects for thermocline paleoceanography, Geochimica Et Cosmochimica Acta, 61(17), 3633-3643.

Rosenthal, Y., et al. (2004), Interlaboratory comparison study of $\mathrm{Mg} / \mathrm{Ca}$ and $\mathrm{Sr} / \mathrm{Ca}$ measurements in planktonic foraminifera for paleoceanographic research, Geochemistry Geophysics Geosystems, 5(4), Q04D09.

Smith, T. M., et al. (2008), Improvements to NOAA's historical merged land-ocean surface temperature analysis (1880-2006), Journal of Climate, 21(10), 2283-2296. Southon, J., et al. (2002), Marine Reservoir Corrections for the Indian Ocean and Southeast Asia, Radiocabon, 44(1), 167-180.

Wang, L. (2000), Isotopic signals in two morphotypes of Globigerinoides rubers (white) from the South China Sea: implications for monsoon climate change during the last glacial cycle, Palaeogeography, Palaeoclimatology, Palaeoecology, 161, 381394.

Xue, Y., et al. (2003), Interdecadal changes of 30-yr SST normals during 1871-2000, Journal of Climate, 16, 1601-1612. 


\title{
Chapter 3
}

\section{The deglacial hydrologic variability of the Tropical Pacific and Indian Oceans inferred from $\delta^{18} 0$ of seawater reconstructions}

\begin{abstract}
The hydrologic cycle of the tropics can change rapidly and dramatically, affecting the amount of water vapor, and potentially temperatures, globally. Previous studies have demonstrated variability in the tropical hydrologic cycle during the last deglaciation and both high and low latitude origin of the variability has been proposed. Here we use the $\mathrm{Mg} / \mathrm{Ca}$-based temperature and the $\delta^{18} \mathrm{O}$ of calcite of planktic foraminifera to solve for the $\delta^{18} 0$ of seawater. We combine new data with previously published $\delta^{18} 0$ of seawater reconstructions from throughout the tropical Eastern and Western Pacific and Eastern Indian Oceans in order to evaluate the possible mechanisms controlling hydrologic changes. Our synthesis of the $\delta^{18} 0$ of the published and new seawater reconstructions suggests that hydrologic conditions at the last glacial maximum and late Holocene were similar. However, $\delta^{18} 0$ of seawater enrichments occurred at most of the sediment sites during the Younger Dryas and Heinrich Stadial 1. Similar enrichments in the East
\end{abstract}


and West tropical Pacific seem to rule out forcing by an El Niño-Southern Oscillation-like mechanism. The spatial pattern of change is instead consistent with a migration of the Intertropical Convergence Zone.

\section{Introduction}

The temperature of the tropics appears to have been relatively stable over the last $20 \mathrm{kyr}$, compared to the high latitudes, which were characterized by large temperature fluctuations [e.g. Alley and Clark, 1999; Dansgaard et al., 1989;

Ruddiman and Mcintyre, 1981]. The large, rapid temperature fluctuations documented in the high latitudes either do not have temperature counterparts in the tropics [Kiefer and Kienast, 2005; Stott et al., 2007] or, if they do, their amplitude is diminished [Kiefer and Kienast, 2005; Lea et al., 2003; Shakun and Carlson, 2010]. On the other hand, recent work has highlighted dramatic hydrologic responses that occurred in concert with high latitude climate change (e.g. [Lynch-Stieglitz et al., 2011; Partin et al., 2007; Stager et al., 2011; Tierney et al., 2008; Yuan et al., 2004]).

During the last deglacial, two prominent Northern hemisphere cooling events occurred -- Heinrich Event 1 (H1; 17.5 to 16 kyr BP) and the Younger Dryas ( 12.9 to 11.7 kyr BP) [Alley and Clark, 1999]. Heinrich Events, first identified by large amounts of ice rafted debris in sediment cores [Heinrich, 1988; Hemming, 2004], appear to coincide with 1) the end of cooling stadials as recorded by the $\delta^{18} 0$ of Greenland ice and 2) very cold Atlantic sea surface temperatures (SSTs) [Bond et al., 1993]. Similarly, the Younger Dryas coincides with ice rafted debris in North Atlantic sediments and cooler temperatures [Bond et al., 1993]. The cause of these 
abrupt cooling events in the North Atlantic is still under debate, but the leading hypothesis is that they resulted from freshwater input at the sites of deepwater formation, which altered the Meridional Overturning Circulation [Broecker, 1991]. The source of freshwater was likely iceberg discharge for Heinrich Events [Bond et al., 1992]. Evidence of the fresh water source is more elusive for the Younger Dryas [Broecker, 2006], though recent work suggests freshwater may have been routed through the Arctic [e.g. Murton et al., 2010].

Terrestrial records indicate that tropical hydrological changes associated with both $\mathrm{H} 1$ and the Younger Dryas were large and pervasive [e.g. Stager et al., 2011; Tierney et al., 2008; Wang et al., 2007; Yuan et al., 2004]. Whereas hydrologic changes over land have been attributed in large part, but not entirely, to southward shifts of the Intertropical Convergence Zone (ITCZ) during North Atlantic cold events (See for example, Stager et al. [2011] and Oppo and Curry [2012] for recent compilations of $\mathrm{H} 1$ terrestrial responses), there is not a consensus in studies of marine sediments. Some have inferred that changes in the mean Pacific state (e.g. east-west SST gradient changes) were a dominant control on tropical Pacific hydrology during these events [e.g. Levi et al., 2007; Rosenthal et al., 2003; Stott et al., 2002], while others have suggested that the data are consistent with a migration of the ITCZ.

The $\delta^{18} 0$ of seawater $\left(\delta^{18} 0_{\text {seawater }}\right)$ can be used to inform us as to past hydrologic changes. The $\delta^{18} 0_{\text {seawater }}$ and salinity often have a positive linear relationship as both quantities are similarly influenced by evaporation and precipitation, with more enriched $\delta^{18} \mathrm{O}_{\text {seawater values corresponding to saltier }}$ 
conditions. This linear relationship varies by region [LeGrande and Schmidt, 2006] as sea ice formation, atmospheric distillation, and river runoff affect salinity differently than they do the $\delta^{18} 0$ of water [Craig and Gordon, 1965]. Moreover, the exact relationship between $\delta^{18} \mathrm{O}_{\text {seawater }}$ and salinity has likely varied in the past [LeGrande and Schmidt, 2011; Oppo et al., 2007]. Thus, the $\delta^{18} 0_{\text {seawater }}$ can best inform us about large-scale changes in the hydrologic cycle, and should not be viewed as a simple paleosalinity proxy [Craig and Gordon, 1965; LeGrande and Schmidt, 2011].

Here, we re-examine the influence of abrupt North Atlantic events on tropical hydrology from a marine perspective. We present a new high-resolution record of the $\delta^{18} 0$ of calcite $\left(\delta^{18} 0_{\text {calcite }}\right)$ of the mixed layer planktic foraminifera Globigerinoides ruber (G. ruber) from the Savu Sea, which is supplied by Indonesian Throughflow (ITF) water entering the Indian Ocean through the Ombai Strait (Figure 1). Using submitted (20ky-present) [Gibbons et al., in revision] and new (35kyr - 20kyr) Mg/Ca-based temperature reconstructions, and following previous work [e.g. Lea et al., 2000] we calculated the $\delta^{18} \mathrm{O}_{\text {seawater }}$ at this site over the past 35 kyr. Recent studies have suggested that the opening of the passages between marginal basins and seas as sea level rose during the last deglaciation, influenced $\delta^{18} \mathrm{O}_{\text {seawater }}$ and freshwater gradients in the region [Ding et al., 2002; Linsley et al., 2010; Rosenthal et al., 2003; Xu et al., 2010]. However in this study, we focus on larger scale, basin-wide variations and the information that $\delta^{18} 0_{\text {seawater }}$ can provide about past changes in the tropical hydrologic cycle. We combine our new record 
with published $\delta^{18} \mathrm{O}_{\text {seawater }}$ reconstructions from throughout the IndoPacific Warm Pool and the Eastern Equatorial Pacific Ocean (Table 1) to determine the most important mechanism(s) of deglacial tropical hydrologic change.

\section{Materials and Methods}

The new data we present was generated on sediment core GeoB10069-3 $\left(9^{\circ}\right.$ $36^{\prime} \mathrm{S}, 120^{\circ} 55^{\prime} \mathrm{E}, 1,250 \mathrm{~m}$; referred to as $\left.69-3\right)$, retrieved from the Savu Basin in the Eastern Indian Ocean. The Savu Basin is in the path of one of the outflow passages of the ITF. Today, minimum temperatures at $69-3$ are $\sim 26^{\circ} \mathrm{C}$ and occur in the boreal summer (all seasons are with respect to the Northern Hemisphere) and maximum temperatures are $\sim 31^{\circ} \mathrm{C}$.

Stable isotope measurements from 69-3 were made at Bremen University on a Finnigan MAT251. Long-term precision of $\delta^{18} 0_{\text {calcite }}$ measurements is $0.07 \%$, based on repeated measurements of a suite of standards. Approximately 5-20 individual tests were used for each measurement.

Approximately 40 G. ruber tests $(212-300 \mu \mathrm{m})$ were used for each $\mathrm{Mg} / \mathrm{Ca}$ measurement. Samples were cleaned with a full trace metal cleaning procedure, including oxidative and reductive steps [Boyle and Keigwin, 1985/6; Rosenthal et al., 1997]. Samples were run on either an Element ICP-MS at Wood Hole Oceanographic Institution or an Element XR ICP-MS at Rutgers University. Internal reproducibility based on repeated measurements of consistency standards is $\sim 1 \%$.

$\mathrm{Mg} / \mathrm{Ca}$ values were converted to temperature using the Anand multispecies equation [Anand et al., 2003]. The equation was adjusted [Gibbons et al., in revision] 
to account for the fact that the Anand calibration was based on foraminifera that had been cleaned only with an oxidative step:

$$
\begin{aligned}
& \text { Original Anand Multi-species equation: } \mathrm{Mg} / \mathrm{Ca}=0.38 \exp (0.090 \mathrm{~T}) \\
& \text { Modified Anand equation: } \mathrm{Mg} / \mathrm{Ca}=0.345 \exp (0.090 \mathrm{~T})
\end{aligned}
$$

$\mathrm{Mg} / \mathrm{Ca}$-based temperature estimates and $\delta^{18} \mathrm{O}_{\text {calcite }}$ data from the same depth

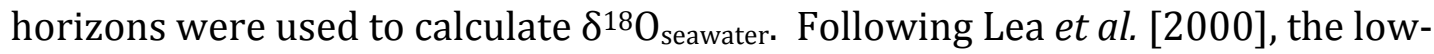
light 0 . universa calibration [Bemis et al., 1998] was used to obtain $\delta^{18} 0_{\text {seawater: }}$ : Bemis low-light $O$. universa equation: $\mathrm{T}\left({ }^{\circ} \mathrm{C}\right)=16.5-4.80\left(\delta^{18} \mathrm{O}_{\text {calcite }}-\delta^{18} \mathrm{O}_{\text {seawater }}\right)-0.27 \%$ o

For 20-0 kyr before present (BP), the change in $\delta^{18} \mathrm{O}_{\text {seawater }}$ due to continental ice decay was removed using the sea level curve of Clark and Mix [2002] and the corresponding change in the global $\delta^{18} \mathrm{O}_{\text {seawater }}$ of $1.0 \%$ [Schrag et al., 2002] allowing us to estimate the $\delta^{18} 0$ of seawater corrected for ice volume $\left(\delta^{18} \mathrm{O}_{\text {seawater- }}\right.$ icevolume). For 35-20kyr BP we used the sea leve curve of Waelbroeck et al. [2002]. We also compiled previously published $\mathrm{Mg} / \mathrm{Ca}$ and $\delta^{18} \mathrm{O}_{\text {calcite }}$ data from planktic foraminifera from cores throughout the Indian and Pacific tropics (Fig 1, Table 1). All records are based on data from G. ruber, with the exception of V21-30, which utilized Globigerinoides sacculifer (G. sacculifer). In our compilation we examine the past $20 \mathrm{kyr}$. We have attempted to treat the data from the cores in the same manner in order to better allow us to compare datasets.

Where possible, $\mathrm{Mg} / \mathrm{Ca}$ was converted to temperature using either the original Anand multispecies or the modified version based on cleaning method (see Table 1). For cores TR163-22 [Lea et al., 2006] and MD41 [Rosenthal et al., 2004], we used the SSTs from the original publication in order to account for the potential

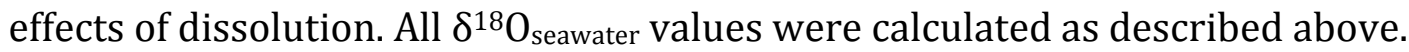


We evaluate the $\delta^{18} \mathrm{O}_{\text {seawater }}$ reconstructions by comparing them to modern water measurements. In each core, we average $\delta^{18} \mathrm{O}_{\text {seawater }}$ samples from 2-0 kyr BP. We plot these "modern" averages against the mean annual World Ocean Atlas 05 salinity [Antonov et al., 2006] from each core location. We compare the resulting $\delta^{18} \mathrm{O}_{\text {seawater }} /$ salinity relationship with regional $\delta^{18} \mathrm{O}_{\text {seawater }}$ and salinity data compiled by LeGrande and Schmidt [2006] (Fig 2). For the IndoPacific coretops, the slopes of the reconstructed $\delta^{18} \mathrm{O}_{\text {seawater }} /$ salinity $(\mathrm{m}=0.48)$ and the modern water $\delta^{18} \mathrm{O}_{\text {seawater}} /$ salinity $(\mathrm{m}=0.44)$ are within error. For the Eastern Equatorial Pacific, the slopes are also very similar $(0.22$ for the water samples and 0.31 for the foraminifera samples).

All age models are based on previously published planktic foraminifera radiocarbon dates with the exception of the 4 oldest dates from 69-3 which are presented here (Appendix A). All radiocarbon dates were converted to calendar ages using the Calib 6.0 program, the Marine 09 calibration, and the global reservoir age [Reimer et al., 2009]. The calendar age with the median probability was selected. Several of the age models were published previously: 69-3, MD62, MD81, MD41, MD65, and MD78 [Gibbons et al., in revision]. Age models for V21-30, 43JC, TR16322, MD65, 29-4, 38-4, MD76, MD70, MD90, and MD38 were created by linearly interpolating between derived calendar ages.

We computed the arithmetic average of our data using 500-year nonoverlapping bins. For each time interval we only averaged the cores with data; cores without data were simply excluded from the time bin. Principal component analysis [Jolliffe, 2002] was also used to explore the common features of the $\delta^{18} \mathrm{O}_{\text {seawater- }}$ 
icevolume. All data were placed into 500-year non-overlapping bins. Missing values were replaced with the average value of the record [following Marchal et al., 2002]. We computed the principal components for the time interval from $1.25 \mathrm{kyr}$ BP to 19.75 kyr BP (Fig 5).

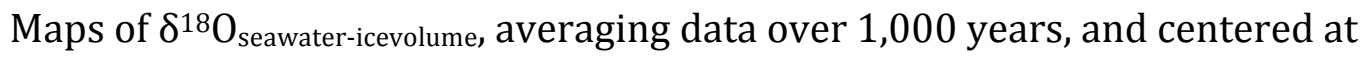
6.5 kyr BP, 12.5 kyr BP, 14.5 kyr BP, 15.5 kyr BP, 17.5 kyr BP, and19.5 kyr BP, provide insight into the spatial pattern of changes through time (Figs 6-9), discussed below.

\section{Results}

GeoB10069-3

The $\delta^{18} \mathrm{O}_{\text {calcite }}$ from $69-3$ increased by $\sim 0.5 \%$ from $35 \mathrm{kyr}$ BP to $20 \mathrm{kyr} \mathrm{BP}$, consistent with the change in global ice volume [Waelbroeck et al., 2002]. $\delta^{18} \mathrm{O}_{\text {calcite }}$ began to decrease at $18 \mathrm{kyr}$ BP, dropping by $\sim 1.75 \%$ o until stabilizing at $\sim 8 \mathrm{kyr}$ (Fig 3). Approximately, $1 \%$ of this decrease can be attributed to the global change in ice volume [Clark and Mix, 2002; Schrag et al., 2002].

The $\mathrm{Mg} / \mathrm{Ca}$ varies between 3.3 and $3.6 \mathrm{mmol} / \mathrm{mol}$ (or $\sim 25^{\circ} \mathrm{C}$ and $26^{\circ} \mathrm{C}$ ) from 35-20kyr BP. Mg/Ca-based temperatures from 20kyr BP until present were previously published [Gibbons et al., in revision], but are described again briefly here. $\mathrm{Mg} / \mathrm{Ca}$ values increase to $3.8 \mathrm{mmol} / \mathrm{mol}\left(\sim 26.5^{\circ} \mathrm{C}\right)$ from $20 \mathrm{kyr}$ until $15 \mathrm{kyr} \mathrm{BP}$. $\mathrm{Mg} / \mathrm{Ca}$ values then remain constant until $\sim 12 \mathrm{kyr} \mathrm{BP} . \mathrm{Mg} / \mathrm{Ca}$ values peak at $10 \mathrm{kyr}$ $\mathrm{BP}\left(4.5 \mathrm{mmol} / \mathrm{mol}, 28.5^{\circ} \mathrm{C}\right)$, and then decrease by $\sim 0.5 \mathrm{mmol} / \mathrm{mol}\left(1.25^{\circ} \mathrm{C}\right)$ by the late Holocene. 
The $\delta^{18} \mathrm{O}_{\text {seawater-icevolume }}$ estimates suggest several notable features. The glacial (35kyr-20kyr BP) portion averages 0.1\%o. There are several enrichment events during this portion of the record. The largest is an $\sim 0.2 \% 0$ enrichment from 32.5 $31 \mathrm{kyr}$ BP, approximately coincident with some estimates of the age of Heinrich Event 3 [Hemming, 2004]. Another small enrichment event occurred at 28kyr BP. The most pronounced events, however, occurred during the deglacial, from 19.5kyr BP until 15kyr BP, and from 12.5kyr until 11.2kyr BP. During the Holocene,

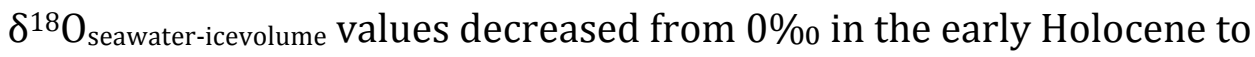
approximately $-0.2 \%$ by $5 \mathrm{kyr}$ BP. $\delta^{18} \mathrm{O}_{\text {seawater-icevolume values then remained }}$ approximately constant for the remainder of the Holocene.

\section{Regional data}

The records that we have compiled from the IPWP and Eastern Equatorial Pacific Ocean show a wide range of deglacial temperature histories (Fig 4b). Although $\delta^{18} 0_{\text {seawater-icevolume trends also vary, most records show generally enriched }}$

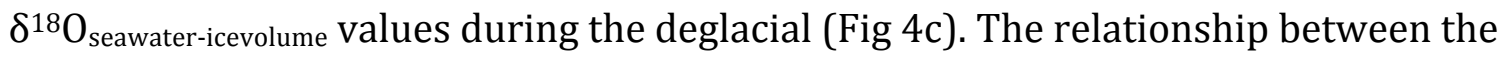
$\delta^{18} \mathrm{O}_{\text {seawater-icevolume }}$ records was explored using principal component analysis. The first principal component (PC1; Fig 5) explains 53\% of the variance in the records. There is a longitudinal, though not latitudinal, coherence to how strongly the records contribute to the first principal component (eigenvector elements or loadings are shown in Fig 6). Cores in the IndoPacific Warm Pool and Eastern Equatorial Pacific have high loadings and contribute approximately equally. The cores with the smallest loadings for the first principal component are the northern 
most cores (MD41 and MD90) and MD78, MD70, and MD76. We will refer to the latter group (MD78, MD70, and MD67) as the "southern cores." Strictly speaking they are not the southernmost cores (see Table 1), but they appear to group together hydrologically. The second and third principal components explain $9 \%$ and $8 \%$, respectively, and there is no regional coherence to the loadings, nor does their temporal pattern appear meaningful (not shown). We thus infer that these principal components are dominated by noise rather than real oceanographic variability.

The arithmetic average of $\delta^{18} \mathrm{O}_{\text {seawater-icevolume from all records results in a }}$ stacked record that contains all the same major features as the first principal component, providing confidence that both represent important basin-wide changes. Average $\delta^{18} 0_{\text {seawater-icewater values were similar in the glacial and late }}$ Holocene, with values of approximately $0 \%$. As with PC1, there were two large enrichment events, of over $0.3 \%$ from $17.75-15.75 \mathrm{yr}$ BP and at $12.25 \mathrm{kyr}$ BP (Fig 4).

\section{Discussion}

\section{Deglacial Changes in hydrology}

Throughout most of the IndoPacific Warm Pool and Eastern Equatorial

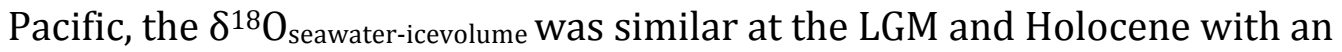
approximately $0.3 \%$ enrichment from $17.75-12 \mathrm{kyr}$ BP. This near basin-scale coherency is surprising in light of the large range in deglacial temperature patterns (Fig 4b). Both PC1 and the average of the $\delta^{18} \mathrm{O}_{\text {seawater-icevolume }}$ records reveal that this enriched period can be divided into two intervals, which correspond to $\mathrm{H} 1$ and the 
Younger Dryas. We note the enriched period corresponding to H1 is much longer than the traditional H1 time interval ( 17.5-16 kyr BP) [Alley and Clark, 1999], and spans the full H1 stadial or extended H1 interval from 19 to $14.6 \mathrm{kyr}$ BP [Hall et al., 2006; McManus et al., 2004; Stanford et al., 2006; Stanford et al., 2011].

The first principal component further suggests that this variability is a shared feature among most of the cores. The loadings from PC1 help us explore the regional coherence in the $\delta^{18} \mathrm{O}_{\text {seawater-icevolume }}$ pattern (Fig 6). Cores from the Eastern Equatorial Pacific and IndoPacific contribute similarly to PC1. The southernmost cores (MD70, MD76, and MD78) in our compilation contribute the least. In fact, not only are these cores minor contributors to the first PC, their $\delta^{18} \mathrm{O}_{\text {seawater-icevolume }}$ records show relatively little variation throughout the last $20 \mathrm{kyr}$. The northernmost cores (MD41 and MD90) are also minor contributors to PC1, though in both cores, there are slightly enriched values corresponding to $\mathrm{H} 1$ and the Younger Dryas, respectively. The reason that MD41 does not contribute to the loading of PC1 is likely due to local factors at MD41 (discussed below) as well as a short $\mathrm{H} 1$ enrichment. At MD90, the $\delta^{18} \mathrm{O}_{\text {seawater-icevolume increases throughout the }}$ Holocene, which has been attributed to increased freshwater (decreased salt) export from the South China Sea due to the flooding of the Sunda Shelf [Linsley et al., 2010]. Additionally, MD90 has a relatively muted expression of the Younger Dryas and H1. The presence of a latitudinal gradient and lack of a longitudinal gradient provides additional insights on possible mechanisms for the dominant hydrologic changes in the tropical Indo-Pacific during the deglacial, captured by $\delta^{18} \mathrm{O}_{\text {seawater- }}$ icevolume. 
In the modern, climate variability described by El Niño-Southern Oscillation (ENSO) results in large precipitation anomalies [e.g. Wang and Schimel, 2003] and several authors have attributed past changes in $\delta^{18} \mathrm{O}_{\text {seawater }}$ to ENSO or changes in Pacific mean state variability [Lea et al., 2000; Levi et al., 2007; Rosenthal et al., 2003; Stott et al., 2002]. For example, the enriched $\delta^{18} 0_{\text {seawater values in MD81 }}$ during high latitude cool events were attributed to "El Niño-like" conditions [Stott et al., 2002]. Though earlier work had suggested a reduced zonal salinity gradient in the Pacific during cold intervals [Lea et al., 2000; Rosenthal et al., 2003], more recent work using an Eastern Equatorial Pacific $\delta^{18} \mathrm{O}_{\text {seawater }}$ record derived from alkenonebased temperature and $\delta^{18} 0_{\text {calcite, suggests synchronous deglacial } \delta^{18} 0_{\text {seawater }}}$ changes in the eastern and western Pacific, arguing against ENSO-like changes [Leduc et al., 2009]. Our results expand on this initial observation using 3 cores from the Eastern Equatorial Pacific and 11 cores from the IndoPacific Warm Pool. Moreover, we focus only on $\delta^{18} \mathrm{O}_{\text {seawater }}$ reconstructions based entirely on foraminifera, which helps to reduce age uncertainty.

Indeed, the data we have compiled suggest that the East-West $\delta^{18} \mathrm{O}_{\text {seawater }}$ gradient remained approximately constant through time (Figs 7-9). As ENSO variability is characterized by opposite precipitation anomalies in the eastern and western tropical Pacific, the data are not consistent with ENSO-type changes. Moreover, speleothem records from two locations in Brazil, which today experience opposite rainfall anomalies associated with ENSO, show synchronous millennialscale changes in precipitation during the deglacial, also suggesting no mean ENSO change from the LGM to present [Wang et al., 2007]. It has been hypothesized that if 
the tropical Pacific becomes "locked" in either an El Niño or La Niña state, the resulting teleconnections could control global climate [Cane, 1998; Clement et al., 1999]. Our compilation, however, does not provide any support for the hypothesis that the tropical Pacific is the source of high latitude millennial-scale climate change, though we cannot rule out that there are some changes in the Walker Cell that our data do not resolve. Currents can advect and mute $\delta^{18} \mathrm{O}_{\text {seawater }}$ signals, and vapor transport over the Isthmus of Panama can change with the migration of the ITCZ, potentially masking a change in the Walker Cell [LeGrande and Schmidt, 2011; Oppo et al., 2007].

The variations in this dataset are most easily explained by changes in the position of the Intertropical Convergence Zone (ITCZ). We first examine the LGM to Holocene difference. Most records suggest there was relatively little $\delta^{18} \mathrm{O}_{\text {seawater- }}$ icvolume change between the LGM and the Holocene. A notable difference between the LGM and Holocene in one record can be attributed to local factors; the relatively depleted $\delta^{18} \mathrm{O}_{\text {seawater-icevolume }}$ conditions in the Sulu Sea (MD41) may be due the lower sea level at the LGM which allowed relatively more fresh South China Sea water than equatorial Pacific water to enter the Sulu Sea, decreasing its $\delta^{18} \mathrm{O}_{\text {seawater values }}$ [Rosenthal et al., 2003]. Speleothem records from China [Yuan et al., 2004] and Borneo [Partin et al., 2007] may suggest a decrease in precipitation during the LGM. However, as noted by Partin [2007] once global $\delta^{18} \mathrm{O}_{\text {seawater }}$ changes are removed, the speleothem $\delta^{18} 0$ changes are smaller, suggesting a modest decrease in the monsoons during the LGM, which can be at least in part attributed to cooler SST. 
Thus the enriched $\delta^{18} 0$ values in Borneo are not inconsistent with $\delta^{18} 0_{\text {seawater-icevolume }}$ evidence suggesting the ITCZ position during the LGM was similar to the Holocene.

Though there is relatively little $\delta^{18} \mathrm{O}_{\text {seawater-icevolume }}$ change from the LGM to modern, the data suggest dramatic hydrologic changes in parallel with Northern Hemisphere high latitude rapid temperature change. Others have suggested a southward migration of the ITCZ during the Younger Dryas and H1 [Benway et al., 2006; Leduc et al., 2009], and the greater spatial coverage of the cores we have compiled allows us to evaluate this hypothesis in greater detail. The two northern most cores (MD41 and MD90) show some enrichment in the $\delta^{18} 0_{\text {seawater-icevolume }}$ values, the equatorial cores (MD62, MD81, MD41, 43JC, V21090, TR163-22, 69-3, MD65, 29-4, and 38-4) show larger $\delta^{18} \mathrm{O}_{\text {seawater-icevolume }}$ enrichments, and the southern cores (MD78, MD76, and MD70) show no change. To the south of our study area, wetter conditions are documented in a peat bog during H1 (though not during the Younger Dryas) [Muller et al., 2008]. As discussed in more detail below, this spatial pattern is consistent with a southward displacement of the ITCZ.

Enriched $\delta^{18} \mathrm{O}$ values in speleothems from Borneo during $\mathrm{H} 1$ have been interpreted as a decrease in local rainfall caused by a southward displacement of the ITCZ [Partin et al., 2007]. Though Partin et al. [2007] claim $\delta^{18} 0$ values are not enriched during the Younger Dryas, we suggest a Younger Dryas enrichment is masked by the global decrease in $\delta^{18} \mathrm{O}_{\text {seawater. }}$ Removing the global ice volumerelated $\delta^{18} 0$ change highlights not only the relatively small changes from the LGM to late Holocene and the relatively enriched period during H1 (a 1.0\%o enrichment), but also shows a $0.5 \%$ enrichment during the Younger Dryas. We also note that two 
of the three speleothems that make up the spliced Borneo record experience a growth hiatus coincident with the Younger Dryas (13.0 kyBP - 11.7 kyr BP for SSCO1 and 12.7 kyr BP to $11.9 \mathrm{kyr}$ BP for BA04) which is consistent with drier conditions. The Borneo record displays a remarkable correspondence with our PC1 (Fig 5). The difference between the LGM and $\mathrm{H} 1$ in the speleothem record at Borneo is $1 \%$. This is over twice as large as is observed in nearby $\delta^{18} 0_{\text {seawater-icevolume }}$ reconstructions (Fig 4c, Fig 5) [Rosenthal et al., 2003; Steinke et al., 2008; Stott et al., 2004; Visser et al., 2003], confirming that the speleothem record reflects some degree of decreased precipitation, and not just a change in source water. Support for a $\delta^{18} 0$ response to reduced precipitation in Borneo during North Atlantic cold events is also provided by a water-isotope-enabled fully coupled model simulations [Lewis et al., 2010].

The $\delta^{18} 0_{\text {seawater-icevolume }}$ data uniformly suggest a southward migration of the ITCZ during H1 and the Younger Dryas, but not during the LGM. In the modern ocean, the ITCZ is biased towards the northern hemisphere. This is generally attributed to the global continental configuration, and the resulting warm bias of the northern hemisphere, but the geometry of the coastlines and oceanic/atmospheric feedbacks may also play a role [Koutavas and Lynch-Stieglitz, 2005]. The warm bias of the Northern Hemisphere is accentuated by the Atlantic Meridional Overturning Circulation, which exports heat northward near the surface at every latitude in the Atlantic Ocean [Houghton et al., 1996]. A reduction in the Atlantic Meridional Overturning Circulation could decrease this heat transfer, and therefore reduce the interhemispheric temperature gradient [Broecker, 1998]. 
Changes in the interhemispheric temperature gradient associated with millennial scale climate events consistent with the predictions of Broecker [1998] have been documented. Using a global compilation of temperature records Shakun and Carlson [2010], show that both H1 and the Younger Dryas were characterized by cooling in the Northern Hemisphere and warming in the Southern Hemisphere, in contrast to the LGM, when cooling was global.

Whether the Atlantic Meridional Overturning Circulation is actually the source of the millennial scale changes in the interhemispheric temperature gradient is still under debate. While many proxies suggest a change in water mass distribution during the LGM [e.g. Boyle and Keigwin, 1987; Curry and Oppo, 2005; Robinson et al., 2005], it is not obvious that this change was associated with a dramatic change in the strength of the overturning circulation [Curry and Oppo, 2005; Hall et al., 2006; McManus et al., 2004; Praetorius et al., 2008; Stanford et al., 2006; Yu et al., 1996], and is consistent with the lack of change in interhemispheric temperature gradient. Thus, one possible explanation for the lack of a LGM minus late Holocene $\delta^{18} \mathrm{O}_{\text {seawater-icevolume }}$ difference in our tropical study area is that the ITCZ was close to its modern position. In addition, the $\delta^{18} \mathrm{O}_{\text {seawater-icevolume }}$ should not be expected to preserve modest differences in the $\delta^{18} 0$ of precipitation, because changes in the ocean are muted due to ocean mixing and advection by currents [e.g. Oppo et al., 2007].

On the other hand, several lines of evidence suggest a significant reduction in the Atlantic Meridional Overturning Circulation during H1 and the Younger Dryas [e.g. Hall et al., 2006; McManus et al., 2004; Oppo and Curry, 2011; Praetorius et al., 
2008; Stanford et al., 2006]. Thus, the decrease in the northward heat transport during $\mathrm{H} 1$ and the Younger Dryas associated with a reduction in the Atlantic Meridional Overturning Circulation may have been more significant than during the LGM.

Modeling sensitivity studies that add freshwater to the North Atlantic (e.g. "hosing" experiments), show a decrease in the Atlantic Meridional Overturning Circulation and a southward shift in the ITCZ [Dahl et al., 2005; Zhang and Delworth, 2005], and specifically a drying in the Indo Pacific Warm Pool region [Zhang and Delworth, 2005]. A freshwater hosing experiment using a water isotope-enabled fully coupled model allows us to directly compare the $\delta^{18} \mathrm{O}_{\text {seawater }}$ data with model output [Lewis et al., 2010]. This model experiment simulates a southward shift in the ITCZ. The $\delta^{18} 0$ of precipitation is enriched in the northern part of the IndoPacific and depleted in the south. Dividing the two regions is a band that experiences no change in the $\delta^{18} 0$ of precipitation. According to the model simulations, this region of no change experiences an increase in summer precipitation (corresponding to depleted $\delta^{18} 0$ ) and a decrease in winter precipitation (corresponding to enriched $\delta^{18} 0$ ). While this band is slightly to the north of the cores that show no change in the

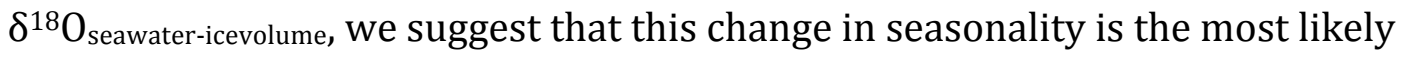
explanation for the lack of $\delta^{18} \mathrm{O}_{\text {seawater-icevolume }}$ change in core MD70, MD76, and MD78 during $\mathrm{H} 1$ and the Younger Dryas. Unfortunately, $\delta^{18} \mathrm{O}_{\text {seawater-icevolume }}$ changes in the entire tropical Pacific and Indian Oceans during the simulated hosing experiment are not significant at the $95 \%$ level, so we cannot directly compare our seawater reconstruction to the modeled $\delta^{18} \mathrm{O}_{\text {seawater }}$ response. However, the similar 
spatial pattern to the $\delta^{18} \mathrm{O}_{\text {seawater }}$ of precipitation lends support to our interpretations.

\section{Conclusion}

Eastern Equatorial Pacific and IndoPacific Warm Pool changes in $\delta^{18} 0_{\text {seawater- }}$ icevolume suggest the migration of the ITCZ controls major hydrologic changes from the LGM to present. The $\delta^{18} \mathrm{O}_{\text {seawater-icevolume }}$ values at the sites we study during the LGM were similar to today's, suggesting relatively small changes in the IndoPacific tropical hydrologic cycle compared to H1 and the Younger Dryas, when the $\delta^{18} \mathrm{O}_{\text {seawater-icevolume }}$ pattern suggests a southward migration of the ITCZ. The spatial

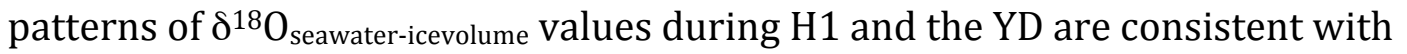
simulated changes in the $\delta^{18} 0$ of precipitation in a hosing experiment. Utilizing our greater spatial resolution, we reject an ENSO-like change from the LGM to present, and instead concur with the findings of those previous studies which suggest that there was a southward ITCZ migration during H1 and the Younger Dryas. Additionally, by focusing on records that derive $\delta^{18} \mathrm{O}_{\text {seawater }}$ entirely from foraminifera, rather than from two sediment constituents (e.g. foraminifera and alkenones), we increase our confidence in the timing of these millennial-scale events. These results, combined with our findings of an ITCZ position at the LGM that is similar to modern, suggest that the migration of the ITCZ was due to changes in the interhemispheric temperature gradient. 


\begin{tabular}{|c|c|c|c|c|c|c|}
\hline Core ID, location & $\begin{array}{l}\text { Core } \\
\text { ID in } \\
\text { text }\end{array}$ & Lat./Long. & $\begin{array}{l}\text { Water } \\
\text { depth } \\
\text { (m) }\end{array}$ & $\begin{array}{l}\text { Average } \\
\text { Sample } \\
\text { interval } \\
(\mathrm{yr})\end{array}$ & $\mathrm{Mg} / \mathrm{Ca}$ equation & Reference \\
\hline $\begin{array}{l}\text { GeoB10029-4, } \\
\text { Eastern Indian Ocean }\end{array}$ & $29-4$ & $\begin{array}{l}1^{\circ} 30^{\prime} \mathrm{S} \\
100^{\circ} 8^{\prime} \mathrm{E}\end{array}$ & 962 & 600 & $\begin{array}{l}\text { Anand et al., } \\
2003\end{array}$ & [Mohtadi et al., 2010] \\
\hline $\begin{array}{l}\text { GeoB10038-4, } \\
\text { Eastern Indian Ocean }\end{array}$ & $38-4$ & $\begin{array}{l}5^{\circ} 56^{\prime} \mathrm{S} \\
103^{\circ} 15^{\prime} \mathrm{E}\end{array}$ & 1,819 & 560 & $\begin{array}{l}\text { Anand et al., } \\
2003\end{array}$ & [Mohtadi et al., 2010] \\
\hline $\begin{array}{l}\text { GeoB10069-3 Savu } \\
\text { Sea }\end{array}$ & $69-3$ & $\begin{array}{l}9^{\circ} 36^{\prime} \mathrm{S} \\
120^{\circ} 55^{\prime} \mathrm{E}\end{array}$ & 1,250 & 190 & modified Anand & this study \\
\hline $\begin{array}{l}\text { MD97-2141, Sulu } \\
\text { Sea }\end{array}$ & MD41 & $\begin{array}{l}8^{\circ} 47^{\prime} \mathrm{N} \\
121^{\circ} 17^{\prime} \mathrm{E}\end{array}$ & 3,633 & 90 & $\begin{array}{l}\text { SSTs from } \\
\text { publication }\end{array}$ & [Rosenthal et al., 2003] \\
\hline $\begin{array}{l}\text { MD98-2162, S. } \\
\text { Makassar St. }\end{array}$ & MD62 & $\begin{array}{l}4^{\circ} 41^{\prime} \mathrm{S} \\
117^{\circ} 54^{\prime} \mathrm{E}\end{array}$ & 1,855 & 415 & $\begin{array}{l}\text { Anand et al., } \\
2003\end{array}$ & [Visser et al., 2003] \\
\hline $\begin{array}{l}\text { MD98-2165, Sumba } \\
\text { St. }\end{array}$ & MD65 & $\begin{array}{l}9^{\circ} 39^{\prime} \mathrm{S} \\
118^{\circ} 20^{\prime} \mathrm{E}\end{array}$ & 2,100 & 200 & $\begin{array}{l}\text { Anand et al., } \\
2003\end{array}$ & [Levi et al., 2007] \\
\hline $\begin{array}{l}\text { MD98-2170, Timor } \\
\text { Sea }\end{array}$ & MD70 & $\begin{array}{l}10^{\circ} 36^{\prime} \mathrm{S} \\
125^{\circ} 23^{\prime} \mathrm{E}\end{array}$ & 832 & 300 & $\begin{array}{l}\text { Anand et al., } \\
2003\end{array}$ & [Stott et al., 2007] \\
\hline $\begin{array}{l}\text { MD98-2176, Seram } \\
\text { Sea }\end{array}$ & MD76 & $\begin{array}{l}5^{\circ} 00^{\prime} \mathrm{S} \\
133^{\circ} 27^{\prime} \mathrm{E}\end{array}$ & 2,382 & 75 & $\begin{array}{l}\text { Anand et al., } \\
2003\end{array}$ & [Stott et al., 2007] \\
\hline $\begin{array}{l}\text { MD98-2181, W. } \\
\text { Pacific, Mindanao }\end{array}$ & MD81 & $\begin{array}{l}6^{\circ} 27^{\prime} \mathrm{N} \\
125^{\circ} 50^{\prime} \mathrm{E}\end{array}$ & 2,114 & 50 & $\begin{array}{l}\text { Anand et al., } \\
2003\end{array}$ & [Stott et al., 2007] \\
\hline $\begin{array}{l}\text { MD01-2378, Timor } \\
\text { Sea }\end{array}$ & MD78 & $\begin{array}{l}13^{\circ} 05^{\prime} \mathrm{S} \\
121^{\circ} 47^{\prime} \mathrm{E}\end{array}$ & 1,783 & 125 & modified Anand & $\begin{array}{l}\text { [Sarnthein et al., 2011; } \\
\text { Xu et al., 2008] }\end{array}$ \\
\hline $\begin{array}{l}\text { MD01-2390, South } \\
\text { China Sea }\end{array}$ & MD90 & $\begin{array}{l}6^{\circ} 38^{\prime} \mathrm{N} \\
113^{\circ} 25^{\prime} \mathrm{E}\end{array}$ & 1,545 & 200 & $\begin{array}{l}\text { Anand et al., } \\
2003\end{array}$ & [Steinke et al., 2008] \\
\hline $\begin{array}{l}\text { ME0005A-43JC } \\
\text { Eastern Eq. Pacific }\end{array}$ & $43 \mathrm{JC}$ & $\begin{array}{l}7^{\circ} 51^{\prime} \mathrm{N} \\
83^{\circ} 37^{\prime} \mathrm{W}\end{array}$ & 1,368 & 240 & $\begin{array}{l}\text { SSTs from } \\
\text { publication }\end{array}$ & [Benway et al., 2006] \\
\hline $\begin{array}{l}\text { TR163-22 Eastern } \\
\text { Eq. Pacific }\end{array}$ & $\begin{array}{l}\text { TR163- } \\
22\end{array}$ & $\begin{array}{l}0^{\circ} 31^{\prime} \mathrm{N} \\
92^{\circ} 24^{\prime} \mathrm{W}\end{array}$ & 2,830 & 270 & $\begin{array}{l}\text { SSTs from } \\
\text { publication }\end{array}$ & [Lea et al., 2006] \\
\hline $\begin{array}{l}\text { V21-30 Eastern Eq. } \\
\text { Pacific }\end{array}$ & $\mathrm{V} 21-30$ & $\begin{array}{l}1^{\circ} 13^{\prime} \mathrm{S} \\
89^{\circ} 41^{\prime} \mathrm{E}\end{array}$ & 617 & 430 & $\begin{array}{l}\text { Anand et al., } \\
2003\end{array}$ & [Koutavas et al., 2002] \\
\hline
\end{tabular}

Table 1: Cores used in this study. All cores use data from G. ruber, except V21-30 which uses $G$. sacculifer. 


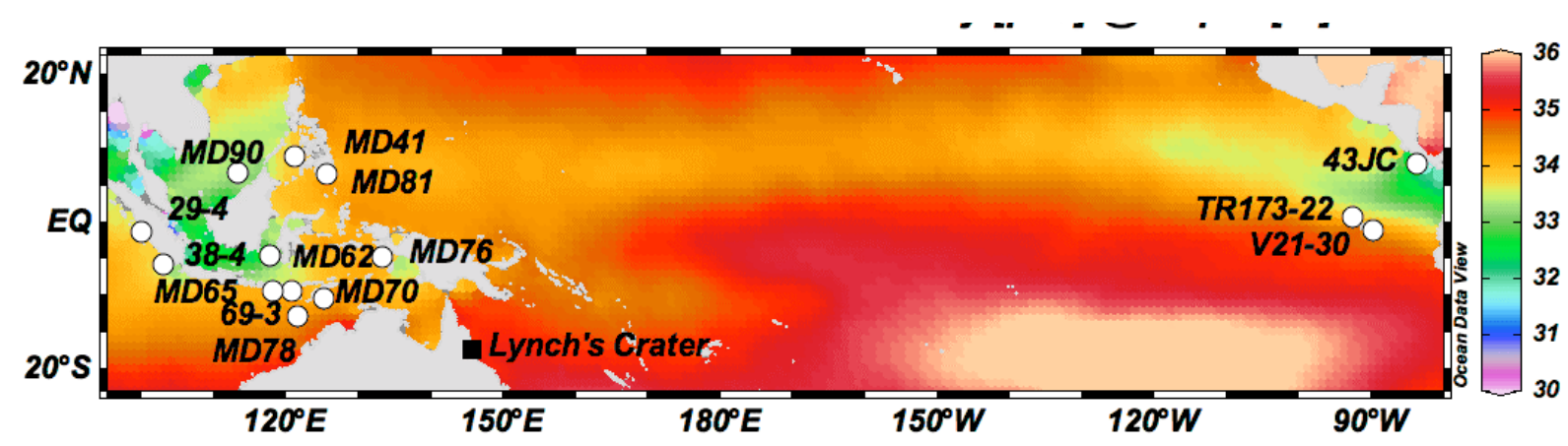

Fig 1:

Core locations and mean annual sea surface salinity from the World Ocean Atlas 05 [Antonov et al., 2006]. 


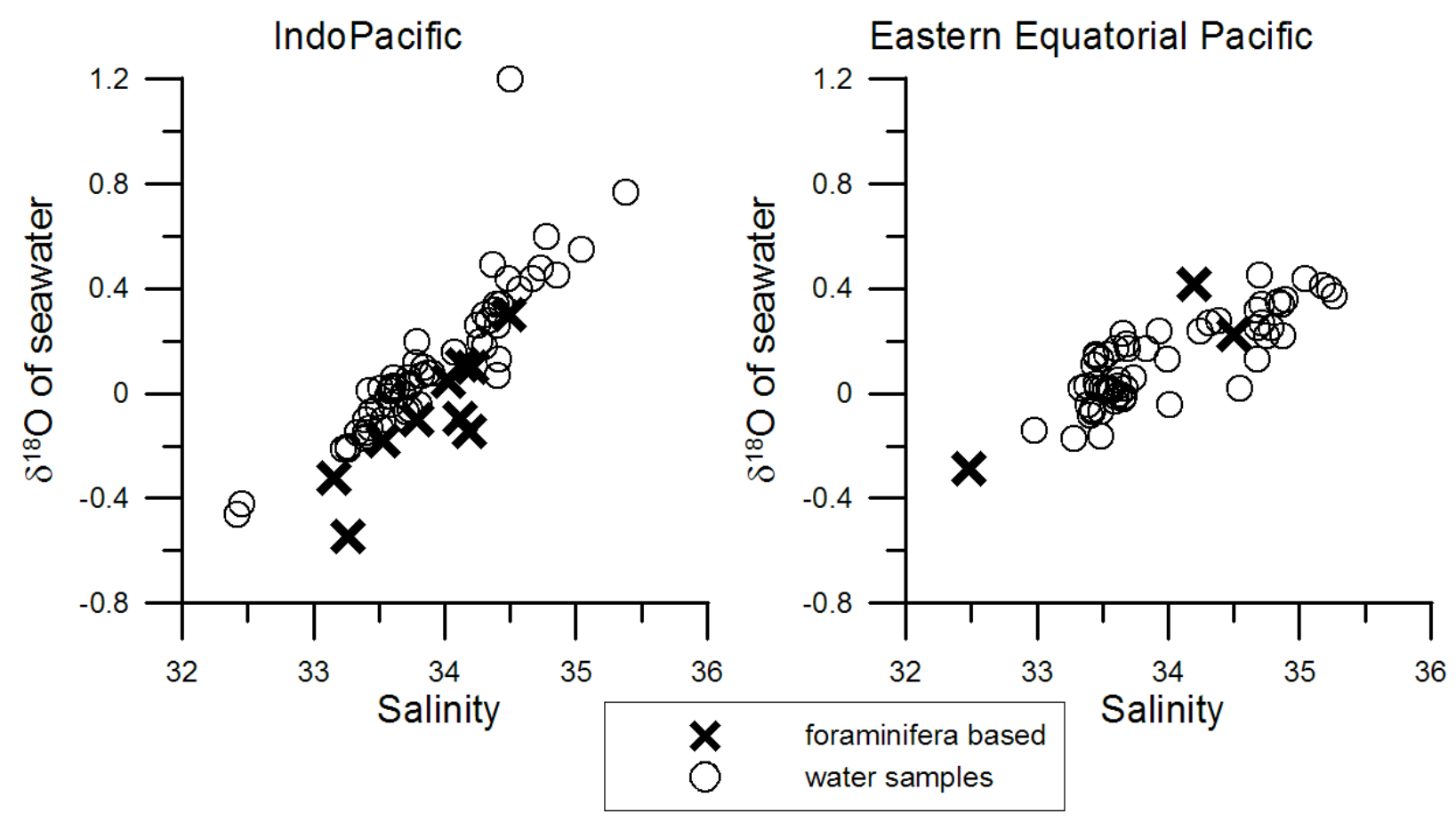

Figure 2: Foraminifera-based reconstructed "modern" $\delta^{18} \mathrm{O}_{\text {seawater }}$ estimates plotted against modern WOA05 salinity data [Antonov et al., 2006]. Modern water $\delta^{18} \mathrm{O}_{\text {seawater }}$ and salinity data [LeGrande and Schmidt, 2006] are also shown. The IndoPacific plot includes all water data from $90^{\circ} \mathrm{E}-140^{\circ} \mathrm{E}$ and $10^{\circ} \mathrm{N}-10^{\circ} \mathrm{S}$. The Eastern Equatorial Pacific plot includes data from $90^{\circ} \mathrm{W}$ to $100^{\circ} \mathrm{W}$ and $11^{\circ} \mathrm{N}$ to $10^{\circ} \mathrm{S}$. All water samples are from $100 \mathrm{~m}$ or above and most are from the surface. For the IndoPacific samples, the slope for the foraminifera-based line is $0.48\left(\mathrm{R}^{2}=0.76\right)$ and for the water samples it is $0.44\left(\mathrm{R}^{2}=0.79\right)$. For the Eastern Equatorial Pacific the slope for the modern is $0.22\left(\mathrm{R}^{2}=0.70\right)$ and the reconstructed $\delta^{18} \mathrm{O}_{\text {seawater values }}$ tend to fall within the scatter of the data. 


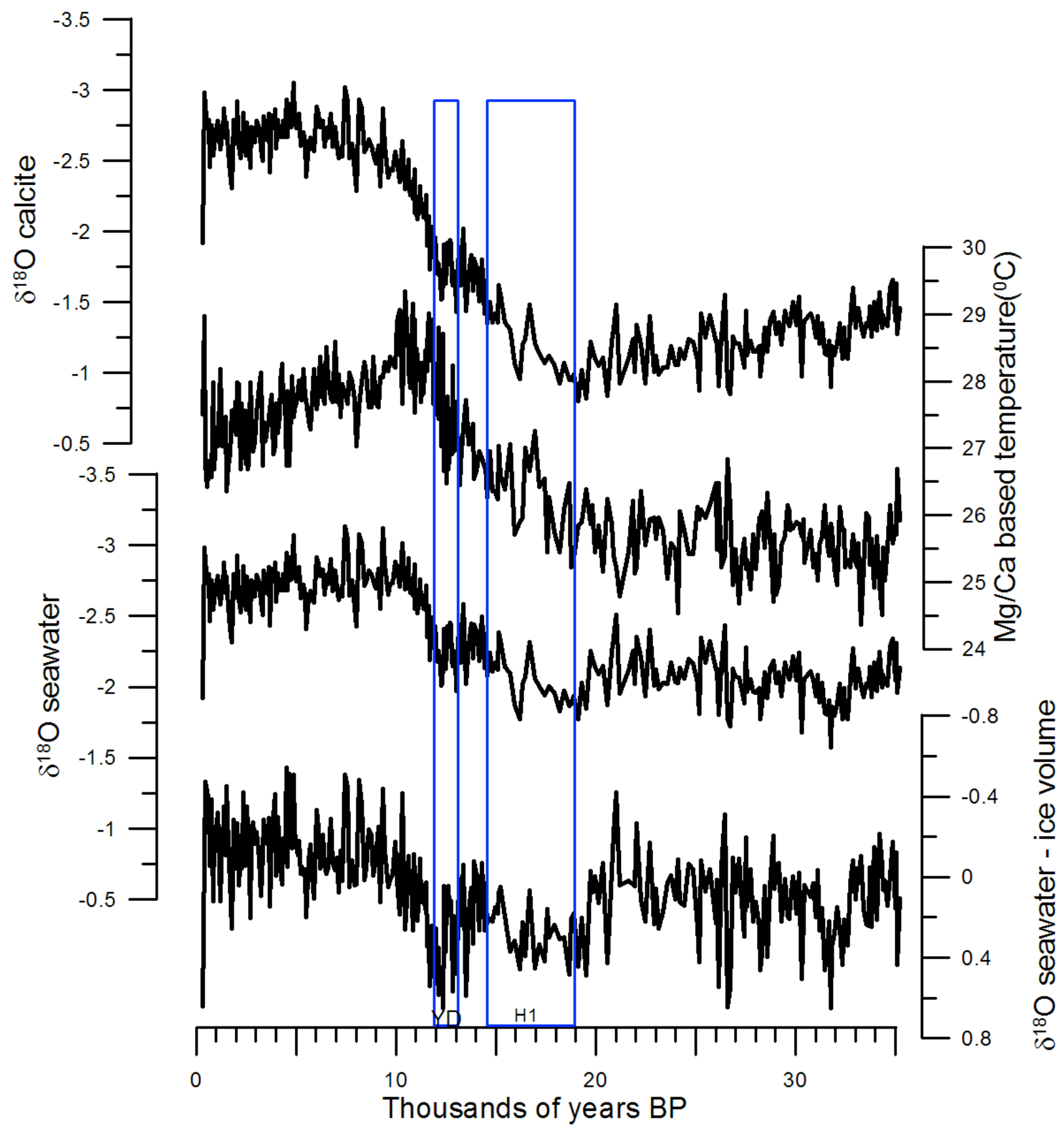

Figure 3: Data from 69-3. Top panel is $\delta^{18} \mathrm{O}$ of calcite. Next panel is the $\mathrm{Mg} / \mathrm{Ca}$-based temperature. These records are combined below [Bemis et al., 1998] to derive the $\delta^{18} \mathrm{O}_{\text {seawater. }}$. Finally, we show the $\delta^{18} \mathrm{O}_{\text {seawater }}$ with the global ice volume effect removed. Northern hemisphere cold events (the Younger Dryas and Heinrich Stadial 1 ), which correspond to periods of enriched $\delta^{18} \mathrm{O}_{\text {seawater }}$ are indicated by blue boxes. 


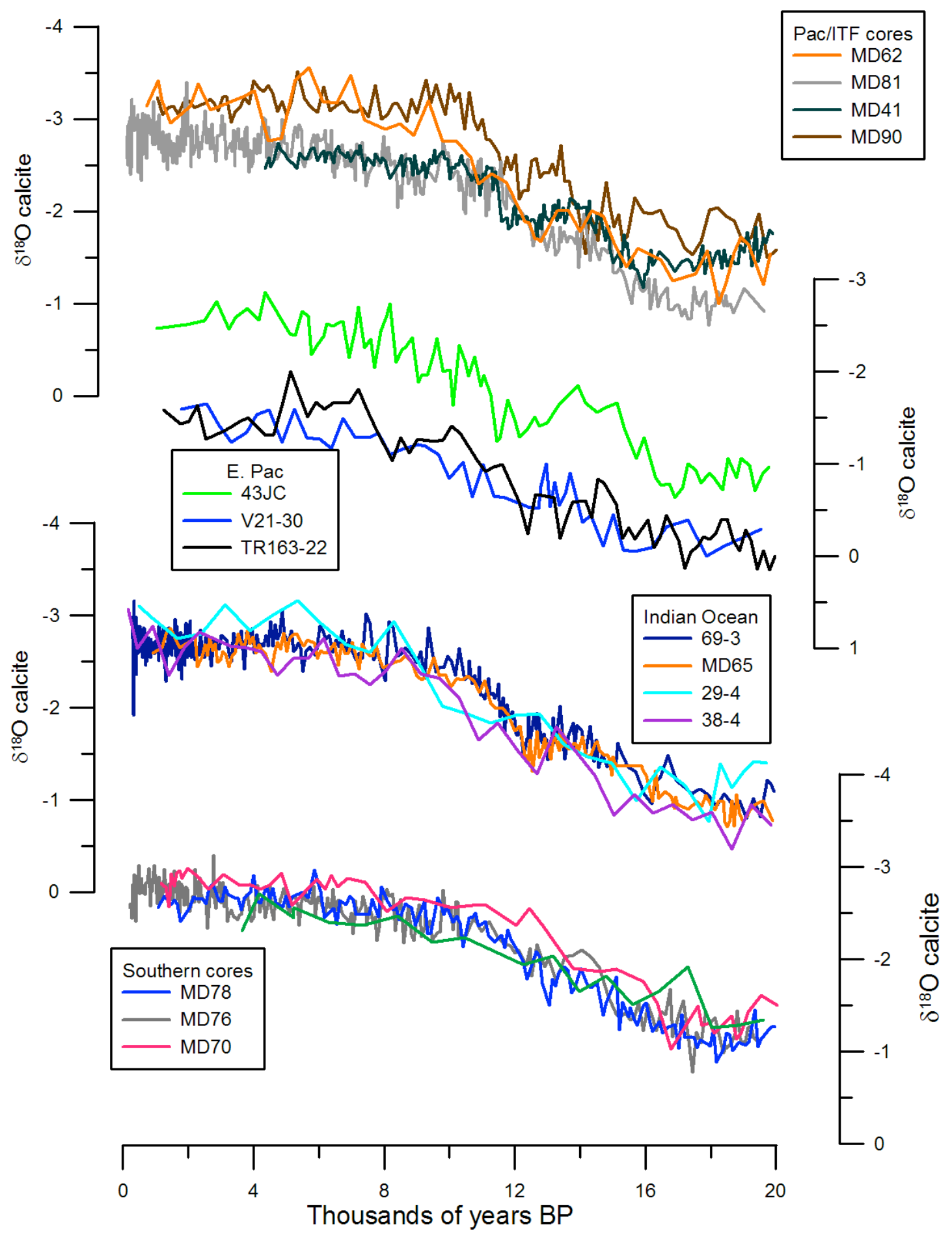

Figure 4a: $\delta^{18} \mathrm{O}_{\text {calcite }}$ data from all cores used in this study. The cores are grouped by region. 


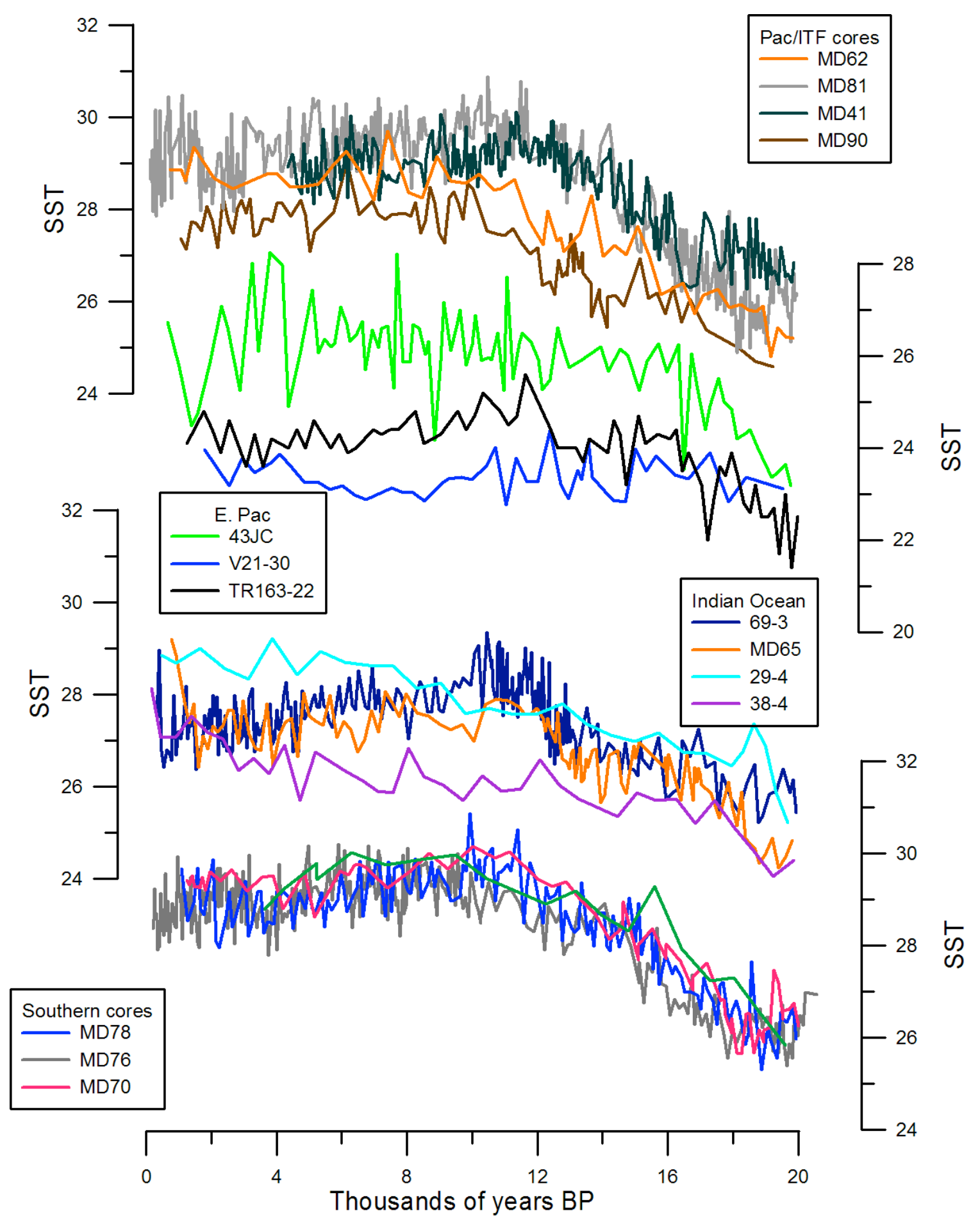

Figure 4b: Mg/Ca-based temperature data from all cores used in this study. Note the wide range of deglacial temperature histories. 


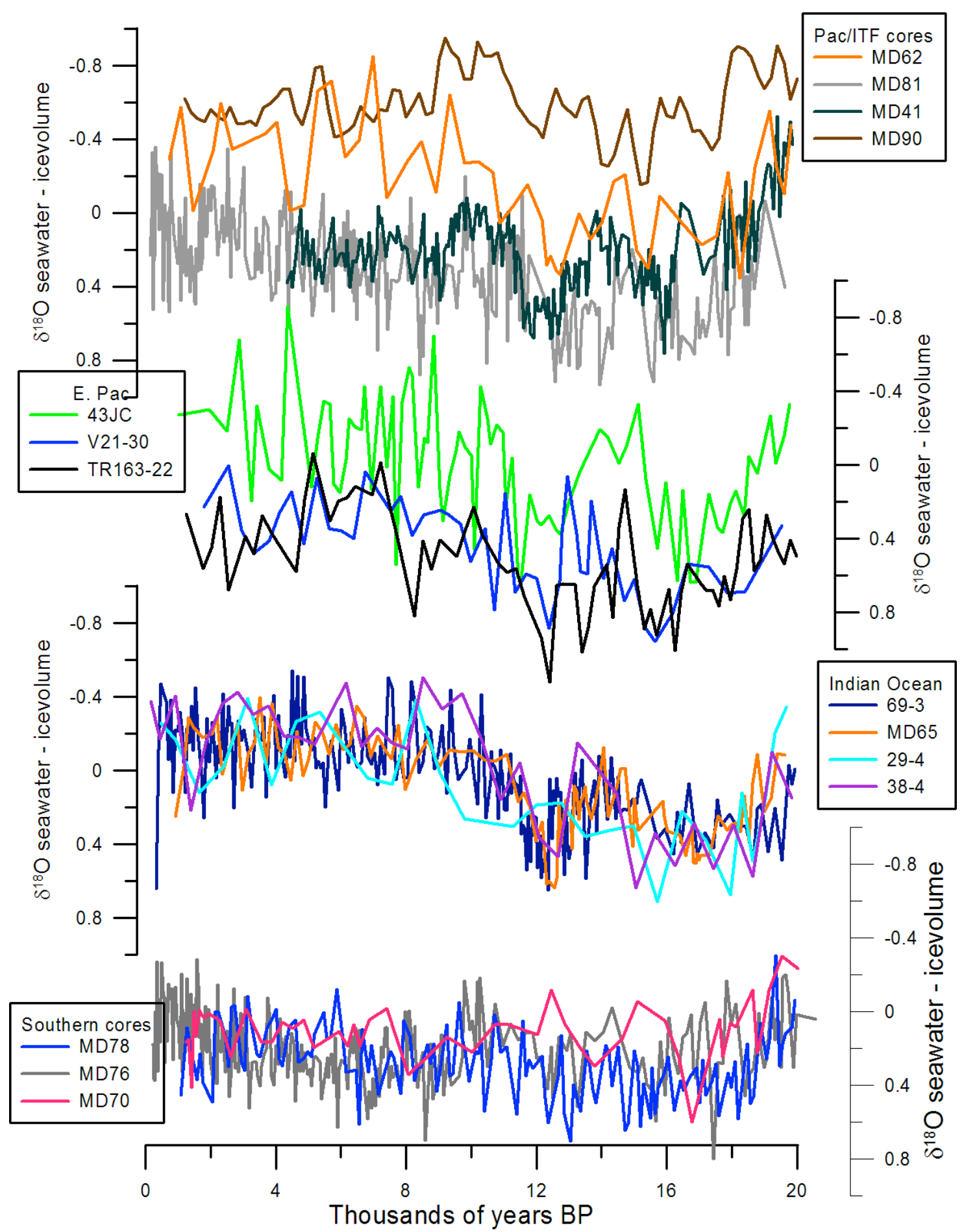

Figure 4c: $\delta^{18} \mathrm{O}_{\text {seawater-icevolume }}$ reconstructions from all cores used in this study. Note the generally similar LGM and late Holocene values for the $\delta^{18} \mathrm{O}_{\text {seawater-icevolume. With }}$ the exception of the southern cores (bottom panel), many of the records show enrichment events during $\mathrm{H} 1$ and the Younger Dryas. 


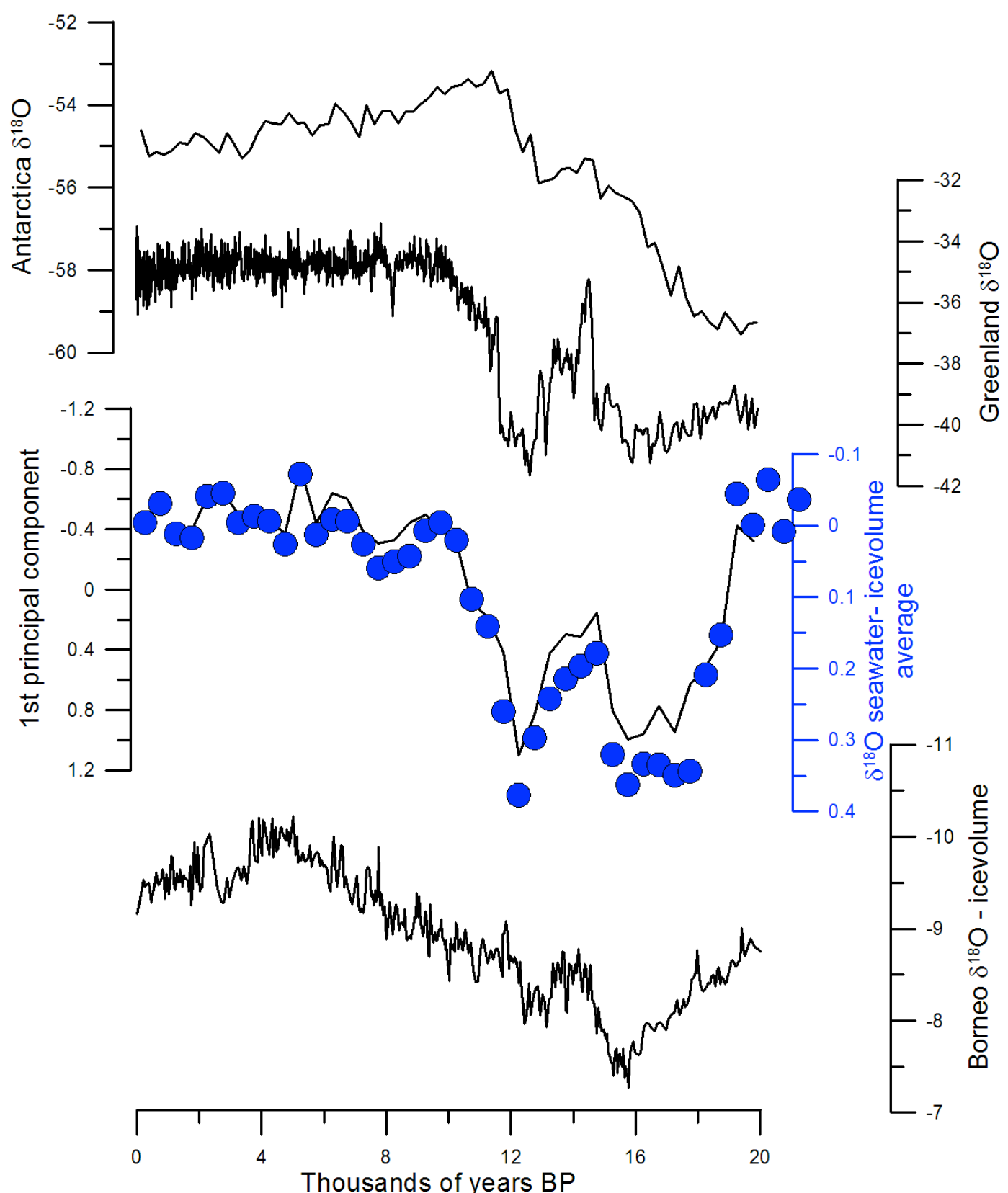

Figure 5: A comparison of climate records. Top panel is a $\delta^{18} 0$ records from Dome Fuji [Kawamura et al., 2007]in the Indian Ocean sector of Antarctica. Second panel is GISP $\delta^{18} 0$ from Greenland [Grootes and Stuiver, 1997]. The third panel is the first principal component (PC1) of all IndoPacific and Eastern Equatorial Pacific $\delta^{18} \mathrm{O}_{\text {seawater-icevolume }}$ records included in this study (see table 1 for included cores). Dots (blue) are an average of all the $\delta^{18} \mathrm{O}_{\text {seawater-icevolume records. Note the inverted }}$ axes for both PC1 and the average $\delta^{18} \mathrm{O}_{\text {seawater-icevolume }}$ record. The final panel is a spliced record of $\delta^{18} 0$ from three Borneo speleothems [Partin et al., 2007], with the global change in $\delta^{18} 0$ due to ice volume removed [Clark and Mix, 2002; Schrag et al., 2002]. 


\section{Eigenvector elements (Loadings) for PC1}

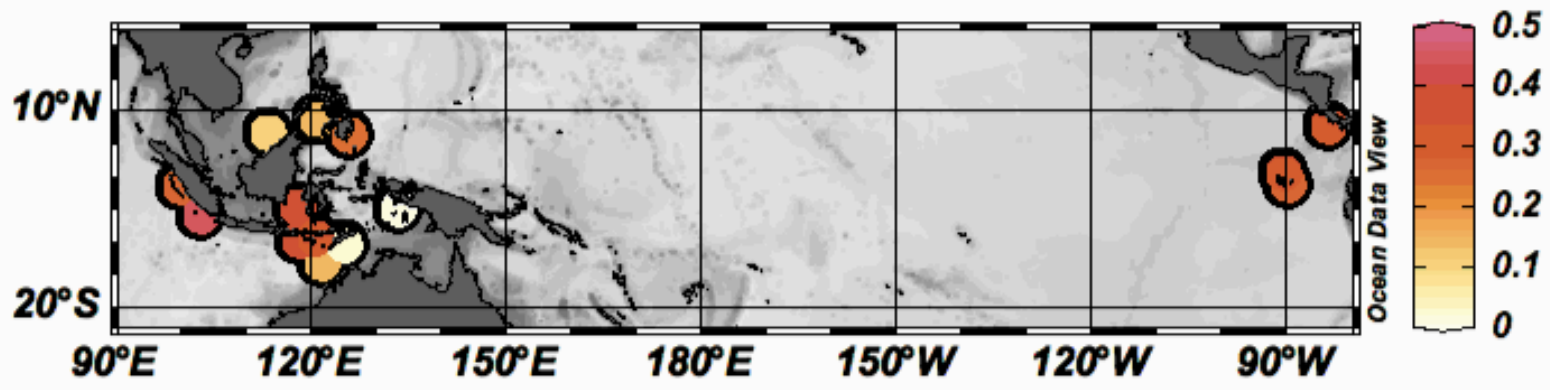

\section{5kyr BP $\delta^{18}$ Oseawater-icevolume anomaly}

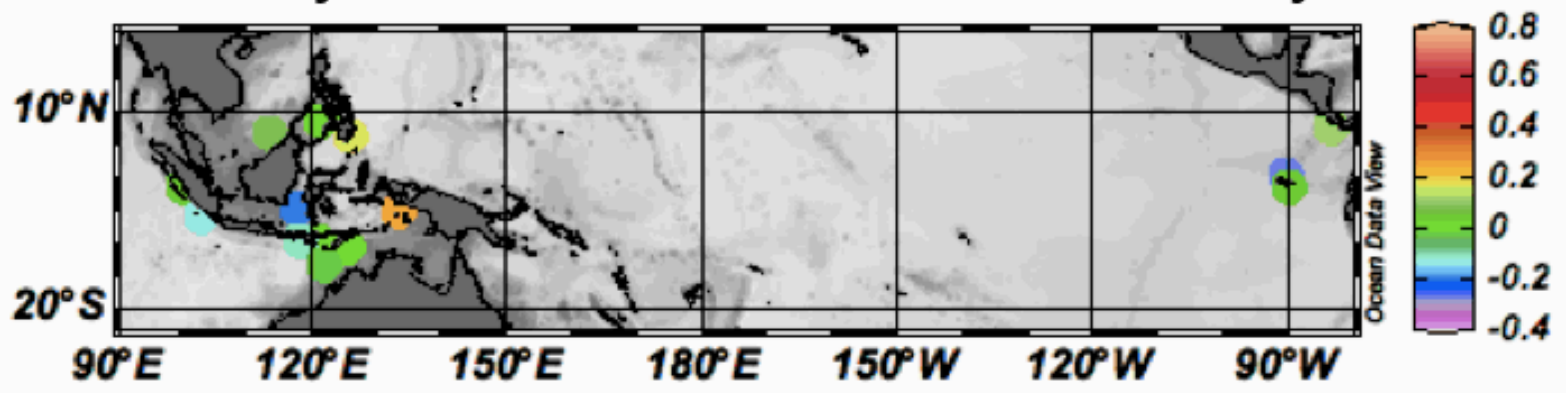

Figure 6: Top panel is eigenvector elements (loadings) for PC1. Following panel is

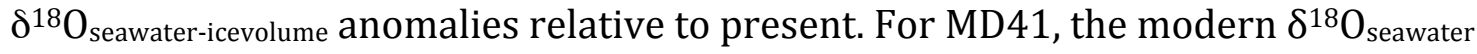
estimate from the gridded data of Le Grade and Schmidt [2006] was used to calculate the anomaly. For all other cores anomalies were calculated with respect to the last 2,000 years. Bottom panel is an average of 1,000 years and is centered on 6.5 kyr BP 


\section{5kyr BP $\delta^{18}$ Oseawater-icevolume anomaly}

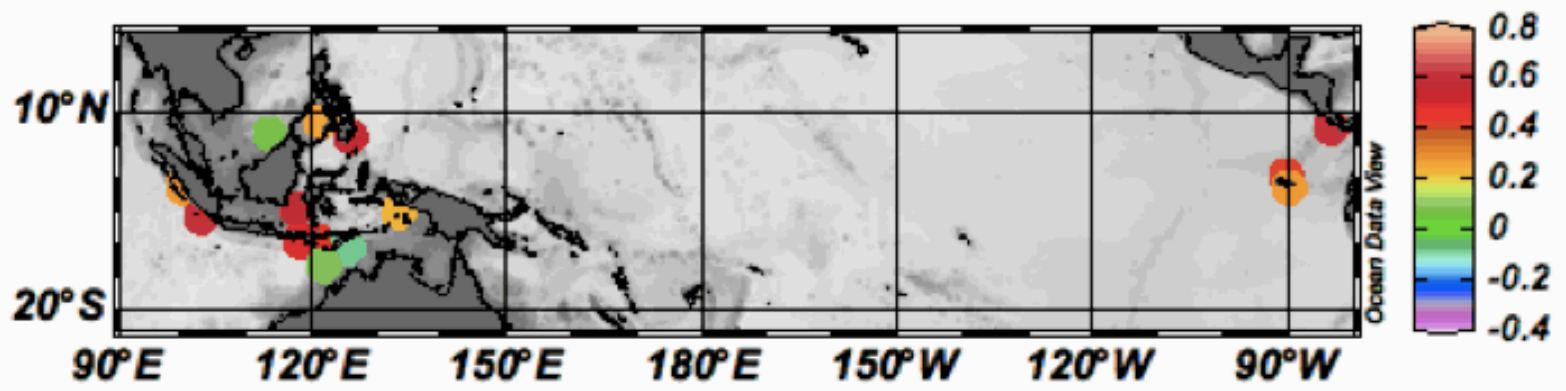

14.5kyr BP $\delta^{18}$ Oseawater-icevolume anomaly

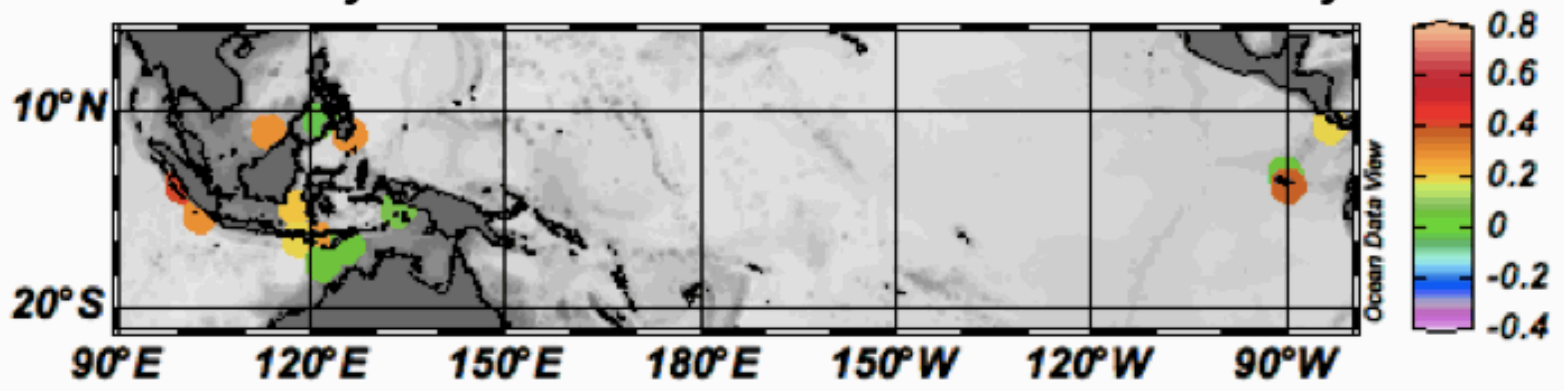

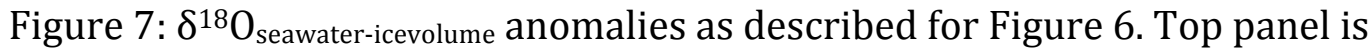
centered on $12.5 \mathrm{kyr}$ BP and bottom panel is centered on $14.5 \mathrm{kyr}$ BP. There are generally enriched conditions during the Younger Dryas (12.5 kyr BP) and a partial recovery to late Holocene conditions during the Bølling-Allerød (14.5 kyr BP). Note the lack of change in the East-West gradient. 


\section{5kyr BP $\delta^{18}$ Oseawater-icevolume anomaly}
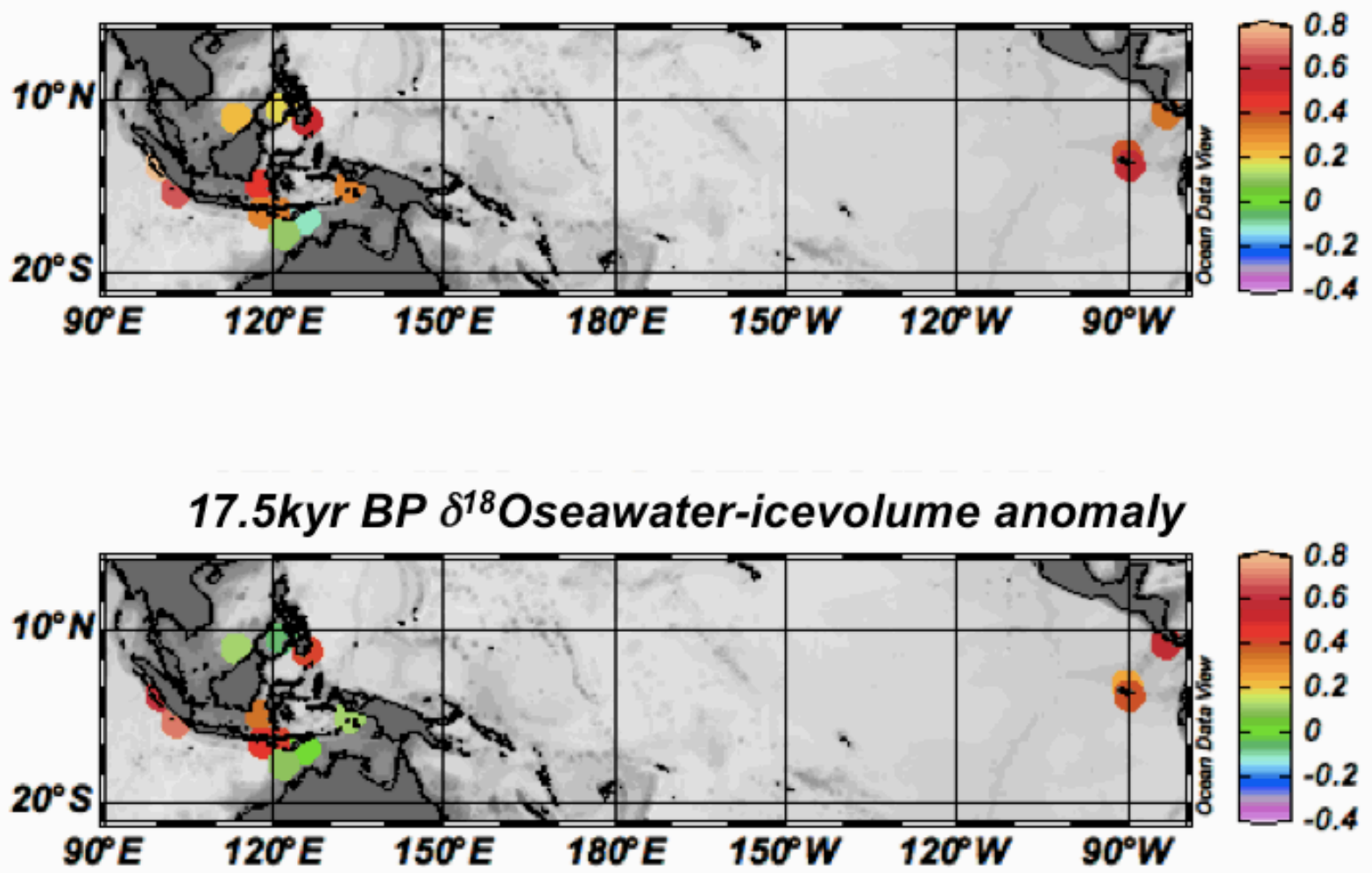

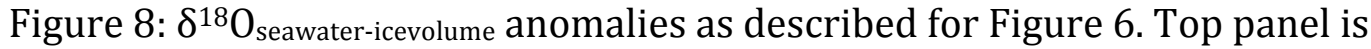
centered on $15.5 \mathrm{kyr}$ BP and bottom panel is centered on $17.5 \mathrm{kyr}$ BP. Enriched conditions occur throughout Heinrich Stadial 1, and are not only confined to Heinrich Event 1. 


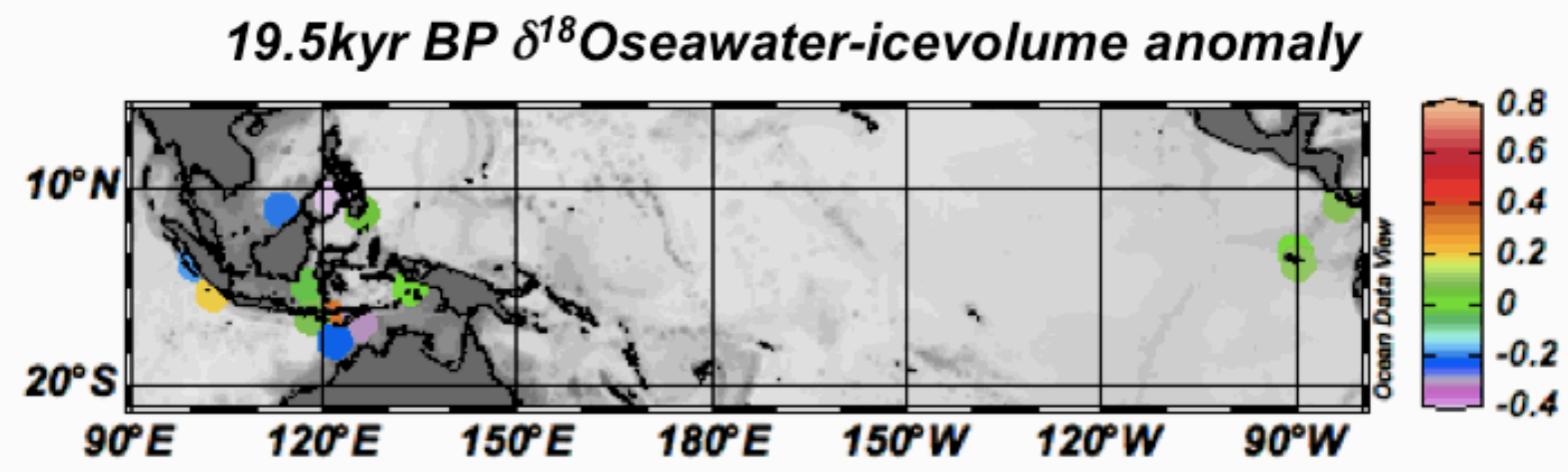

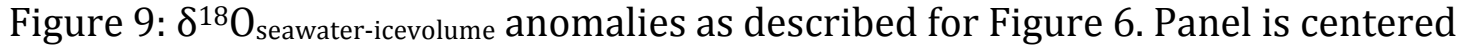
on 19.5kyr BP (the LGM). Relatively small anomalies suggest the position of the ITCZ at the LGM was very similar to the Late Holocene. 
Alley, R. B., and P. U. Clark (1999), The deglaciation of the northern hemisphere: A global perspective, Annual Review of Earth and Planetary Sciences, 27, 149-182. Anand, P., et al. (2003), Calibration of $\mathrm{Mg} / \mathrm{Ca}$ thermometry in planktonic foraminifera from a sediment trap time series, Paleoceanography, 18(2), 15. Antonov, J. I., et al. (2006), World Ocean Atlas 2005, Volume 2: Salinity, NOAA Atlas NESDIS 62.

Bemis, B. E., et al. (1998), Reevaluation of the oxygen isotopic composition of planktonic foraminifera: Experimental results and revised paleotemperature equations, Paleoceanography, 13(2), 150-160.

Benway, H. M., et al. (2006), Eastern Pacific Warm Pool paleosalinity and climate variability: 0-30 kyr, Paleoceanography, 21(3).

Bond, G., et al. (1992), Evidence for Massive Discharges of Icebergs into the NorthAtlantic Ocean during the Last Glacial Period, Nature, 360(6401), 245-249.

Bond, G., et al. (1993), Correlations between Climate Records from North-Atlantic Sediments and Greenland Ice, Nature, 365(6442), 143-147.

Boyle, E. A., and L. D. Keigwin (1985/6), Comparison of Atlantic and Pacific Paleochemical Records for the Last 215,000 Years - Changes in Deep Ocean Circulation and Chemical Inventories, Earth and Planetary Science Letters, 76(1-2), 135-150.

Boyle, E. A., and L. Keigwin (1987), North-Atlantic Thermohaline Circulation during the Past 20,000 Years Linked to High-Latitude Surface-Temperature, Nature, 330 (6143), 35-40.

Broecker, W. S. (1991), The Great Ocean Conveyor, Oceanography, 4(2), 79-89.

Broecker, W. S. (1998), Paleocean circulationduring the last deglaciation: A bipolar seesaw?, Paleoceanography, 13(2), 119-121.

Broecker, W. S. (2006), Was the younger dryas triggered by a flood?, Science, 312(5777), 1146-1148.

Cane, M. A. (1998), Climate change - A role for the tropical Pacific Science, 282(5386), 59.

Clark, P. U., and A. C. Mix (2002), Ice sheets and sea level of the Last Glacial Maximum, Quaternary Science Reviews, 21(1-3), 1-7.

Clement, A. C., et al. (1999), Orbital controls on the El Nino/Southern Oscillation and the tropical climate, Paleoceanography, 14(4), 441-456.

Craig, H., and L. I. Gordon (1965), Deuterium and oxygen 18 variations in the ocean and the marine atmosphere, Consiglio Nazionale Delle Ricerche, Spoleto.

Curry, W. B., and D. W. Oppo (2005), Glacial water mass geometry and the distribution of delta C-13 of Sigma CO2 in the western Atlantic Ocean, Paleoceanography, 20(1), 13.

Dahl, K., et al. (2005), Assessing the role of North Atlantic freshwater forcing in millennial scale climate variability: a tropical Atlantic perspective, Climate Dynamics, 24(4), 325-346.

Dansgaard, W., et al. (1989), The Abrupt Termination of the Younger Dryas Climate Event, Nature, 339(6225), 532-534. 
Ding, X., et al. (2002), Evolution of heat transport pathways in the Indonesian Archipelago during last deglaciation, Chinese Science Bulletin, 47(22), 1912-1917. Gibbons, F. T., et al. (in revision), Southern Hemisphere Influence on the Indonesian Throughflow, Nature, In Revision.

Grootes, P. M., and M. Stuiver (1997), Oxygen 18/16 variability in Greenland snow and ice with $10^{\wedge} 3$ to $10^{\wedge} 5$-year time resolution., Journal of Geophysical Research, 102, 26455-26470.

Hall, I. R., et al. (2006), Accelerated drawdown of meridional overturning in the lateglacial Atlantic triggered by transient pre-H event freshwater perturbation, Geophysical Research Letters, 33(16).

Heinrich, H. (1988), Origin and Consequences of Cyclic Ice Rafting in the Northeast Atlantic-Ocean during the Past 130,000 Years, Quaternary Research, 29(2), 142-152. Hemming, S. R. (2004), Heinrich events: Massive late pleistocene detritus layers of the North Atlantic and their global climate imprint, Reviews of Geophysics, 42(1). Houghton, J. T., et al. (1996), Chapter 1: The climate system: an overview. Jolliffe, I. T. (2002), Principal Component Analysis, 2nd edition, Springer. Kawamura, K., et al. (2007), Northern Hemisphere forcing of climatic cycles in Antarctica over the past 360,000 years, Nature, 448, 912-916.

Kiefer, T., and M. Kienast (2005), Patterns of deglacial warming in the Pacific Ocean: a review with emphasis on the time interval of Heinrich event 1, Quaternary Science Reviews, 24, 1063-1081.

Koutavas, A., et al. (2002), El Nino-like pattern in ice age tropical Pacific sea surface temperature, Science, 297(5579), 226-230.

Koutavas, A., and J. Lynch-Stieglitz (2005), Variability of the marine ITCZ over the eastern Pacific during the past 30,000 years: Regional perspective and global context, Springer.

Lea, D. W., et al. (2000), Climate impact of late quaternary equatorial Pacific sea surface temperature variations, Science, 289(5485), 1719-1724.

Lea, D. W., et al. (2003), Synchroneity of tropical and high-latitude Atlantic temperatures over the last glacial termination, Science, 301(5638), 1361-1364. Lea, D. W., et al. (2006), Paleoclimate history of Galapagos surface waters over the last 135,000 yr, Quaternary Science Reviews, 25(11-12), 1152-1167.

Leduc, G., et al. (2009), ITCZ rather than ENSO signature for abrupt climate changes across the tropical Pacific?, Quaternary Research, 72(1), 123-131.

LeGrande, A. N., and G. A. Schmidt (2006), Global gridded data set of the oxygen isotopic composition in seawater, Geophysical Research Letters, 33(12), 5.

LeGrande, A. N., and G. A. Schmidt (2011), Water isotopologues as a quantitative paleosalinity proxy, Paleoceanography, 26.

Levi, C., et al. (2007), Low-latitude hydrological cycle and rapid climate changes during the last deglaciation, Geochemistry Geophysics Geosystems, 8(5), Q05N12. Lewis, S. C., et al. (2010), Water vapour source impacts on oxygen isotope variability in tropical precipitation during Heinrich events, Climate of the Past, 6(3), 325-343. Linsley, B. K., et al. (2010), Holocene evolution of the Indonesian throughflow and the western Pacific warm pool, Nature Geoscience, 3, 578-583.

Lynch-Stieglitz, J., et al. (2011), Evidence from the Florida Straits for Younger Dryas ocean circulation changes, Paleoceanography, 26. 
Marchal, O., et al. (2002), Apparent long-term cooling of the sea surface in the northeast Atlantic and Mediterranean during the Holocene, Quaternary Science Reviews, 21(4-6), 455-483.

McManus, J. F., et al. (2004), Collapse and rapid resumption of Atlantic meridional circulation linked to deglacial climate changes, Nature, 428(6985), 834-837.

Mohtadi, M., et al. (2010), Glacial to Holocene surface hydrography of the tropical eastern Indian Ocean, Earth and Planetary Science Letters, 292, 89-97.

Muller, J., et al. (2008), Possible evidence for wet Heinrich phases in tropical NE Australia: the Lynch's Crater deposit, Quaternary Science Reviews, 27(5-6), 468-475. Murton, J. B., et al. (2010), Identification of Younger Dryas outburst flood path from Lake Agassiz to the Arctic Ocean, Nature, 464(7289), 740-743.

Oppo, D. W., et al. (2007), Seawater isotope constraints on tropical hydrology during the Holocene, Geophysical Research Letters, 34(13).

Oppo, D. W., and W. B. Curry (2011), Deep Atlantic Circulation During the Last Glacial Maximum and Deglaciation, Nature Education.

Oppo, D. W., and W. B. Curry (2012), Deep Atlantic Circulation During the Last Glacial Maximum and Deglaciation, Nature Education.

Partin, J. W., et al. (2007), Millennial-scale trends in west Pacific warm pool hydrology since the Last Glacial Maximum, Nature, 449(7161), 452-U453.

Praetorius, S. K., et al. (2008), Episodic reductions in bottom-water currents since the last ice age, Nature Geoscience, 1(7), 449-452.

Reimer, P. J., et al. (2009), INTCAL09 AND MARINE09 Radiocarbon age calibration curves, 0-50,000 years cal BP, Radiocabon, 51(4), 1111-1150.

Robinson, L. F., et al. (2005), Radiocarbon variability in the western North Atlantic during the last deglaciation, Science, 310(5753), 1469-1473.

Rosenthal, Y., et al. (1997), Temperature control on the incorporation of magnesium, strontium, fluorine, and cadmium into benthic foraminiferal shells from Little Bahama Bank: Prospects for thermocline paleoceanography, Geochimica Et Cosmochimica Acta, 61(17), 3633-3643.

Rosenthal, Y., et al. (2003), The amplitude and phasing of climate change during the last deglaciation in the Sulu Sea, western equatorial Pacific, Geophysical Research Letters, 30(8).

Rosenthal, Y., et al. (2004), Interlaboratory comparison study of $\mathrm{Mg} / \mathrm{Ca}$ and $\mathrm{Sr} / \mathrm{Ca}$ measurements in planktonic foraminifera for paleoceanographic research, Geochemistry Geophysics Geosystems, 5(4), Q04D09.

Ruddiman, W. F., and A. Mcintyre (1981), The North-Atlantic Ocean during the Last Deglaciation, Palaeogeography Palaeoclimatology Palaeoecology, 35(2-4), 145-214. Sarnthein, M., et al. (2011), Tropical warming in the timor sea led deglacial antarctic warming and atmospheric $\mathrm{CO} 2$ rise by more than $500 \mathrm{yr}$, Earth and Planetary Science Letters, 302(3-4), 337-348.

Schrag, D. P., et al. (2002), The oxygen isotopic composition of seawater during the Last Glacial Maximum, Quaternary Science Reviews, 21(1-3), 331-342.

Shakun, J. D., and A. E. Carlson (2010), A global perspective on Last Glacial Maximum to Holocene climate change, Quaternary Science Reviews, 29(15-16), 1801-1816. Stager, J. C., et al. (2011), Catastrophic Drought in the Afro-Asian Monsoon Region During Heinrich Event 1, Science, 331(6022), 1299-1302. 
Stanford, J. D., et al. (2006), Timing of meltwater pulse $1 \mathrm{a}$ and climate responses to meltwater injections, Paleoceanography, 21(4).

Stanford, J. D., et al. (2011), A new concept for the paleoceanographic evolution of Heinrich event 1 in the North Atlantic, Quaternary Science Reviews, 30(9-10), 10471066.

Steinke, S., et al. (2008), Proxy dependence of the temporal pattern of deglacial warming in the tropical South China Sea: toward resolving seasonality, Quaternary Science Reviews, 27(7-8), 688-700.

Stott, L., et al. (2002), Super ENSO and Global Climate Oscillations at Millennial Time Scales, Science, 297, 222-226.

Stott, L., et al. (2004), Decline of surface temperature and salinity in the western tropical Pacific Ocean in the Holocene epoch, Nature, 431(7004), 56-59.

Stott, L., et al. (2007), Southern Hemisphere and Deep-Sea Warming Led Deglacial Atmospheric CO2 Rise and Tropical Warming, Science, 318, 435-438.

Tierney, J. E., et al. (2008), Northern hemisphere controls on tropical southeast African climate during the past 60,000 years, Science, 322(5899), 252-255.

Visser, K., et al. (2003), Magnitude and timing of temperature change in the IndoPacific warm pool during deglaciation, Nature, 421, 152-155.

Waelbroeck, C., et al. (2002), Sea-level and deep water temperature changes derived from benthic foraminifera isotopic records, Quaternary Science Reviews, 21(1-3), 295-305.

Wang, G. L., and D. Schimel (2003), Climate change, climate modes, and climate impacts, Annual Review of Environment and Resources, 28, 1-28.

Wang, X., et al. (2007), Millennial-scale interhemispheric asymmetry of low-latitude precipitation: speleothem evidence and possible high-latitude forcing., 279-295 pp., AGU, Washington, D.C.

$\mathrm{Xu}$, J., et al. (2008), Changes in the thermocline structure of the Indonesian outflow during Terminations I and II, Earth and Planetary Science Letters, 273(1-2), 152-162. $\mathrm{Xu}$, J., et al. (2010), Indo-Pacific Warm Pool variability during the Holocene and Last Glacial Maximum, Paleoceanography, 25(PA4230).

$\mathrm{Yu}$, E. F., et al. (1996), Similar rates of modern and last-glacial ocean thermohaline circulation inferred from radiochemical data, Nature, 379(6567), 689-694. Yuan, D., et al. (2004), Timing, Duration, and Transitions of the Last Interglacial Asian Monsoon, Science, 304, 575-578.

Zhang, R., and T. L. Delworth (2005), Simulated tropical response to a substantial weakening of the Atlantic thermohaline circulation, Journal of Climate, 18(12), 18531860. 


\title{
Chapter 4
}

\section{The thermocline structure of the IndoPacific Warm Pool from the Last Glacial}

\author{
Abstract \\ The thermocline structure of the IndoPacific Warm Pool is influenced by both \\ global and local processes. Several studies suggest that it responds to changes in the \\ Walker Circulation, and others suggest that it is sensitive to the inflow of fresh \\ water from the South China Sea. However, observations and paleoceanographic \\ reconstructions are sparse throughout the IndoPacific Warm Pool, and there is still \\ considerable uncertainty related to the influence of the atmospheric circulation \\ variability and the South China Sea inflow on the thermocline structure, especially in \\ the Indonesian Throughflow region. Here we present thermocline reconstructions \\ using the $\delta^{18} \mathrm{O}$ of calcite, $\mathrm{Mg} / \mathrm{Ca}$-based temperature estimates, and $\delta^{18} \mathrm{O}$ of seawater \\ estimates using the mixed layer foraminifera Globigerinoides ruber (G. ruber) and \\ the thermocline-dwelling foraminifera Pulleniatina obliquiloculata $(P$. \\ obliquiloculata). We present data from both coretops and a suite of downcore \\ records from throughout the IndoPacific Warm Pool. Our results suggest that in the \\ modern ocean, the Mg/Ca-based temperature of $P$. obliquiloculata is a valid proxy
}


for upper thermocline temperature, whereas some caution is required in its use downcore. If the $\mathrm{Mg} / \mathrm{Ca}$-based thermocline temperatures for the Last Glacial Maximum (LGM) are reliable, our data suggest the temperature difference between surface and subsurface waters in IndoPacific Warm Pool was uniformly smaller at the LGM, perhaps consistent with a more vigorous Walker Circulation [DiNezio et al., 2011]. Further our suite of data argue against the hypothesis that the flooding of the Sunda Shelf, which allowed South China Sea water to enter the Indonesian Seas, caused the cool thermocline temperatures observed in the outflow passages of the Indonesian Throughflow after $\sim 10 \mathrm{kyr}$ before present (BP). We note, however, there is difficulty in reconciling the $\delta^{18} \mathrm{O}_{\text {calcite }}$ and $\mathrm{Mg} / \mathrm{Ca}$-based temperature data from $P$. obliquiloculata, and suggest further calibration work is required.

\section{Introduction}

The Indonesian Throughflow (ITF) connects the Pacific to the Indian Ocean through a series of passages between Indonesian islands. It forms the only lowlatitude, inter-ocean connection, allowing direct heat and salinity exchanges between the Pacific and Indian Oceans [Gordon, 2005]. ITF water has been identified in Aghulas eddies within the South Atlantic Ocean, and it is believed to contribute to the warm water return limb of the global overturning circulation [Gordon, 1986]. A relatively higher sea level in the western equatorial Pacific Ocean drives the ITF into the Indian Ocean [Wyrtki, 1987]. Approximately 85\% (8 Sv) of the water transported through the ITF enters from the Sulawesi Sea and passes through the Makassar Strait [Gordon et al., 2003]. From there, most flows into the 
Flores Sea, and then to the Banda Sea (Figure 1). Within the Banda Sea, vigorous mixing with local freshwater creates characteristic low-salinity ITF water [Fieux et al., 1994; Gordon, 2005]. There are three main exits for the ITF: the Lombok Strait, the Ombai Strait, and the Timor Sea, and they respectively account for approximately $20 \%, 30 \%$, and $50 \%$ of the total ITF outflow [Sprintall et al., 2009].

Estimates of the total ITF transport vary widely due to sparse direct observations, large seasonal and interannual variability, and the difficulty of modeling the region [reviewed in Godfrey, 1996]. The most recent measurements suggest that the transport is between 9 and 15 Sv [Gordon, 2005; Sprintall et al., 2009] with the monsoon [Gordon et al., 2003; Sprintall et al., 2009], El NiñoSouthern Oscillation (ENSO) [Ffield et al., 2000; Gordon et al., 2008], and the Indian Ocean Dipole (IOD) [Sprintall et al., 2009] all contributing to the observed variability.

During the boreal winter monsoon (all seasons are discussed with respect to the Northern Hemisphere), fresh surface water from the South China Sea is advected through the Java Sea into the southern Makassar Strait and Flores Sea (dashed arrow in Figure 1) [Fang et al., 2010]. This buoyant fresh water reduces the sea surface salinity of the Makassar Strait in relation to the Western Pacific Warm Pool. Previous work has suggested that this "freshwater plug" reduces the density gradient along the strait, inhibits the flow of surface water through the Makassar Strait, and intensifies the thermocline flow [Gordon et al., 2008]. While this mechanism may contribute to the thermocline dominated flow observed in the Makassar Strait, it cannot be the only explanation. The "freshwater plug" is only 
present during the winter monsoon, but the flow is greater in the thermocline than in the surface in the Makassar Strait throughout the year [Gordon et al., 2008]. A complementary, or perhaps alternative, mechanism involves the persistently higher sea level in the southern Java Sea compared to the Flores Sea. The pressure gradient that results from this should be associated with a northward geostrophic flow in the Makassar Strait surface layer, but not in the thermocline, which is below the sill depth of Java Sea [Gibbons et al., in revision]. Regardless of mechanism, the South China Sea inflow has a profound affect on the net volume and heat transport of the Makassar Strait, and contributes to the fresh nature of the ITF [Gordon, 2005].

The extent to which this thermocline dominated flow in the Makassar Strait contributes to characteristics of the ITF is a topic of investigation. It has been proposed that the thermocline dominated flow of the Makassar Strait reduces the transport-averaged temperature of the Makassar Strait by $2^{\circ} \mathrm{C}$ [Tozuka et al., 2007] and has the net effect of cooling the Indian Ocean [Gordon, 2005]. Evidence that the ITF cools comes from the subsurface temperature of the Indian Ocean. The ITF can be identified as a cool tongue at $\sim 200 \mathrm{~m}$ depth that stretches across the equatorial Indian Ocean [Gordon, 2005]. However, it has been shown recently that surface water from the Java Sea is a source of heat to the ITF [Fang et al., 2010], which likely compensates for the decreased surface heat transport through the Makassar Strait. The apparently cool nature of the ITF is more likely due to the intense upwelling in the Banda Sea, which brings cool deep water to the surface [Gibbons et al., in revision; Koch-Larrouy et al., 2008]. 
Much of the shallow Java Sea was exposed during the Last Glacial Maximum (LGM), which prevented South China Sea waters from entering the ITF. The early Holocene, therefore, represents a unique opportunity to evaluate whether and how the inflow from the South China Sea influences the ITF, and in turn, the influence of the ITF on the region's salinity and temperature distribution. A recent study documented a relative freshening (lighter $\delta^{18} 0$ of seawater) in the surface of the southern Makassar Strait relative to the Western Pacific Warm Pool when the connection between the South China Sea and the Makassar Strait was established at 9-10 kyrBP [Linsley et al., 2010]. Initial work suggested that the flooding of the Sunda Shelf did not affect regional sea surface temperature (SST) gradients [Xu et al., 2008; Xu et al., 2010]. More recent work has shown a distinct warming in the Makassar Strait at the time of the flooding of the Sunda Shelf, but not in the outflow passages, suggesting that the opening of the Java Sea between the South China Sea and the ITF inhibited surface flow through the Makassar Strait, trapping heat that was previously exported [Gibbons et al., in revision]. Furthermore, it has been suggested that the flooding of the Sunda Shelf cooled thermocline temperatures and intensified thermocline flow [Xu et al., 2008], a hypothesis we examine in this study.

Here, we present $\delta^{18} \mathrm{O}_{\text {calcite, }} \mathrm{Mg} / \mathrm{Ca}$-based temperature, and $\delta^{18} \mathrm{O}_{\text {seawater }}$ of $P$. obliquiloculata from coretops and downcore records throughout the IndoPacific Warm Pool. These new records, in conjunction with published data from the mixed layer dweller G. ruber from the same cores [Gibbons et al., in revision; Linsley et al., 2010; Rosenthal et al., 2003], and published surface and thermocline records from a 
single Timor Sea core [Xu et al., 2008] (Table 1) allow us to examine regional changes in thermocline structure that occurred throughout the last deglaciation.

\section{Materials and Methods}

All samples for the coretop study were taken with a multi-coring device, on three cruises in the Indonesian Throughflow region and the Eastern Indian Ocean (Figure 1, dots). We develop downcore P. obliquiloculata records from the Makassar Strait (BJ8-03 70GGC and 23GGC), the Ombai Strait (GeoB10069-3), the Flores Sea (BJ8-03 136GGC), and the Sulu Sea (MD97-2141). These core locations are indicated by diamonds in Figure 1.

The core sites are influenced to varying degree by monsoon winds. SSTs in the Makassar Strait, Flores Sea, and Savu Basin are highest in winter and coldest in summer, reflecting the influence of the monsoon winds on upwelling. Maximum SSTs are $\sim 31^{\circ} \mathrm{C}$ at $70 \mathrm{GGC}$ on the Sulawesi margin, $\sim 31^{\circ} \mathrm{C}$ at $69-3$ in the Savu Basin, and $\sim 1^{\circ} \mathrm{C}$ cooler at $23 \mathrm{GGC}$ in the south central Makassar Strait and 136GGC in the Flores Sea. Minimum SSTs are $\sim 28^{\circ} \mathrm{C}$ at $70 \mathrm{GGC}, 27^{\circ} \mathrm{C}$ at $23 \mathrm{GGC}$ and $136 \mathrm{GGC}$, and $26^{\circ} \mathrm{C}$ at $69-3$. The mixed layer is $\sim 50 \mathrm{~m}$ deep in the Makassar Strait (23GGC and 70GGC) and Flores Sea (136GGC) [Wyrtki, 1961]. The Savu Sea (69-3) has a very steep thermocline and a mixed layer that is no more than 20m deep [Molcard et al., 2001; Wyrtki, 1961]. MD41, in the Sulu Sea, is the only sediment core in this study from the northern hemisphere. SSTs at MD41 peak during summer $\left(\sim 30^{\circ} \mathrm{C}\right)$ and reach a minimum of $\sim 27^{\circ} \mathrm{C}$ during the winter. The mixed layer is $\sim 30 \mathrm{~m}$ deep [Wyrtki, 1961]. 
Approximately, 20 P. obliquiloculata (355-425um) were used for $\mathrm{Mg} / \mathrm{Ca}$ analysis. Samples were gently crushed prior to cleaning in order to open the chambers. Approximately 40-70 $\mu \mathrm{g}$ was set aside for stable isotope analysis (described below). Samples were cleaned using a full trace metal cleaning method, including oxidative and reductive cleaning steps [modified from Boyle and Keigwin, 1985/6; Rosenthal et al., 1999] and run on an Element XR ICP-MS at Rutgers University or an Element 2 ICP-MS at the Woods Hole Oceanographic Institution (WHOI). To construct downcore records, $\mathrm{Mg} / \mathrm{Ca}$ data were converted to temperatures using the Anand [2003] multispecies equation, modified to account for cleaning technique [Gibbons et al., in revision]:

$$
\begin{aligned}
& \text { Anand multispecies equation: } \mathrm{Mg} / \mathrm{Ca}=0.38 \exp (0.090 \mathrm{~T}) \\
& \text { Modified Anand equation: } \mathrm{Mg} / \mathrm{Ca}=0.345 \exp (0.090 \mathrm{~T})
\end{aligned}
$$

We note that there is a wide discrepancy in temperature reconstructions depending on the temperature calibration used. Others have suggested that the equation $\mathrm{Mg} / \mathrm{Ca}=0.78 \times \mathrm{xp}(0.052 \mathrm{~T}$ ) [Cleroux et al., 2008; Mohtadi et al., 2011a] is more appropriate for P. obliquiloculata. This issue is discussed below.

Stable isotope measurements were made at WHOI on a Finnigan MAT253. Long-term precision of $\delta^{18} \mathrm{O}_{\text {calcite }}$ measurements is $0.07 \%$, based on repeated measurements of a suite of standards.

All age models are based on radiocarbon dates from planktic foraminifera. Radiocarbon years were covered to calendar ages using Calib 6.0 and Marine09 [Reimer et al., 2009]. Age models are based on linearly interpreting between radiocarbon dates (23GGC, 70GGC, 136GGC, and 69-3), a linear fit through the 
radiocarbon dates (MD78), or a polynomial fit (MD41). Details of the age model construction and original dates for 23GGC, 136GGC, 70GGC and 69-3 can be found in Gibbons et al. [in revision]. See Sarnthein et al. [2011] (MD78) and de GaridelThoron et al. [2001] (MD41) for the rest of the radiocarbon dates.

We explored the potential for an age bias between radiocarbon dates from surface dwelling foraminifera (a mix of G. ruber and G. sacculifer) and $P$. obliquiloculata, as there has been a documented age offset between dissolution prone (G. sacculifer) and dissolution-resistant (such as P. obliquiloculata or N. dutertrei) species [Barker et al., 2007; Broecker and Clark, 2011]. We selected several depth intervals from 70GGC and 69-3 to compare the radiocarbon ages of these species. In all cases we examined, the offset between species was small (Table 2). These results support the conclusion of Broecker and Clark [2011] that there is minimal age offset in high sedimentation rate cores. We therefore applied no offset for our age models and used only the radiocarbon values that were measured on $G$. ruber and G. sacculifer, and not on P. obliquiloculata.

\section{Results}

\subsection{Coretop results}

We reconstructed the Mg/Ca-based temperature [Anand et al., 2003; Gibbons et al., in revision] of P. obliquiloculata from 22 coretops from throughout the ITF region and the Eastern Indian Ocean. We estimated depth habitats by comparing our $\mathrm{Mg} / \mathrm{Ca}$ based temperature estimates with the CTD data collected on the coring cruises. These cruises were all during the upwelling season, and the CTD data only 
provide us with a snapshot of subsurface temperature conditions. However, the paucity of subsurface data in the World Ocean Atlas in the ITF and the Eastern Indian Ocean could make CTD data the most reliable estimate of subsurface temperature. The depth habitat estimates suggest that $P$. obliquiloculata calcifies within the upper thermocline, at approximately 80-100 m depth (Fig 2). Core-top $P$. obliquiloculata temperature estimates at 23GGC, 70GGC, and 69-3 are also consistent with an 80-100 m depth habitat.

\subsection{Downcore Results}

The downcore P. obliquiloculata $\delta^{18} \mathrm{O}_{\text {calcite }}$ records are shown in Figure 3-7. At 69-3 (Fig 3) the glacial $\delta^{18} 0_{\text {calcite }}$ values were approximately $0 \%$. The deglacial decrease in $\delta^{18} \mathrm{O}_{\text {calcite }}$ began at $\sim 19 \mathrm{kyr} \mathrm{BP}$, with a plateau from approximately $14 \mathrm{kyr}$ BP to $11 \mathrm{kyr}$ BP. The $\delta^{18} \mathrm{O}_{\text {calcite }}$ continued to decrease until $\sim 8 \mathrm{kyr} \mathrm{BP}$, reaching $1.6 \%$, and then remained approximately constant until the late Holocene. The 70GGC core (Fig 4) did not reach the LGM and so the record begins during the deglacial. There is no change in the $\delta^{18} \mathrm{O}_{\text {calcite }}$ from the start of the record at $14 \mathrm{kyr}$ $\mathrm{BP}$ until $\sim 11.5 \mathrm{kyr} \mathrm{BP}$; during this period $\delta^{18} \mathrm{O}_{\text {calcite }}$ was $\sim-0.5 \%$. After $11.5 \mathrm{kyr} \mathrm{BP}$, the $\delta^{18} \mathrm{O}_{\text {calcite }}$ continued to decrease until $\sim 7 \mathrm{kyr} \mathrm{BP}$, reaching a value of $-2 \%$, where it remained for the rest of the Holocene. The 23GGC record (Fig 5) spans $10 \mathrm{kyr}$ BP to the late Holocene and $\delta^{18} \mathrm{O}_{\text {calcite }}$ values were very similar to $70 \mathrm{GGC}$. The $\delta^{18} \mathrm{O}_{\text {calcite }}$ record of MD41 (Fig 6) shows considerable variability, likely due to the low sampling resolution, from $22 \mathrm{kyr}$ BP until $12 \mathrm{kyr} \mathrm{BP}$, with an average value of $0.5 \%$. $\delta^{18} \mathrm{O}_{\text {calcite }}$ values reached a minimum of approximately $-2 \% 0$ at $7 \mathrm{kyr}$ BP and 
then increased by over 1\%o by 4 kyr BP (the top of the core). At 136GGC (Fig 7)

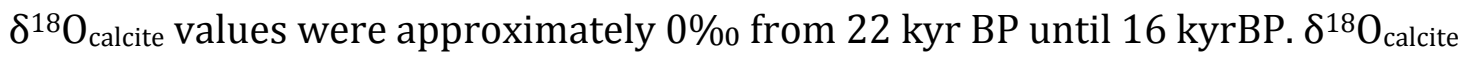
then decreased to $-2 \%$ by $10 \mathrm{kyr}$ BP, and remained constant until modern.

Our downcore records of $\mathrm{Mg} / \mathrm{Ca}$-based temperature estimates are shown in Figures 3-7. Generally, thermocline temperatures were nearly as warm during the LGM as in the late Holocene. Thermocline temperatures peaked at $10.5 \mathrm{ky}$ BP in the Makassar Strait (23GGC and 70GGC) (Fig 4 and 5) and Flores Sea (136GGC) (Fig 7), remained warm until $5.5 \mathrm{ky} \mathrm{BP}$, and then gradually cooled by $\sim 1^{\circ} \mathrm{C}$. In the Savu Basin (69-3) (Fig 3), where glacial and interglacial thermocline temperatures were similar, temperatures peaked at $10.5 \mathrm{ky} \mathrm{BP}$, but the cooling trend began earlier and was approximately $1^{\circ} \mathrm{C}$ larger than in the Makassar Strait. The temperature trends from the Sulu Sea (MD41) (Fig 6) are similar to those observed in the Savu Sea. Thermocline temperatures peak at $10.5 \mathrm{kyr} \mathrm{BP}$ and cool by $\sim 3^{\circ} \mathrm{C}$ until $4.3 \mathrm{kyr} \mathrm{BP}$, when the record ends.

\section{Discussion}

\subsection{Geochemistry of $P$. obliquiloculata as a thermocline indicator}

Numerous lines of evidence, including data from plankton tows [Fairbanks et al., 1982], sediment traps [Anand et al., 2003; Mohtadi et al., 2009], and coretops [Anand et al., 2003; Sadekov et al., 2009; Xu et al., 2006; Xu et al., 2008; Zuraida et al., 2009], suggest that within the modern tropics, P. obliquiloculata has an upper thermocline depth habitat. Our data are consistent with these studies. 
An issue that requires exploration is the use of the difference between the $\mathrm{Mg} /$ Ca-based temperature of G. ruber and P. obliquiloculata in order to derive a thermal gradient. Previous studies have interpreted this difference in opposite ways. Xu et al. [2008] suggest that a small thermal gradient is indicative of a deep thermocline. Using data from the same core, Sarnthein et al. [2011] claim that a small thermal gradient indicates a shallow thermocline with more intense upwelling. Steinke et al. [2010] interpret a large difference to indicate a smaller mixed layer depth, which is qualitatively equivalent to the Xu et al. [2008] interpretation. While it is difficult to determine thermocline structure with only two points, we suggest that the coretop data can guide us to the appropriate interpretation. In upwelling regions, such as along the southern coast of Java, our coretop data show a larger difference between the $\mathrm{Mg} / \mathrm{Ca}$ derived temperature of $G$. ruber and P. obliquiloculata (Fig 2). To highlight this, we combine our data with the extensive coretop work of Mohtadi et al. [2011a] and bin all data into regional averages (Fig 8). Thus, coretop evidence strongly suggests that the most valid interpretation of the reconstructed thermal gradient is consistent with that of Xu et al. [2008] and Steinke et al. [2010], and is not consistent with Sarnthein et al. [2011]. A larger difference between the temperature of G. ruber and $P$. obliquiloculata is found in areas of upwelling, while a smaller thermal gradient is found in areas with a more stratified water column.

Previous work has examined the relationship of the difference in $\delta^{18} \mathrm{O}_{\text {calcite }}$ between G. ruber and P. obliquiloculata to infer upper water column structure. Consistent with the $\mathrm{Mg} / \mathrm{Ca}$-based temperature difference described above, coretop 
results from the South China Sea suggest that a larger difference between G. ruber and P. obliquiloculata occurs in areas with more upwelling [Tian et al., 2005]. This result has also been generally found when comparing the $\delta^{18} 0_{\text {calcite }}$ of other surface and thermocline dwelling foraminifera [Mohtadi et al., 2011a; Ravelo and Fairbanks, 1992; Ravelo and Andreasen, 1999].

Although the coretop $\mathrm{Mg} / \mathrm{Ca}$ and $\delta^{18} \mathrm{O}_{\text {calcite }}$ differences between $G$. ruber and P. obliquiloculata are consistent in the water column structure they suggest (Fig 8), if we attribute the $\delta^{18} \mathrm{O}_{\text {calcite }}$ changes entirely to temperature, the results are quantitatively different. We use pooled Eastern Indian Ocean data from this paper, Mohtadi et al. [2011a] and Gibbons et al. [in revision], to examine the predicted water column structure difference between an area of intense upwelling (the Java Basin or JB in Fig 8) and an area with a stratified water column (the Nias Basin or NB). The G. ruber - P. obliquiloculata $\mathrm{Mg} / \mathrm{Ca}$-based temperature in the Java Basin is $8.4^{\circ} \mathrm{C}$ and at the Nias basin it is $6.2^{\circ} \mathrm{C}$. The G. ruber $-P$. obliquiloculata difference in $\delta^{18} \mathrm{O}_{\text {calicite }}$ is $-1.4 \%$ at the Java Basin and $-0.7 \% 0$ at the Nias basin. If we convert the $\delta^{18} \mathrm{O}_{\text {calcite }}$ difference to temperature (using the low-light $O$. universa equation from Bemis et al. [1998]) this is equivalent to a $6.7^{\circ} \mathrm{C}$ temperature difference in the Java Basin and a $3.4^{\circ} \mathrm{C}$ temperature difference in the Nias Basin. In order to reconcile these differences, the subsurface water must have more depleted $\delta^{18} \mathrm{O}_{\text {seawater }}$ values than the surface waters. Modern observations indicate that the subsurface water in the Eastern Indian Ocean is saltier than the surface water (eg. WOA05 [Antonov et al., 2006]). Thus if subsurface waters actually have more depleted $\delta^{18} 0_{\text {seawater, }}$ lower 
$\delta^{18} \mathrm{O}_{\text {seawater }}$ values are associated with saltier conditions. Generally, however, salinity and $\delta^{18} \mathrm{O}_{\text {seawater }}$ are positively correlated [LeGrande and Schmidt, 2006].

Due to the scarcity of $\delta^{18} \mathrm{O}_{\text {seawater }}$ measurements in the region, particularly at the subsurface, we cannot directly examine whether $\delta^{18} 0_{\text {seawater }}$ values are more depleted with depth in the region. We examine this problem indirectly by utilizing the conservative nature of $\delta^{18} \mathrm{O}_{\text {seawater }}$ and taking advantage of the relative abundance of surface $\delta^{18} \mathrm{O}_{\text {seawater }}$ measurements compared to subsurface $\delta^{18} \mathrm{O}_{\text {seawater }}$ measurements. At several core sites in the IndoPacific Warm Pool, we use the Total Matrix Intercomparison method developed by Gebbie and Huybers [2010]. Total Matrix Intercomparison uses six water properties to trace back the surface source region(s) of a water parcel. This method allows for multiple source regions to contribute to each water parcel. We identify the major source regions at each location and use an average $\delta^{18} \mathrm{O}_{\text {seawater }}$ surface value from the gridded data of LeGrande and Schmidt [2006] to predicted the $\delta^{18} \mathrm{O}_{\text {seawater }}$ at varying depths in the IndoPacific Warm Pool. This approach suggests that $\delta^{18} \mathrm{O}_{\text {seawater }}$ does become more depleted with depth in this region, with an approximate change of $-0.06 \%$ per $100 \mathrm{~m}$. While this may contribute to the difference between the $\delta^{18} \mathrm{O}_{\text {calcite }}$ and $\mathrm{Mg} / \mathrm{Ca}$ based temperature gradients, it is not large enough to resolve the discrepancy between the thermal gradient based on $\mathrm{Mg} / \mathrm{Ca}$ versus $\delta^{18} \mathrm{O}_{\text {calcite. }}$.

Previous authors [Steinke et al., 2010] have noted the apparent difficulty in reconciling the $\delta^{18} \mathrm{O}_{\text {calcite }}$ difference of G. ruber - P. obliquiloculata and the $\mathrm{Mg} / \mathrm{Ca}$ based temperature difference. While Steinke et al. [2010] attributed this to the local hydrology of the South China Sea, our data suggest this discrepancy may be 
widespread. Others [Cleroux et al., 2008; Mohtadi et al., 2011a] have used the predicted temperature based on modern oceanographic data and an assumed

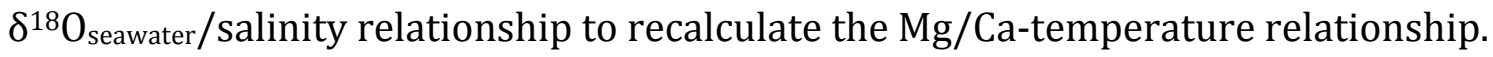
This approach forces a reconciliation of the $\mathrm{Mg} /$ Ca-based temperature and $\delta^{18} \mathrm{O}_{\text {calcite }}$ and suggests that the sensitivity of the $\mathrm{Mg} / \mathrm{Ca}$ of $P$. obliquiloculata to temperature change is approximately half that found by other studies in areas where the oceanographic conditions, including the $\delta^{18} \mathrm{O}_{\text {seawater/salinity relationship were better }}$ known [Anand et al., 2003]. Further work, specifically on the modern $\delta^{18} \mathrm{O}_{\text {seawater }}$ relationship to water mass properties, the depth habitat of P. obliquiloculata via plankton tows, and the sensitivity of P. obliquiloculata $\mathrm{Mg} / \mathrm{Ca}$ and $\delta^{18} \mathrm{O}_{\text {calcite }}$ to temperature changes via culturing work are required to clarify the situation.

\subsection{Changes in the upper water column - The LGM and deglacial}

We interpret our downcore data assuming that our temperature estimates using $\mathrm{Mg} / \mathrm{Ca}$ and the modified Anand et al. [2003] multispecies calibration are correct. This allows us to compare our results with previous work that used the $\mathrm{Mg} / \mathrm{Ca}$ of G. ruber and P. obliquiloculata to infer changes in thermocline structure. We compare these interpretations to the thermocline structure derived from the $\delta^{18} \mathrm{O}_{\text {calcite. }}$ Finally, we examine possible reasons for the discrepancy between these two methods.

\subsubsection{The LGM and deglacial - climatic implications based on $\mathrm{Mg} / \mathrm{Ca}$}


70GGC and 23GGC do not contain LGM sediment, but in all our cores that have data from the LGM, reconstructed thermocline temperatures are no more than $1^{\circ} \mathrm{C}$ cooler than modern. This is a striking regional feature that is observed in the Sulu Sea (MD41, Fig 6), the Flores Sea (136GG, Fig 7), and the Savu Basin (69-3, Fig 3). It has also been documented in the Timor Sea [Xu et al., 2008], the Timor Strait [Holbourn et al., 2011], and the South China Sea [Steinke et al., 2010; Yang and ZhiMin, 2009]. The only Mg/Ca-based P. obliquiloculata record that shows a larger cooling (nearly $2^{\circ} \mathrm{C}$ ) is MD67 from the Mindanao dome [Bolliet et al., 2011].

The warm LGM thermocline temperatures create a smaller vertical thermal gradient between the surface and the thermocline (Fig 9), which our coretop data suggest indicate more stratified oceanic conditions (Fig 8). Greater LGM stratification is consistent with previous work from the Western Pacific Warm Pool. Planktic foraminifera abundances suggest that the thermocline was deeper throughout the Western Pacific Warm Pool at the LGM [Andreasen and Ravelo, 1997]. Using a combination of Mg/Ca-based SST reconstruction (using G. ruber), alkenone (Uk' ${ }_{37}$ ), and foraminferal transfer functions, de Garidel-Thoron et al. [2007] suggest LGM SSTs were $\sim 2.5^{\circ} \mathrm{C}$ cooler and subsurface temperatures were $1.8^{\circ} \mathrm{C}$ cooler, again implying more stratified conditions.

Andreasen and Ravelo [1997] and de Garidel-Thoron [2007] suggest their data are consistent with an enhanced Walker circulation at the LGM. Support for this mechanism comes from a compilation of six LGM modeling simulations, four of which show an enhanced Walker Circulation. In these four glacial simulations, the upper water column is more stratified, and thermocline temperatures show less 
cooling than surface temperatures [DiNezio et al., 2011]. Less cooling in the glacial thermocline compared to the surface is also simulated in the eastern equatorial Indian Ocean [Otto-Bliesner et al., 2009]. The large regional extent of the relatively warm glacial thermocline in these models is consistent with our proxy data. However, we note our proxy data show yet warmer thermocline temperatures than suggested by the average of the modeling simulations.

\subsubsection{The LGM and deglacial - climatic implications based on $\delta^{18} 0_{\text {calcite }}$}

Though the G. ruber - P. obliquiloculata Mg/Ca-based temperature differences suggest a deeper thermocline (smaller thermal gradient) at the LGM, these results are inconsistent with the $\delta^{18} 0_{\text {calcite }}$ results. In most continuous records (MD41, 69-3, MD90 [Steinke et al., 2010], and MD67 [Bolliet et al., 2011], the $\delta^{18} \mathrm{O}_{\text {calcite }}$ difference between $G$. ruber and P. obliquiloculata is approximately the same at the LGM as it is at the modern (within $0.3 \%$ or approximately $1^{\circ} \mathrm{C}$ if attributed to temperature), suggesting either no change or a slightly less stratified IndoPacific Warm Pool at the LGM. This is in contrast to the Mg/Ca-based temperature reconstructions which suggest a more stratified LGM, with the temperature gradient approximately $2^{\circ} \mathrm{C}$ smaller than modern. MD94 [Yang and ZhiMin, 2009] in the South China Sea is the only record in which the $\delta^{18} \mathrm{O}_{\text {calcite }}$ gradient and the $\mathrm{Mg} /$ Ca-based temperature gradient show the same trend; the $\delta^{18} \mathrm{O}_{\text {calcite }}$ records suggest a modest deepening of the thermocline at the LGM, though still less than based on the $\mathrm{Mg} / \mathrm{Ca}$-based temperature. 
As discussed above, this apparent inconsistency between the $\mathrm{Mg} / \mathrm{Ca}$-based temperature and $\delta^{18} \mathrm{O}_{\text {calcite-based temperature gradients may result from more }}$ depleted $\delta^{18} \mathrm{O}_{\text {seawater }}$ in the thermocline than surface. In this case, a deeper thermocline would bathe P. obliquiloculata in waters that were both warmer and

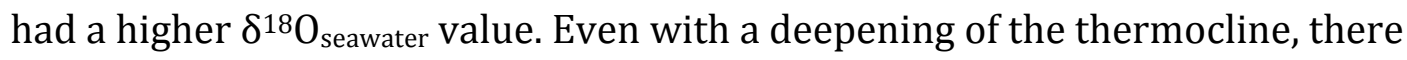
could be no change in the $\delta^{18} O_{\text {calcite }}$ of $P$. obliquiloculata as the warming and higher $\delta^{18} \mathrm{O}_{\text {seawater }}$ values could offset each other.

\subsubsection{The LGM and deglacial - potential biases: is there a thermal limit to $P$. obliquiloculata or is salinity influencing our $\mathrm{Mg}$ /Ca-based temperature estimates?}

We examine two potential sources of bias in our records: firstly, whether the lower thermal limit for $P$. obliquiloculata is approached during the LGM, shifting $P$. obliquiloculata towards warmer conditions and secondly, whether the generally saltier conditions of the LGM could raise $\mathrm{Mg} / \mathrm{Ca}$ ratios independent of temperature [Arbuszewski et al., 2010; Mathien-Blard and Bassinot, 2009]. We explore each of these possibilities below.

In the modern oceans $P$. obliquiloculata is an abundant species in the IndoPacific, but abundances quickly decline in cooler waters [Bé and Hutson, 1977; Cullen and Prell, 1984; Martinez et al., 1998; Ujiie and Ujiie, 2000]. The relatively warm $\mathrm{Mg} / \mathrm{Ca}$-based thermocline temperatures at most locations during the LGM as described above could be due to $P$. obliquiloculata migrating upward in the water 
column, switching its growth to the warm season or only growing during warm years.

Support for a thermal limit come from regional abundance records. Within the South China Sea, P. obliquiloculata disappears almost entirely during Heinrich Event 1 [Yang and ZhiMin, 2009]. In the Sulu Sea P. obliquiloculata disappears during the last glacial period, even while G. ruber abundance remains high [Linsley and Thunell, 1990], suggesting that P. obliquiloculata has a narrower optimal habitat than G. ruber. Abundance counts from within the Makassar Strait [Ding et al., 2006] show similar results to Linsley and Thunell [1990] suggesting that even within the heart of the IndoPacific Warm Pool, the lower thermal limit for P. obliquiloculata was approached during glacial conditions. If we attribute changes in the $\delta^{18} \mathrm{O}_{\text {calcite }}$ records primarily to temperature, these data suggest $P$. obliquiloculata is not biased by cold temperatures, but as discussed above, the uncertainty in interpreting past (or present) $\delta^{18} 0_{\text {seawater }}$ values make it difficult to rule out a thermal limit.

Another possibility is that our warm glacial thermocline reconstructions are due to the influence of salinity on $\mathrm{Mg} / \mathrm{Ca}$. Evidence is increasing that at high salinities, Mg/Ca values are elevated in G. ruber [Arbuszewski et al., 2010; MathienBlard and Bassinot, 2009]. Even though there is some debate as to the exact mechanisms of salinity influence on $\mathrm{Mg} / \mathrm{Ca}$, it appears that at salinities below 35 [Arbuszewski et al., 2010] or 36 [Gibbons et al., in revision], the effect is negligible. CTD data (not shown) and World Ocean Atlas 05 data [Antonov et al., 2006] suggest salinities at $100 \mathrm{~m}$ at our core sites are less than 35 . The mean ocean was $\sim 1$ saltier at the LGM [Adkins et al., 2002], leaving thermocline salinities at our sites still below 
the likely threshold for a salinity influence on $\mathrm{Mg} / \mathrm{Ca}$ if this was the only factor affecting salinity. However, within the ITF, the thermocline was likely even saltier due to the absence of freshwater from the Java Sea [Linsley et al., 2010], which freshens the thermocline today [Gordon, 2005]. Thus, it is possible that thermocline salinities exceeded 36, and contributed to the high $\mathrm{Mg} / \mathrm{Ca}$ during the LGM in our ITF sites (136GGC, and 69-3). Moreover, the effect of salinity on the $\mathrm{Mg} / \mathrm{Ca}$ of $P$. obliquiloculata is not established.

We can test whether the salinity effect is a reasonable explanation for our warm LGM temperatures. We first assume that there was no change in the thermal gradient at our sites. In other words, G. ruber and P. obliquiloculata should have both been cooler by the same amount at the LGM. We use the difference in our Mg/Cabased G. ruber temperatures between 20-18 kyr BP and 2-0 kyr BP to assign the magnitude of thermocline cooling at the LGM. We subtract this cooling from our "modern" P. obliquiloculata temperature, to estimate P. obliquiloculata's LGM temperature. We then calculate predicted $\mathrm{Mg} / \mathrm{Ca}$ values based on these estimated LGM values and the modified Anand [2003] multispecies calibration. We subtract this predicted $\mathrm{Mg} / \mathrm{Ca}$ from our measured $\mathrm{Mg} / \mathrm{Ca}$, and use this value in a similar manner to the "excess Mg/Ca" explored by Arbuszewski et al. [2010]. We can use the dataset of excess $\mathrm{Mg} / \mathrm{Ca}$ and salinity compiled by Gibbons et al. [in revision] to predict the salinity associated with an excess $\mathrm{Mg} / \mathrm{Ca}$ value (Fig 10). At salinities above 36 , the relationship between excess $-\mathrm{Mg} / \mathrm{Ca}$ and salinity can be described by: Excess $\mathrm{Mg} / \mathrm{Ca}=1.4018^{*}$ salinity -50.449 
If we assume, instead the critical threshold for salinity is 35 , the relationship changes only slightly:

Excess $\mathrm{Mg} / \mathrm{Ca}=1.1032 *$ salinity -39.456

Using our excess $\mathrm{Mg} / \mathrm{Ca}$ values, we solve for salinity. The salinities required to produce the LGM excess Mg/Ca are 36.2 at 136GGC and 69-3 and 36.4 at MD78 using the first equation and 36.0 at $136 \mathrm{GGC}$ and $69-3$ and 36.2 at MD78 using the second equation. The relatively modest increase in salinity required to affect $\mathrm{Mg} / \mathrm{Ca}$ based temperature estimates suggests this is a potential concern for the use of $P$. obliquiloculata at the LGM, especially as the sensitivity of $\mathrm{Mg} / \mathrm{Ca}$ in P. obliquiloculata to salinity is unknown.

\subsection{Changes in the upper water column during the Holocene - The flooding of the Sunda Shelf}

We suggest that during the Holocene, the $\mathrm{Mg} /$ Ca-based temperature of $P$. obliquiloculata is a reliable proxy for thermocline temperature. P. obliquiloculata is relatively abundant [Ding et al., 2006; Linsley and Thunell, 1990], suggesting it is well within its prime habitat, and after the disintegration of the ice sheets [Clark and Mix, 2002] salinities in the IndoPacific Warm Pool are likely low enough where $\mathrm{Mg} / \mathrm{Ca}$ is primarily dependent on temperature.

Previous work has suggested that the flooding of the Sunda Shelf that occurred at $10 \mathrm{kyr}$ BP cooled the thermocline of the ITF outflow passages [Holbourn et al., 2011; Xu et al., 2008; Xu et al., 2010]. This hypothesis is based on the idea that there is a reduction of warm surface waters that pass through the Makassar Strait 
when the Sunda Shelf floods. By contrast, others have argued based on modern data [Fang et al., 2010; Qu et al., 2006] and paleo reconstructions [Gibbons et al., in revision] that the decreased heat flow through the Makassar Strait would be balanced by heat from the Java Sea. As a result, there would be no net change in heat transport or thermocline stratification as a result of the flooding of the Sunda Shelf.

We test whether the flooding of the Sunda Shelf changed the thermocline thermal gradient of either the Makassar Strait or the outflow passages by computing the Kendall $\tau$ coefficient [Kendall and Gibbons, 1990] for each core. The Kendall $\tau$ coefficient is a nonparamentric measure of trend, which can range from - 1 to 1 . It is robust against both outliers and inaccuracies in chronology. In neither 69-3 ( $\tau=-$ $0.18 ; \mathrm{p}=0.13)$, nor MD78 $(\tau=-0.20 ; \mathrm{p}=0.12)$ is there a significant increase in thermal gradient from 10-6 kyr BP, which suggests that the flooding of the Sunda Shelf did not change the thermal structure of the outflow passages.

We note that the finding of no change in the thermal gradient due to the flooding of the Sunda Shelf is sensitive to the $\mathrm{Mg} / \mathrm{Ca}$ temperature equation used. If we instead use the equation suggested by Cleroux et al. [2008] and Mohtadi et al. [2011a], there is a dramatic increase in the thermal gradient at 69-3 $(\tau=-0.27 ; \mathrm{p}=$ 0.02) from 10-6kyrBP. The increase in thermal gradient at MD78 is also larger, though there is still no significant trend at MD78 $(\tau=-0.19 ; p=0.12)$. In light of the relatively modest Holocene temperature variation in the surface waters (Fig 3 shows a $2^{\circ} \mathrm{C}$ cooling), the extremely large Holocene thermocline temperature variation produced by this equation (a Holocene cooling of $4.5^{\circ} \mathrm{C}$ in $69-3$ ), suggests that this calibration may overestimate past temperature changes. Using this 
equation, the thermal gradient during the early Holocene is only $2.5^{\circ} \mathrm{C}$, suggesting extremely stratified conditions at 69-3. This is difficult to reconcile with strong evidence of a northerly displaced ITCZ [Yuan et al., 2004] and increased monsoon upwelling [Mohtadi et al., 2011b], which would extend the upwelling season at 69-3. Nevertheless, the considerable uncertainty in the $\mathrm{Mg} / \mathrm{Ca}$-temperature calibration of P. obliquiloculata requires further work.

Regardless of the calibration, however, the data support a previously noted larger Holocene than glacial vertical thermal gradient (a shoaling thermocline) in the outflow passages, previously attributed to the flooding of the Sunda Shelf [Xu et al., 2008; Xu et al., 2010]. However, our records demonstrate that the change in thermocline structure was not uniquely associated with the flooding of the Sunda Shelf at $\sim 10$ kyr BP but instead occurs as a gradual trend that began at the LGM and continued until modern (Fig 4). Moreover, MD41, from the Sulu Sea, should not have been directly affected by the flooding of the Sunda Shelf [Sathiamurthy and Voris, 2006] yet it has a similar change in thermal gradient to the other cores. The observation that the increase in thermal gradient is both long in duration and widespread in occurrence suggests that it cannot be explained due to a change in thermocline temperature resulting from the flooding of the Sunda Shelf.

\section{Conclusion:}

More work remains before we can confidently use the geochemistry of $P$. obliquiloculata as a robust indicator of thermocline conditions. In both our coretop and downcore records, it is difficult to reconcile the trends from the $\mathrm{Mg} / \mathrm{Ca}$-based 


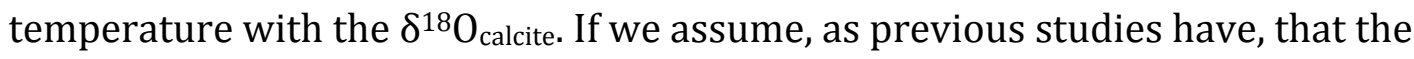
$\mathrm{Mg} / \mathrm{Ca}$-based temperature gradient between G. ruber and P. obliquiloculata is an indicator of thermocline structure, our results suggest that thermocline temperatures were warm at the LGM relative to surface water, and gradually increased to a peak in the early Holocene. These data are consistent with an enhanced in the Walker Circulation during the LGM [DiNezio et al., 2011]. Our data are inconsistent with the hypothesis that the flooding of the Sunda Shelf caused a cooling in the thermocline as inferred from the $\mathrm{Mg} / \mathrm{Ca}$-based temperature difference of G. ruber and P. obliquiloculata. The increase in thermal gradient occurs throughout the deglacial and is observed in a core that is not located in an outflow passage of the ITF (MD41). 


\begin{tabular}{|c|c|c|c|}
\hline Core ID, location & $\begin{array}{l}\text { Core ID in } \\
\text { text }\end{array}$ & Lat./Long. & $\begin{array}{l}\text { Water depth } \\
\text { (m) }\end{array}$ \\
\hline BJ8-03 13GGC, Flores Sea & $13 \mathrm{GGC}$ & $\begin{array}{l}7^{\circ} 24^{\prime} \mathrm{S}, 115^{\circ} \\
13^{\prime} \mathrm{E} \\
5^{\circ} 12^{\prime} \mathrm{S}, 117^{\circ}\end{array}$ & 594 \\
\hline $\begin{array}{l}\text { BJ8-03 23GGC, S Makassar Strait } \\
\text { BJ8-03 70GGC, SW Sulawesi, Makassar }\end{array}$ & $23 \mathrm{GGC}$ & $\begin{array}{ll}29^{\prime} \mathrm{E} \\
3^{\circ} 34^{\prime} \mathrm{S} 119^{\circ}\end{array}$ & 1189 \\
\hline Strait & $70 \mathrm{GGC}$ & $\begin{array}{l}23^{\prime} \mathrm{E} \\
5^{\circ} 56^{\prime} \mathrm{S}, 120^{\circ}\end{array}$ & 482 \\
\hline BJ8-03 136GGC, Flores Sea & 136GGC & $\begin{array}{l}14^{\prime} \mathrm{E} \\
9^{\circ} 36^{\prime} \mathrm{S}, 120^{\circ}\end{array}$ & 526 \\
\hline GeoB10069-3 Savu Sea & $69-3$ & $\begin{array}{l}55^{\prime} \mathrm{E} \\
8^{\circ} 47^{\prime} \mathrm{N}, 121^{\circ}\end{array}$ & 1,250 \\
\hline MD97-2141, Sulu Sea & MD41 & $17^{\prime} \mathrm{E}$ & 3,633 \\
\hline
\end{tabular}

Table 1 - Core locations and depths. 


\begin{tabular}{|c|c|c|c|c|c|c|c|}
\hline Core & $\begin{array}{c}\text { Depth } \\
(\mathrm{cm})\end{array}$ & $\begin{array}{c}\text { G. } \\
\text { ruber/sac } \\
\text { C-14 } \\
\text { Age } \\
\text { (yrs) }\end{array}$ & $\begin{array}{c}\mathrm{G} . \\
\text { ruber/sac } \\
\text { calendar } \\
\text { age }(\mathrm{yrs})\end{array}$ & $\begin{array}{c}\text { Depth } \\
(\mathrm{cm})\end{array}$ & $\begin{array}{c}\text { P. obliq } \\
\text { C-14 } \\
\text { Age } \\
\text { (yrs) }\end{array}$ & $\begin{array}{l}\text { P. obliq } \\
\text { calendar } \\
\text { age } \\
(\mathrm{yrs})\end{array}$ & $\begin{array}{l}\text { Age } \\
\text { difference } \\
\text { (yrs) }\end{array}$ \\
\hline $69-3$ & 88 & 1970 & 1525 & 88 & 1910 & 1453 & 72 \\
\hline $69-3$ & $\begin{array}{c}468 \\
(478) \\
\end{array}$ & 6800 & $\begin{array}{c}7328 \\
(7566) \\
\end{array}$ & 478 & 6830 & 7353 & $(213)$ \\
\hline 70GGC & 64 & 1310 & 853 & 64.5 & 1310 & 853 & 0 \\
\hline 70GGC & 321 & 7190 & 7653 & 320.5 & 7270 & 7731 & -78 \\
\hline $70 \mathrm{GGC}$ & 362 & 10250 & 11223 & 361.5 & 10100 & 11132 & 91 \\
\hline
\end{tabular}

Table 2 - Difference in radiocarbon dates between $G$. ruber/G. sacculifer and $P$. obliquiloculata. Dissolution-prone foraminifera have approximately the same age as the dissolution-resistant foraminifera $P$. obliquiloculata. Due to a mismatch in depth intervals, the 69-3 P. obliquiloculata date from $478 \mathrm{~cm}$ was compared to the predicted $G$. ruber/sacculifer age at $478 \mathrm{~cm}$ based on the age model. The predicted value is listed in parentheses. 


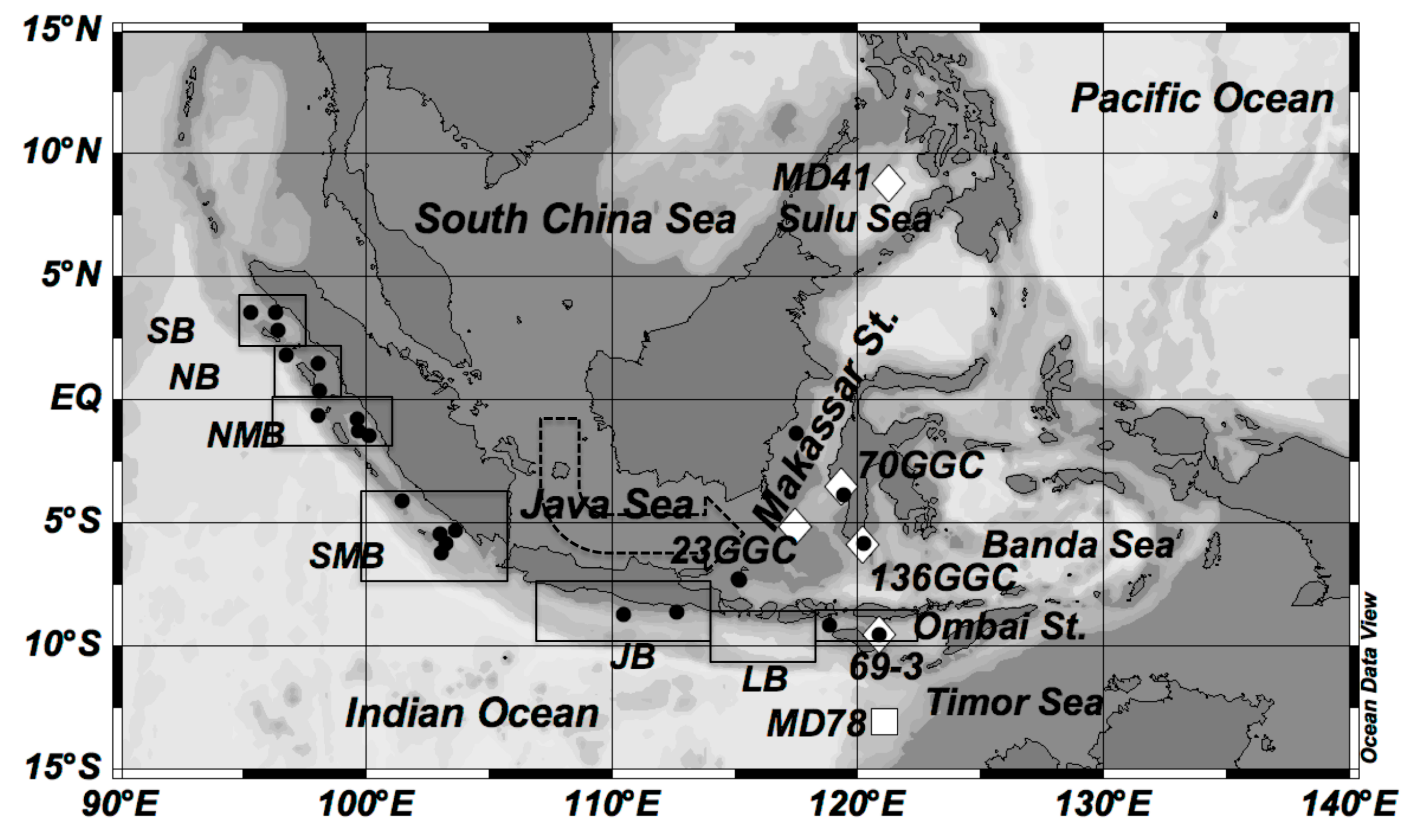

Figure 1 - Map of study location. Dots indicate locations of multicores used in coretop study. Diamonds are the location of cores with new P. obliquiloculata downcore records. The square symbol is MD78 [Xu et al., 2008]. Boxes indicated regional groupings for Figure 3 (from north to south SB: Simeulue Basin; NB: Nias Basin; NMB: Northern Mentawai Bain; SMB: Southern Mentawai Basin; JB: Java Basin; LB: Lombok Basin) and core 69-3 is located in the Savu Sea. Dashed arrow indicates path of freshwater from the South China Sea into the Indonesian Throughflow. 


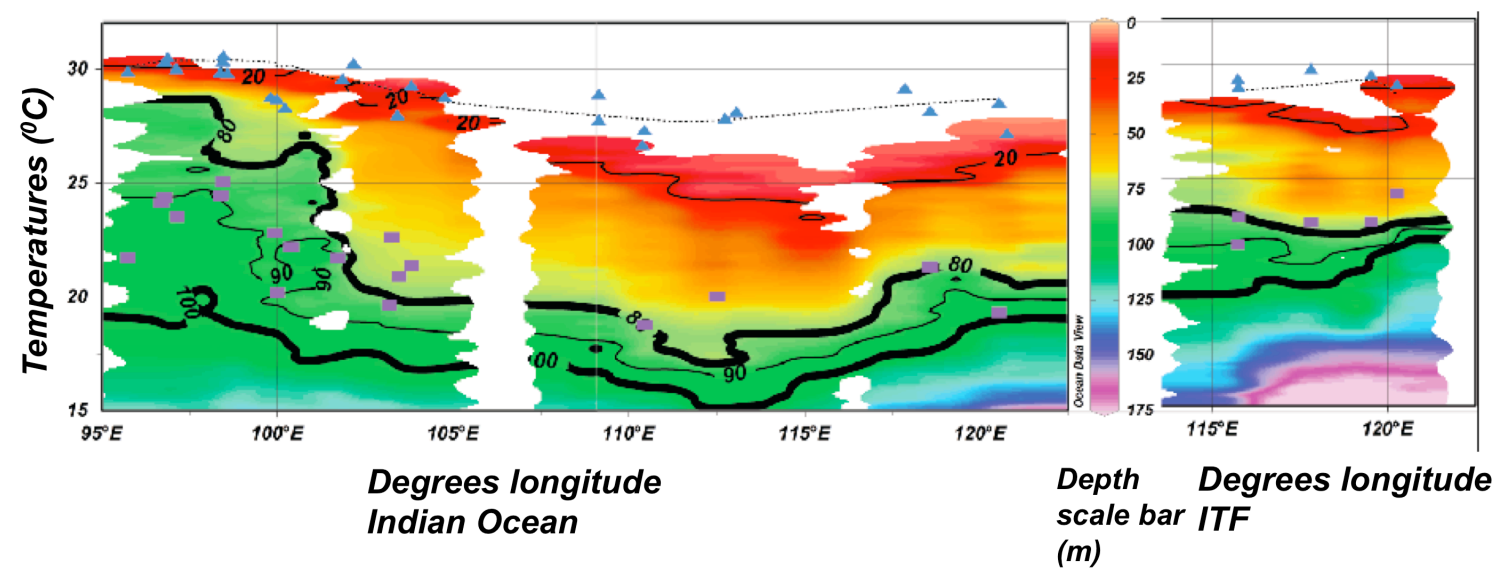

Figure 2 - Core top results. The $\mathrm{Mg} / \mathrm{Ca}$ based temperature estimates of $G$. ruber [Gibbons et al., in revision] (blue triangles) and P. obliquiloculata (purple squares). Coretop data are plotted against CTD data from the coring cruises. Dashed line is satellite derived mean annual SST (http://reason.gsfc.nasa.gov/Giovanni/).

Temperatures (both CTD and $\mathrm{Mg} / \mathrm{Ca}$ based) are plotted on the Y-axis. Isodepth lines are plotted through temperature data. The $\mathrm{Mg} /$ Ca-based temperature of $P$. obliquiloculata is consistent with temperatures found between $80-100 \mathrm{~m}$. Additionally, in areas of more upwelling, such as more eastern Indian Ocean sites, the reconstructed temperature difference between $G$. ruber and $P$. obliquiloculata is larger. 


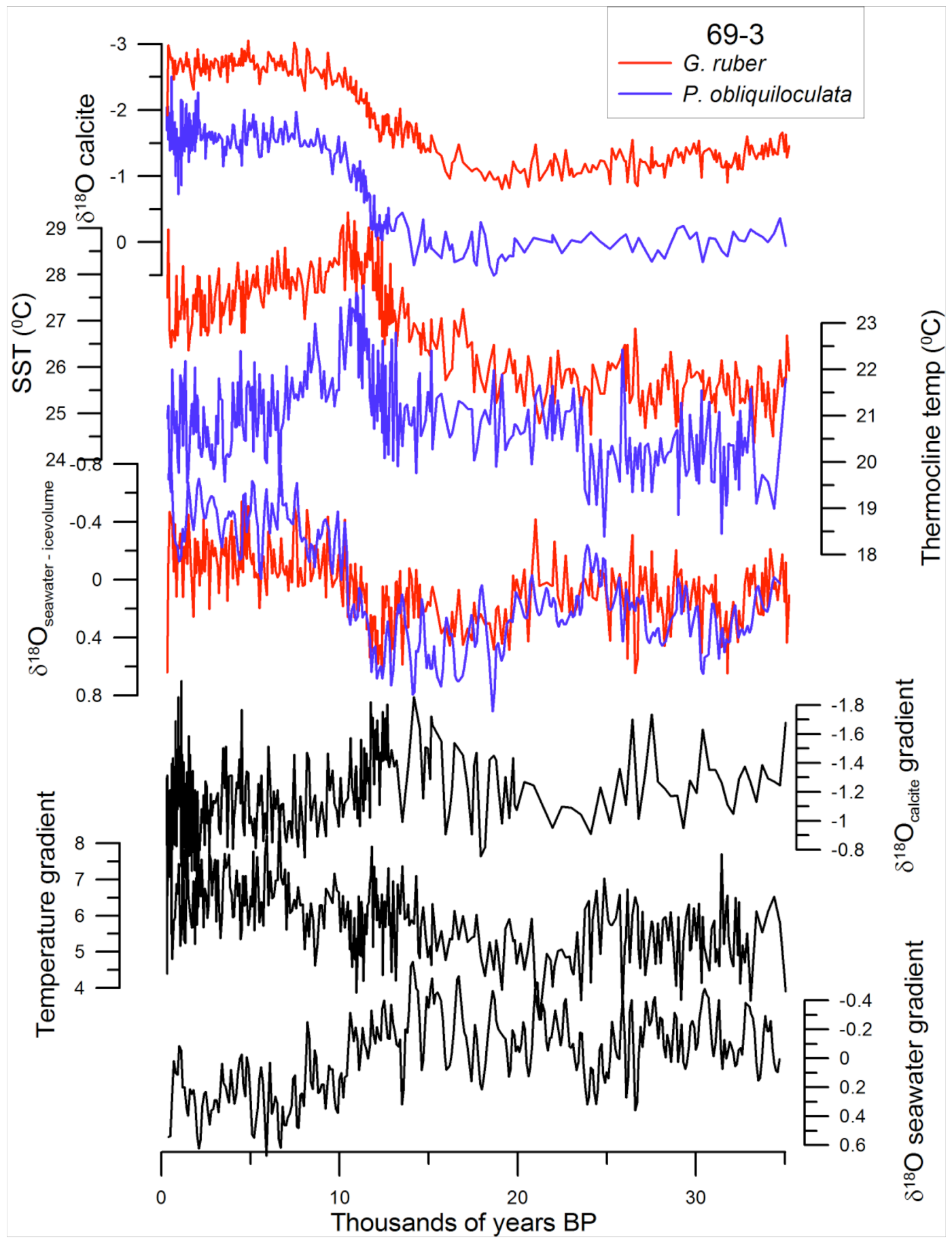

Figure 3 - Downcore records from 69-3 (Savu Sea). G. ruber (red) [Gibbons et al., in revision] and P. obliquiloculata (blue) $\delta^{18} \mathrm{O}_{\text {calcite, }} \mathrm{Mg} / \mathrm{Ca}$-based temperature estimates, and $\delta^{18} \mathrm{O}_{\text {seawater }}$ estimates. Note the inverted axes for $\delta^{18} 0$. Gradients are G. ruber - P. obliquiloculata with the axes orientation as in Figure 3 (gradients corresponding to upwelling conditions in the coretop data are up). Axes are scaled so that $1 \%$ o $\delta^{18} \mathrm{O}$ corresponds to $4^{\circ} \mathrm{C}$. 


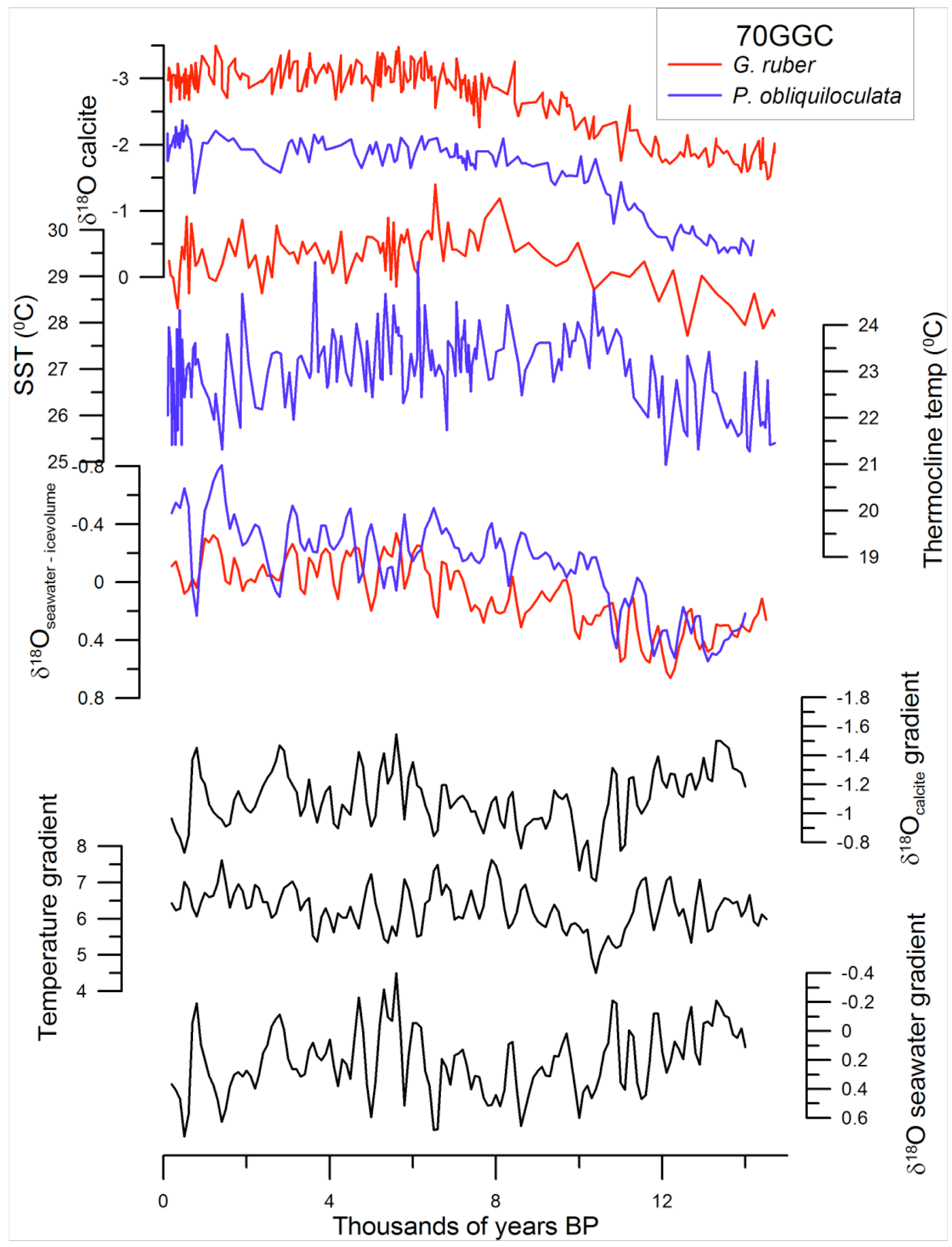

Figure 4 - Downcore records from 70GGC (Southern Makassar Strait). G. ruber (red) [Linsley et al., 2010] and P. obliquiloculata (blue) $\delta^{18} \mathrm{O}_{\text {calcite, }} \mathrm{Mg} / \mathrm{Ca}$-based temperature estimates, and $\delta^{18} 0_{\text {seawater }}$ estimates. Note the inverted axes for $\delta^{18} 0$. Gradients are G. ruber - P. obliquiloculata with the axes orientation as in Figure 3 (gradients corresponding to upwelling conditions in the coretop data are up). Axes are scaled so that $1 \% \delta^{18} 0$ corresponds to $4^{\circ} \mathrm{C}$. 


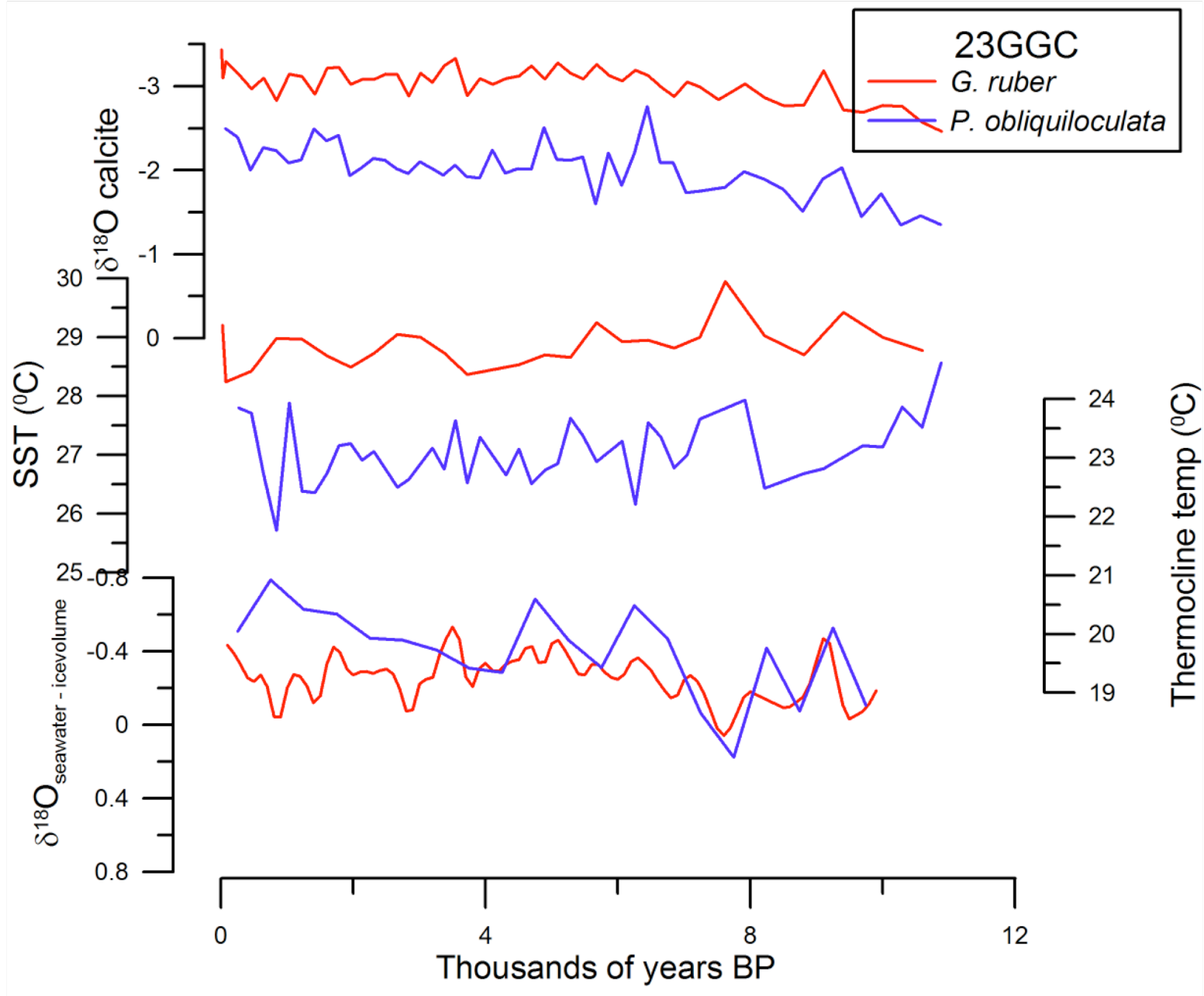

Figure 5 - Downcore records from 23GGC (Southern Makassar Strait). G. ruber (red) and P. obliquiloculata (blue) $\delta^{18} \mathrm{O}_{\text {calcite, }} \mathrm{Mg} / \mathrm{Ca}$-based temperature estimates,

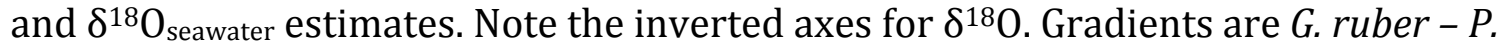
obliquiloculata with the axes orientation as in Figure 3 (gradients corresponding to upwelling conditions in the coretop data are up). Axes are scaled so that $1 \% \delta^{18} \mathrm{O}$ corresponds to $4^{\circ} \mathrm{C}$. 


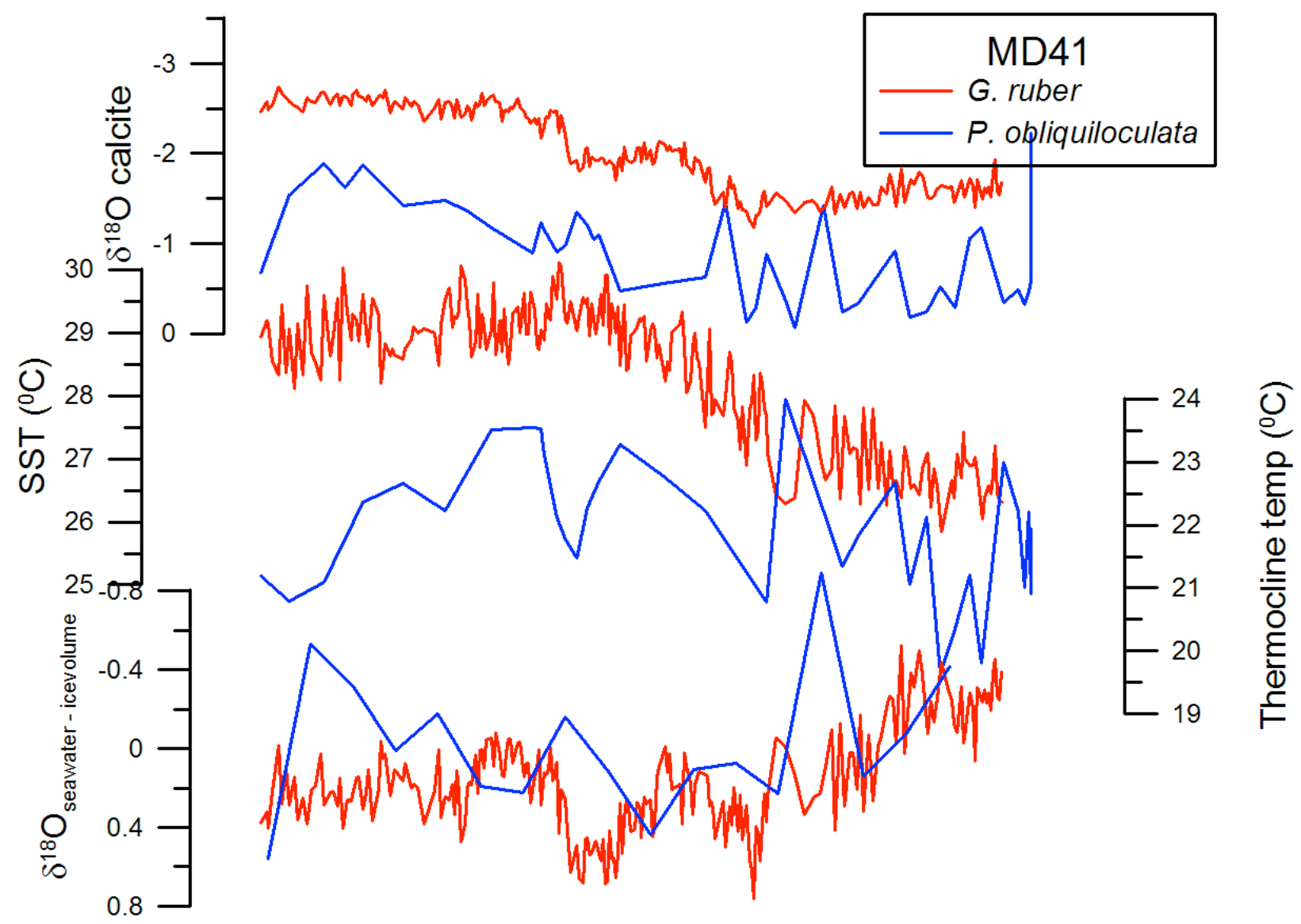

Figure 6 - Downcore records from MD41 (Sulu Sea). G. ruber (red) and $P$.

obliquiloculata (blue) $\delta^{18} \mathrm{O}_{\text {calcite, }} \mathrm{Mg} / \mathrm{Ca}$-based temperature estimates, and $\delta^{18} \mathrm{O}_{\text {seawater }}$ estimates. Note the inverted axes for $\delta^{18} 0$. Gradients are $G$. ruber - P. obliquiloculata with the axes orientation as in Figure 3 (gradients corresponding to upwelling conditions in the coretop data are up). Axes are scaled so that $1 \%{ }^{18} 0$ corresponds to $4^{\circ} \mathrm{C}$. 


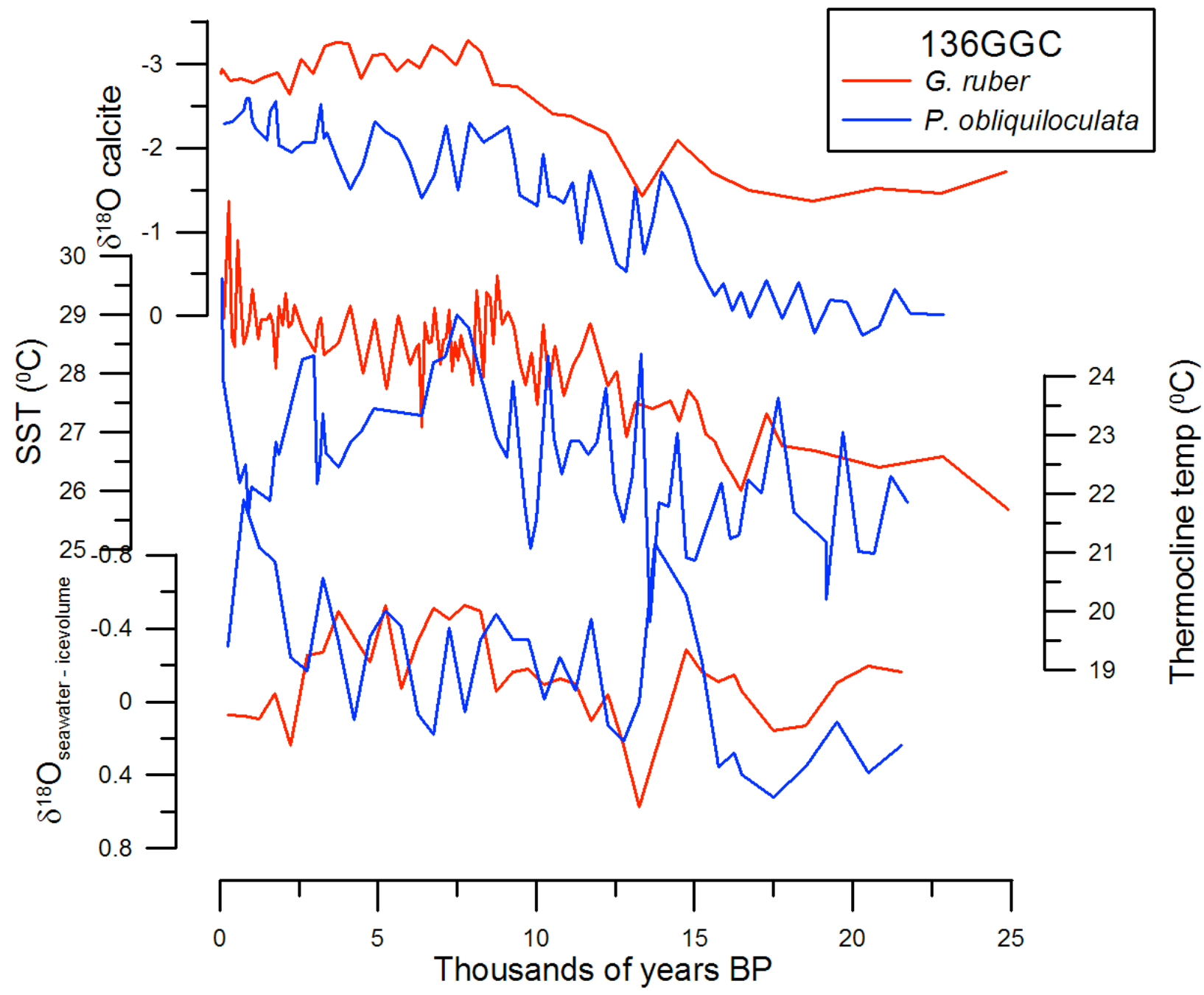

Figure 7 - Downcore records from 136GGC (Flores Sea). G. ruber (red) and $P$. obliquiloculata (blue) $\delta^{18} \mathrm{O}_{\text {calcite, }} \mathrm{Mg} / \mathrm{Ca}$-based temperature estimates, and $\delta^{18} \mathrm{O}_{\text {seawater }}$ estimates. Note the inverted axes for $\delta^{18} 0$. Gradients are G. ruber - P. obliquiloculata with the axes orientation as in Figure 3 (gradients corresponding to upwelling conditions in the coretop data are up). Axes are scaled so that $1 \% 0 \delta^{18} 0$ corresponds to $4^{\circ} \mathrm{C}$. 


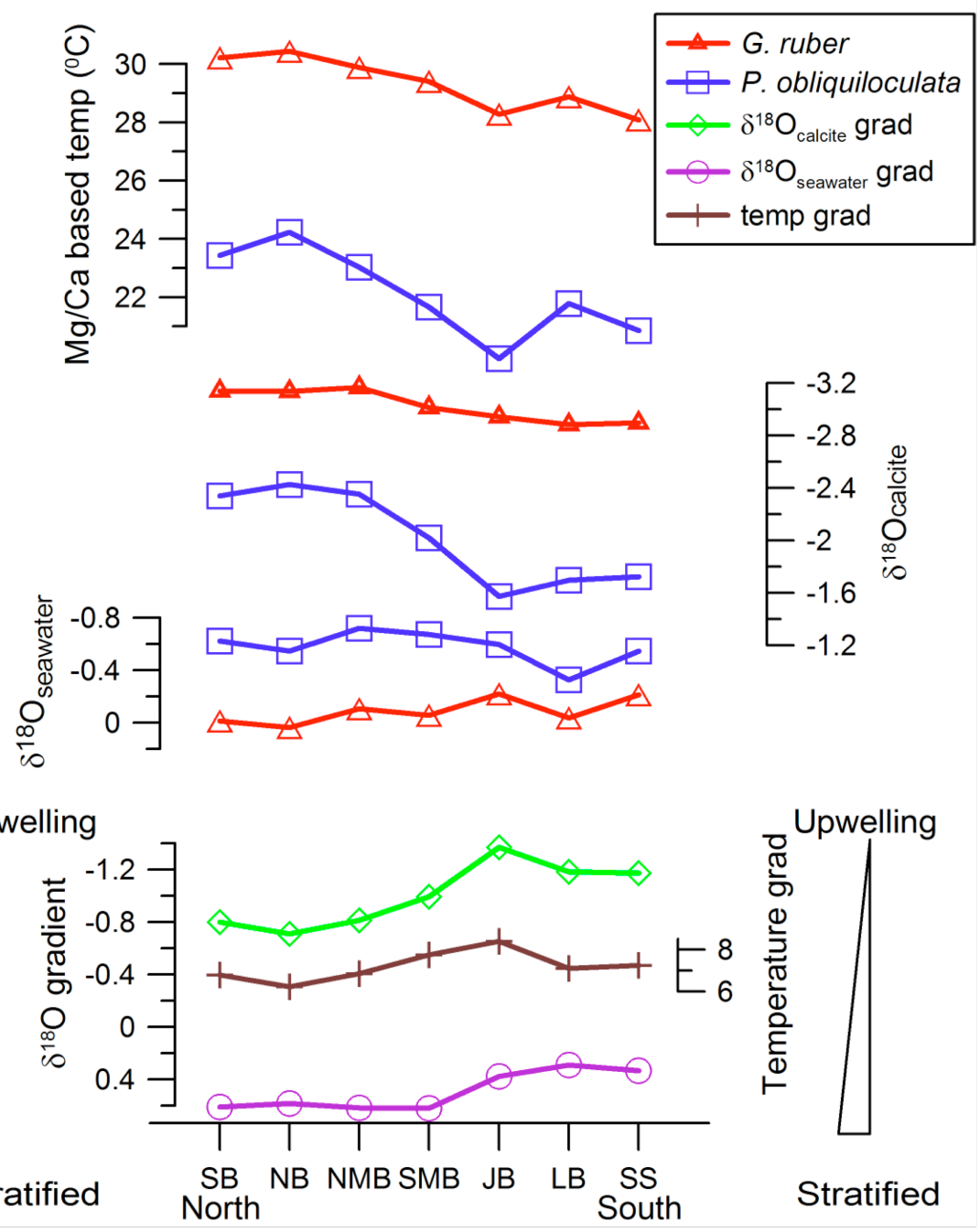

Figure 8 - Coretop summary - G. ruber (red) and P. obliquiloculata (blue) $\mathrm{Mg} / \mathrm{Ca}$ based temperature estimates, $\delta^{18} \mathrm{O}_{\text {calcite, }}$ and $\delta^{18} \mathrm{O}_{\text {seawater }}$ estimates [this paper, Gibbons et al., in revision; Mohtadi et al., 2011a]. The gradients between G. ruber and P. obliquiloculata are shown in the bottom panel. Data are pooled into the regions indicated in Figure 1. Areas that have increased upwelling in the modern ocean, such as the Java Basin (JB), have a larger $\mathrm{Mg} / \mathrm{Ca}$-based temperature gradient and a more negative $\delta^{18} \mathrm{O}_{\text {calcite }}$ gradient. Areas that are more stratified in the modern ocean, such as the Nias Basin (NB), show the opposite, a smaller $\mathrm{Mg} / \mathrm{Ca}$ based temperature gradient and a less negative $\delta^{18} \mathrm{O}_{\text {calcite }}$ gradient. Axes are scaled so that $1 \% 0 \delta^{18} \mathrm{O}$ corresponds to $4^{\circ} \mathrm{C}$. 


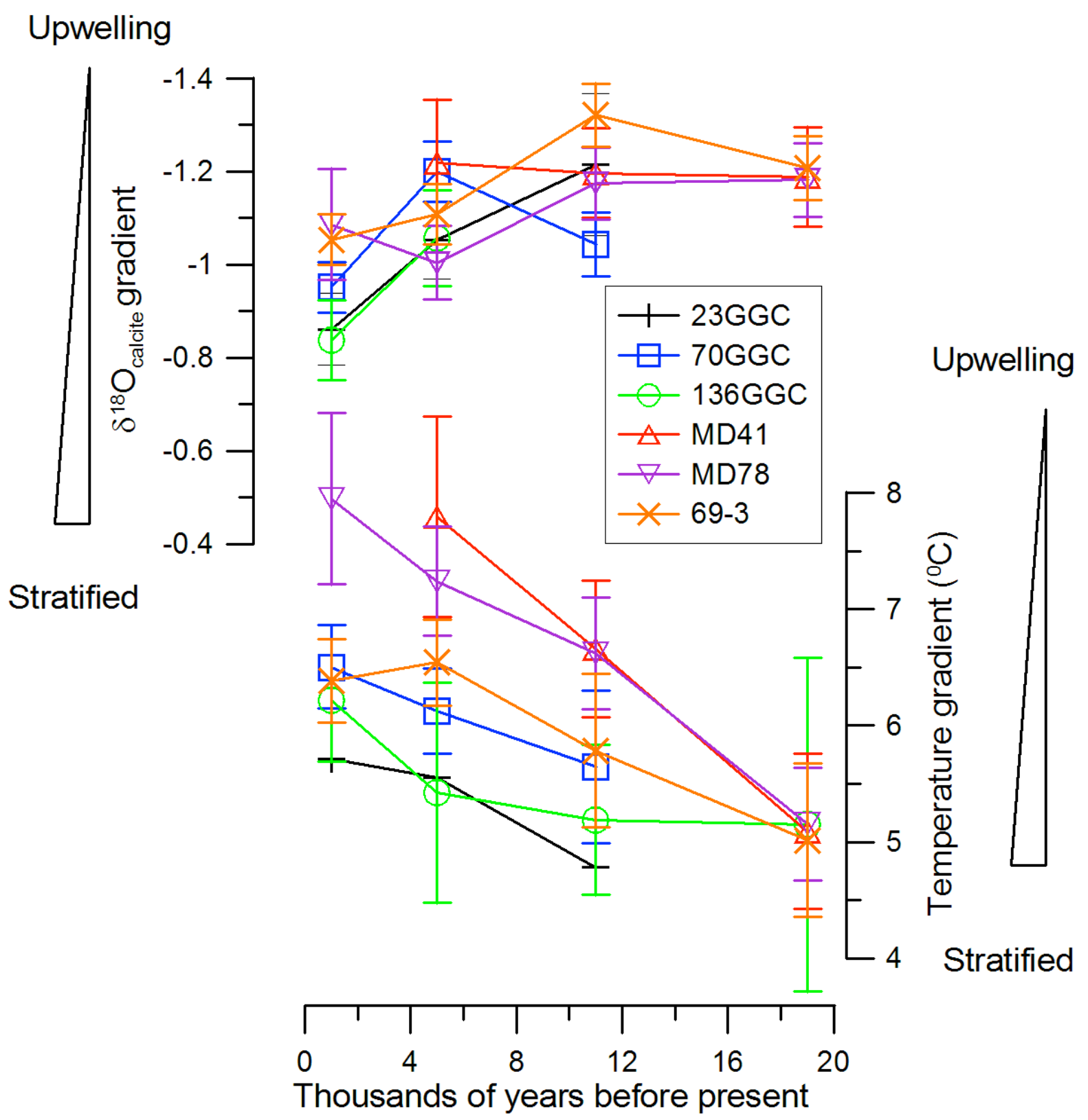

Figure 9 - Temperature and $\boldsymbol{\delta}^{\mathbf{1 8}} \mathbf{O}_{\text {calcite }}$ gradients from selected timeslices. The gradients are G. ruber - P. obliquiloculata. Timeslices are 2,000 year averages and are centered on $19 \mathrm{kyr} \mathrm{BP}, 11 \mathrm{kyr} \mathrm{BP}, 5 \mathrm{kyr} \mathrm{BP}$, and $1 \mathrm{kyr} \mathrm{BP}$. Axes are scaled so that $1 \% 0 \delta^{18} 0$ corresponds to $4^{\circ} \mathrm{C}$. Error bars are $+/-\sigma$. For $\mathrm{Mg} / \mathrm{Ca}$-based temperature, errors were calculated as described in Chapter 2, and $\sigma^{2}$ Temp grad $=\sigma^{2}$ ruber temp $+\sigma^{2}$ obliq temp. $\sigma$ of the $\delta^{18} \mathrm{O}_{\text {calcite }}$ is based on $\sim 50 \mathrm{G}$. ruber replicates in 23GGC and is $0.22 \%$. It is assumed that $P$. obliquiloculata has the same error. For each timeslice $\sigma$ ${ }^{2} \delta 180$ calcite ave $=\left(\sigma^{2} \delta 180\right.$ calcite $) / \mathrm{N}$, where $\mathrm{N}$ is the number of samples, and $\sigma^{2} \delta 180$ calcite grad $=$ $\sigma^{2} \delta 180$ calcite ave ruber $+\sigma^{2} \delta 180$ calcite ave obliq. 


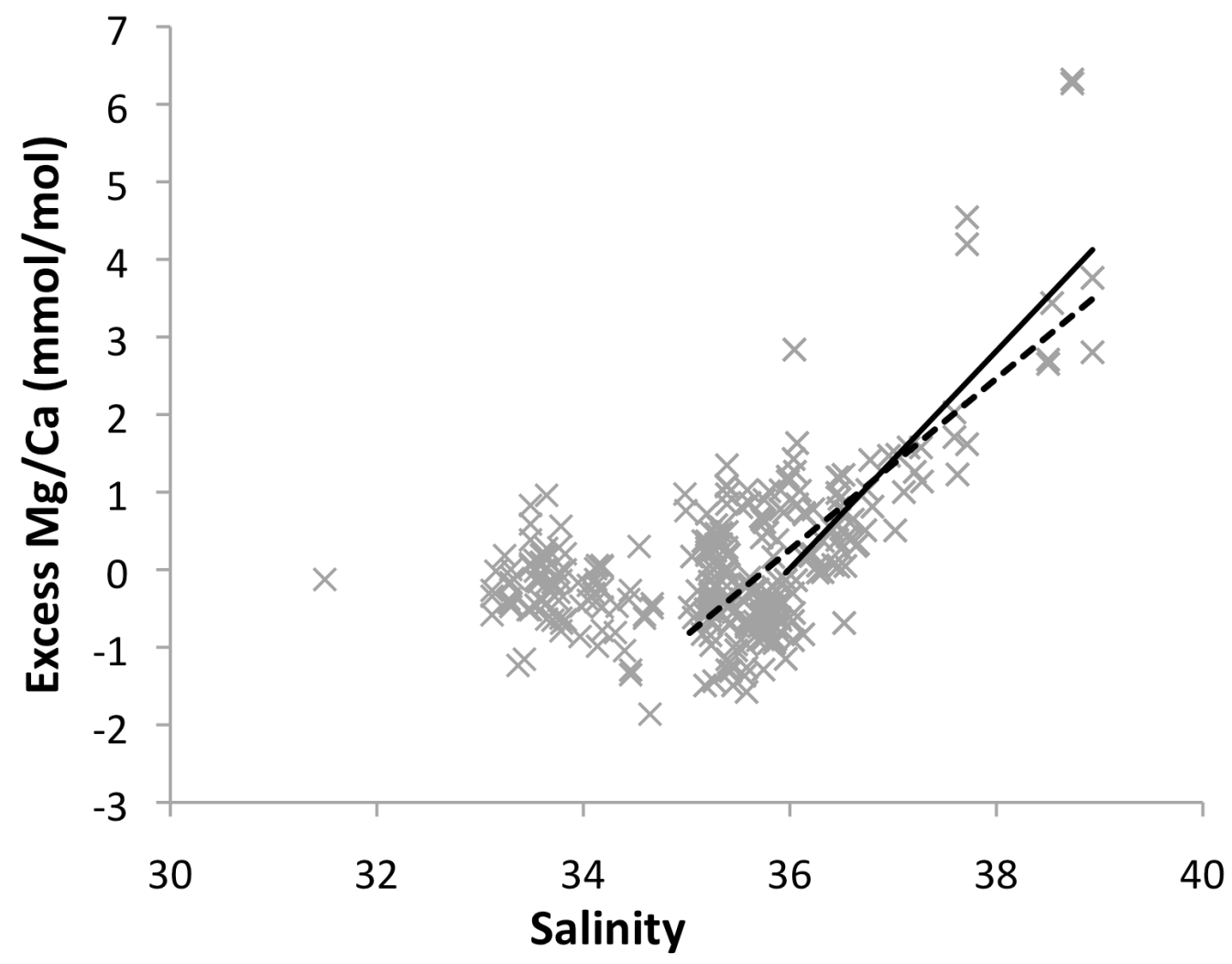

Figure 10 - Excess $\mathrm{Mg} / \mathrm{Ca}$ and salinity from $\mathrm{G}$. ruber. Lines were used to calculate the excess salinity required to cause our warm P. obliquiloculata $\mathrm{Mg} / \mathrm{Ca}$ based temperature reconstruction at the LGM. Solid line shows the relationship between excess $\mathrm{Mg} / \mathrm{Ca}$ and salinity, assuming a salinity threshold of $36(\mathrm{y}=1.4018 \mathrm{x}$ $-50.449 ; R^{2}=0.62$ ) and the dashed line is the relationship assuming a salinity threshold of $35\left(\mathrm{y}=1.1032 \mathrm{X}-39.456 ; \mathrm{R}^{2}=0.54\right)$. 
Adkins, J. F., et al. (2002), The salinity, temperature, and delta 0-18 of the glacial deep ocean, Science, 298(5599), 1769-1773.

Anand, P., et al. (2003), Calibration of Mg/Ca thermometry in planktonic foraminifera from a sediment trap time series, Paleoceanography, 18(2), 15. Andreasen, D. J., and A. C. Ravelo (1997), Tropical Pacific Ocean thermocline depth reconstructions for the last glacial maximum, Paleoceanography, 12(3), 395-413. Antonov, J. I., et al. (2006), World Ocean Atlas 2005, Volume 2: Salinity, NOAA Atlas NESDIS 62.

Arbuszewski, J., et al. (2010), On the fidelity of shell-derived $\delta 180$ seawater estimates, Earth and Planetary Science Letters, 300(3-4), 185-196.

Barker, S., et al. (2007), Radiocarbon age offsets of foraminifera resulting from differential dissolution and fragmentation within the sedimentary bioturbated zone, Paleoceanography, 22(2).

Bé, A. W. H., and W. H. Hutson (1977), Ecology of Planktonic Foraminifera and Biogeographic Patterns of Life and Fossil Assemblages in the Indian Ocean, Micropaleontology, 23(4), 369-314.

Bemis, B. E., et al. (1998), Reevaluation of the oxygen isotopic composition of planktonic foraminifera: Experimental results and revised paleotemperature equations, Paleoceanography, 13(2), 150-160.

Bolliet, T., et al. (2011), Mindanao Dome variability over the last 160 kyr: Episodic glacial cooling of the West Pacific Warm Pool, Paleoceanography, 26. Boyle, E. A., and L. D. Keigwin (1985/6), Comparison of Atlantic and Pacific Paleochemical Records for the Last 215,000 Years - Changes in Deep Ocean Circulation and Chemical Inventories, Earth and Planetary Science Letters, 76(1-2), 135-150.

Broecker, W., and E. Clark (2011), Radiocarbon-age differences among coexisting planktic foraminifera shells: The Barker Effect, Paleoceanography, 26.

Clark, P. U., and A. C. Mix (2002), Ice sheets and sea level of the Last Glacial Maximum, Quaternary Science Reviews, 21(1-3), 1-7.

Cleroux, C., et al. (2008), Mg/Ca and $\mathrm{Sr} / \mathrm{Ca}$ ratios in planktonic foraminifera: Proxies for upper water column temperature reconstruction, Paleoceanography, 23(3). Cullen, J. L., and W. L. Prell (1984), Planktonic Foraminifera of the Northern Indian Ocean: Distribution and Preservation in Surface Sediments, Marine Micropaleontology, 9, 1-52.

de Garidel-Thoron, T., et al. (2001), Millennial-scale dynamics of the East Asian winter monsoon during the last 200,000 years, Paleoceanography, 16(5), 491-502. de Garidel-Thoron, T., et al. (2007), A multiproxy assessment of the western equatorial Pacific hydrography during the last $30 \mathrm{kyr}$, Paleoceanography, 22(3). DiNezio, P. N., et al. (2011), The response of the Walker circulation to Last Glacial Maximum forcing: Implications for detection in proxies, Paleoceanography, 26. Ding, X., et al. (2006), Distribution and ecology of planktonic foraminifera from the seas around the Indonesian Archipelago, Marine Micropaleontology, 58(2), 114-134. 
Fairbanks, R. G., et al. (1982), Vertical-distribution and isotopic fractionation of living planktonic-foraminifera from the Panama Basin, Nature, 298(5877), 841-844. Fang, Q., et al. (2010), Volume, heat, and freshwater transports from the South China Sea to Indonesian seas in the boreal winter of 2007-2008, Journal Of Geophysical Research, 115(C12020).

Ffield, A., et al. (2000), Temperature variability within Makassar Strait, Geophysical Research Letters, 27(2), 237-240.

Fieux, M., et al. (1994), Measurements within the Pacific Indian Oceans Throughoughflow Region, Deep-Sea Research Part I-Oceanographic Research Papers, 41(7), 1091-1130.

Gebbie, G., and P. Huybers (2010), Total matrix intercomparison: A method for resolving the geometry of water mass pathways, Journal of Physical Oceanography, 40(8), 1710-1728.

Gibbons, F. T., et al. (in revision), Southern Hemisphere Influence on the Indonesian Throughflow, Nature, In Revision.

Godfrey, J. S. (1996), The effect of the Indonesian throughflow on ocean circulation and heat exchange with the atmosphere: A review, Journal of Geophysical ResearchOceans, 101(C5), 12217-12237.

Gordon, A. L. (1986), Inter-Ocean Exchange of Thermocline Water, Journal of Geophysical Research-Oceans, 91(C4), 5037-5046.

Gordon, A. L., et al. (2003), Cool Indonesian throughflow as a consequence of restricted surface layer flow, Nature, 425(6960), 824-828.

Gordon, A. L. (2005), Oceanography of the Indonesian Seas and Their Throughflow, Oceanography, 18(4), 14-27.

Gordon, A. L., et al. (2008), Makassar Strait throughflow, 2004 to 2006, Geophysical Research Letters, 35(24).

Holbourn, A., et al. (2011), Indonesian Throughflow variability during the last $140 \mathrm{ka}$ : the Timor Sea outflow, Geological Society, London.

Kendall, M., and J. D. Gibbons (1990), Rank Correlation Methods, Oxford University Press, New York.

Koch-Larrouy, A., et al. (2008), Physical processes contributing to the water mass transformation of the Indonesian Throughflow, Ocean Dynamics, 58(3-4), 275-288. LeGrande, A. N., and G. A. Schmidt (2006), Global gridded data set of the oxygen isotopic composition in seawater, Geophysical Research Letters, 33(12), 5.

Linsley, B. K., and R. C. Thunell (1990), The Record of Deglaciation in the Sulu Sea: Evidence for the Younger Dryas Event in the Tropical Western Pacific, Paleoceanography, 5(6), 1,025-021,039.

Linsley, B. K., et al. (2010), Holocene evolution of the Indonesian throughflow and the western Pacific warm pool, Nature Geoscience, 3, 578-583.

Martinez, J. I., et al. (1998), Planktonic foraminifera from the eastern Indian Ocean: distribution and ecology in relation to the Western Pacific Warm Pool (WPWP), Marine Micropaleontology, 34(3-4), 121-151.

Mathien-Blard, E., and F. Bassinot (2009), Salinity bias on the foraminifera Mg/Ca thermometry: Correction procedure and implications for past ocean hydrographic reconstructions, Geochemistry Geophysics Geosystems, 10(12). 
Mohtadi, M., et al. (2009), Low-latitude control on seasonal and interannual changes in planktonic foraminiferal flux and shell geochemistry off south Java: A sediment trap study, Paleoceanography, 24.

Mohtadi, M., et al. (2011a), Reconstructing the thermal structure of the upper ocean: Insights from planktic foraminifera shell chemistry and alkenones in modern sediments of the tropical eastern Indian Ocean, Paleoceanography, 26.

Mohtadi, M., et al. (2011b), Glacial to Holocene swings of the Australian-Indonesian monsoon, Nature Geoscience, 4(8), 540-544.

Molcard, R., et al. (2001), The throughflow within the Ombai Strait, Deep-Sea Research Part I-Oceanographic Research Papers, 48, 1237-1253.

Otto-Bliesner, B. L., et al. (2009), A comparison of PMIP2 model simulations and the MARGO proxy reconstruction for tropical sea surface temperatures at last glacial maximum, Climate Dynamics, 32(6), 799-815.

$\mathrm{Qu}, \mathrm{T}$., et al. (2006), South China Sea throughflow: A heat and freshwater conveyor, Geophysical Research Letters, 33(L23617), doi:10.1029/2006GL028350.

Ravelo, A. C., and R. G. Fairbanks (1992), Oxygen Isotopic Composition of Multiple Species of Planktonic Foraminifera: Recorders of the Modern Photic Zone Temperature Gradient Paleoceanography, 7(6), 815.

Ravelo, A. C., and D. H. Andreasen (1999), Using Planktonic Foraminifera as Monitors of the Tropical Surface Ocean, Kluwer Academic/Plenum Publishers, New York.

Reimer, P. J., et al. (2009), INTCAL09 AND MARINE09 Radiocarbon age calibration curves, 0-50,000 years cal BP, Radiocabon, 51(4), 1111-1150.

Rosenthal, Y., et al. (1999), Precise determination of element/calcium ratios in calcareous samples using sector field inductively coupled plasma mass spectrometry, Analytical Chemistry, 71(15), 3248-3253.

Rosenthal, Y., et al. (2003), The amplitude and phasing of climate change during the last deglaciation in the Sulu Sea, western equatorial Pacific, Geophysical Research Letters, 30(8).

Sadekov, A., et al. (2009), Surface and subsurface seawater temperature reconstruction using $\mathrm{Mg} / \mathrm{Ca}$ microanalysis of planktonic foraminifera Globigerinoides ruber, Globigerinoides sacculifer, and Pulleniatina obliquiloculata, Paleoceanography, 24.

Sarnthein, M., et al. (2011), Tropical warming in the timor sea led deglacial antarctic warming and atmospheric CO2 rise by more than $500 \mathrm{yr}$, Earth and Planetary Science Letters, 302(3-4), 337-348.

Sathiamurthy, E., and H. Voris (2006), Maps of Holocene Sea Level Transgression and Submerged Lakes on the Sunda Shelf, The Natural History Journal of Chulalongkorn University, Supplement 2, 1-44.

Sprintall, J., et al. (2009), Direct estimates of the Indonesian Throughflow entering the Indian Ocean: 2004-2006, Journal of Geophysical Research-Oceans, 114.

Steinke, S., et al. (2010), Reconstructing the southern South China Sea upper water column structure since the Last Glacial Maximum: Implications for the East Asian winter monsoon development, Paleoceanography, 25(PA2219).

Tian, J., et al. (2005), Quaternary upper ocean thermal gradient variations in the South China Sea: Implications for east Asian monsoon climate, Paleoceanography, 20(4). 
Tozuka, T., et al. (2007), Dramatic impact of the South China Sea on the Indonesian Throughflow, Geophysical Research Letters, 34(12).

Ujiie, Y., and H. Ujiie (2000), Distribution and Oceanographic Relationship of Modern Planktonic Foraminifera in the Ryukyu Arc Region, Northwest Pacific Ocean, Journal of Foraminiferal Research, 30(4), 336-360.

Wyrtki, K. (1961), Physical Oceanography of the Southeast Asain Waters, NAGA REPORT, 2.

Wyrtki, K. (1987), Indonesian Through Flow and the Associated Pressure Gradient, Journal Of Geophysical Research, 92(C12), 12,941-912,946.

$\mathrm{Xu}$, J., et al. (2006), Changes in the vertical profile of the Indonesian Throughflow during Termination II: Evidence from the Timor Sea, Paleoceanography, 21(4), 14. $\mathrm{Xu}$ J., et al. (2008), Changes in the thermocline structure of the Indonesian outflow during Terminations I and II, Earth and Planetary Science Letters, 273(1-2), 152-162. $\mathrm{Xu}$, J., et al. (2010), Indo-Pacific Warm Pool variability during the Holocene and Last Glacial Maximum, Paleoceanography, 25(PA4230).

Yang, A., and J. ZhiMin (2009), Pulleniatina Minimum Event during the last deglaciation in the southern South China Sea, Chinese Science Bulletin, 54, 45144519.

Yuan, D. X., et al. (2004), Timing, duration, and transitions of the Last Interglacial Asian Monsoon, Science, 304(5670), 575-578.

Zuraida, R., et al. (2009), Evidence for Indonesian Throughflow slowdown during Heinrich events 3-5, Paleoceanography, 24, doi:10.1029/2008PA001653. 


\section{Conclusions}

This work has provided insight into the dynamics of the hydrology and oceanography of the Indonesian Throughflow. The data presented here strongly suggest that the Java Sea inflow does not have a cooling effect on the outflow of the Indonesian Throughflow. The appearance of a cool tongue of Indonesian water in the equatorial Indian Ocean is more likely due to the vigorous upwelling in the Banda Sea. This work also shows that the Intertropical Convergence Zone migrates in concert with high latitude Northern Hemisphere cooling events, possibly in response to the decreased interhemispheric temperature gradient. Additionally, the continued need for ongoing proxy development work is clearly demonstrated. I show the tremendous difficulty in reconciling the $\delta^{18} \mathrm{O}_{\text {calicte }}$ and $\mathrm{Mg} / \mathrm{Ca}$ of $P$. obliquiloculata data variations, despite these proxies being in widespread use.

There are several ways to move this work forward. Of upmost importance is the need for more $\delta^{18} \mathrm{O}_{\text {seawater }}$ measurements, particularly in the subsurface. Not only would this aid our understanding of modern hydrology in the region, it is vital for our interpretation of thermocline (and benthic) records.

Additionally, more work on the geochemistry of P. obliquiloculata is required. Perhaps there is a species-specific $\mathrm{Mg} / \mathrm{Ca}$ or $\delta^{18} \mathrm{O}$ temperature relationship that is 
more suitable. Given the difficulty in simultaneously assessing depth habitat and geochemical sensitivity to temperature, culturing work would yield the most straightforward answer.

There is more work to be done on constraining the migration of the Intertropical Convergence Zone. Within the IndoPacific Warm Pool, the data show a clear band of no temporal change in $\delta^{18} \mathrm{O}_{\text {seawater }}$ over the past 20,000 years. I speculate that during high latitude Northern Hemisphere coolings these locations experience an increase in boreal summer precipitation and a decrease in boreal winter precipitation. The geographic coverage of the records I use allows me to constrain the migration of the Intertropical Convergence Zone. In the Eastern Equatorial Pacific, the southern most $\delta^{18} \mathrm{O}_{\text {seawater }}$ record in this study is from a core retrieved from $1^{\circ} \mathrm{S}$. If we could reconstruct $\delta^{18} \mathrm{O}_{\text {seawater }}$ at cores farther south, I would expect to find a location where $\delta^{18} \mathrm{O}_{\text {seawater }}$ does not change during times of high latitude Northern Hemisphere cold events. Even farther south, I would expect to see

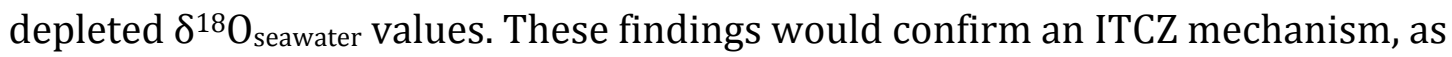
we currently cannot rule out that changes in the Eastern Equatorial Pacific are due to variations in moisture transport across the Isthmus of Panama.

We can also test whether changes in the interhemispheric temperature gradient consistently respond to hydrologic changes. Our longest record (69-3) shows a drying event that is possibly consistent with Heinrich Event 3, but no expression of Heinrich Event 2. If this finding holds with increased sampling resolution and better dating, then it would suggest that changes in the 
interhemispheric temperature gradient did not always occur during Heinrich Events. This is a hypothesis that can likely be explored using existing data.

Finally, the mechanisms I propose for temperature controls in the Indonesian Throughflow can be more thoroughly examined. My hypothesis requires intermediate-depth water temperature changes to resemble Antarctic air temperature changes. By deriving temperatures from benthic foraminifera from thermocline and intermediate water depth cores in the region, this oceanic transport mechanism can be tested.

Most importantly, as we move forward and generate new observational and paleo data from the Indonesian Throughflow, we should be prepared to reevaluate our current hypotheses for both modern oceanography and past variations. 
Appendix A: All radiocarbon dates generated for this thesis.

\begin{tabular}{|c|c|c|c|c|c|c|}
\hline $\begin{array}{l}\text { Core } \\
\text { B]8-03 }\end{array}$ & $\begin{array}{l}\text { Depth } \\
(\mathrm{cm})\end{array}$ & $\begin{array}{l}\mathrm{C}-14 \mathrm{Age} \\
(\mathrm{yr} \mathrm{BP})\end{array}$ & Error (yr) & $\begin{array}{l}\text { Calendar age } \\
\text { (median } \\
\text { probability) } \\
(y r \text { BP) }\end{array}$ & $\begin{array}{l}\text { Lower cal } \\
\text { range ( } 1 \\
\text { sigma } \\
(y r)\end{array}$ & $\begin{array}{l}\text { upper cal } \\
\text { range (1 } \\
\text { sigma) } \\
(y r)\end{array}$ \\
\hline 13GGC & 32 & 925 & 30 & 526 & 547 & 497 \\
\hline & 100 & 2190 & 30 & 1786 & 1831 & 1735 \\
\hline & 272 & 5050 & 40 & 5398 & 5447 & 5330 \\
\hline & 408 & 8220 & 45 & 8738 & 8840 & 8631 \\
\hline & 505 & 9610 & 60 & 10474 & 10546 & 10415 \\
\hline
\end{tabular}

B]8-03

23GGC

$\begin{array}{rr}7 & 30 \\ 73 & 2040 \\ 169 & 3780 \\ 329 & 7160 \\ 409 & 9730\end{array}$

25
30
35
45
70

30

1607

3723

7627

10592

$\begin{array}{rr}1657 & 1557 \\ 3792 & 3672 \\ 7665 & 7581 \\ 10662 & 10516\end{array}$

BJ8-03

70GGC

$\begin{array}{rr}64 & 1310 \\ 104 & 2750 \\ 176 & 4240 \\ 202 & 4850 \\ 242 & 5410 \\ 280 & 6160 \\ 321 & 7190 \\ 331 & 8080 \\ 341 & 8700 \\ 351 & 9210 \\ 362 & 10250 \\ 394 & 12550 \\ 406 & 12900\end{array}$

30

50

50

40

35

60

45

40

45

45

40

50

45

853

2472

4341

5155

5789

6594

7653

8538

9380

10030

11223

13990

14649

901

2540

816

4413

2352

5245

4269

5079

5847

5737

6666

6513

7695

7598

8589

8481

9438

9325

10124

9954

11251

11187

14064

13898

14934

14257

B]8-03

136GGC

$\begin{array}{rr}3 & 485 \\ 169 & 7440 \\ 185 & 8230 \\ 205 & 9740 \\ 249 & 14000 \\ 313 & 29000 \\ 401 & 37700\end{array}$

25

92

135

7903

8752

10594

16758

33006

42063

7943

8842

7863

35

50

55

210

290

10643

8657

10539

16859

16675

33358

32688

42299

41822

GeoB10

069-3

$\begin{array}{rr}8 & 755 \\ 65 & 1680 \\ 88 & 1970 \\ 107 & 2260\end{array}$

35

30

396

449

336

1241

1278

1213

35

1525

1584

1477

1867

1907

1821 


$\begin{array}{rrrrrr}122 & 2360 & 30 & 1982 & 2032 & 1931 \\ 188 & 2910 & 35 & 2698 & 2738 & 2670 \\ 268 & 3950 & 35 & 3939 & 3990 & 3872 \\ 378 & 5140 & 35 & 5511 & 5557 & 5473 \\ 468 & 6800 & 45 & 7328 & 7380 & 7279 \\ 593 & 9450 & 65 & 10307 & 10378 & 10221 \\ 644 & 10600 & 50 & 11882 & 11970 & 11747 \\ 693 & 11700 & 55 & 13194 & 13250 & 13132 \\ 724 & 13200 & 75 & 15215 & 15481 & 15007 \\ 753 & 16050 & 75 & 18789 & 18867 & 18701 \\ 786 & 19050 & 90 & 22267 & 22391 & 22159 \\ 818 & 21900 & 110 & 25723 & 25968 & 25524 \\ 894 & 27100 & 160 & 31177 & 31268 & 31085 \\ 953 & 31000 & 240 & 35043 & 35228 & 34766\end{array}$


Appendix B: Coretop data generated for this thesis.

\begin{tabular}{|c|c|c|c|c|c|c|c|}
\hline $\begin{array}{l}\text { Sediment } \\
\text { core }\end{array}$ & $\begin{array}{l}\text { Latitude } \\
\qquad\left[{ }^{\circ} \mathrm{N}\right]\end{array}$ & $\begin{array}{l}\text { Longitude } \\
\left.\qquad{ }^{\circ} \mathrm{E}\right]\end{array}$ & $\begin{array}{c}\text { water } \\
\text { depth } \\
{[\mathrm{m}]}\end{array}$ & $\begin{array}{c}\mathrm{Mg} / \mathrm{Ca} \\
\text { ruber } \\
{[\mathrm{mmol} / \mathrm{mol}]}\end{array}$ & $\begin{array}{c}\delta^{18} \mathrm{O} \\
\text { ruber } \\
{[\% \text { PDB] }}\end{array}$ & $\begin{array}{c}\mathrm{Mg} / \mathrm{Ca} \\
\text { obliq } \\
{[\mathrm{mmol} / \mathrm{mol}]}\end{array}$ & $\begin{array}{c}\delta^{18} \mathrm{O} \text { obliq } \\
{[\% \circ \mathrm{PDB}]}\end{array}$ \\
\hline \multicolumn{8}{|l|}{ GeoB } \\
\hline $114 \mathrm{MC}$ & 3.49 & 95.33 & 1535 & 4.88 & & 2.40 & \\
\hline $118 \mathrm{MC}$ & 3.52 & 96.31 & 804 & 5.21 & & 3.01 & \\
\hline 89 MC & 2.78 & 96.42 & 916 & 4.86 & & 3.08 & \\
\hline $139 \mathrm{MC}$ & 1.76 & 96.77 & 1854 & 5.30 & & 2.84 & \\
\hline $60 \mathrm{MC}$ & 1.45 & 98.05 & 551 & 4.92 & & 3.10 & \\
\hline $147 \mathrm{MC}$ & -0.69 & 98.07 & 1052 & 5.07 & & 3.11 & \\
\hline $41 \mathrm{MC}$ & 0.34 & 98.13 & 674 & 4.79 & & 3.29 & \\
\hline $10027-3$ & -0.81 & 99.65 & 875 & 5.48 & -3.13 & 2.66 & -2.31 \\
\hline $31 \mathrm{MC}$ & -1.30 & 99.72 & 1734 & 4.59 & & 2.08 & \\
\hline $10033-3$ & -1.56 & 99.95 & 1756 & 4.96 & -3.18 & & -2.34 \\
\hline $10029-3$ & -1.50 & 100.13 & 974 & 5.31 & -3.27 & 2.51 & -2.46 \\
\hline $10034-3$ & -4.16 & 101.50 & 995 & 4.67 & -3.00 & 2.40 & -2.14 \\
\hline $03 \mathrm{MC}$ & -4.70 & 101.96 & 1707 & 4.64 & & & \\
\hline $02 \mathrm{MC}$ & -5.48 & 103.01 & 1972 & 4.90 & & 1.97 & \\
\hline $10041-3$ & -6.27 & 103.09 & 1540 & 4.69 & -2.68 & 2.61 & -2.15 \\
\hline $10038-3$ & -5.94 & 103.25 & 1891 & 4.96 & -3.01 & & -2.18 \\
\hline $10039-3$ & -5.87 & 103.29 & 1799 & 5.03 & -3.19 & 2.23 & -2.34 \\
\hline $10036-3$ & -5.34 & 103.66 & 1502 & 5.10 & -3.23 & 2.32 & -2.35 \\
\hline $10042-2$ & -7.11 & 104.64 & 2457 & 4.43 & -3.19 & & -2.34 \\
\hline $10049-5$ & -8.78 & 110.50 & 1288 & 4.55 & -2.87 & 1.82 & -2.03 \\
\hline $10058-1$ & -8.68 & 112.64 & 1103 & 4.44 & -3.09 & 2.04 & -1.85 \\
\hline $10065-9$ & -9.22 & 118.89 & 1284 & 4.37 & -2.91 & 2.31 & -1.62 \\
\hline $10069-4$ & -9.60 & 120.92 & 1249 & 4.34 & -2.92 & 1.92 & -2.17 \\
\hline \multicolumn{8}{|l|}{ BJ8-03 } \\
\hline MC16 & -7.32 & 115.18 & 409 & 5.06 & -2.87 & 2.55 & -1.96 \\
\hline MC11 & -7.39 & 115.21 & 590 & 4.89 & -2.87 & 2.86 & -1.67 \\
\hline MC84 & -1.40 & 117.53 & 401 & 5.27 & -3.17 & 2.79 & \\
\hline MC31 & -3.88 & 119.45 & 459 & 5.14 & -2.78 & 2.80 & -2.27 \\
\hline MC125 & -5.89 & 120.29 & 427 & 4.94 & -2.81 & 3.15 & -1.85 \\
\hline
\end{tabular}


Appendix C: Downcore data generated for this thesis.

\begin{tabular}{|c|c|c|c|}
\hline $\begin{array}{l}\text { GeoB10069-3 } \\
\text { Depth }(\mathrm{cm})\end{array}$ & $\begin{array}{c}\text { G. ruber } \\
\mathrm{Mg} / \mathrm{Ca} \\
(\mathrm{mmol} / \mathrm{mol})\end{array}$ & $\begin{array}{c}\text { Depth } \\
\text { (cm) }\end{array}$ & $\begin{array}{c}\delta^{18} \mathrm{O} \\
\% \text { PDB }\end{array}$ \\
\hline 3 & 4.10 & 0 & -2.760 \\
\hline 8 & 4.68 & 1 & -2.870 \\
\hline 13 & 3.84 & 2 & -2.990 \\
\hline 18 & 3.72 & 3 & -1.920 \\
\hline 23 & 3.85 & 4 & -3.160 \\
\hline 28 & 3.83 & 5 & -2.930 \\
\hline 33 & 3.77 & 6 & -2.770 \\
\hline 38 & 4.28 & 7 & -2.690 \\
\hline 43 & 3.81 & 8 & -2.980 \\
\hline 48 & 3.99 & 9 & -2.360 \\
\hline 53 & 3.93 & 10 & -2.690 \\
\hline 58 & 4.04 & 11 & -2.580 \\
\hline 63 & 4.36 & 12 & -2.760 \\
\hline 68 & 3.93 & 13 & -2.880 \\
\hline 73 & 4.07 & 14 & -2.600 \\
\hline 78 & 4.03 & 15 & -2.780 \\
\hline 83 & 4.09 & 16 & -2.880 \\
\hline 88 & 3.70 & 17 & -2.790 \\
\hline 93 & 3.83 & 18 & -2.760 \\
\hline 98 & 3.89 & 19 & -2.850 \\
\hline 103 & 4.12 & 20 & -2.720 \\
\hline 108 & 4.01 & 21 & -2.810 \\
\hline 113 & 4.10 & 22 & -2.540 \\
\hline 118 & 4.17 & 23 & -2.790 \\
\hline 123 & 3.99 & 24 & -2.870 \\
\hline 128 & 4.28 & 25 & -2.860 \\
\hline 133 & 4.11 & 26 & -2.730 \\
\hline 138 & 4.27 & 27 & -2.790 \\
\hline 143 & 3.81 & 28 & -2.460 \\
\hline 148 & 4.16 & 29 & -2.660 \\
\hline 153 & 3.93 & 30 & -2.500 \\
\hline 158 & 3.87 & 31 & -2.610 \\
\hline 163 & 4.12 & 32 & -2.650 \\
\hline 168 & 3.84 & 33 & -2.750 \\
\hline 173 & 3.87 & 34 & -2.760 \\
\hline 178 & 3.81 & 35 & -2.690 \\
\hline 183 & 3.84 & 36 & -2.700 \\
\hline 188 & 4.28 & 37 & -2.710 \\
\hline 193 & 4.13 & 38 & -2.540 \\
\hline 198 & 3.90 & 39 & -2.740 \\
\hline 203 & 3.95 & 40 & -2.720 \\
\hline 208 & 4.11 & 41 & -2.610 \\
\hline 213 & 3.86 & 42 & -2.710 \\
\hline 218 & 4.26 & 43 & -2.610 \\
\hline
\end{tabular}




\begin{tabular}{|c|c|c|c|}
\hline 223 & 4.34 & 44 & -2.680 \\
\hline 228 & 3.83 & 45 & -2.620 \\
\hline 233 & 4.06 & 46 & -2.580 \\
\hline 238 & 3.96 & 47 & -2.710 \\
\hline 243 & 4.02 & 48 & -2.710 \\
\hline 248 & 4.08 & 49 & -2.720 \\
\hline 253 & 4.13 & 50 & -2.720 \\
\hline 258 & 4.21 & 51 & -2.740 \\
\hline 263 & 3.89 & 52 & -2.600 \\
\hline 268 & 3.93 & 53 & -2.780 \\
\hline 273 & 4.16 & 54 & -2.610 \\
\hline 278 & 4.00 & 55 & -2.510 \\
\hline 283 & 4.09 & 56 & -2.890 \\
\hline 288 & 4.29 & 57 & -2.830 \\
\hline 293 & 4.39 & 58 & -2.730 \\
\hline 298 & 4.17 & 59 & -2.740 \\
\hline 303 & 4.19 & 60 & -2.770 \\
\hline 308 & 3.83 & 61 & -2.630 \\
\hline 313 & 4.23 & 62 & -2.720 \\
\hline 318 & 3.83 & 63 & -2.580 \\
\hline 323 & 4.12 & 64 & -2.670 \\
\hline 328 & 4.32 & 65 & -2.870 \\
\hline 333 & 4.09 & 66 & -2.660 \\
\hline 338 & 4.13 & 67 & -2.660 \\
\hline 343 & 4.16 & 68 & -2.690 \\
\hline 348 & 4.24 & 69 & -2.420 \\
\hline 353 & 4.29 & 70 & -2.640 \\
\hline 358 & 4.19 & 71 & -2.280 \\
\hline 363 & 4.18 & 72 & -2.610 \\
\hline 368 & 4.36 & 73 & -2.690 \\
\hline 373 & 4.20 & 74 & -2.580 \\
\hline 378 & 4.18 & 75 & -2.560 \\
\hline 383 & 4.07 & 76 & -2.640 \\
\hline 388 & 4.02 & 77 & -2.820 \\
\hline 393 & 4.19 & 78 & -2.870 \\
\hline 398 & 4.36 & 79 & -2.580 \\
\hline 403 & 4.13 & 80 & -2.740 \\
\hline 408 & 4.21 & 81 & -2.790 \\
\hline 413 & 4.43 & 82 & -2.620 \\
\hline 418 & 4.20 & 83 & -2.660 \\
\hline 423 & 4.16 & 84 & -2.580 \\
\hline 428 & 4.49 & 85 & -2.570 \\
\hline 433 & 4.31 & 86 & -2.640 \\
\hline 438 & 4.19 & 87 & -2.640 \\
\hline 443 & 4.17 & 88 & -2.770 \\
\hline 449 & 4.52 & 89 & -2.800 \\
\hline 453 & 4.17 & 90 & -2.710 \\
\hline 458 & 4.33 & 91 & -2.670 \\
\hline 463 & 4.09 & 92 & -2.960 \\
\hline
\end{tabular}




\begin{tabular}{|c|c|c|c|}
\hline 468 & 4.27 & 93 & -2.560 \\
\hline 473 & 4.22 & 94 & -2.880 \\
\hline 478 & 4.16 & 95 & -2.660 \\
\hline 483 & 4.34 & 96 & -2.520 \\
\hline 488 & 4.29 & 97 & -2.680 \\
\hline 493 & 4.18 & 98 & -2.410 \\
\hline 498 & 3.93 & 99 & -2.710 \\
\hline 503 & 4.15 & 100 & -2.730 \\
\hline 508 & 4.28 & 101 & -2.820 \\
\hline 513 & 4.40 & 102 & -2.710 \\
\hline 518 & 4.34 & 103 & -2.310 \\
\hline 523 & 4.14 & 104 & -2.630 \\
\hline 528 & 4.14 & 105 & -2.730 \\
\hline 533 & 4.43 & 106 & -2.770 \\
\hline 538 & 4.16 & 107 & -2.500 \\
\hline 543 & 4.14 & 108 & -2.790 \\
\hline 548 & 4.31 & 109 & -2.700 \\
\hline 553 & 4.31 & 110 & -2.460 \\
\hline 557 & 4.40 & 111 & -2.590 \\
\hline 563 & 4.35 & 112 & -2.750 \\
\hline 568 & 4.43 & 113 & -2.620 \\
\hline 573 & 4.39 & 114 & -2.880 \\
\hline 578 & 4.37 & 115 & -2.560 \\
\hline 583 & 4.65 & 116 & -2.920 \\
\hline 588 & 4.72 & 117 & -2.610 \\
\hline 593 & 4.16 & 118 & -2.640 \\
\hline 598 & 4.84 & 119 & -2.730 \\
\hline 602 & 4.52 & 120 & -2.540 \\
\hline 603 & 4.59 & 121 & -2.580 \\
\hline 603 & 4.51 & 122 & -2.660 \\
\hline 604 & 4.35 & 123 & -2.640 \\
\hline 606 & 4.25 & 124 & -2.680 \\
\hline 608 & 4.28 & 125 & -2.560 \\
\hline 608 & 4.73 & 126 & -2.800 \\
\hline 610 & 4.76 & 127 & -2.830 \\
\hline 612 & 4.22 & 128 & -2.920 \\
\hline 613 & 4.63 & 129 & -2.940 \\
\hline 613 & 4.69 & 130 & -2.670 \\
\hline 614 & 4.11 & 131 & -2.770 \\
\hline 616 & 4.48 & 132 & -2.540 \\
\hline 618 & 4.65 & 133 & -2.720 \\
\hline 618 & 4.21 & 138 & -2.610 \\
\hline 620 & 4.33 & 143 & -2.520 \\
\hline 622 & 4.29 & 148 & -2.630 \\
\hline 623 & 4.35 & 153 & -2.570 \\
\hline 623 & 4.44 & 158 & -2.840 \\
\hline 624 & 4.17 & 163 & -2.620 \\
\hline 626 & 4.29 & 168 & -2.540 \\
\hline 628 & 4.34 & 173 & -2.770 \\
\hline
\end{tabular}




\begin{tabular}{|c|c|c|c|}
\hline 628 & 4.10 & 178 & -2.630 \\
\hline 630 & 4.47 & 183 & -2.660 \\
\hline 632 & 4.43 & 188 & -2.450 \\
\hline 633 & 4.29 & 193 & -2.740 \\
\hline 633 & 4.41 & 198 & -2.710 \\
\hline 634 & 4.49 & 203 & -2.630 \\
\hline 636 & 4.70 & 208 & -2.780 \\
\hline 638 & 4.30 & 218 & -2.730 \\
\hline 638 & 4.52 & 223 & -2.590 \\
\hline 640 & 4.42 & 228 & -2.500 \\
\hline 642 & 4.66 & 233 & -2.810 \\
\hline 643 & 4.51 & 238 & -2.650 \\
\hline 643 & 4.28 & 243 & -2.670 \\
\hline 644 & 4.16 & 248 & -2.830 \\
\hline 646 & 4.32 & 253 & -2.420 \\
\hline 648 & 4.16 & 258 & -2.820 \\
\hline 650 & 4.39 & 263 & -2.730 \\
\hline 652 & 4.11 & 268 & -2.860 \\
\hline 653 & 4.08 & 273 & -2.590 \\
\hline 654 & 4.61 & 278 & -2.790 \\
\hline 656 & 4.29 & 283 & -2.670 \\
\hline 658 & 3.93 & 288 & -2.690 \\
\hline 660 & 3.94 & 293 & -2.670 \\
\hline 662 & 4.57 & 298 & -2.780 \\
\hline 663 & 3.80 & 303 & -2.670 \\
\hline 664 & 3.91 & 308 & -2.930 \\
\hline 666 & 3.99 & 313 & -2.670 \\
\hline 668 & 3.74 & 318 & -2.900 \\
\hline 670 & 4.20 & 323 & -2.740 \\
\hline 672 & 3.81 & 328 & -2.810 \\
\hline 673 & 3.86 & 333 & -3.050 \\
\hline 674 & 4.13 & 338 & -2.790 \\
\hline 676 & 4.09 & 343 & -2.730 \\
\hline 678 & 3.89 & 348 & -2.730 \\
\hline 680 & 4.38 & 353 & -2.830 \\
\hline 682 & 3.90 & 358 & -2.610 \\
\hline 683 & 3.95 & 363 & -2.640 \\
\hline 684 & 4.17 & 368 & -2.700 \\
\hline 686 & 3.91 & 373 & -2.640 \\
\hline 688 & 4.00 & 378 & -2.390 \\
\hline 692 & 3.92 & 383 & -2.610 \\
\hline 693 & 3.73 & 388 & -2.660 \\
\hline 694 & 3.84 & 393 & -2.600 \\
\hline 696 & 4.03 & 398 & -2.570 \\
\hline 698 & 4.18 & 403 & -2.880 \\
\hline 700 & 3.94 & 408 & -2.830 \\
\hline 702 & 3.99 & 413 & -2.740 \\
\hline 703 & 4.05 & 418 & -2.780 \\
\hline 704 & 3.76 & 423 & -2.600 \\
\hline
\end{tabular}




\begin{tabular}{|c|c|c|c|}
\hline 706 & 3.80 & 428 & -2.730 \\
\hline 708 & 3.90 & 433 & -2.660 \\
\hline 710 & 3.87 & 438 & -2.830 \\
\hline 712 & 3.82 & 443 & -2.600 \\
\hline 713 & 3.83 & 448 & -2.740 \\
\hline 714 & 3.67 & 453 & -2.610 \\
\hline 716 & 3.90 & 458 & -2.520 \\
\hline 718 & 3.70 & 463 & -2.590 \\
\hline 720 & 3.70 & 468 & -2.530 \\
\hline 722 & 3.66 & 473 & -3.020 \\
\hline 723 & 3.93 & 478 & -2.920 \\
\hline 724 & 3.78 & 483 & -2.520 \\
\hline 726 & 3.71 & 488 & -2.620 \\
\hline 728 & 3.94 & 493 & -2.430 \\
\hline 730 & 3.49 & 498 & -2.290 \\
\hline 732 & 3.55 & 503 & -2.930 \\
\hline 733 & 3.57 & 508 & -2.870 \\
\hline 734 & 3.92 & 513 & -2.560 \\
\hline 736 & 3.80 & 518 & -2.580 \\
\hline 738 & 4.01 & 523 & -2.650 \\
\hline 740 & 3.72 & 528 & -2.610 \\
\hline 742 & 3.76 & 533 & -2.550 \\
\hline 743 & 3.41 & 538 & -2.480 \\
\hline 744 & 3.67 & 543 & -2.610 \\
\hline 746 & 3.50 & 548 & -2.320 \\
\hline 748 & 3.41 & 553 & -2.870 \\
\hline 750 & 3.61 & 558 & -2.600 \\
\hline 752 & 3.74 & 563 & -2.380 \\
\hline 753 & 3.34 & 568 & -2.440 \\
\hline 754 & 3.38 & 573 & -2.430 \\
\hline 756 & 3.53 & 578 & -2.560 \\
\hline 758 & 3.55 & 583 & -2.500 \\
\hline 760 & 3.71 & 588 & -2.350 \\
\hline 762 & 3.54 & 593 & -2.640 \\
\hline 763 & 3.63 & 598 & -2.300 \\
\hline 764 & 3.41 & 602 & -2.340 \\
\hline 766 & 3.53 & 603 & -2.510 \\
\hline 768 & 3.32 & 604 & -2.340 \\
\hline 770 & 3.66 & 606 & -2.260 \\
\hline 772 & 3.54 & 608 & -2.350 \\
\hline 773 & 3.39 & 610 & -2.230 \\
\hline 774 & 3.34 & 612 & -2.320 \\
\hline 776 & 3.21 & 613 & -2.440 \\
\hline 780 & 3.41 & 614 & -2.130 \\
\hline 782 & 3.65 & 616 & -2.130 \\
\hline 783 & 3.15 & 618 & -2.090 \\
\hline 783 & 3.48 & 620 & -2.190 \\
\hline 784 & 3.34 & 622 & -2.320 \\
\hline 786 & 3.70 & 623 & -2.160 \\
\hline
\end{tabular}




\begin{tabular}{|c|c|c|c|}
\hline 788 & 3.44 & 624 & -2.140 \\
\hline 790 & 3.56 & 626 & -2.160 \\
\hline 792 & 3.57 & 628 & -2.100 \\
\hline 793 & 3.47 & 630 & -2.150 \\
\hline 794 & 3.57 & 632 & -2.260 \\
\hline 796 & 3.51 & 633 & -1.900 \\
\hline 798 & 3.29 & 634 & -2.020 \\
\hline 800 & 3.45 & 636 & -2.110 \\
\hline 802 & 3.42 & 638 & -1.730 \\
\hline 803 & 3.14 & 640 & -2.030 \\
\hline 804 & 3.60 & 642 & -1.900 \\
\hline 806 & 3.51 & 643 & -1.900 \\
\hline 808 & 3.40 & 644 & -1.870 \\
\hline 810 & 3.40 & 646 & -1.960 \\
\hline 812 & 3.62 & 648 & -1.870 \\
\hline 813 & 3.56 & 650 & -1.720 \\
\hline 814 & 3.61 & 652 & -1.700 \\
\hline 816 & 3.57 & 653 & -1.720 \\
\hline 818 & 3.63 & 654 & -1.770 \\
\hline 820 & 3.58 & 656 & -1.660 \\
\hline 822 & 3.74 & 658 & -1.520 \\
\hline 823 & 3.42 & 660 & -1.530 \\
\hline 824 & 3.74 & 662 & -1.670 \\
\hline 826 & 3.34 & 663 & -1.630 \\
\hline 828 & 3.39 & 664 & -1.910 \\
\hline 830 & 3.86 & 666 & -1.630 \\
\hline 832 & 3.62 & 668 & -1.740 \\
\hline 833 & 3.37 & 670 & -1.920 \\
\hline 834 & 3.26 & 672 & -1.840 \\
\hline 836 & 3.42 & 673 & -1.770 \\
\hline 838 & 3.18 & 674 & -1.940 \\
\hline 840 & 3.38 & 676 & -1.920 \\
\hline 842 & 3.47 & 678 & -1.660 \\
\hline 843 & 3.33 & 680 & -1.620 \\
\hline 844 & 3.37 & 682 & -1.720 \\
\hline 846 & 3.24 & 683 & -1.660 \\
\hline 848 & 3.49 & 684 & -1.660 \\
\hline 850 & 3.33 & 686 & -1.430 \\
\hline 852 & 3.57 & 688 & -1.550 \\
\hline 853 & 3.56 & 690 & -1.570 \\
\hline 854 & 3.60 & 692 & -1.890 \\
\hline 856 & 3.43 & 693 & -1.780 \\
\hline 858 & 3.69 & 694 & -1.620 \\
\hline 860 & 3.48 & 696 & -2.020 \\
\hline 862 & 3.19 & 698 & -1.440 \\
\hline 863 & 3.49 & 700 & -1.700 \\
\hline 864 & 3.22 & 702 & -1.830 \\
\hline 866 & 3.26 & 703 & -1.580 \\
\hline 868 & 3.44 & 704 & -1.810 \\
\hline
\end{tabular}




\begin{tabular}{|c|c|c|c|}
\hline 870 & 3.48 & 706 & -1.750 \\
\hline 872 & 3.63 & 708 & -1.510 \\
\hline 873 & 3.60 & 710 & -1.800 \\
\hline 874 & 3.51 & 712 & -1.420 \\
\hline 876 & 3.52 & 713 & -1.650 \\
\hline 878 & 3.55 & 714 & -1.350 \\
\hline 880 & 3.54 & 716 & -1.500 \\
\hline 882 & 3.48 & 718 & -1.360 \\
\hline 883 & 3.56 & 720 & -1.420 \\
\hline 884 & 3.36 & 722 & -1.360 \\
\hline 888 & 3.51 & 723 & -1.620 \\
\hline 890 & 3.34 & 724 & -1.560 \\
\hline 892 & 3.40 & 726 & -1.360 \\
\hline 893 & 3.28 & 728 & -1.310 \\
\hline 894 & 3.44 & 730 & -1.070 \\
\hline 896 & 3.48 & 732 & -0.960 \\
\hline 898 & 3.63 & 733 & -1.200 \\
\hline 900 & 3.44 & 734 & -1.240 \\
\hline 902 & 3.39 & 736 & -1.480 \\
\hline 903 & 3.54 & 738 & -1.210 \\
\hline 904 & 3.52 & 740 & -1.140 \\
\hline 906 & 3.33 & 742 & -1.070 \\
\hline 908 & 3.26 & 743 & -1.100 \\
\hline 910 & 3.62 & 744 & -1.120 \\
\hline 912 & 3.51 & 746 & -1.060 \\
\hline 913 & 3.51 & 748 & -0.930 \\
\hline 914 & 3.34 & 750 & -1.070 \\
\hline 916 & 3.37 & 752 & -0.950 \\
\hline 918 & 3.34 & 753 & -0.950 \\
\hline 920 & 3.49 & 754 & -0.990 \\
\hline 922 & 3.36 & 756 & -0.800 \\
\hline 923 & 3.34 & 758 & -1.020 \\
\hline 924 & 3.45 & 760 & -0.820 \\
\hline 926 & 3.09 & 762 & -1.220 \\
\hline 928 & 3.34 & 763 & -1.170 \\
\hline 930 & 3.59 & 764 & -1.100 \\
\hline 932 & 3.57 & 766 & -1.050 \\
\hline 933 & 3.35 & 768 & -1.110 \\
\hline 934 & 3.47 & 770 & -0.840 \\
\hline 936 & 3.25 & 772 & -1.220 \\
\hline 938 & 3.48 & 773 & -1.310 \\
\hline 940 & 3.26 & 774 & -1.480 \\
\hline 942 & 3.13 & 776 & -0.930 \\
\hline 943 & 3.43 & 778 & -1.330 \\
\hline 944 & 3.28 & 780 & -1.100 \\
\hline 946 & 3.43 & 782 & -1.240 \\
\hline 948 & 3.63 & 783 & -1.010 \\
\hline 950 & 3.45 & 784 & -1.340 \\
\hline 952 & 3.51 & 786 & -1.200 \\
\hline
\end{tabular}




\begin{tabular}{|c|c|c|c|}
\hline 953 & 3.49 & 788 & -0.930 \\
\hline 954 & 3.81 & 790 & -1.400 \\
\hline \multirow[t]{47}{*}{956} & 3.56 & 792 & -1.010 \\
\hline & & 793 & -1.120 \\
\hline & & 794 & -0.990 \\
\hline & & 796 & -1.040 \\
\hline & & 798 & -1.040 \\
\hline & & 800 & -1.190 \\
\hline & & 802 & -1.060 \\
\hline & & 803 & -1.060 \\
\hline & & 804 & -1.170 \\
\hline & & 806 & -1.100 \\
\hline & & 808 & -1.240 \\
\hline & & 810 & -1.220 \\
\hline & & 812 & -1.090 \\
\hline & & 813 & -0.880 \\
\hline & & 814 & -1.420 \\
\hline & & 816 & -1.250 \\
\hline & & 818 & -1.410 \\
\hline & & 822 & -1.220 \\
\hline & & 823 & -1.230 \\
\hline & & 824 & -0.910 \\
\hline & & 826 & -1.250 \\
\hline & & 828 & -1.550 \\
\hline & & 830 & -0.900 \\
\hline & & 832 & -0.850 \\
\hline & & 833 & -1.080 \\
\hline & & 834 & -1.260 \\
\hline & & 836 & -1.210 \\
\hline & & 838 & -1.210 \\
\hline & & 840 & -1.140 \\
\hline & & 842 & -1.040 \\
\hline & & 843 & -1.440 \\
\hline & & 844 & -1.130 \\
\hline & & 846 & -1.230 \\
\hline & & 848 & -1.150 \\
\hline & & 850 & -1.150 \\
\hline & & 852 & -1.190 \\
\hline & & 853 & -0.980 \\
\hline & & 854 & -1.090 \\
\hline & & 856 & -1.320 \\
\hline & & 858 & -1.150 \\
\hline & & 860 & -1.370 \\
\hline & & 862 & -1.430 \\
\hline & & 863 & -1.380 \\
\hline & & 864 & -1.280 \\
\hline & & 866 & -1.360 \\
\hline & & 868 & -1.200 \\
\hline & & 870 & -1.440 \\
\hline
\end{tabular}




\begin{tabular}{ll}
872 & -1.360 \\
873 & -1.330 \\
874 & -1.360 \\
876 & -1.500 \\
878 & -1.340 \\
880 & -1.540 \\
882 & -0.980 \\
883 & -1.330 \\
884 & -1.370 \\
886 & -1.380 \\
888 & -1.420 \\
890 & -1.370 \\
892 & -1.250 \\
893 & -1.400 \\
894 & -1.210 \\
896 & -1.350 \\
898 & -1.140 \\
900 & -1.130 \\
902 & -1.230 \\
903 & -0.900 \\
904 & -1.190 \\
906 & -1.130 \\
908 & -1.210 \\
910 & -1.350 \\
912 & -1.100 \\
913 & -1.320 \\
914 & -1.120 \\
916 & -1.100 \\
918 & -1.390 \\
920 & -1.600 \\
922 & -1.320 \\
923 & -1.460 \\
924 & -1.460 \\
926 & -1.340 \\
928 & -1.260 \\
930 & -1.350 \\
932 & -1.330 \\
933 & -1.470 \\
934 & -1.260 \\
936 & -1.500 \\
938 & -1.300 \\
940 & -1.570 \\
942 & -1.320 \\
943 & -1.410 \\
944 & -1.350 \\
946 & -1.330 \\
948 & -1.610 \\
950 & -1.660 \\
952 & -1.370 \\
\hline & \\
\hline
\end{tabular}




$$
\begin{array}{ll}
953 & -1.630 \\
954 & -1.280 \\
956 & -1.450
\end{array}
$$

$\begin{array}{cccc}\text { GeoB10069-3 } & \begin{array}{c}\text { P. obliquiloculata } \\ \text { Mg/Ca }\end{array} & \begin{array}{c}\text { Depth } \\ \text { Depth (cm) }\end{array} & \begin{array}{c}\mathbf{1 8} \mathbf{O} \\ \text { (m)oo PDB }\end{array} \\ 3 & 4.10 & 1 & -2.037 \\ 8 & 4.68 & 2 & -1.691 \\ 13 & 3.84 & 3 & -1.977 \\ 18 & 3.72 & 4 & -1.847 \\ 23 & 3.85 & 6 & -2.061 \\ 28 & 3.83 & 7 & -1.548 \\ 33 & 3.77 & 8 & -1.935 \\ 38 & 4.28 & 9 & -1.666 \\ 43 & 3.81 & 11 & -1.727 \\ 48 & 3.99 & 13 & -1.779 \\ 53 & 3.93 & 14 & -1.388 \\ 58 & 4.04 & 15 & -1.956 \\ 63 & 4.36 & 16 & -1.934 \\ 68 & 3.93 & 17 & -1.879 \\ 73 & 4.07 & 18 & -1.864 \\ 78 & 4.03 & 19 & -1.748 \\ 83 & 4.09 & 20 & -2.506 \\ 88 & 3.70 & 21 & -1.413 \\ 93 & 3.83 & 22 & -1.531 \\ 98 & 3.89 & 23 & -1.990 \\ 103 & 4.12 & 24 & -1.825 \\ 108 & 4.01 & 25 & -1.426 \\ 113 & 4.10 & 26 & -1.647 \\ 118 & 4.17 & 27 & -1.530 \\ 123 & 3.99 & 28 & -1.558 \\ 128 & 4.28 & 29 & -1.563 \\ 133 & 4.11 & 30 & -1.331 \\ 138 & 4.27 & 31 & -1.378 \\ 143 & 3.81 & 32 & -1.817 \\ 148 & 4.16 & 33 & -1.375 \\ 153 & 3.93 & 34 & -1.516 \\ 158 & 3.87 & 35 & -1.000 \\ 163 & 4.12 & 36 & -1.434 \\ 173 & 3.87 & 37 & -1.229 \\ 178 & 3.81 & 38 & -1.717 \\ 183 & 3.84 & 40 & -1.227 \\ 188 & 4.28 & 41 & -1.533 \\ 193 & 4.13 & 42 & -1.311 \\ 198 & 3.90 & 43 & -1.386 \\ 203 & 4.95 & -1.216 \\ 208 & & 46 & -0.724\end{array}$




\begin{tabular}{|c|c|c|c|}
\hline 213 & 3.86 & 47 & -1.165 \\
\hline 218 & 4.26 & 48 & -1.586 \\
\hline 223 & 4.34 & 49 & -1.379 \\
\hline 228 & 3.83 & 50 & -1.327 \\
\hline 233 & 4.06 & 51 & -1.404 \\
\hline 238 & 3.96 & 52 & -1.503 \\
\hline 243 & 4.02 & 53 & -1.265 \\
\hline 248 & 4.08 & 54 & -1.413 \\
\hline 253 & 4.13 & 55 & -1.414 \\
\hline 258 & 4.21 & 56 & -2.154 \\
\hline 263 & 3.89 & 57 & -0.862 \\
\hline 268 & 3.93 & 58 & -2.047 \\
\hline 273 & 4.16 & 59 & -1.570 \\
\hline 278 & 4.00 & 60 & -1.312 \\
\hline 283 & 4.09 & 61 & -2.136 \\
\hline 288 & 4.29 & 62 & -1.694 \\
\hline 293 & 4.39 & 63 & -1.725 \\
\hline 298 & 4.17 & 65 & -1.464 \\
\hline 303 & 4.19 & 67 & -1.441 \\
\hline 308 & 3.83 & 68 & -1.729 \\
\hline 313 & 4.23 & 70 & -1.379 \\
\hline 318 & 3.83 & 70 & -1.388 \\
\hline 323 & 4.12 & 71 & -1.467 \\
\hline 328 & 4.32 & 72 & -1.447 \\
\hline 333 & 4.09 & 73 & -1.784 \\
\hline 338 & 4.13 & 74 & -1.746 \\
\hline 343 & 4.16 & 75 & -1.553 \\
\hline 348 & 4.24 & 76 & -2.040 \\
\hline 353 & 4.29 & 77 & -1.584 \\
\hline 358 & 4.19 & 78 & -2.094 \\
\hline 363 & 4.18 & 79 & -1.629 \\
\hline 368 & 4.36 & 80 & -1.730 \\
\hline 373 & 4.20 & 81 & -1.454 \\
\hline 378 & 4.18 & 82 & -1.705 \\
\hline 383 & 4.07 & 83 & -1.671 \\
\hline 388 & 4.02 & 84 & -1.785 \\
\hline 393 & 4.19 & 85 & -1.635 \\
\hline 398 & 4.36 & 86 & -1.879 \\
\hline 403 & 4.13 & 87 & -1.611 \\
\hline 408 & 4.21 & 88 & -1.484 \\
\hline 413 & 4.43 & 89 & -1.214 \\
\hline 418 & 4.20 & 90 & -1.954 \\
\hline 423 & 4.16 & 91 & -1.349 \\
\hline 428 & 4.49 & 92 & -1.501 \\
\hline 433 & 4.31 & 93 & -1.623 \\
\hline 438 & 4.19 & 94 & -1.848 \\
\hline 443 & 4.17 & 95 & -1.679 \\
\hline 449 & 4.52 & 96 & -1.453 \\
\hline 453 & 4.17 & 97 & -1.651 \\
\hline
\end{tabular}




\begin{tabular}{|c|c|c|c|}
\hline 458 & 4.33 & 98 & -1.757 \\
\hline 463 & 4.09 & 99 & -1.385 \\
\hline 468 & 4.27 & 100 & -1.738 \\
\hline 473 & 4.22 & 101 & -1.473 \\
\hline 478 & 4.16 & 102 & -1.521 \\
\hline 483 & 4.34 & 103 & -1.475 \\
\hline 488 & 4.29 & 104 & -1.798 \\
\hline 493 & 4.18 & 105 & -1.949 \\
\hline 498 & 3.93 & 106 & -1.563 \\
\hline 503 & 4.15 & 107 & -1.842 \\
\hline 508 & 4.28 & 108 & -1.815 \\
\hline 513 & 4.40 & 109 & -1.794 \\
\hline 518 & 4.34 & 110 & -1.758 \\
\hline 523 & 4.14 & 111 & -1.378 \\
\hline 528 & 4.14 & 112 & -1.806 \\
\hline 533 & 4.43 & 113 & -1.931 \\
\hline 538 & 4.16 & 114 & -1.725 \\
\hline 543 & 4.14 & 115 & -1.588 \\
\hline 548 & 4.31 & 116 & -2.145 \\
\hline 553 & 4.31 & 117 & -1.510 \\
\hline 563 & 4.35 & 118 & -1.975 \\
\hline 568 & 4.43 & 119 & -1.979 \\
\hline 573 & 4.39 & 120 & -1.824 \\
\hline 578 & 4.37 & 121 & -1.569 \\
\hline 583 & 4.65 & 122 & -2.015 \\
\hline 588 & 4.72 & 123 & -1.925 \\
\hline 593 & 4.16 & 124 & -2.134 \\
\hline 598 & 4.84 & 125 & -2.053 \\
\hline 602 & 4.52 & 126 & -1.812 \\
\hline 603 & 4.55 & 127 & -1.629 \\
\hline 604 & 4.35 & 128 & -1.815 \\
\hline 606 & 4.25 & 129 & -1.797 \\
\hline 610 & 4.76 & 130 & -2.265 \\
\hline 612 & 4.22 & 131 & -1.962 \\
\hline 613 & 4.66 & 132 & -1.823 \\
\hline 614 & 4.11 & 133 & -1.856 \\
\hline 616 & 4.48 & 138 & -1.812 \\
\hline 618 & 4.43 & 143 & -1.542 \\
\hline 620 & 4.33 & 148 & -1.549 \\
\hline 622 & 4.29 & 153 & -1.583 \\
\hline 623 & 4.40 & 158 & -1.662 \\
\hline 624 & 4.17 & 163 & -1.790 \\
\hline 626 & 4.29 & 168 & -1.266 \\
\hline 628 & 4.22 & 173 & -1.528 \\
\hline 630 & 4.47 & 178 & -1.650 \\
\hline 632 & 4.43 & 183 & -1.589 \\
\hline 633 & 4.35 & 188 & -1.672 \\
\hline 634 & 4.49 & 193 & -1.553 \\
\hline 636 & 4.70 & 198 & -1.674 \\
\hline
\end{tabular}




\begin{tabular}{|c|c|c|c|}
\hline 638 & 4.41 & 203 & -1.494 \\
\hline 640 & 4.42 & 208 & -1.657 \\
\hline 642 & 4.66 & 213 & -1.518 \\
\hline 643 & 4.40 & 218 & -1.536 \\
\hline 644 & 4.16 & 223 & -1.641 \\
\hline 646 & 4.32 & 228 & -1.590 \\
\hline 648 & 4.16 & 233 & -1.558 \\
\hline 650 & 4.39 & 238 & -1.147 \\
\hline 652 & 4.11 & 243 & -1.443 \\
\hline 653 & 4.08 & 248 & -1.315 \\
\hline 654 & 4.61 & 253 & -1.603 \\
\hline 656 & 4.29 & 258 & -1.511 \\
\hline 658 & 3.93 & 263 & -1.420 \\
\hline 660 & 3.94 & 268 & -1.547 \\
\hline 662 & 4.57 & 273 & -1.786 \\
\hline 663 & 3.80 & 278 & -1.765 \\
\hline 664 & 3.91 & 283 & -1.569 \\
\hline 666 & 3.99 & 288 & -1.423 \\
\hline 668 & 3.74 & 293 & -1.448 \\
\hline 670 & 4.20 & 298 & -1.355 \\
\hline 672 & 3.81 & 303 & -1.551 \\
\hline 673 & 3.86 & 308 & -1.161 \\
\hline 674 & 4.13 & 313 & -1.687 \\
\hline 676 & 4.09 & 318 & -2.002 \\
\hline 678 & 3.89 & 323 & -1.488 \\
\hline 680 & 4.38 & 328 & -1.467 \\
\hline 682 & 3.90 & 333 & -1.721 \\
\hline 683 & 3.95 & 338 & -1.806 \\
\hline 684 & 4.17 & 343 & -1.699 \\
\hline 686 & 3.91 & 348 & -1.763 \\
\hline 688 & 4.00 & 353 & -1.933 \\
\hline 692 & 3.92 & 358 & -1.591 \\
\hline 693 & 3.73 & 363 & -1.831 \\
\hline 694 & 3.84 & 368 & -1.642 \\
\hline 696 & 4.03 & 373 & -1.385 \\
\hline 698 & 4.18 & 378 & -1.285 \\
\hline 700 & 3.94 & 383 & -1.298 \\
\hline 702 & 3.99 & 388 & -1.801 \\
\hline 703 & 4.05 & 393 & -1.549 \\
\hline 704 & 3.76 & 398 & -1.658 \\
\hline 706 & 3.80 & 403 & -1.365 \\
\hline 708 & 3.90 & 408 & -1.584 \\
\hline 710 & 3.87 & 413 & -1.892 \\
\hline 712 & 3.82 & 418 & -1.576 \\
\hline 713 & 3.83 & 423 & -1.518 \\
\hline 714 & 3.67 & 428 & -1.517 \\
\hline 716 & 3.90 & 433 & -1.709 \\
\hline 718 & 3.70 & 438 & -1.719 \\
\hline 720 & 3.70 & 443 & -1.482 \\
\hline
\end{tabular}




\begin{tabular}{|c|c|c|c|}
\hline 722 & 3.66 & 449 & -1.830 \\
\hline 723 & 3.93 & 453 & -1.757 \\
\hline 724 & 3.78 & 458 & -1.523 \\
\hline 726 & 3.71 & 463 & -1.592 \\
\hline 728 & 3.94 & 468 & -1.647 \\
\hline 730 & 3.49 & 473 & -1.562 \\
\hline 732 & 3.55 & 478 & -1.977 \\
\hline 733 & 3.57 & 483 & -1.700 \\
\hline 734 & 3.92 & 488 & -1.449 \\
\hline 736 & 3.80 & 493 & -1.461 \\
\hline 738 & 4.01 & 498 & -1.545 \\
\hline 740 & 3.72 & 503 & -1.460 \\
\hline 742 & 3.76 & 508 & -1.446 \\
\hline 743 & 3.41 & 513 & -1.558 \\
\hline 744 & 3.67 & 518 & -1.455 \\
\hline 746 & 3.50 & 523 & -1.473 \\
\hline 748 & 3.41 & 528 & -1.721 \\
\hline 750 & 3.61 & 533 & -1.523 \\
\hline 752 & 3.74 & 538 & -1.349 \\
\hline 753 & 3.34 & 543 & -1.617 \\
\hline 754 & 3.38 & 548 & -1.426 \\
\hline 756 & 3.53 & 553 & -1.403 \\
\hline 758 & 3.55 & 557 & -1.390 \\
\hline 760 & 3.71 & 563 & -1.032 \\
\hline 762 & 3.54 & 568 & -1.321 \\
\hline 763 & 3.63 & 573 & -1.359 \\
\hline 764 & 3.41 & 578 & -1.601 \\
\hline 766 & 3.53 & 583 & -1.203 \\
\hline 768 & 3.32 & 588 & -1.325 \\
\hline 770 & 3.66 & 593 & -1.516 \\
\hline 772 & 3.54 & 598 & -1.144 \\
\hline 773 & 3.39 & 602 & -0.958 \\
\hline 774 & 3.34 & 603 & -0.938 \\
\hline 776 & 3.21 & 604 & -0.906 \\
\hline 780 & 3.41 & 606 & -1.033 \\
\hline 782 & 3.65 & 608 & -1.177 \\
\hline 783 & 3.15 & 610 & -1.154 \\
\hline 783 & 3.48 & 612 & -0.990 \\
\hline 784 & 3.34 & 613 & -1.061 \\
\hline 786 & 3.70 & 614 & -0.784 \\
\hline 788 & 3.44 & 616 & -1.115 \\
\hline 790 & 3.56 & 618 & -0.931 \\
\hline 792 & 3.57 & 620 & -1.228 \\
\hline 793 & 3.47 & 622 & -0.760 \\
\hline 794 & 3.57 & 623 & -0.879 \\
\hline 796 & 3.51 & 626 & -1.095 \\
\hline 798 & 3.29 & 628 & -0.597 \\
\hline 800 & 3.45 & 630 & -1.003 \\
\hline 802 & 3.42 & 632 & -0.794 \\
\hline
\end{tabular}




\begin{tabular}{|c|c|c|c|}
\hline 803 & 3.14 & 633 & -0.625 \\
\hline 804 & 3.60 & 634 & -0.675 \\
\hline 806 & 3.51 & 636 & -0.743 \\
\hline 808 & 3.40 & 638 & -0.710 \\
\hline 810 & 3.40 & 640 & -0.208 \\
\hline 812 & 3.62 & 642 & -0.322 \\
\hline 813 & 3.56 & 643 & -0.185 \\
\hline 814 & 3.61 & 644 & -0.253 \\
\hline 816 & 3.57 & 646 & -0.711 \\
\hline 818 & 3.63 & 648 & -0.246 \\
\hline 820 & 3.58 & 650 & -0.086 \\
\hline 822 & 3.74 & 652 & -0.278 \\
\hline 823 & 3.42 & 653 & -0.025 \\
\hline 824 & 3.74 & 654 & -0.252 \\
\hline 826 & 3.34 & 656 & -0.226 \\
\hline 828 & 3.39 & 658 & -0.411 \\
\hline 830 & 3.86 & 660 & -0.056 \\
\hline 832 & 3.62 & 662 & -0.262 \\
\hline 833 & 3.37 & 663 & -0.018 \\
\hline 834 & 3.26 & 664 & -0.155 \\
\hline 836 & 3.42 & 666 & -0.216 \\
\hline 838 & 3.18 & 668 & -0.310 \\
\hline 840 & 3.38 & 670 & -0.212 \\
\hline 842 & 3.47 & 672 & -0.419 \\
\hline 843 & 3.33 & 673 & -0.225 \\
\hline 844 & 3.37 & 674 & -0.134 \\
\hline 846 & 3.24 & 676 & -0.522 \\
\hline 848 & 3.49 & 678 & -0.291 \\
\hline 850 & 3.33 & 683 & -0.172 \\
\hline 852 & 3.57 & 688 & -0.174 \\
\hline 853 & 3.56 & 693 & -0.361 \\
\hline 854 & 3.60 & 698 & -0.448 \\
\hline 856 & 3.43 & 703 & -0.212 \\
\hline 858 & 3.69 & 708 & 0.345 \\
\hline 860 & 3.48 & 713 & -0.011 \\
\hline 862 & 3.19 & 716 & -0.345 \\
\hline 863 & 3.49 & 718 & 0.148 \\
\hline 864 & 3.22 & 720 & 0.080 \\
\hline 866 & 3.26 & 722 & -0.074 \\
\hline 868 & 3.44 & 723 & 0.102 \\
\hline 870 & 3.48 & 724 & 0.104 \\
\hline 872 & 3.63 & 728 & 0.239 \\
\hline 873 & 3.60 & 730 & -0.163 \\
\hline 874 & 3.51 & 732 & 0.118 \\
\hline 876 & 3.52 & 733 & 0.031 \\
\hline 878 & 3.55 & 734 & 0.299 \\
\hline 880 & 3.54 & 738 & 0.242 \\
\hline 882 & 3.48 & 740 & 0.090 \\
\hline 883 & 3.56 & 742 & -0.164 \\
\hline
\end{tabular}




\begin{tabular}{|c|c|c|c|}
\hline 884 & 3.36 & 743 & 0.285 \\
\hline 888 & 3.51 & 744 & 0.351 \\
\hline 890 & 3.34 & 746 & -0.306 \\
\hline 892 & 3.40 & 748 & -0.114 \\
\hline 893 & 3.28 & 750 & 0.353 \\
\hline 894 & 3.44 & 752 & 0.501 \\
\hline 896 & 3.48 & 753 & 0.469 \\
\hline 898 & 3.63 & 754 & 0.258 \\
\hline 900 & 3.44 & 756 & 0.181 \\
\hline 902 & 3.39 & 758 & 0.283 \\
\hline 903 & 3.54 & 760 & 0.199 \\
\hline 904 & 3.52 & 762 & 0.213 \\
\hline 906 & 3.33 & 763 & -0.062 \\
\hline 908 & 3.26 & 764 & -0.025 \\
\hline 910 & 3.62 & 768 & 0.158 \\
\hline 912 & 3.51 & 773 & -0.065 \\
\hline 913 & 3.51 & 783 & 0.001 \\
\hline 914 & 3.34 & 783 & -0.116 \\
\hline 916 & 3.37 & 788 & 0.167 \\
\hline 918 & 3.34 & 793 & -0.030 \\
\hline 920 & 3.49 & 798 & 0.003 \\
\hline 922 & 3.36 & 803 & -0.153 \\
\hline 923 & 3.34 & 808 & -0.009 \\
\hline 928 & 3.34 & 813 & 0.103 \\
\hline 933 & 3.35 & 818 & -0.051 \\
\hline 938 & 3.48 & 823 & -0.121 \\
\hline 943 & 3.43 & 828 & 0.151 \\
\hline 948 & 3.63 & 833 & -0.069 \\
\hline \multirow[t]{21}{*}{953} & 3.49 & 838 & 0.117 \\
\hline & & 843 & 0.296 \\
\hline & & 848 & 0.121 \\
\hline & & 853 & 0.247 \\
\hline & & 858 & 0.020 \\
\hline & & 863 & -0.205 \\
\hline & & 868 & -0.250 \\
\hline & & 873 & -0.052 \\
\hline & & 878 & -0.148 \\
\hline & & 883 & 0.300 \\
\hline & & 888 & -0.069 \\
\hline & & 893 & -0.049 \\
\hline & & 898 & 0.124 \\
\hline & & 903 & 0.211 \\
\hline & & 908 & -0.162 \\
\hline & & 913 & -0.030 \\
\hline & & 918 & -0.015 \\
\hline & & 923 & -0.198 \\
\hline & & 928 & -0.129 \\
\hline & & 933 & -0.083 \\
\hline & & 938 & -0.006 \\
\hline
\end{tabular}




$\begin{array}{ll}943 & -0.140 \\ 948 & -0.365 \\ 953 & 0.046\end{array}$

\begin{tabular}{|c|c|c|c|}
\hline $\begin{array}{l}\text { BJ8-03 } \\
\text { 70GGC } \\
\text { Depth }(\mathrm{cm})\end{array}$ & $\begin{array}{c}\text { P. } \\
\text { obliquiloculata } \\
\mathrm{Mg} / \mathrm{Ca} \\
\text { (mmol/mol) }\end{array}$ & $\begin{array}{c}\text { Depth } \\
(\mathbf{c m})\end{array}$ & $\begin{array}{c}\delta^{18} 0 \\
\% \text { PDB }\end{array}$ \\
\hline 7.5 & 2.51 & 7.5 & -2.168 \\
\hline 9.5 & 2.98 & 8.5 & -1.746 \\
\hline 13.5 & 2.85 & 13.5 & -1.992 \\
\hline 15.5 & 2.37 & 21.5 & -2.143 \\
\hline 17.5 & 2.75 & 29.5 & -1.987 \\
\hline 21.5 & 2.37 & 15.5 & -1.969 \\
\hline 23.5 & 2.56 & 23.5 & -1.953 \\
\hline 24.5 & 2.97 & 24.5 & -2.269 \\
\hline 25.5 & 2.44 & 31.5 & -2.172 \\
\hline 29.5 & 3.08 & 32.5 & -1.948 \\
\hline 31.5 & 2.75 & 37.5 & -2.365 \\
\hline 32.5 & 2.37 & 39.5 & -2.043 \\
\hline 33.5 & 2.91 & 45.5 & -2.291 \\
\hline 37.5 & 2.60 & 47.5 & -2.244 \\
\hline 39.5 & 2.65 & 48.5 & -2.137 \\
\hline 41.5 & 2.75 & 53.5 & -2.070 \\
\hline 45.5 & 2.78 & 56.5 & -1.869 \\
\hline 47.5 & 2.72 & 61.5 & -1.267 \\
\hline 48.5 & 2.68 & 69.5 & -2.025 \\
\hline 49.5 & 2.60 & 72.5 & -2.019 \\
\hline 53.5 & 2.86 & 77.5 & -2.210 \\
\hline 56.5 & 2.89 & 80.5 & -2.148 \\
\hline 57.5 & 2.77 & 85.5 & -2.053 \\
\hline 61.5 & 2.80 & 88.5 & -2.091 \\
\hline 65.5 & 2.67 & 93.5 & -1.923 \\
\hline 69.5 & 2.59 & 101.5 & -1.933 \\
\hline 72.5 & 2.49 & 109.5 & -1.724 \\
\hline 73.5 & 2.62 & 125.5 & -1.572 \\
\hline 77.5 & 2.35 & 133.5 & -2.028 \\
\hline 80.5 & 2.94 & 136.5 & -2.068 \\
\hline 81.5 & 2.89 & 141.5 & -1.854 \\
\hline 85.5 & 2.62 & 144.5 & -2.096 \\
\hline 88.5 & 2.45 & 149.5 & -1.912 \\
\hline 89.5 & 3.18 & 152.5 & -1.726 \\
\hline 93.5 & 2.77 & 157.5 & -2.153 \\
\hline 97.5 & 2.55 & 160.5 & -2.016 \\
\hline 101.5 & 2.54 & 165.5 & -2.124 \\
\hline 105.5 & 2.73 & 168.5 & -1.922 \\
\hline 109.5 & 2.83 & 173.5 & -1.939 \\
\hline 113.5 & 2.84 & 181.5 & -1.985 \\
\hline 117.5 & 2.83 & 189.5 & -2.083 \\
\hline
\end{tabular}




\begin{tabular}{|c|c|c|c|}
\hline 121.5 & 2.55 & 192.5 & -1.848 \\
\hline 125.5 & 2.73 & 197.5 & -1.642 \\
\hline 129.5 & 2.49 & 205.5 & -1.989 \\
\hline 133.5 & 2.80 & 208.5 & -1.854 \\
\hline 136.5 & 2.82 & 213.5 & -2.036 \\
\hline 137.5 & 2.80 & 221.5 & -1.677 \\
\hline 141.5 & 2.74 & 229.5 & -1.999 \\
\hline 144.5 & 2.70 & 232.5 & -1.991 \\
\hline 145.5 & 2.73 & 237.5 & -1.735 \\
\hline 149.5 & 3.38 & 240.5 & -1.765 \\
\hline 152.5 & 2.73 & 245.5 & -2.102 \\
\hline 153.5 & 2.81 & 248.5 & -1.914 \\
\hline 157.5 & 2.87 & 253.5 & -1.962 \\
\hline 160.5 & 2.65 & 256.5 & -1.643 \\
\hline 161.5 & 2.67 & 261.5 & -1.864 \\
\hline 165.5 & 2.97 & 264.5 & -1.969 \\
\hline 168.5 & 2.90 & 269.5 & -2.125 \\
\hline 169.5 & 2.68 & 272.5 & -1.926 \\
\hline 173.5 & 2.93 & 277.5 & -2.064 \\
\hline 177.5 & 2.73 & 285.5 & -2.096 \\
\hline 181.5 & 2.66 & 288.5 & -1.889 \\
\hline 185.5 & 3.00 & 293.5 & -1.946 \\
\hline 189.5 & 2.82 & 296.5 & -1.803 \\
\hline 192.5 & 2.63 & 300.5 & -1.826 \\
\hline 193.5 & 2.90 & 301.5 & -2.008 \\
\hline 197.5 & 2.60 & 302.5 & -2.007 \\
\hline 201.5 & 3.06 & 303.5 & -1.791 \\
\hline 205.5 & 2.70 & 306.5 & -1.824 \\
\hline 208.5 & 2.69 & 307.5 & -1.715 \\
\hline 209.5 & 2.93 & 308.5 & -1.790 \\
\hline 213.5 & 3.18 & 310.5 & -1.609 \\
\hline 217.5 & 2.93 & 311.5 & -1.904 \\
\hline 221.5 & 2.72 & 314.5 & -1.682 \\
\hline 225.5 & 3.11 & 315.5 & -1.715 \\
\hline 229.5 & 2.95 & 316.5 & -1.699 \\
\hline 232.5 & 2.98 & 318.5 & -1.628 \\
\hline 233.5 & 2.93 & 319.5 & -1.891 \\
\hline 237.5 & 2.93 & 322.5 & -1.895 \\
\hline 240.5 & 2.57 & 323.5 & -1.829 \\
\hline 245.5 & 2.64 & 324.5 & -1.666 \\
\hline 248.5 & 2.80 & 326.5 & -2.090 \\
\hline 249.5 & 2.83 & 327.5 & -1.676 \\
\hline 253.5 & 2.71 & 330.5 & -1.814 \\
\hline 256.5 & 2.80 & 331.5 & -1.714 \\
\hline 257.5 & 3.38 & 332.5 & -1.718 \\
\hline 261.5 & 2.60 & 334.5 & -1.668 \\
\hline 264.5 & 2.88 & 335.5 & -1.684 \\
\hline 265.5 & 3.11 & 338.5 & -1.724 \\
\hline 269.5 & 2.86 & 339.5 & -1.456 \\
\hline
\end{tabular}




\begin{tabular}{|c|c|c|c|}
\hline 272.5 & 2.74 & 340.5 & -1.388 \\
\hline 273.5 & 2.85 & 342.5 & -1.599 \\
\hline 277.5 & 2.71 & 343.5 & -1.520 \\
\hline 281.5 & 2.77 & 344.5 & -1.533 \\
\hline 285.5 & 2.71 & 346.5 & -1.520 \\
\hline 288.5 & 2.44 & 347.5 & -1.821 \\
\hline 289.5 & 2.90 & 348.5 & -1.418 \\
\hline 293.5 & 2.86 & 349.5 & -1.443 \\
\hline 296.5 & 2.71 & 351.5 & -1.782 \\
\hline 297.5 & 3.13 & 352.5 & -1.564 \\
\hline 300.5 & 2.75 & 354.5 & -1.256 \\
\hline 301.5 & 2.73 & 355.5 & -1.225 \\
\hline 302.5 & 2.92 & 356.5 & -0.805 \\
\hline 303.5 & 2.91 & 358.5 & -1.432 \\
\hline 305 & 3.02 & 359.5 & -1.122 \\
\hline 306.5 & 2.78 & 360.5 & -1.005 \\
\hline 307.5 & 2.73 & 362.5 & -1.042 \\
\hline 308.5 & 2.88 & 363.5 & -1.109 \\
\hline 310.5 & 2.63 & 364.5 & -1.037 \\
\hline 311.5 & 2.77 & 366.5 & -0.968 \\
\hline 314.5 & 2.86 & 367.5 & -0.840 \\
\hline 315.5 & 2.80 & 368.5 & -0.748 \\
\hline 316.5 & 2.88 & 370.5 & -0.645 \\
\hline 318.5 & 3.02 & 371.5 & -0.606 \\
\hline 319.5 & 2.98 & 372.5 & -0.605 \\
\hline 322.5 & 2.69 & 374.5 & -0.597 \\
\hline 323.5 & 2.70 & 375.5 & -0.510 \\
\hline 324.5 & 2.84 & 376.5 & -0.399 \\
\hline 326.5 & 2.86 & 377.5 & -0.613 \\
\hline 327.5 & 3.11 & 379.5 & -0.791 \\
\hline 329.5 & 2.88 & 380.5 & -0.683 \\
\hline 330.5 & 2.78 & 382.5 & -0.649 \\
\hline 331.5 & 2.61 & 383.5 & -0.769 \\
\hline 332.5 & 2.74 & 384.5 & -0.620 \\
\hline 334.5 & 2.82 & 386.5 & -0.559 \\
\hline 335.5 & 2.88 & 387.5 & -0.504 \\
\hline 336.5 & 2.89 & 388.5 & -0.476 \\
\hline 338.5 & 2.89 & 389.5 & -0.636 \\
\hline 339.5 & 2.89 & 391.5 & -0.516 \\
\hline 340.5 & 2.68 & 392.5 & -0.360 \\
\hline 342.5 & 2.80 & 394.5 & -0.450 \\
\hline 343.5 & 2.74 & 395.5 & -0.365 \\
\hline 344.5 & 3.00 & 346.5 & -0.439 \\
\hline 345.5 & 2.94 & 398.5 & -0.443 \\
\hline 346.5 & 2.81 & 399.5 & -0.352 \\
\hline 347.5 & 2.90 & 400.5 & -0.583 \\
\hline 348.5 & 2.90 & 402.5 & -0.459 \\
\hline 349.5 & 3.01 & 403.5 & -0.321 \\
\hline 351.5 & 2.91 & 404.5 & -0.545 \\
\hline
\end{tabular}




\begin{tabular}{|c|c|}
\hline 352.5 & 2.75 \\
\hline 353.5 & 3.20 \\
\hline 354.5 & 2.93 \\
\hline 355.5 & 2.98 \\
\hline 356.5 & 2.83 \\
\hline 358.5 & 2.97 \\
\hline 359.5 & 2.92 \\
\hline 360.5 & 2.71 \\
\hline 361.5 & 2.80 \\
\hline 362.5 & 2.60 \\
\hline 366.5 & 2.50 \\
\hline 367.5 & 2.82 \\
\hline 368.5 & 2.70 \\
\hline 369.5 & 2.50 \\
\hline 370.5 & 2.71 \\
\hline 371.5 & 2.28 \\
\hline 372.5 & 2.40 \\
\hline 374.5 & 2.69 \\
\hline 375.5 & 2.55 \\
\hline 376.5 & 2.44 \\
\hline 377.5 & 2.41 \\
\hline 377.5 & 2.82 \\
\hline 379.5 & 2.67 \\
\hline 380.5 & 2.35 \\
\hline 382.5 & 2.72 \\
\hline 383.5 & 2.84 \\
\hline 384.5 & 2.63 \\
\hline 385.5 & 2.62 \\
\hline 386.5 & 2.56 \\
\hline 387.5 & 2.50 \\
\hline 388.5 & 2.45 \\
\hline 389.5 & 2.49 \\
\hline 391.5 & 2.41 \\
\hline 392.5 & 2.43 \\
\hline 393.5 & 2.73 \\
\hline 394.5 & 2.36 \\
\hline 395.5 & 2.34 \\
\hline 396.5 & 2.49 \\
\hline 398.5 & 2.79 \\
\hline 399.5 & 2.56 \\
\hline 400.5 & 2.46 \\
\hline 401.5 & 2.48 \\
\hline 402.5 & 2.45 \\
\hline 403.5 & 2.69 \\
\hline 404.5 & 2.37 \\
\hline 406.5 & 2.38 \\
\hline
\end{tabular}

BJ8-03

23GGC G. ruber 


\begin{tabular}{|c|c|c|c|}
\hline Depth (cm) & $\begin{array}{c}\mathrm{Mg} / \mathrm{Ca} \\
(\mathrm{mmol} / \mathrm{mol})\end{array}$ & $\begin{array}{l}\text { Depth } \\
\text { (cm) }\end{array}$ & $\begin{array}{c}\delta^{18} 0 \\
\% \text { PDE }\end{array}$ \\
\hline 5.5 & 4.78 & 5.5 & -3.392 \\
\hline 8.5 & 4.38 & 5.5 & -3.477 \\
\hline 24.5 & 4.46 & 6.5 & -3.049 \\
\hline 40.5 & 4.68 & 6.5 & -3.149 \\
\hline 56.5 & 4.68 & 8.5 & -3.316 \\
\hline 72.5 & 4.56 & 8.5 & -3.281 \\
\hline 88.5 & 4.48 & 16.5 & -3.143 \\
\hline 104.5 & 4.58 & 16.5 & -3.154 \\
\hline 120.5 & 4.71 & 24.5 & -3.030 \\
\hline 136.5 & 4.69 & 24.5 & -2.915 \\
\hline 152.5 & 4.58 & 32.5 & -3.053 \\
\hline 168.5 & 4.43 & 32.5 & -3.142 \\
\hline 200.5 & 4.50 & 40.5 & -2.761 \\
\hline 216.5 & 4.57 & 40.5 & -2.901 \\
\hline 232.5 & 4.55 & 48.5 & -3.075 \\
\hline 248.5 & 4.80 & 48.5 & -3.217 \\
\hline 264.5 & 4.66 & 56.5 & -3.178 \\
\hline 280.5 & 4.67 & 56.5 & -3.058 \\
\hline 296.5 & 4.61 & 64.5 & -2.787 \\
\hline 312.5 & 4.69 & 64.5 & -3.025 \\
\hline 328.5 & 5.11 & 72.5 & -3.240 \\
\hline 344.5 & 4.70 & 72.5 & -3.188 \\
\hline 360.5 & 4.57 & 80.5 & -3.179 \\
\hline 376.5 & 4.87 & 80.5 & -3.275 \\
\hline 392.5 & 4.69 & 88.5 & -3.019 \\
\hline \multirow[t]{22}{*}{408.5} & 4.60 & 88.5 & -3.031 \\
\hline & & 96.5 & -3.019 \\
\hline & & 96.5 & -3.141 \\
\hline & & 104.5 & -3.058 \\
\hline & & 104.5 & -3.108 \\
\hline & & 112.5 & -3.062 \\
\hline & & 112.5 & -3.232 \\
\hline & & 120.5 & -3.004 \\
\hline & & 120.5 & -3.270 \\
\hline & & 128.5 & -3.053 \\
\hline & & 128.5 & -2.710 \\
\hline & & 136.5 & -3.082 \\
\hline & & 136.5 & -3.238 \\
\hline & & 144.5 & -3.043 \\
\hline & & 144.5 & -3.047 \\
\hline & & 152.5 & -3.074 \\
\hline & & 152.5 & -3.412 \\
\hline & & 160.5 & -3.263 \\
\hline & & 160.5 & -3.409 \\
\hline & & 168.5 & -2.890 \\
\hline & & 168.5 & -2.883 \\
\hline & & 176.5 & -3.289 \\
\hline
\end{tabular}




$\begin{array}{cc}176.5 & -2.899 \\ 184.5 & -2.868 \\ 184.5 & -3.174 \\ 192.5 & -3.216 \\ 192.5 & -2.976 \\ 200.5 & -2.996 \\ 200.5 & -3.243 \\ 208.5 & -3.184 \\ 208.5 & -3.302 \\ 216.5 & -2.888 \\ 216.5 & -3.291 \\ 224.5 & -3.363 \\ 224.5 & -3.197 \\ 232.5 & -3.228 \\ 232.5 & -3.089 \\ 240.5 & -2.941 \\ 240.5 & -3.241 \\ 248.5 & -3.196 \\ 248.5 & -3.325 \\ 256.5 & -3.294 \\ 256.5 & -2.965 \\ 264.5 & -2.988 \\ 264.5 & -3.139 \\ 272.5 & -3.346 \\ 272.5 & -3.040 \\ 280.5 & -3.172 \\ 280.5 & -3.080 \\ 288.5 & -3.023 \\ 288.5 & -2.961 \\ 296.5 & -3.098 \\ 296.5 & -2.659 \\ 304.5 & -3.068 \\ 304.5 & -3.031 \\ 312.5 & -3.150 \\ 312.5 & -2.835 \\ 324 & -2.832 \\ 324 & -2.853 \\ 328.5 & -2.941 \\ 328.5 & -2.841 \\ 336.5 & -2.895 \\ 336.5 & -3.168 \\ 344.5 & -3.017 \\ 344.5 & -2.717 \\ 352.5 & -2.827 \\ 352.5 & -2.711 \\ 360.5 & -2.953 \\ 360.5 & -2.601 \\ 368.5 & -3.120 \\ 368.5 & -3.251\end{array}$




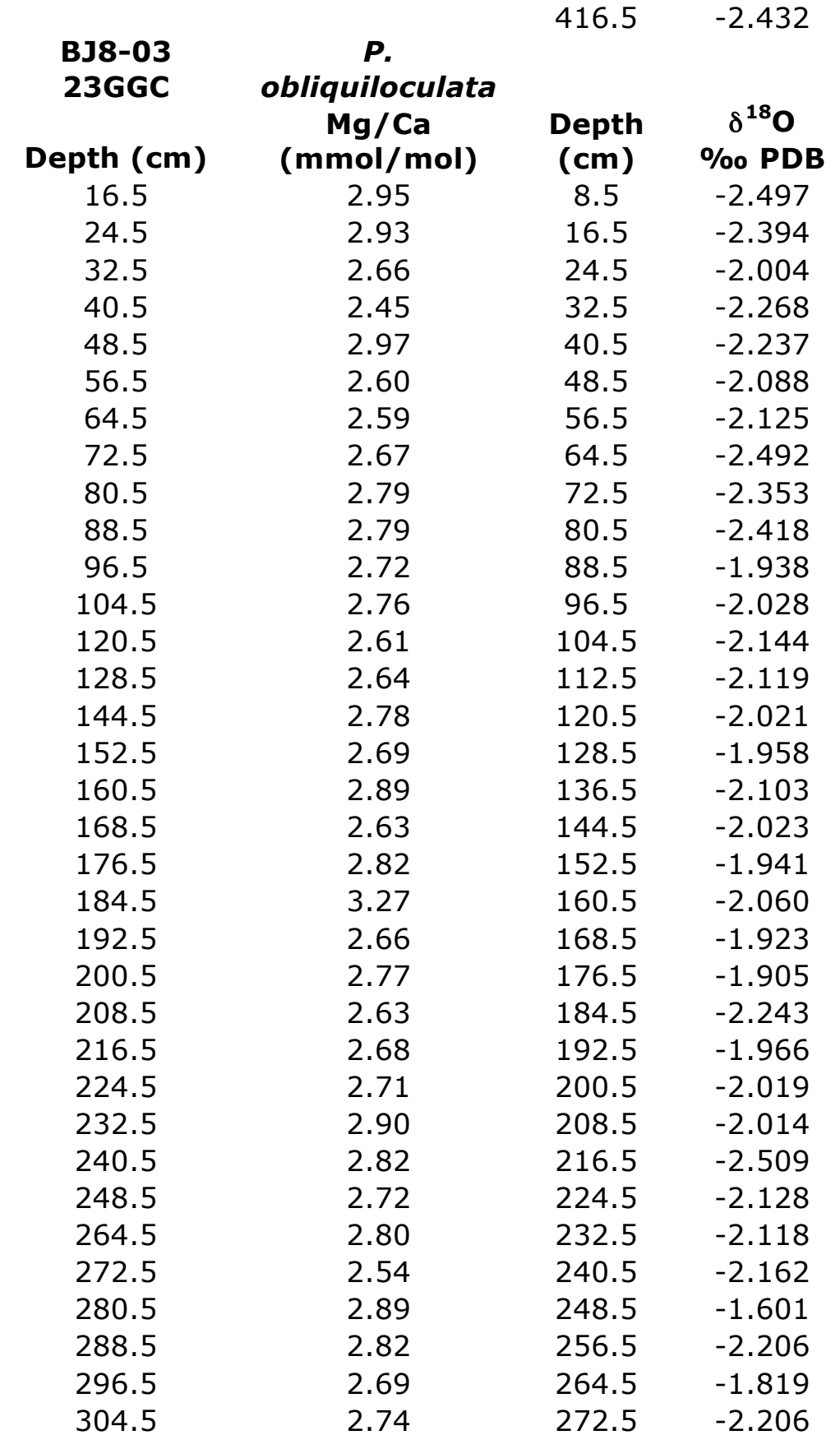

$\begin{array}{ll}376.5 & -2.676 \\ 376.5 & -2.763 \\ 384.5 & -2.779 \\ 384.5 & -2.608 \\ 392.5 & -2.617 \\ 392.5 & -2.927 \\ 400.5 & -2.603 \\ 400.5 & -2.919 \\ 408.5 & -2.398 \\ 408.5 & -2.753 \\ 416.5 & -2.498 \\ 416.5 & -2.432\end{array}$

Depth $\quad \delta^{18} \mathrm{O}$

$16.5-2.394$

$24.5-2.004$

$32.5-2.268$

$40.5 \quad-2.237$

$48.5-2.088$

$56.5-2.125$

$64.5-2.492$

$72.5-2.353$

$80.5-2.418$

$88.5-1.938$

$96.5-2.028$

$104.5-2.144$

$-2.119$

$120.5-2.021$

$128.5-1.958$

$136.5-2.103$

$144.5-2.023$

$152.5-1.941$

$160.5-2.060$

$168.5-1.923$

$176.5-1.905$

$184.5-2.243$

$192.5-1.966$

$200.5 \quad-2.019$

$208.5-2.014$

$216.5-2.509$

$224.5-2.128$

$232.5-2.118$

$240.5-2.162$

$248.5-1.601$

$256.5-2.206$

$272.5-2.206$ 


$\begin{array}{llll}312.5 & 2.90 & 280.5 & -2.759 \\ 320.5 & 2.93 & 288.5 & -2.097 \\ 328.5 & 3.91 & 296.5 & -2.091 \\ 336.5 & 2.99 & 304.5 & -1.734 \\ 344.5 & 2.61 & 312.5 & -1.754 \\ 360.5 & 2.67 & 328.5 & -1.795 \\ 368.5 & 2.69 & 336.5 & -1.985 \\ 384.5 & 2.78 & 344.5 & -1.896 \\ 392.5 & 2.78 & 352.5 & -1.772 \\ 400.5 & 2.96 & 360.5 & -1.514 \\ 408.5 & 2.86 & 368.5 & -1.897 \\ 416.5 & 3.16 & 376.5 & -2.034 \\ & & 384.5 & -1.448 \\ & & 392.5 & -1.724 \\ & & 400.5 & -1.346 \\ & & 408.5 & -1.458 \\ & & 416.5 & -1.355\end{array}$

P.

MD97-2141 obliquiloculata

$\begin{array}{cccc}\text { Depth } \mathbf{( c m )} & \begin{array}{c}\text { Mg/Ca } \\ (\mathbf{m m o l} / \mathbf{m o l})\end{array} & \begin{array}{c}\text { Depth } \\ \mathbf{( c m )}\end{array} & \begin{array}{c}\mathbf{\delta}^{\mathbf{1 8}} \mathbf{O} \\ \mathbf{\%} \mathbf{\text { PDB }}\end{array} \\ 0.5 & 2.32 & 0.5 & -0.671 \\ 20 & 2.24 & 20 & -1.533 \\ 40 & 2.30 & 40 & -1.883 \\ 60 & 2.58 & 51 & -1.623 \\ 80 & 2.65 & 60 & -1.881 \\ 100 & 2.55 & 80 & -1.427 \\ 121 & 2.86 & 100 & -1.484 \\ 140 & 2.87 & 110 & -1.361 \\ 144 & 2.87 & 121 & -1.171 \\ 145 & 2.76 & 140 & -0.896 \\ 151 & 2.53 & 144 & -1.234 \\ 155 & 2.45 & 145 & -1.148 \\ 160 & 2.38 & 151 & -0.910 \\ 165 & 2.56 & 155 & -0.978 \\ 170 & 2.66 & 160 & -1.353 \\ 180 & 2.80 & 165 & -1.204 \\ 200 & 2.68 & 168 & -1.045 \\ 220 & 2.55 & 170 & -1.091 \\ 250 & 2.24 & 180 & -0.472 \\ 260 & 2.99 & 200 & -0.560 \\ 290 & 2.35 & 220 & -0.632 \\ 299 & 2.46 & 230 & -1.462 \\ 320 & 2.66 & 240 & -0.123 \\ 329 & 2.29 & 245 & -0.290 \\ 340 & 2.53 & 250 & -0.888 \\ 349 & 2.02 & 260 & -0.367 \\ 360 & 2.16 & 265 & -0.064 \\ 371 & 2.33 & 280 & -1.426\end{array}$




$\begin{array}{llll}380 & 2.05 & 290 & -0.248 \\ 401 & 2.73 & 299 & -0.333 \\ 419 & 2.55 & 320 & -0.921 \\ 430 & 2.28 & 329 & -0.180 \\ 441 & 2.55 & 340 & -0.248 \\ 450 & 2.26 & 349 & -0.519 \\ 460 & 2.48 & 360 & -0.292 \\ & & 371 & -1.058 \\ & & 380 & -1.173 \\ & & 401 & -0.348 \\ & & 419 & -0.488 \\ & & 430 & -0.323 \\ & & 441 & -0.463 \\ & & 450 & -0.582 \\ & & 460 & -2.210\end{array}$

\section{BJ8-03}

136GGC

Depth (cm)

2.5

3.5

6.5

8.5

10.5

12.5

14.5

16.5

18.5

20.5

22.5

24.5

26.5

28.5

32.5

34.5

36.5

38.5

40.5

42.5

44.5

46.5

48.5

50.5

56.5

64.5

66.5

68.5

70.5

80.5

\section{G. ruber \\ $\mathrm{Mg} / \mathrm{Ca}$}

( $\mathrm{mmol} / \mathrm{mol}$ )

4.94

4.66

5.59

4.54

4.47

5.26

4.83

4.49

4.55

4.67

4.88

4.70

4.52

4.65

4.66

4.70

4.61

4.32

4.76

4.62

4.85

4.60

4.62

4.76

4.57

4.43

4.62

4.67

4.41

4.49

\section{Depth $\quad \delta^{18} \mathrm{O}$}

(cm) \% PDB

$2.5-2.886$

$3.5-2.939$

$8.5-2.798$

$16.5-2.825$

$24.5-2.777$

$32.5-2.851$

$40.5 \quad-2.898$

$48.5-2.636$

$56.5-3.059$

$64.5-2.885$

$72.5 \quad-3.217$

$80.5-3.253$

$88.5-3.243$

$96.5-2.821$

$104.5-3.105$

$112.5-3.118$

$120.5-2.921$

$128.5-3.045$

$136.5-2.958$

$144.5-3.229$

$152.5-3.132$

$160.5-2.986$

$168.5-3.283$

$176.5-3.157$

$184.5-2.762$

$192.5-2.736$

$200.5 \quad-2.404$

$208.5 \quad-2.378$

$216.5-2.174$

$224.5-1.432$ 


\begin{tabular}{|c|c|c|c|}
\hline 88.5 & 4.76 & 232.5 & -2.093 \\
\hline 96.5 & 4.29 & 240.5 & -1.712 \\
\hline 104.5 & 4.65 & 248.5 & -1.502 \\
\hline 112.5 & 4.19 & 256.5 & -1.363 \\
\hline 120.5 & 4.68 & 264.5 & -1.524 \\
\hline 128.5 & 4.34 & 272.5 & -1.461 \\
\hline 132.5 & 4.45 & 280.5 & -1.719 \\
\hline 134.5 & 4.49 & 288.5 & -1.590 \\
\hline 136.5 & 3.95 & 296.5 & -2.050 \\
\hline 138.5 & 4.64 & 304.5 & -1.744 \\
\hline 140.5 & 4.50 & 312.5 & -1.625 \\
\hline 142.5 & 4.50 & 320.5 & -1.736 \\
\hline 144.5 & 4.74 & 328.5 & -1.809 \\
\hline 146.5 & 4.55 & 336.5 & -1.694 \\
\hline 148.5 & 4.35 & 344.5 & -1.643 \\
\hline 150.5 & 4.51 & 352.5 & -1.490 \\
\hline 152.5 & 4.53 & 360.5 & -1.695 \\
\hline 154.5 & 4.73 & 368.5 & -1.917 \\
\hline 156.5 & 4.30 & 376.5 & -1.562 \\
\hline 158.5 & 4.50 & 384.5 & -1.442 \\
\hline 160.5 & 4.38 & 392.5 & -1.263 \\
\hline 162.5 & 4.55 & 400.5 & -1.991 \\
\hline 164.5 & 4.44 & & \\
\hline 166.5 & 4.40 & & \\
\hline 168.5 & 4.34 & & \\
\hline 170.5 & 4.21 & & \\
\hline 172.5 & 4.87 & & \\
\hline 174.5 & 4.62 & & \\
\hline 176.5 & 4.26 & & \\
\hline 178.5 & 4.86 & & \\
\hline 180.5 & 4.81 & & \\
\hline 182.5 & 4.49 & & \\
\hline 184.5 & 4.98 & & \\
\hline 186.5 & 4.62 & & \\
\hline 188.5 & 4.72 & & \\
\hline 190.5 & 4.61 & & \\
\hline 192.5 & 4.36 & & \\
\hline 194.5 & 4.21 & & \\
\hline 196.5 & 4.42 & & \\
\hline 198.5 & 4.08 & & \\
\hline 200.5 & 4.62 & & \\
\hline 202.5 & 4.20 & & \\
\hline 204.5 & 4.47 & & \\
\hline 206.5 & 4.14 & & \\
\hline 208.5 & 4.33 & & \\
\hline 210.5 & 4.44 & & \\
\hline 212.5 & 4.63 & & \\
\hline 216.5 & 4.21 & & \\
\hline 218.5 & 4.30 & & \\
\hline
\end{tabular}




\begin{tabular}{|c|c|c|c|}
\hline 220.5 & 3.89 & & \\
\hline 222.5 & 4.10 & & \\
\hline 226.5 & 4.06 & & \\
\hline 228.5 & 4.08 & & \\
\hline 230.5 & 4.11 & & \\
\hline 232.5 & 3.98 & & \\
\hline 234.5 & 4.18 & & \\
\hline 236.5 & 4.11 & & \\
\hline 238.5 & 3.91 & & \\
\hline 240.5 & 3.87 & & \\
\hline 242.5 & 3.75 & & \\
\hline 244.5 & 3.67 & & \\
\hline 246.5 & 3.58 & & \\
\hline 250.5 & 4.03 & & \\
\hline 252.5 & 3.84 & & \\
\hline 256.5 & 3.81 & & \\
\hline 264.5 & 3.71 & & \\
\hline 272.5 & 3.78 & & \\
\hline 280.5 & 3.48 & & \\
\hline 286.5 & 3.45 & & \\
\hline 296.5 & 3.57 & & \\
\hline 304.5 & 3.44 & & \\
\hline 312.5 & 3.64 & & \\
\hline 320.5 & 3.66 & & \\
\hline 328.5 & 3.34 & & \\
\hline 336.5 & 3.69 & & \\
\hline 344.5 & 3.63 & & \\
\hline 352.5 & 3.50 & & \\
\hline 360.5 & 3.76 & & \\
\hline 368.5 & 3.56 & & \\
\hline 376.5 & 3.39 & & \\
\hline 384.5 & 3.43 & & \\
\hline 392.5 & 3.31 & & \\
\hline 400.5 & 3.10 & & \\
\hline $\begin{array}{l}\text { BJ8-03 } \\
136 G G C\end{array}$ & $\begin{array}{c}P . \\
\text { obliquiloculata }\end{array}$ & & \\
\hline Depth $(\mathrm{cm})$ & $\begin{array}{c}\mathrm{Mg} / \mathrm{Ca} \\
(\mathrm{mmol} / \mathrm{mol})\end{array}$ & $\begin{array}{c}\text { Depth } \\
(\mathrm{cm})\end{array}$ & $\begin{array}{c}\delta^{18} \mathrm{O} \\
\% \text { \% PDB }\end{array}$ \\
\hline 2.5 & 3.47 & 3.5 & -2.286 \\
\hline 3.5 & 2.98 & 8.5 & -2.313 \\
\hline 14.5 & 2.54 & 16.5 & -2.443 \\
\hline 18.5 & 2.61 & 18.5 & -2.591 \\
\hline 20.5 & 2.43 & 20.5 & -2.592 \\
\hline 22.5 & 2.52 & 22.5 & -2.315 \\
\hline 34.5 & 2.47 & 24.5 & -2.247 \\
\hline 38.5 & 2.70 & 32.5 & -2.093 \\
\hline 40.5 & 2.65 & 34.5 & -2.429 \\
\hline 56.5 & 3.07 & 38.5 & -2.563 \\
\hline 64.5 & 3.09 & 40.5 & -2.032 \\
\hline
\end{tabular}




\begin{tabular}{|c|c|c|c|}
\hline 66.5 & 2.54 & 48.5 & -1.947 \\
\hline 68.5 & 2.61 & 56.5 & -2.064 \\
\hline 70.5 & 2.82 & 64.5 & -2.065 \\
\hline 72.5 & 2.66 & 68.5 & -2.526 \\
\hline 80.5 & 2.60 & 70.5 & -2.113 \\
\hline 88.5 & 2.70 & 72.5 & -2.189 \\
\hline 96.5 & 2.75 & 80.5 & -1.827 \\
\hline 104.5 & 2.85 & 88.5 & -1.509 \\
\hline 136.5 & 2.82 & 96.5 & -1.805 \\
\hline 144.5 & 3.05 & 104.5 & -2.319 \\
\hline 152.5 & 3.09 & 112.5 & -2.190 \\
\hline 160.5 & 3.29 & 120.5 & -2.100 \\
\hline 168.5 & 3.22 & 128.5 & -1.818 \\
\hline 184.5 & 2.73 & 136.5 & -1.406 \\
\hline 188.5 & 2.64 & 144.5 & -1.684 \\
\hline 190.5 & 2.97 & 152.5 & -2.264 \\
\hline 194.5 & 2.46 & 160.5 & -1.501 \\
\hline 196.5 & 2.30 & 168.5 & -2.298 \\
\hline 198.5 & 2.40 & 176.5 & -2.063 \\
\hline 202.5 & 3.09 & 188.5 & -2.254 \\
\hline 204.5 & 2.72 & 190.5 & -1.916 \\
\hline 206.5 & 2.58 & 192.5 & -1.440 \\
\hline 208.5 & 2.71 & 196.5 & -1.353 \\
\hline 210.5 & 2.71 & 198.5 & -1.315 \\
\hline 212.5 & 2.65 & 200.5 & -1.925 \\
\hline 214.5 & 2.71 & 202.5 & -1.424 \\
\hline 216.5 & 2.94 & 204.5 & -1.420 \\
\hline 218.5 & 2.51 & 206.5 & -1.342 \\
\hline 220.5 & 2.39 & 208.5 & -1.586 \\
\hline 222.5 & 2.57 & 210.5 & -0.863 \\
\hline 224.5 & 3.09 & 212.5 & -1.727 \\
\hline 226.5 & 2.05 & 214.5 & -1.408 \\
\hline 228.5 & 2.46 & 216.5 & -0.998 \\
\hline 230.5 & 2.45 & 218.5 & -0.625 \\
\hline 232.5 & 2.74 & 220.5 & -0.533 \\
\hline 234.5 & 2.27 & 222.5 & -1.547 \\
\hline 236.5 & 2.26 & 224.5 & -0.731 \\
\hline 242.5 & 2.54 & 226.5 & -1.137 \\
\hline 244.5 & 2.33 & 228.5 & -1.715 \\
\hline 246.5 & 2.34 & 230.5 & -1.538 \\
\hline 248.5 & 2.55 & 234.5 & -1.026 \\
\hline 250.5 & 2.50 & 236.5 & -0.631 \\
\hline 252.5 & 2.89 & 240.5 & -0.230 \\
\hline 254.5 & 2.43 & 242.5 & -0.383 \\
\hline 258.5 & 2.32 & 244.5 & -0.057 \\
\hline 258.5 & 2.13 & 246.5 & -0.276 \\
\hline 260.5 & 2.75 & 248.5 & 0.026 \\
\hline 262.5 & 2.29 & 250.5 & -0.417 \\
\hline 264.5 & 2.28 & 252.5 & 0.029 \\
\hline
\end{tabular}




\begin{tabular}{|c|c|c|c|}
\hline \multirow{9}{*}{$\begin{array}{l}266.5 \\
268.5\end{array}$} & 2.57 & 254.5 & -0.395 \\
\hline & 2.47 & 256.5 & 0.204 \\
\hline & & 258.5 & -0.190 \\
\hline & & 260.5 & -0.162 \\
\hline & & 262.5 & 0.235 \\
\hline & & 264.5 & 0.127 \\
\hline & & 266.5 & -0.322 \\
\hline & & 268.5 & -0.019 \\
\hline & & 272.5 & -0.009 \\
\hline
\end{tabular}

